\title{
Cochrane
}

Library

Cochrane Database of Systematic Reviews

\section{Closed-system drug-transfer devices plus safe handling of hazardous drugs versus safe handling alone for reducing exposure to infusional hazardous drugs in healthcare staff (Review)}

Gurusamy KS, Best LMJ, Tanguay C, Lennan E, Korva M, Bussières JF

Gurusamy KS, Best LMJ, Tanguay C, Lennan E, Korva M, Bussières JF.

Closed-system drug-transfer devices plus safe handling of hazardous drugs versus safe handling alone for reducing exposure to infusional hazardous drugs in healthcare staff.

Cochrane Database of Systematic Reviews 2018, Issue 3. Art. No.: CD012860.

DOI: 10.1002/14651858.CD012860.pub2.

www.cochranelibrary.com

Closed-system drug-transfer devices plus safe handling of hazardous drugs versus safe handling alone for reducing exposure to infusional hazardous drugs in healthcare staff (Review) 
TABLE OF CONTENTS

HEADER

ABSTRACT

PLAIN LANGUAGE SUMMARY

SUMMARY OF FINDINGS

BACKGROUND

OBJECTIVES

METHODS

RESULTS

Figure 1.

Figure 2.

Figure 3.

Figure 4.

DISCUSSION

AUTHORS' CONCLUSIONS

ACKNOWLEDGEMENTS

REFERENCES

CHARACTERISTICS OF STUDIES

DATA AND ANALYSES

Analysis 1.1. Comparison 1 Closed-system transfer device plus safe handling versus safe handling alone, Outcome 1 Urine tests for exposure.

Analysis 1.2. Comparison 1 Closed-system transfer device plus safe handling versus safe handling alone, Outcome 2 Proportion of surfaces contaminated.

Analysis 1.3. Comparison 1 Closed-system transfer device plus safe handling versus safe handling alone, Outcome 3 Quantity of surface contamination $\left(\mathrm{pg} / \mathrm{cm}^{2}\right)$.

Analysis 2.1. Comparison 2 Subgroup analysis (based on study design and device), Outcome 1 Urine tests for exposure (PhaSeal only).

Analysis 2.2. Comparison 2 Subgroup analysis (based on study design and device), Outcome 2 Proportion of surfaces contaminated with cyclophosphamide in pharmacy areas: stratified by study design.

Analysis 2.3. Comparison 2 Subgroup analysis (based on study design and device), Outcome 3 Proportion of surfaces contaminated with ifosfamide in pharmacy areas: stratified by study design.

Analysis 2.4. Comparison 2 Subgroup analysis (based on study design and device), Outcome 4 Proportion of surfaces contaminated with methotrexate in pharmacy areas: stratified by study design.

Analysis 2.5. Comparison 2 Subgroup analysis (based on study design and device), Outcome 5 Proportion of surfaces contaminated with 5 -fluorouracil in pharmacy areas: stratified by study design.

Analysis 2.6. Comparison 2 Subgroup analysis (based on study design and device), Outcome 6 Proportion of surfaces contaminated (PhaSeal only).

Analysis 2.7. Comparison 2 Subgroup analysis (based on study design and device), Outcome 7 Proportion of surfaces contaminated (Tevadaptor only).

Analysis 2.8. Comparison 2 Subgroup analysis (based on study design and device), Outcome 8 Quantity of surface contamination with cyclophosphamide in pharmacy areas $\left(\mathrm{pg} / \mathrm{cm}^{2}\right)$ : stratified by study design.

Analysis 2.9. Comparison 2 Subgroup analysis (based on study design and device), Outcome 9 Quantity of surface contamination with ifosfamide in pharmacy areas $\left(\mathrm{pg} / \mathrm{cm}^{2}\right)$ : stratified by study design.

Analysis 2.10. Comparison 2 Subgroup analysis (based on study design and device), Outcome 10 Quantity of surface contamination with methotrexate in pharmacy areas $\left(\mathrm{pg} / \mathrm{cm}^{2}\right)$ : stratified by study design.

Analysis 2.11. Comparison 2 Subgroup analysis (based on study design and device), Outcome 11 Quantity of surface contamination with 5-fluorouracil in pharmacy areas $\left(\mathrm{pg} / \mathrm{cm}^{2}\right)$ : stratified by devices.

Analysis 2.12. Comparison 2 Subgroup analysis (based on study design and device), Outcome 12 Quantity of surface contamination with 5 -fluorouracil in pharmacy areas $\left(\mathrm{pg} / \mathrm{cm}^{2}\right)$ : stratified by study design.

Analysis 2.13. Comparison 2 Subgroup analysis (based on study design and device), Outcome 13 Quantity of surface contamination $\left(\mathrm{pg} / \mathrm{cm}^{2}\right)$ : stratified by devices.

Analysis 3.1. Comparison 3 Sensitivity analysis, Outcome 1 Urine tests for exposure (ICC $=0.05)$.

Analysis 3.2. Comparison 3 Sensitivity analysis, Outcome 2 Urine tests for exposure $(I C C=0.01)$.

Analysis 3.3. Comparison 3 Sensitivity analysis, Outcome 3 Urine tests for exposure (ICC $=0.00)$. 
Analysis 3.5. Comparison 3 Sensitivity analysis, Outcome 5 Proportion of surfaces contaminated (ICC $=0.01$ ).

Analysis 3.6. Comparison 3 Sensitivity analysis, Outcome 6 Proportion of surfaces contaminated $($ ICC $=0.00)$.

Analysis 3.7. Comparison 3 Sensitivity analysis, Outcome 7 Quantity of surface contamination $\left(\mathrm{pg} / \mathrm{cm}^{2}\right)($ ICC $=0.05)$.

Analysis 3.8. Comparison 3 Sensitivity analysis, Outcome 8 Quantity of surface contamination $\left(\mathrm{pg} / \mathrm{cm}^{2}\right)($ ICC $=0.01)$.

Analysis 3.9. Comparison 3 Sensitivity analysis, Outcome 9 Quantity of surface contamination $\left(\mathrm{pg} / \mathrm{cm}^{2}\right)($ ICC $=0.00)$.

ADDITIONAL TABLES

APPENDICES

FEEDBACK

WHAT'S NEW

CONTRIBUTIONS OF AUTHORS

DECLARATIONS OF INTEREST

SOURCES OF SUPPORT 
[Intervention Review]

\section{Closed-system drug-transfer devices plus safe handling of hazardous drugs versus safe handling alone for reducing exposure to infusional hazardous drugs in healthcare staff}

Kurinchi Selvan Gurusamy¹, Lawrence MJ Best² ${ }^{2}$ Cynthia Tanguay ${ }^{3}$, Elaine Lennan4, Mika Korva ${ }^{5}$, Jean-François Bussières ${ }^{3}$

1Division of Surgery and Interventional Science, University College London, London, UK. 2Department of Surgery, Royal Free Campus, UCL Medical School, London, UK. 3Unité de Recherche en Pratique Pharmaceutique, CHU Sainte-Justine, Montreal, Canada. ${ }^{4}$ Department of Chemotherapy, University Hospital Southampton, Southampton, UK. ${ }^{5}$ Finnish Institute of Occupational Health, Turku, Finland

Contact address: Kurinchi Selvan Gurusamy, Division of Surgery and Interventional Science, University College London, 9th Floor, Royal Free Hospital, Rowland Hill Street, London, NW3 2PF, UK. k.gurusamy@ucl.ac.uk.

Editorial group: Cochrane Work Group.

Publication status and date: Edited (no change to conclusions), comment added to review, published in Issue 2, 2019.

Citation: Gurusamy KS, Best LMJ, Tanguay C, Lennan E, Korva M, Bussières JF. Closed-system drug-transfer devices plus safe handling of hazardous drugs versus safe handling alone for reducing exposure to infusional hazardous drugs in healthcare staff. Cochrane Database of Systematic Reviews 2018, Issue 3. Art. No.: CD012860. DOI: 10.1002/14651858.CD012860.pub2.

Copyright @ 2019 The Cochrane Collaboration. Published by John Wiley \& Sons, Ltd.

\section{A B S T R A C T}

\section{Background}

Occupational exposure to hazardous drugs can decrease fertility and result in miscarriages, stillbirths, and cancers in healthcare staff. Several recommended practices aim to reduce this exposure, including protective clothing, gloves, and biological safety cabinets ('safe handling'). There is significant uncertainty as to whether using closed-system drug-transfer devices (CSTD) in addition to safe handling decreases the contamination and risk of staff exposure to infusional hazardous drugs compared to safe handling alone.

\section{Objectives}

To assess the effects of closed-system drug-transfer of infusional hazardous drugs plus safe handling versus safe handling alone for reducing staff exposure to infusional hazardous drugs and risk of staff contamination, and to determine if the better reuse of multi-dose vials leads to cost savings.

\section{Search methods}

We searched the Cochrane Central Register of Controlled Trials (CENTRAL), MEDLINE, Embase, OSH-UPDATE, CINAHL, Science Citation Index Expanded, economic evaluation databases, the World Health Organization International Clinical Trials Registry Platform, and ClinicalTrials.gov to October 2017.

\section{Selection criteria}

We included comparative studies of any study design (irrespective of language, blinding, or publication status) that compared CSTD plus safe handling versus safe handling alone for infusional hazardous drugs.

\section{Data collection and analysis}

Two review authors independently identified trials and extracted data. We calculated the risk ratio (RR) and mean difference (MD) with $95 \%$ confidence intervals $(\mathrm{Cl})$ using both fixed-effect and random-effects models. We assessed risk of bias according to the risk of bias in non-randomised studies of interventions (ROBINS-I) tool, used an intracluster correlation coefficient of 0.10 , and we assessed the quality of the evidence using GRADE. 


\section{Main results}

We included 24 observational cluster studies (359 hospitals) in this review. We did not find any randomised controlled trials or formal economic evaluations. In 22 studies, the people who used the intervention (CSTD plus safe handling) and control (safe handling alone) were pharmacists or pharmacy technicians; in the other two studies, the people who used the intervention and control were nurses, pharmacists, or pharmacy technicians. Therefore, the evidence is mainly applicable to pharmacists or pharmacy technicians. The CSTD used in the studies were PhaSeal (13 studies), Tevadaptor (2 studies), SpikeSwan (1 study), PhaSeal and Tevadaptor ( 1 study), varied (5 studies), and not stated (2 studies). Therefore, the evidence is mainly applicable for PhaSeal. The studies' descriptions of the control groups were varied. Twenty-two studies provide data on one or more outcomes for this systematic review. All the studies are at serious risk of bias. The quality of evidence is very low for all the outcomes.

Very low certainty evidence from small studies is insufficient to determine whether there is any important difference between CSTD and control groups in the proportion of people with positive urine tests for exposure between the CSTD and control groups for any of the drugs: cyclophosphamide alone (RR 0.83, 95\% Cl 0.46 to 1.52; $I^{2}=12 \%$; 2 studies; 2 hospitals; 20 participants; CSTD: 76.1\% versus control: $91.7 \%$ ); cyclophosphamide or ifosfamide (RR 0.09, 95\% Cl 0.00 to 2.79; 1 study; 1 hospital; 14 participants; CSTD: 6.4\% versus control: $71.4 \%$ ); and cyclophosphamide, ifosfamide, or gemcitabine (RR not estimable; 1 study; 1 hospital; 36 participants; $0 \%$ in both groups).

Very low certainty evidence from small studies is insufficient to determine whether there is any important difference between CSTD and control groups in the proportion of surfaces contaminated or the quantity of contamination. Overall, out of 24 comparisons in pharmacy areas or patient-care areas, there was a reduction in the proportion of surfaces contaminated in only one comparison and out of 15 comparisons in pharmacy areas or patient-care areas, there was a reduction in the quantity of contamination in only two comparisons.

None of the studies report on atmospheric contamination, blood tests, or other measures of exposure to infusional hazardous drugs such as urine mutagenicity, chromosomal aberrations, sister chromatid exchanges, or micronuclei induction.

None of the studies report short-term health outcomes such as reduction in skin rashes, medium-term reproductive health outcomes such as fertility and parity, or long-term health outcomes related to the development of any type of cancer or adverse events.

Five studies (six hospitals) report the potential cost savings through the use of CSTD. The studies used different methods of calculating the costs, and the results were not reported in a format that could be pooled via meta-analysis. There is significant variability between the studies in terms of whether CSTD resulted in cost savings (the point estimates of the average potential cost savings ranged from (2017) USD $-642,656$ to (2017) USD 221,818).

The healthcare professionals in the studies that provide data were mostly pharmacists or pharmacy technicians. Therefore, the evidence is mainly applicable to pharmacists and pharmacy technicians. Most of the studies that provide information for this review evaluated the use of PhaSeal; therefore the findings are mostly applicable to PhaSeal.

\section{Authors' conclusions}

Currently, no firm conclusions can be drawn on the effect of CSTD combined with safe handling versus safe handling alone due to very low certainty evidence available for the main outcomes.

Multicentre randomised controlled trials may be feasible depending upon the proportion of people with exposure. The next best study design is interrupted time-series. Future studies should evaluate exposure to a relevant selection of hazardous drugs used in the hospital, and they should measure direct short-term health outcomes.

\section{PLAIN LANGUAGE SUMMARY}

\section{Closed-system drug-transfer devices for reducing exposure to infusional hazardous medicines in healthcare staff}

Some medicines - whether given as tablets or as a drip through the veins - are hazardous to the healthcare staff who handle them. Patients receive infusional hazardous medicines through the veins as treatment for serious diseases like cancer. When healthcare staff are exposed to these medicines, they can decrease their fertility and result in miscarriages, stillbirths, and cancers. Several recommended practices can reduce healthcare staff exposure to these hazardous medicines. These include protective clothing, gloves, and special cabinets where staff can prepare the hazardous medicines prior to giving them to patients. Together, these practices constitute 'safe handling'. A closedsystem drug-transfer device (CSTD) is a device system that mechanically prevents the escape of hazardous drug outside the system. In addition, the systems also attempt to prevent microbiological contamination of the drug, potentially enabling reuse of multi-dose vials (drug containers which have been designed in such a way that the medicines in the container can be used multiple times and for multiple patients) and decreasing the costs.

\section{What is the aim of this review?}

There is significant uncertainty as to whether using CSTD in addition to safe handling decreases the exposure and risk of staff contamination to hazardous medicines compared to safe handling alone and whether CSTD can lead to cost-savings by allowing better reuse of multidose vials. We sought to resolve this issue by searching for existing studies on the topic. 


\section{Key messages}

Short or long-term health outcomes were not reported in any studies. We found very low quality evidence (the best evidence available currently) that there is no considerable difference in exposure between CSTD plus safe handling versus safe handling alone. We also found very low quality evidence (the best evidence available currently) that there is no considerable effect of CSTD on the percentage of surfaces contaminated and the amount of contamination in in pharmacy and patient-care areas for most drugs even though there was a small effect on contamination for one drug out of 24 studied and on amount of drug contamination for two drugs out of 15 studied. Therefore, no firm conclusions can be drawn on the effect of CSTD plus safe handling versus safe handling alone due to very low quality evidence available. Since most of the studies were conducted in pharmacy technicians and pharmacists and the CSTD used was PhaSeal, the evidence is applicable mainly to pharmacy technicians and pharmacists, and to PhaSeal.

\section{What was studied in the review?}

We included all types of studies that compared CSTD plus safe handling ('CSTD group') and safe handling alone ('control group').

\section{What are the main results of the review?}

We included 24 studies (359 hospitals) in this review, none of which used the gold standard study design (randomised controlled trial) or explored a treatment's value for money. In 22 studies, the people who used the CSTD and safe handling were pharmacists or pharmacy technicians. Nineteen studies provide information that could be included for this study.

No firm conclusion can be drawn on the effects of using CSTD on indirect measures of exposure such as the presence of the hazardous drug in the urine of the healthcare professionals or on the contamination of surfaces or the floor.

There is significant variability between the studies in terms of whether the use of CSTD resulted in cost savings, with some studies reporting increased costs and others reporting decreased costs after introducing CSTD. None of the studies report on short or long-term health outcomes such as reduction in skin rashes, infertility, miscarriage, development of any type of cancer, or adverse events.

We judged the certainty of evidence for all outcomes to be very low because all the studies had one or more significant limitations in their design. Therefore, the reported effects of interventions are uncertain.

\section{How up-to-date is this review?}

We searched for studies up until 26 October 2017. 


\section{SUMMARY OF FINDINGS}

Summary of findings for the main comparison. Closed-system transfer device plus safe handling versus safe handling alone for reducing healthcare staff exposure to infusional hazardous drugs: exposure and surface contamination

Closed-system transfer device safe handling versus safe handling alone for reducing healthcare staff exposure to infusional hazardous drugs: exposure and contamination

Patient or population: healthcare staff who handle infusional hazardous drugs

Settings: hospitals

Intervention: closed-system transfer device plus safe handling

Control: safe handling alone

\begin{tabular}{|c|c|c|c|c|c|}
\hline \multirow[t]{3}{*}{ Outcomes } & \multicolumn{2}{|c|}{ Illustrative comparative risks* $(95 \% \mathrm{Cl})$} & \multirow{3}{*}{$\begin{array}{l}\text { Relative effect } \\
(95 \% \mathrm{CI})\end{array}$} & \multirow{3}{*}{$\begin{array}{l}\text { No of hospitals } \\
\text { (samples; studies) }\end{array}$} & \multirow{3}{*}{$\begin{array}{l}\text { Quality of the evi- } \\
\text { dence } \\
\text { (GRADE) }\end{array}$} \\
\hline & Assumed risk & Corresponding risk & & & \\
\hline & Safe handling alone & $\begin{array}{l}\text { Closed-system transfer device plus } \\
\text { safe handling }\end{array}$ & & & \\
\hline \multicolumn{6}{|c|}{ Exposure (urine tests for exposure) } \\
\hline $\begin{array}{l}\text { Cyclophosphamide } \\
\text { alone }\end{array}$ & 917 per 1000 & $\begin{array}{l}761 \text { per } 1000 \\
\text { (422 to } 1393)\end{array}$ & $\begin{array}{l}\text { RR } 0.83 \\
(0.46 \text { to } 1.52)\end{array}$ & $\begin{array}{l}2 \text { hospitals } \\
\text { (20 participants; } 2 \text { studies) }\end{array}$ & $\begin{array}{l}\oplus \odot \odot \ominus \\
\text { Very lowa,b,c }\end{array}$ \\
\hline $\begin{array}{l}\text { Cyclophosphamide } \\
\text { or ifosfamide }\end{array}$ & 714 per 1000 & $\begin{array}{l}64 \text { per } 1000 \\
(0 \text { to } 1000)\end{array}$ & $\begin{array}{l}\mathbf{R R} 0.09 \\
\text { (0.00 to } 2.79 \text { ) }\end{array}$ & $\begin{array}{l}1 \text { hospital } \\
\text { (14 participants; } 1 \text { study) }\end{array}$ & $\begin{array}{l}\oplus \odot \odot \ominus \\
\text { Very lowa,b,c }\end{array}$ \\
\hline $\begin{array}{l}\text { Cyclophos- } \\
\text { phamide, ifos- } \\
\text { famide, or gemc- } \\
\text { itabine }\end{array}$ & \multicolumn{3}{|c|}{ There were no participants with exposure in either group. } & $\begin{array}{l}4 \text { hospitals } \\
\text { (36 participants; } 1 \text { study) }\end{array}$ & $\begin{array}{l}\oplus \odot \odot \odot \\
\text { Very low } a, b, c\end{array}$ \\
\hline $\begin{array}{l}\text { Other measures of } \\
\text { exposure }\end{array}$ & \multicolumn{5}{|c|}{$\begin{array}{l}\text { None of the studies report on blood tests or other measures of exposure to infusional hazardous drugs such as urine mutagenicity, chromosomal } \\
\text { aberrations, sister chromatid exchanges, or micronuclei induction. }\end{array}$} \\
\hline \multicolumn{6}{|c|}{ Surface contamination (proportion of surfaces contaminated) } \\
\hline \multicolumn{6}{|l|}{ Pharmacy areas } \\
\hline Cyclophosphamide & 507 per 1000 & $\begin{array}{l}\mathbf{4 5 1} \text { per } \mathbf{1 0 0 0} \\
\text { (395 to } 512)\end{array}$ & $\begin{array}{l}\text { RR } 0.89 \\
\text { (0.78 to } 1.01 \text { ) }\end{array}$ & $\begin{array}{l}338 \text { hospitals } \\
\text { (2937 samples; } 13 \text { studies) }\end{array}$ & $\begin{array}{l}\oplus \ominus \ominus \ominus \\
\text { Very lowa,b,d,e }\end{array}$ \\
\hline
\end{tabular}

$\rightarrow$

Very lowa,b,d,e 


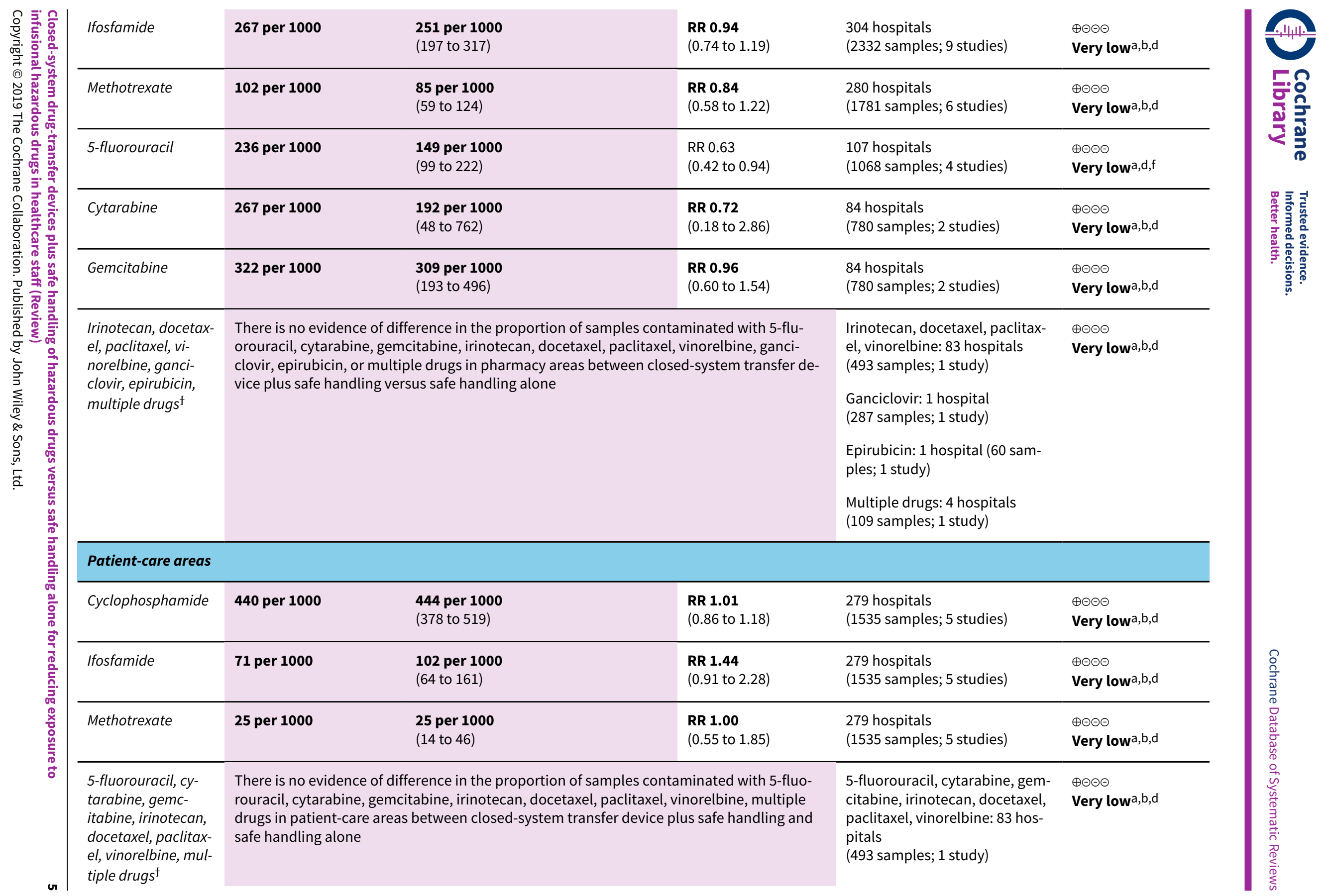




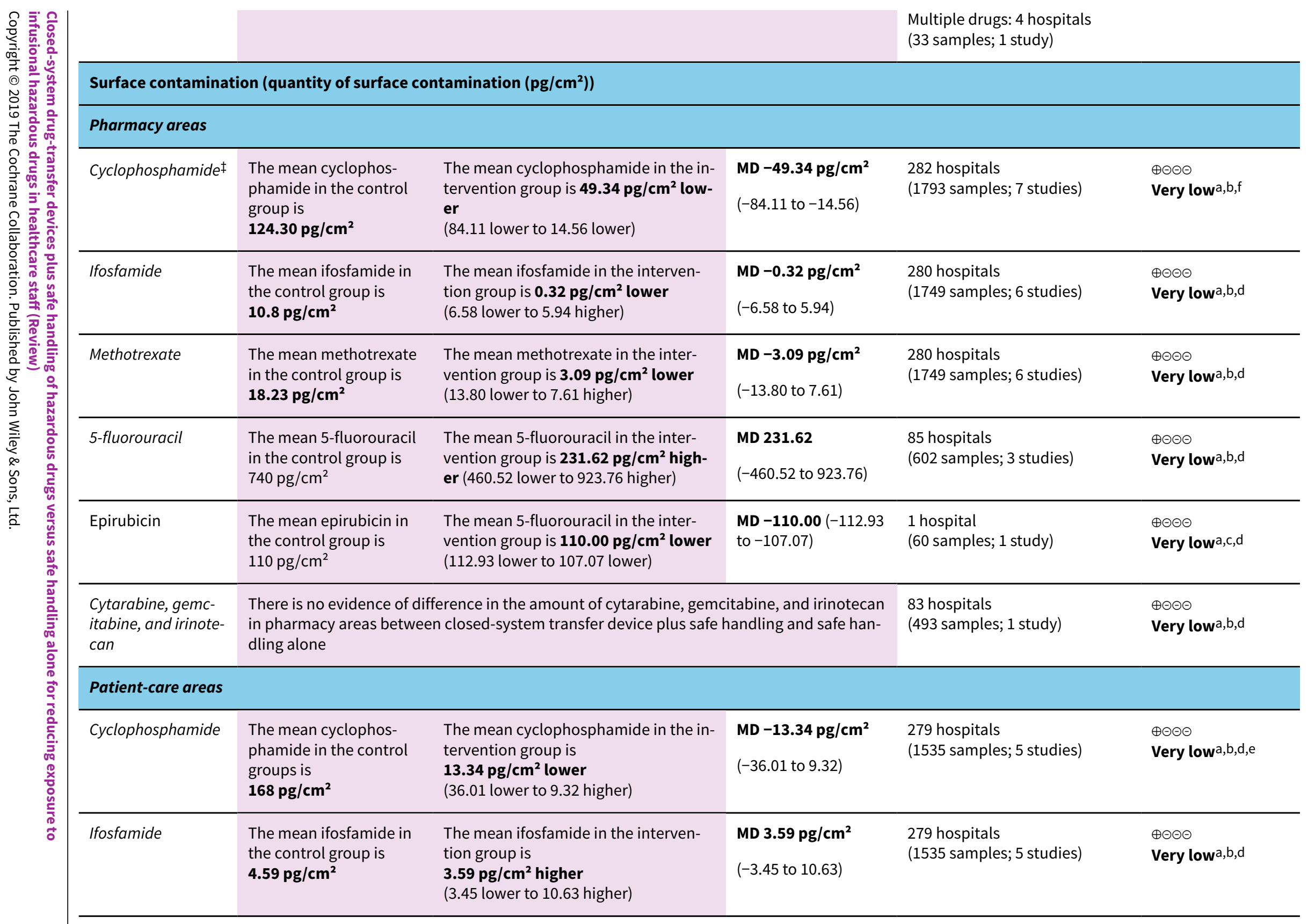




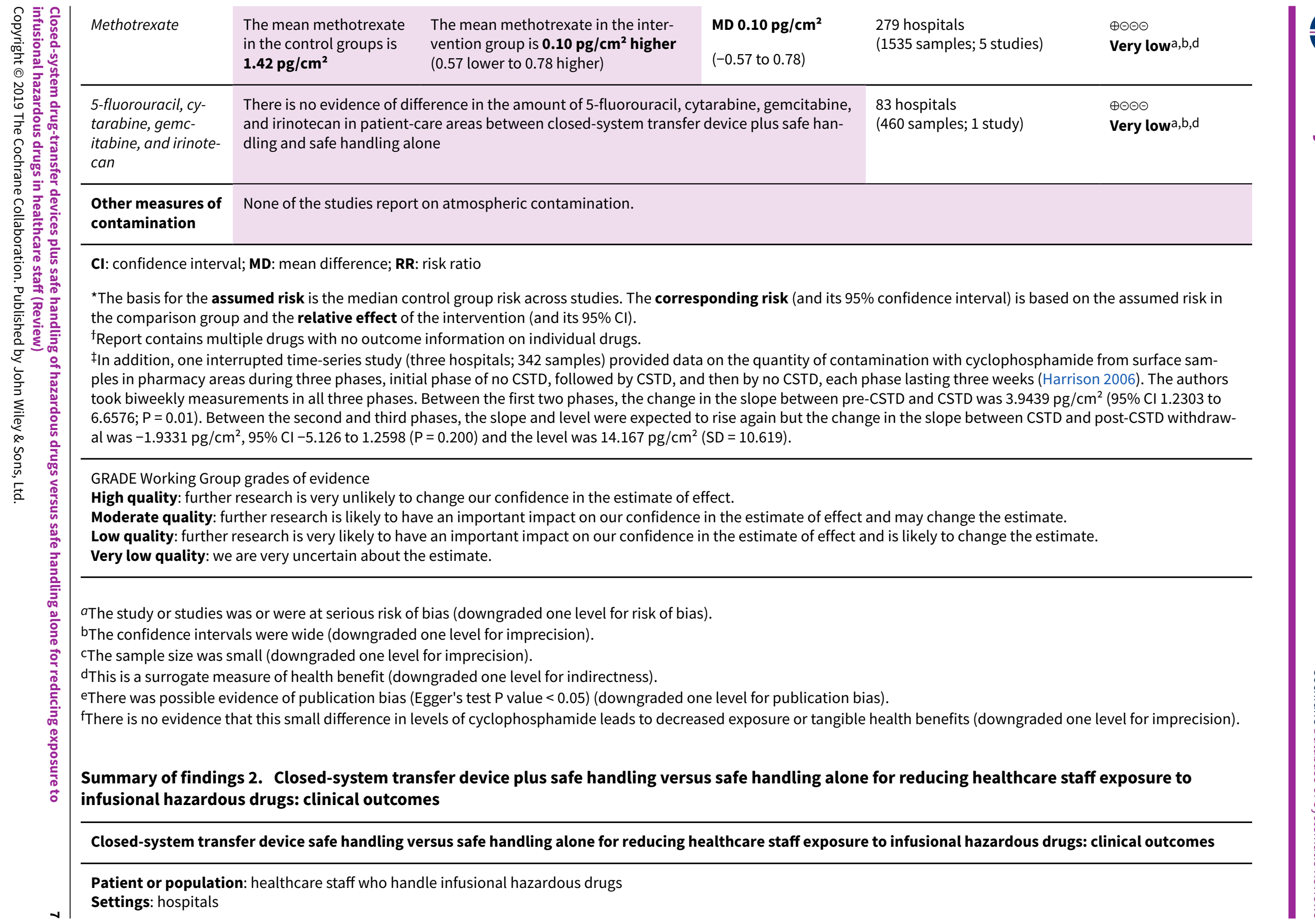


Intervention: closed-system transfer device plus safe handling Control: safe handling alone

\begin{tabular}{|c|c|c|c|c|c|}
\hline \multirow[t]{3}{*}{ Outcomes } & \multicolumn{2}{|c|}{ Illustrative comparative risks $(95 \% \mathrm{Cl})$} & \multirow{3}{*}{$\begin{array}{l}\text { Relative effect } \\
(95 \% \mathrm{CI})\end{array}$} & \multirow{3}{*}{$\begin{array}{l}\text { No of hospitals } \\
\text { (studies) }\end{array}$} & \multirow{3}{*}{$\begin{array}{l}\text { Quality of the evi- } \\
\text { dence } \\
\text { (GRADE) }\end{array}$} \\
\hline & Assumed risk & Corresponding risk & & & \\
\hline & Safe handling alone & $\begin{array}{l}\text { Closed-system transfer device plus } \\
\text { safe handling }\end{array}$ & & & \\
\hline Health outcomes & \multicolumn{5}{|c|}{$\begin{array}{l}\text { None of the studies report health outcomes such as skin rashes, reproductive health effects (infertility or miscarriage), or development of any type of } \\
\text { cancer. }\end{array}$} \\
\hline Adverse events & \multicolumn{5}{|c|}{ None of the studies report this outcome. } \\
\hline $\begin{array}{l}\text { Potential cost sav- } \\
\text { ings }\end{array}$ & \multicolumn{3}{|c|}{$\begin{array}{l}\text { The studies used different methods of calculating the costs and reported results in formats that could } \\
\text { not be pooled via meta-analysis. There is significant variability between the studies in terms of whether } \\
\text { the use of CSTD results in cost savings (the point estimates of the average potential cost savings ranged } \\
\text { between (2017) US D- } 642,656 \text { and (2017) USD }+221,818^{*} \text {. }\end{array}$} & $\begin{array}{l}6 \text { hospitals } \\
\text { (5 studies) }\end{array}$ & $\begin{array}{l}\oplus \odot \odot \odot \\
\text { Very lowa,b }\end{array}$ \\
\hline
\end{tabular}

*Negative sign indicates cost savings and positive sign indicate increased costs due to the use of closed-system transfer device.

Cl: confidence interval; CSTD: closed-system transfer device.

GRADE Working Group grades of evidence

High quality: further research is very unlikely to change our confidence in the estimate of effect.

Moderate quality: further research is likely to have an important impact on our confidence in the estimate of effect and may change the estimate.

Low quality: further research is very likely to have an important impact on our confidence in the estimate of effect and is likely to change the estimate.

Very low quality: we are very uncertain about the estimate.

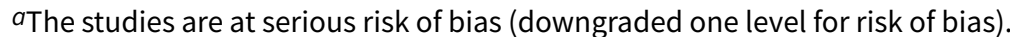

bThere is very serious inconsistency in magnitude and direction of effect (downgraded two levels for inconsistency). 


\section{B A C K G R O U N D}

\section{Description of the condition}

Hazardous drugs include those used for cancer chemotherapy, antiviral drugs, hormones, some bioengineered drugs, and other drugs (NIOSH 2004). Although there is some variation in the definition of hazardous drugs, the National Institute for Occupational Safety and Health (NIOSH) describes hazardous drugs as those that have the potential to cause one or more of the following: carcinogenicity (inducing cancer), teratogenicity (causing birth defects), developmental toxicity (having an adverse impact on development), reproductive toxicity (interfering with normal reproduction), organ toxicity at low doses (damaging organs), or genotoxicity (causing mutations, i.e. alterations in the genetic structure) (NIOSH 2004). New drugs that have a structure and toxicity profile that mimics existing drugs considered hazardous according to the above criteria are also considered hazardous (NIOSH 2004). There is a subtle difference between cytotoxic drugs and hazardous drugs. Cytotoxic drugs are medicines that are toxic to human cells (NCBI 1978), while hazardous drugs include cytotoxic drugs and new drugs that have a structure and toxicity profile similar to cytotoxic drugs.

The various types of hazardous drugs include alkylating drugs (e.g. cyclophosphamide, chlorambucil), anthracyclines and other cytotoxic antibiotics (e.g. daunorubicin, doxorubicin), antimetabolites (e.g. methotrexate, fluorouracil, gemcitabine), vinca alkaloids and etoposide (e.g. vinblastine, vincristine), and some antineoplastic drugs (e.g. bevacizumab, denosumab, pertuzumab, rituximab, trastuzumab, mitotane) (BNF 2017). The mechanism of action varies between different types of cytotoxic drugs. In general, cytotoxic drugs interfere with cell replication by damaging DNA or by preventing normal cell division (BNF 2017).

Cytotoxic drugs have anticancer activity and immunosuppressive properties (Brogan 2000). Therefore, they are used in the treatment of many cancers (e.g. breast cancer, bowel cancer, stomach cancer, sarcoma, leukaemia) and noncancerous conditions that require immunosuppression (e.g. polyarteritis nodosa, Wegener's granulomatosis, systemic lupus erythematosus, idiopathic nephrotic syndrome, inflammatory bowel disease, mixed connective tissue disease, scleroderma, multiple sclerosis, idiopathic inflammatory myopathy, sarcoidosis, primary membranous nephropathy, membranoproliferative glomerulonephritis, transplantation) (Awad 2009; BNF 2017; Brogan 2000; Cassidy 2011; Fernandes Moca Trevisani 2013; Ge 2015; Hartman 2001; Hazlewood 2016; Mulder 2015; Nunes 2015; Poormoghim 2012; Rodriguez-Peralvarez 2017; Zhu 2017).

Hazardous drugs can be administered orally, intravenously by infusions, or intrathecally (BNF 2017). When hazardous drugs are given by intravenous infusion, there is a risk of contamination, which means that staff handling the infusional hazardous drugs, particularly the pharmacy technicians who prepare the drugs and the nurses who administer them, may come into contact with them. The hazardous drug aerosol, formed due to the spillage of drugs during preparation, transport, or administration, can be inhaled or absorbed through the skin (Chu 2012; Hon 2014; Poupeau 2016; Ramphal 2014; Schierl 2016; Sessink 2011; Sessink 2015; Sugiura 2011; Viegas 2014; Yoshida 2011; Yoshida 2013). Other staff (e.g. pharmacists, respiratory therapists, physicians, support staff) working in the hospital that administers hazardous drugs can also be exposed to the contamination, not just those who handle the hazardous drugs) (Hon 2014; Ramphal 2014).

Occupational exposure to hazardous drugs increases mutations that predispose the exposed staff to the development of cancer (HSE 2017; Mahmoodi 2017; McDiarmid 2010; McDiarmid 2014; Moretti 2015; NIOSH 2004; Skov 1992). Maternal occupational exposure to hazardous drugs during pregnancy can cause congenital abnormalities, miscarriages, stillbirths, and low birthweight (Connor 2014; HSE 2017; NIOSH 2004). Occupational exposure to hazardous drugs can also decrease fertility in women (Connor 2014; HSE 2017; NIOSH 2004). Other adverse effects include skin rash, hair loss, light-headedness, abnormal blood counts, liver damage, abdominal pain, and vomiting (HSE 2017; NIOSH 2004).

Several methods have been proposed to decrease the risk of exposure to hazardous drugs. These include the use of biological safety cabinets with laminar airflow for drug preparation, robotic drug preparation, centralisation of priming of intravenous tubing, personal protective equipment, staff education for safe handling of hazardous drugs, and closed-system drug transfer devices (Guillemette 2014; Schierl 2016; Sessink 2011; Sessink 2015; Yoshida 2013). There are several guidelines for safe handling of hazardous drugs including those issued by the UK Health and Safety Executive (HSE), NHS Pharmaceutical Quality Assurance Committee, US NIOSH, US Pharmacopeial Convention (USP), Program in Evidence-Based Care guidelines, International Society of Oncology Pharmacy Practitioners Standards, American Society of Health-System Pharmacists, and Association paritaire pour la santé et la sécurité du travail du secteur affaires sociales (ASSTSAS) (ASSTSAS 2008; ASHP 2006; Bateman 2015; Easty 2015; HSE 2017; ISOPP 2007; NIOSH 2004; USP 2017). Broadly, these guidelines recommend the identification of the risk, use of biological safety cabinets, use of closed-system drug-transfer devices where reasonably practicable, and control of exposure at source (e.g. by using adequate extraction systems and appropriate organisational measures, issuing personal protective equipment, monitoring exposure at the workplace, providing health surveillance programmes, providing employee information and training, maintaining equipment appropriately, having appropriate procedures for dealing with spillages or contamination of people or work surfaces, and providing safe waste disposal) (ASSTSAS 2008; ASHP 2006; Bateman 2015; Easty 2015; HSE 2017; ISOPP 2007; NIOSH 2004; USP 2017).

\section{Description of the intervention}

A closed-system drug-transfer device is an apparatus that mechanically prohibits the transfer of environmental contaminants into the system and the escape of hazardous drug or vapour outside the system (NIOSH 2004). Some examples of closedsystem drug-transfer devices are: PhaSeal system, ChemoClave system, Equashield system, and Chemo Safety system. These devices include a method to access the intravenous infusion (e.g. a spike designed to prevent leaks and spillages), and a leakproof connection that attempts to transfer drugs without leaks or spillage, as a minimum (B Braun 2017a; BD 2017a; BD 2017b; Equashield 2017; ICUMED 2017). However, some devices used in compounding hazardous drugs are not fully considered closedsystem drug-transfer devices, as they are not conceived or have not been demonstrated to capture aerosols such as hydrophobicair-venting filters or chemotherapy transfer/reconstitution spikes 
(B Braun 2017b; Healthmark 2017). In this review, we will accept any device described as a closed-system drug-transfer device by the manufacturer.

\section{How the intervention might work}

Closed-system drug-transfer devices work by attempting to provide a leak-proof connection that prevents leaks and spills (B Braun 2017a; BD 2017a; BD 2017b; Equashield 2017; ICUMED 2017). This may decrease surface contamination and atmospheric contamination (with drug aerosol), thereby decreasing occupational exposure to infusional hazardous drugs. This in turn might result in fewer adverse events related to exposure. In addition, the systems also attempt to prevent microbiological contamination of the drug (BD 2017a; Equashield 2017; ICUMED 2017), potentially enabling reuse of vials and decreasing the costs.

\section{Why it is important to do this review}

There is significant variation in the way hazardous drugs are handled by staff. Legislation requires organisations to protect workers' health and safety (HSE 2017). All the staff working in hospitals that administer hazardous drugs are at potential risk of exposure to the drugs, which can result in the serious consequences described above (see Description of the condition). Even when staff handle hazardous drugs according to all instructions and as safely as possible, there is still the possibility of accidental contamination of surfaces around them, which exposes other staff members to the drugs and their serious consequences. Therefore, it is important to use the most effective methods to decrease the risk of staff contact with infusional hazardous drugs. Some studies have shown that closed-system drug-transfer devices may decrease surface contamination compared to current safe handling practices including biological safety cabinets and use of personal protective equipment (Harrison 2006; Sessink 2011). However, there are additional costs associated with using closed-system drug-transfer devices compared to safe handling of infusional hazardous drugs, and it is unclear whether these devices provide good value for money (i.e. whether the cost-benefit ratio is favourable to using closed-system drug-transfer devices compared to conventional safe handling of infusional hazardous drugs). There is also major uncertainty about whether these devices are effective in reducing the risk of exposure. In one study, pharmacists considered that the use of a closed-system drug-transfer device increased technical issues, increased the risk of spillage, was slower and more cumbersome to use, and increased the risk of drug absorption through the skin and by inhalation (Guillemette 2014). In addition, there is concern that the observed differences in surface contamination attributed to the addition of closedsystem drug-transfer devices to safe handling could actually be due to differences in the removal of previous drug residue. Further concerns include the possible contamination of the exterior of the hazardous drug vials at the manufacturing site (Connor 2005; Favier 2003; Fleury-Souverain 2014; Hedmer 2005; Mason 2003; Naito 2012), which may decrease the effectiveness of the closed-system drug-transfer devices in real-life situations compared to controlled laboratory situations. Several studies have shown high levels of drug vial exterior contamination (Connor 2005; Favier 2003; Fleury-Souverain 2014; Hedmer 2005; Mason 2003; Naito 2012), although there are exceptions to this (Power 2014). The risk of contamination may be dependent upon the manufacturing process used, for example due to different decontamination procedures and the encasing of the vials using protective sleeves (Connor 2005; Power 2014). Because of the uncertainty in the effectiveness of the closed-system drug-transfer devices, there is variation in the recommendations of different guidelines about the use of these devices. For example, USP recommends mandatory use of closed-system drug-transfer devices for administration when the dosage form allows, while NIOSH only recommends considering their use when transferring hazardous drugs (NIOSH 2004; USP 2017). Furthermore, the staff handling hazardous drugs may be anxious about the serious consequences and want to know how well these devices protect them.

Other purposes of the device, a more efficient use of drugs, could possibly lead to savings in the use of drugs because unused leftovers can be used for other patients. However, this is unrelated to worker protection but this could then be regarded as a free extra. Therefore, we wanted to know if the use of the devices led to more efficient use of drugs that could outweigh the device costs.

There is currently no systematic review on the effect of closedsystem drug-transfer devices versus conventional safe handling for reducing the risk of staff contamination to infusional hazardous drugs or their potential cost savings. This Cochrane Review will provide the best available evidence regarding this issue.

\section{O B JECTIVES}

To assess the effects of closed-system drug-transfer of infusional hazardous drugs plus safe handling versus safe handling alone for reducing staff exposure to infusional hazardous drugs and risk of staff contamination, and to determine if better reuse of multi-dose vials leads to cost savings.

\section{METHODS}

\section{Criteria for considering studies for this review}

\section{Types of studies}

Due to the complex nature of the intervention, which is applied at the group level in work situations rather than at the individual level, randomised controlled trials (RCTs) are not very feasible, which is one of the major reasons for including non-randomised studies in Cochrane Reviews (Ijaz 2014). Therefore, we included other study designs in addition to RCTs. We considered comparative studies that are commonly performed in this field, that is, uncontrolled before-after studies and cohort studies. We also included interrupted time-series, controlled before-after (CBA) studies, and case-control studies. This is because interrupted timeseries may account for time trends in improvement of practices, and CBA studies may account for any interim changes in policies. We included case-control studies because the outcomes following exposure are rare.

\section{Types of participants}

We included studies conducted on adult healthcare staff (aged 18 years or above) involved in the preparation, transport, delivery, administration, and disposal of waste of infusional hazardous drugs. We also considered healthcare organisations where healthcare staff were exposed to infusional hazardous drugs as participants with regards to outcomes such as surface contamination and aerosol contamination. 


\section{Types of interventions}

We included trials that evaluated the effectiveness of closedsystem drug transfer of infusional hazardous drugs (e.g. PhaSeal system and ChemoClave system) plus safe handling of infusional hazardous drugs (e.g. including class II biological safety cabinet, isolator, and personal protective equipment) versus safe handling alone. We accepted any device whose manufacturer described it as a closed-system drug-transfer device. We included trials with any co-interventions provided they were not part of the randomised treatment or were applied equally in both arms in non-randomised studies.

\section{Types of outcome measures}

\section{Primary outcomes}

- Measures of exposure to infusional hazardous drugs such as urine mutagenicity, chromosomal aberrations, sister chromatid exchanges, and micronuclei induction

- Environmental contamination measured with surrogate outcomes for exposure: surface samples, splashes, leakage tests, or atmospheric contamination

- Short-term health outcomes such as skin rashes

- Medium-term health outcomes such as infertility or miscarriage

- Long-term health outcomes such as cancer (any type of cancer)

We accepted any methods used by the study authors, for example, routine screening for the presence or absence of outcomes or assessment of these outcomes in only people with symptoms suggestive of the presence of these outcomes. The Board of the UK Oncology Nursing Society identified these outcomes as the most important outcomes for the target population by as part of their funding call.

\section{Secondary outcomes}

- Adverse events (e.g. personal injury due to the use of spikes or needles resulting in infections)

- Potential cost savings due to reuse of multi-dose vials

We considered follow-up times for primary and secondary outcome measurement as: short term (up to one year), medium term (one to five years), and long term (longer than five years).

Reporting one or more of the primary or secondary outcomes listed here is not an inclusion criterion for the review.

\section{Search methods for identification of studies}

\section{Electronic searches}

We conducted a systematic literature search to identify all published and unpublished trials that were potentially eligible for inclusion in this review. We adapted the search strategy developed for MEDLINE (see Appendix 1) for use in the other electronic databases. We imposed no restrictions on language of publication and translated the key sections of potentially eligible non-English language papers to assess them fully for potential inclusion in the review as necessary.

We searched the following electronic databases from inception to 26 October 2017 to identify potential studies. The only exception was the databases searched through OSH-UPDATE search platform, which we searched on 3 October 2017.
- Cochrane Central Register of Controlled Trials (CENTRAL) (Wiley Online Library) (Appendix 2).

- MEDLINE (OvidSP) (Appendix 1).

- Embase (OvidSP) (Appendix 3).

- NIOSHTIC (OSH-UPDATE) (Appendix 4).

- NIOSHTIC-2 (OSH-UPDATE) (Appendix 4).

- HSELINE (OSH-UPDATE) (Appendix 4).

- CISDOC (OSH-UPDATE) (Appendix 4).

- CINAHL (EBSCO) (Appendix 5).

- Science Citation Index Expanded (including Conference Proceedings) (Appendix 6).

- NHS Economic Evaluation Database (NHS EED) (Appendix 7).

- Cost-Effectiveness Analysis Registry (CEA) at Tufts University (Appendix 7).

We also conducted a search for unpublished trials in ClinicalTrials.gov (www.clinicaltrials.gov) and the World Health Organization (WHO) trials portal (www.who.int/ictrp/en/) (Appendix 8) on 26 October 2017.

\section{Searching other resources}

We checked reference lists of all primary studies and review articles for additional references and contacted experts in the field to identify additional unpublished material.

\section{Data collection and analysis}

\section{Selection of studies}

We conducted the selection of eligible studies in two stages. First, two review authors (KG and LB) independently screened titles and abstracts of all potentially relevant studies found with our systematic search to exclude studies that clearly did not fulfil the criteria for inclusion. CT identified additional studies by reviewing bibliographies to identify further full-text records for potential inclusion. The same review authors coded records as 'include' (eligible or potentially eligible/unclear) or 'exclude'. We excluded all references that clearly did not fulfil our inclusion criteria or that fulfilled our exclusion criteria. Second, we retrieved the full-text study reports/publications, and two review authors (KG and LB) independently assessed the full-text to identify studies for inclusion. At this stage, we included all references that fulfilled our inclusion criteria. We recorded reasons for excluding studies based on assessment of the full text and reported these in a 'Characteristics of excluded studies' table. We resolved any disagreements through discussion. We identified and excluded duplicates and collated multiple reports of the same study so that each study rather than each report was the unit of interest in the review. We recorded the selection process in sufficient detail to complete a PRISMA study flow diagram.

\section{Data extraction and management}

We used an Excel-based data collection form for study characteristics and outcome data that was piloted on two studies in the review. Two review authors (KG and LB) extracted the following study characteristics from included studies.

- Methods: study design, duration of study, study location, study setting, withdrawals, and date of study. 
- Participants: number of participants, number of clusters (hospitals or wards), mean age or age range, sex, inclusion criteria, and exclusion criteria.

- Interventions: description of intervention, comparison (elements included in safe handling in the control group), and co-interventions.

- Outcomes: description of primary and secondary outcomes specified and collected, and at which time points reported.

- Notes: funding for trial, and notable conflicts of interest of trial authors.

Two review authors (KG and LB) independently extracted outcome data from included studies. We noted in the 'Characteristics of included studies' table if authors did not report outcome data in a usable way. We resolved disagreements by consensus. One review author (KG) transferred data into Review Manager 5 (RevMan 2014). We double-checked the data entry by comparing the data presented in the systematic review with the study reports. A third review author (CT) spot-checked study characteristics and data for accuracy against the trial report. The author team was proficient in all languages of the studies included in the review (English and French).

\section{Assessment of risk of bias in included studies}

For each RCT, two review authors (KG and LB) independently planned to assess risk of bias using criteria outlined in the Cochrane Handbook for Systematic Reviews of Interventions (Higgins 2011). We planned to resolve any disagreements by discussion. We planned to assess the risk of bias according to the following domains.

- Random sequence generation.

- Allocation concealment.

- Blinding of participants and personnel.

- Blinding of outcome assessment.

- Incomplete outcome data.

- Selective outcome reporting.

- Other bias (including source of funding and whether the duration of exposure to hazardous drugs in the intervention group and control group was measured reliably after ensuring that the participants were free from the outcome at the beginning of the study).

We planned to grade each potential risk of bias as high, low, or unclear, and we provided a quotation from the study report together with a justification for our judgement in the 'Risk of bias' table. We planned to summarise the risk of bias judgements across different studies for each of the domains listed. We planned to consider blinding separately for different key outcomes where necessary. To classify studies as being at low risk of bias in measurement of outcome, we required them to have carried out blinded assessment of all outcomes except for contamination of surface samples, where we accepted samples obtained and analysed by an automated machine as being at low risk of bias regardless of blinding. For urinary levels, we accepted this outcome as being at low risk of bias regardless of blinding. Where information on risk of bias relates to unpublished data or correspondence with a trialist, we planned to note this in the 'Risk of bias' table.
For each non-randomised study, the same two review authors (KG and LB) assessed the risk of bias independently using the risk of bias in non-randomised studies of interventions (ROBINS-I) tool (Sterne 2016). We considered the following as possible sources of confounding.

- Changes or differences in other factors for genetic and chromosomal damage such as stress from work, working long hours, and smoking that might lead to fewer genetic and chromosomal abnormalities compared to the intervention.

- Differences in drug residue on a surface prior to contamination (e.g. thorough cleaning before the study in only one group).

- Changes or differences in drug residue on the drug vials because of different batches or different manufacturers of the drug.

In terms of bias due to classification of interventions, we considered studies to be at low risk of bias when it was clear that the intervention group was CSTD and the control group was no CSTD.

We considered the following co-interventions.

- Changes or differences in layout, ventilation, fume cupboards, etc., that might lead to less contamination compared to the intervention.

- Changes or differences in policies that might lead to less contamination compared to the intervention.

- Education, training, and experience of healthcare staff that might lead to less contamination compared to the intervention.

- Differences in the supervision for drug preparation or drug administration that might lead to less contamination compared to the intervention.

We planned to assess the risk of bias in the included economic evaluations using either the Consensus Health Economic Criteria (CHEC) list for assessment of methodological quality of economic evaluations, described in Evers 2005, or the Philips 2004 checklist.

We considered all domains other than blinding of healthcare providers to be key domains. We judged a study to be at high risk of bias overall when we judged one or more key domains to be at high risk of bias. Conversely, we judged a study to be at low risk of bias when we assigned a low risk of bias for all key domains.

When considering treatment effects, we took into account the risk of bias for the studies that contributed to that outcome.

\section{Assessment of bias in conducting the systematic review}

We conducted the review according to the published protocol and reported any deviations from it in Differences between protocol and review.

\section{Measures of treatment effect}

We entered the outcome data for each study into the data tables in RevMan 5 to calculate the treatment effects unadjusted for clustering (RevMan 2014). As we did not find any case-control studies, we used the risk ratio (RR) for dichotomous outcomes (this is because RRs are much easier to interpret; however, they cannot be calculated in case-control studies without the use of risk from another study), and mean differences (MDs) for continuous outcomes. If studies reported only effect estimates and their $95 \%$ confidence intervals (Cls) or standard errors, we planned to enter these data into RevMan 5 using the generic inverse variance method 
(RevMan 2014). We ensured that higher scores for continuous outcomes have the same meaning for the particular outcome. When the results could not be entered in either way, we entered the data into additional tables.

For interrupted time-series studies, we extracted data from the original papers and reanalysed them according to the recommended methods for analysing interrupted time-series designs for inclusion in systematic reviews (Ramsay 2003). We planned to use the standardised change in level and change in slope as effect measures.

\section{Unit of analysis issues}

For studies that employed a cluster-design and reported sufficient data to be included in the meta-analysis but did not make an allowance for the design effect, we calculated the design effect based on a fairly large assumed intracluster correlation coefficient (ICC) of 0.10 . We based this assumption of 0.10 being a realistic estimate by analogy with studies about implementation research (Campbell 2001). We followed the methods stated in the Cochrane Handbook for Systematic Reviews of Interventions for the calculations, and we entered the data adjusted for clustering as generic inverse variance data (Higgins 2011). This involved calculating the average cluster size ' $M$ ' (by dividing the total number of samples by the total number of hospitals) and calculating the design effect by using the formula $1+(\mathrm{M}-1)$ ICC. We multiplied the standard error for each cluster study by the square root of the design effect to obtain a standard error adjusted for clustering. This adjusted standard error was then used to calculate the confidence intervals.

\section{Dealing with missing data}

We contacted investigators or study sponsors to verify key study characteristics and obtain missing numerical outcome data where possible (e.g. when a study was reported as abstract only). Where this was not possible, and if the missing data were thought to introduce serious bias, we would have explored the impact of including such studies in the overall assessment of results by a sensitivity analysis.

If numerical outcome data were missing, such as standard deviations or correlation coefficients, and they could not be obtained from the authors, we planned to calculate them from other available statistics such as $\mathrm{P}$ values, according to the methods described in the Cochrane Handbook for Systematic Reviews of Interventions (Higgins 2011).

\section{Assessment of heterogeneity}

We assessed the clinical homogeneity of the results of included studies based on similarity of population, intervention, outcome, and follow-up. We considered populations as similar when they were staff who were exposed to infusional hazardous drugs, for example, oncology nurses, pharmacy technicians, or pharmacists who handled infusional hazardous drugs. We considered interventions as similar when it was clear that the system was a closed-system drug transfer device. We combined results data produced by each of the measures of contamination separately (e.g. urine tests, surface contamination, and atmospheric contamination), and we planned to combine cancer- and fertility-related outcome data separately. We considered short-term (up to one year), medium-term (one to five years), and long-term (more than five years) follow-up times as different.

We used the $\mathrm{I}^{2}$ statistic to measure heterogeneity among the trials in each analysis. If we identified substantial heterogeneity (above $50 \%$, as described in Higgins 2011), we planned to report it and explore possible causes by prespecified subgroup analysis.

\section{Assessment of reporting biases}

If we were able to pool more than five trials in any single metaanalysis, we created and examined a funnel plot to explore possible small-study biases. We used Egger's test to identify reporting biases (Egger 1997). We considered a P value of less than 0.05 as statistically significant reporting bias.

\section{Data synthesis}

We pooled data from studies we judged to be clinically homogeneous using RevMan 5 software (RevMan 2014). If two or more studies provided usable data in any single comparison, we performed meta-analyses. However, we did not plan to pool data from different study designs (i.e. RCT and non-randomised studies). We analysed different drugs in separate analyses since drugs are reconstituted differently, administered differently (for example, some are intravenous only while others can be used intravenously, subcutaneously, or orally), used in different quantities, and can lead to different levels of exposure and contamination. Furthermore, these are dangerous at different dosages. In addition, we analysed the pharmacy areas and patient-care areas separately since the levels of exposure and contamination vary between them.

For costs, we used an international exchange rate based on purchasing power parities (PPP) to convert cost estimates to US dollars (USD), and we used the gross domestic product (GDP) deflators (or implicit price deflators for GDP) to convert cost estimates to 2017 USD using PPP conversion rates and GDP deflator values available from the International Monetary Fund in the World Economic Outlook Database (updated biannually: see www.imf.org/external/data.htm). We used both a fixed-effect model and a random-effects model to perform the meta-analyses and reported the more conservative model. When the $\mathrm{I}^{2}$ statistic was higher than $75 \%$, we did not plan to pool results of studies in meta-analysis.

Where a single trial reported multiple trial arms, we included only the relevant arms. If two comparisons (e.g. device $A$ versus safe handling and device $B$ versus safe handling) were combined in the same meta-analysis, we planned to halve the control group to avoid double-counting.

\section{Subgroup analysis and investigation of heterogeneity}

We planned to carry out the following subgroup analyses.

- Study design: CBA studies versus other non-randomised study designs; individual versus cluster unit of analysis. These were planned subgroup analyses. We also performed a post hoc subgroup analysis of uncontrolled before-after studies versus cross-sectional studies, as these were the two types of studies that contributed data for the analysis. This analysis can assess the impact of trend in improving safe handling practices that could be problematic in uncontrolled before-after studies. 
- Professional role: pharmacy technician versus chemotherapy nurse versus other healthcare staff.

- Duration of possible exposure.

- Intervention: any closed-system drug-transfer device.

- Control: safe handling following UK HSE standards.

We planned to perform subgroup analyses for primary outcomes (i.e. immediate to short-term contamination, short-term health outcomes, long-term reproductive health outcomes, and development of any type of cancers). We planned to use the $\mathrm{Chi}^{2}$ test to test for subgroup interactions in Review Manager 5 (RevMan 2014).

\section{Sensitivity analysis}

We planned to perform a sensitivity analysis involving studies with low risk of bias versus studies with high risk of bias defined a priori to assess the robustness of our conclusions.

We performed a post hoc sensitivity analysis to assess the impact of the influence of different intracluster correlation coefficients on the results to determine if the differences in conclusions between our systematic review and primary research studies could be due to the lack of adjusting for cluster effect in primary research studies.

\section{Summary of findings table}

We created a 'Summary of findings' table using all outcomes (i.e. exposure, environmental contamination, health outcomes, adverse events, and potential cost savings). We used the five GRADE considerations (study limitations, consistency of effect, imprecision, indirectness, and publication bias) to assess the quality of a body of evidence as it related to the studies that contributed data to the meta-analyses for the prespecified outcomes. We used methods and recommendations described in Section 8.5 and Chapter 12 of the Cochrane Handbook for Systematic Reviews of Interventions (Higgins 2011), using GRADEpro software (GRADEpro GDT). We justified all decisions to downgrade or upgrade the quality of studies using footnotes.

Since we described all the decisions to downgrade or upgrade the quality of studies using the footnotes and described the reason in detail under each outcome in the text, we did not compile an additional GRADE table showing all our decisions about the quality of evidence and their justifications.

\section{Reaching conclusions}

We based our conclusions only on findings from the quantitative or narrative synthesis of included studies for this review. We avoided making recommendations for practice as these depend on additional considerations such as availability of resources, clinician values and preferences, among other context-specific factors. Our implications for research suggest priorities for future research and outline what the remaining uncertainties are in the area.

\section{RE S U L T S}

\section{Description of studies}

\section{Results of the search}

We identified a total of 9033 records from CENTRAL (70 references), MEDLINE (695 references), Embase (1043 references), OSH-UPDATE (8 references), CINAHL (253 references), Science Citation Index Expanded (including Conference Proceedings) 6830 references), NHS EED (0 references), CEA at Tufts University (0 references), ClinicalTrials.gov (131 references), and the World Health Organization (WHO) trials portal (3 references). After excluding 1463 duplicate records and seeking 17 other references based on handsearching, we screened the titles and abstracts of 7587 records. We obtained full texts for 83 potentially eligible studies. Of these, we excluded 55 references for the reasons detailed in Characteristics of excluded studies and summarised in Excluded studies. In total, we included 24 studies (28 references). See the study inclusion process explained in Figure 1. 
Figure 1. PRISMA study flow diagram. CSTD: closed-system transfer device

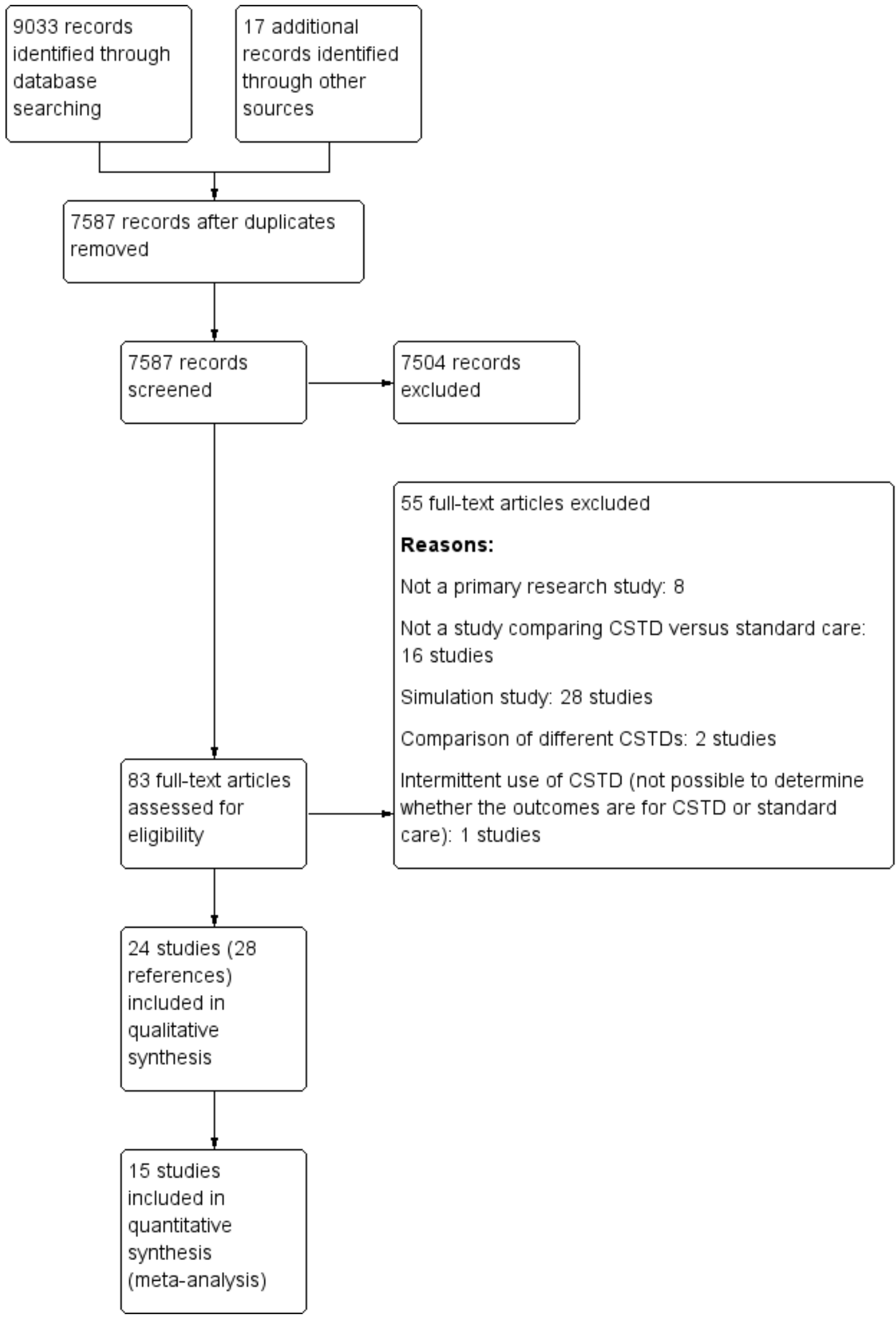




\section{Included studies}

All 24 included studies are cluster studies, that is, the comparison is between hospitals that used CSTD versus those that did not (crosssectional studies) or between the period in which CSTD was used versus the period in which it was not (interrupted time-series or uncontrolled before-after studies). Of the 24 included studies, 1 study (3 hospitals) is an interrupted time-series (Harrison 2006), 14 (66 hospitals) are uncontrolled before-after studies (Chan 2016; Edwards 2013; Guillemette 2014; Hama 2012; Juhasz 2016; Miyake 2013; Mullot 2008; Ozyaman 2016; Sessink 2011; Sessink 2013; Siderov 2010; Vyas 2016; Wick 2003; Yoshida 2009), and 9 (290 hospitals) are cross-sectional studies (Berruyer 2015; Chauchat 2017; Forges 2011; Janes 2015; Poupeau 2016; Roland 2017; Simon 2016; Sottani 2012; Yoshida 2011). In one cross-sectional study, a hospital used the same isolators during the same period to prepare drugs using CSTD and no CSTD (Forges 2011). In another, the same hospital used two different isolators to prepare drugs over the same period: CSTD in one isolator and no CSTD in the other (Simon 2016). In the remaining seven cross-sectional studies, 91 hospitals used CSTD and 197 hospitals did not (Berruyer 2015; Chauchat 2017; Janes 2015; Poupeau 2016; Roland 2017; Sottani 2012; Yoshida 2011). We did not find any randomised controlled trials or formal economic evaluations. Overall, 359 hospitals in Australia, Canada, France, Hungary, Italy, Japan, Malaysia, Turkey, UK, and the USA took part. Most hospitals were from Canada and the USA. There was also an overlap between hospitals included in the different studies, although there was minimal or no overlap in the period when the samples were collected (i.e. the samples were included only once in the analysis).

In 22 studies, the people who used the intervention (CSTD plus safe handling) and control (safe handling alone) were pharmacists or pharmacy technicians (Berruyer 2015; Chan 2016; Chauchat 2017; Edwards 2013; Forges 2011; Guillemette 2014; Hama 2012; Harrison 2006; Janes 2015; Juhasz 2016; Miyake 2013; Ozyaman 2016; Poupeau 2016; Roland 2017; Sessink 2011; Sessink 2013; Siderov 2010; Simon 2016; Sottani 2012; Vyas 2016; Yoshida 2009; Yoshida 2011); in two studies, the people who used the intervention and control were nurses in addition to pharmacists or pharmacy technicians (Mullot 2008; Wick 2003).

The CSTDs used in the studies were PhaSeal (13 studies: Chan 2016; Edwards 2013; Guillemette 2014; Hama 2012; Harrison 2006; Miyake 2013; Ozyaman 2016; Sessink 2011; Sessink 2013; Siderov 2010; Simon 2016; Wick 2003; Yoshida 2009), Tevadaptor (2 studies: Juhasz 2016; Vyas 2016), SpikeSwan (1 study: Forges 2011), PhaSeal and Tevadaptor (1 study: Mullot 2008), varied (5 studies: Berruyer 2015; Chauchat 2017; Janes 2015; Poupeau 2016; Roland 2017), and not stated (2 studies: Yoshida 2011; Sottani 2012). The descriptions of the control groups varied; although we provide the details reported in Characteristics of included studies, additional safety measures are likely to have been in place.

The outcomes reported in the studies are exposure (4 studies: Miyake 2013; Sottani 2012; Wick 2003; Yoshida 2009), surface contamination (17 studies: Berruyer 2015; Chauchat 2017; Forges 2011; Guillemette 2014; Harrison 2006; Janes 2015; Miyake 2013; Poupeau 2016; Roland 2017; Sessink 2011; Sessink 2013; Siderov 2010; Simon 2016; Sottani 2012; Vyas 2016; Wick 2003; Yoshida 2009), and potential cost savings (5 studies: Chan 2016; Edwards 2013; Juhasz 2016; Mullot 2008; Ozyaman 2016). None of the studies that report exposure reported the intracluster correlation coefficient. The remaining two studies did not report the outcomes in a format that could be tabulated or pooled with meta-analysis, as key information was missing and we were unable to obtain it from study authors (Hama 2012; Yoshida 2011).

The duration of exposure of people to CSTD and control measures is relevant only for studies that reported the presence of hazardous drugs in urine (Miyake 2013; Sottani 2012; Wick 2003; Yoshida 2009). This was seven months in Miyake 2013; not reported in Sottani 2012; six months to CSTD without any information on the duration of exposure in the control group in Wick 2003; and two weeks in Yoshida 2009.

With regard to funding, eight studies received no special funding (Berruyer 2015; Chauchat 2017; Edwards 2013, Guillemette 2014, Janes 2015, Juhasz 2016; Poupeau 2016; Roland 2017), six studies received funding from manufacturers of the device being evaluated (Harrison 2006; Sessink 2011; Sessink 2013; Siderov 2010; Simon 2016; Wick 2003), and the remaining ten studies did not report funding (Chan 2016; Forges 2011; Hama 2012; Miyake 2013; Mullot 2008; Ozyaman 2016; Sottani 2012; Vyas 2016; Yoshida 2009; Yoshida 2011).

\section{Excluded studies}

We excluded 55 studies after full-text assessment (Characteristics of excluded studies). The main reasons for exclusion are as follows.

- Not a primary research study: eight studies (Hospital Infection Control 2005; Kunneva 2016; Laws 2016; Lennan 2017; Meade 2015; Oncology Nurse Advisor 2017; Talsmar 2015).

- Not a study comparing CSTD plus standard care versus standard care: 16 studies (Clark 2013; Connor 2010; Contractor 2015; Cox 2017; Enciso-Zarate 2016; Gilles 2009; Hong 2017; Idell 2009; Kopp 2013; Kurihara 2017; Nygren 2005; Nyman 2007; Odraska 2013; Sessink 1999; Tyler 2017; Yoshida 2013). This reason encompasses studies that introduced other safety measures such as biosafety cabinets or change in the layout of the pharmacy in addition to CSTD as well as studies that cleaned the surfaces for only the CSTD group prior to exposure to hazardous drugs, which clearly does not estimate the benefits or harms of CSTD plus safe handling versus safe handling alone.

- Simulation study: 28 studies (Blazawski 2013; Chantry 2015; De Ausen 2013; De Prijck 2008; DeFreitas 2012; Favier 2012; Fernandez 2013; Garrigue 2016; Gebel 2015; Gomez-Alvarez 2016; Gonzalez-Haba Pena 2016; Hama 2011; Ikeno 2014; Jorgenson 2008; Le Garlantezec 2011; Lin 2017; McMichael 2011; Nishigaki 2010; Nygren 2008; Perlo 2015; Queruau Lamerie 2012; Rupp 2017; Sanchez-Rubio Ferrandez 2012; SanchezRubio Ferrandez 2012; Sato 2010; Simon 2010; Smith 2014; Thomas Carey 2011).

- Comparison of different CSTDs: two studies (Amos 2012; Ledford 2010).

- Intermittent use of CSTD (not possible to determine whether the outcomes were for CSTD or standard care): one study (McDiarmid 2010).

\section{Risk of bias in included studies}

The risk of bias in the included studies is summarised in Figure 2. 
Figure 2. Risk of bias summary: review authors' judgements about each risk of bias item for each included study. Green +: Low risk of bias. Yellow ?: Moderate risk of bias or 'No information'. Red -: Serious or critical risk of bias.

\begin{tabular}{|c|c|c|c|c|c|c|c|}
\hline & 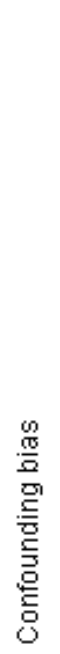 & 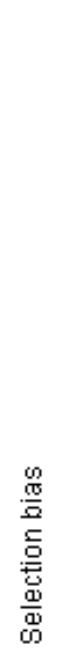 & 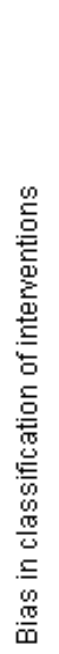 & 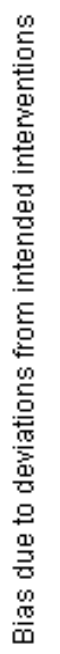 & 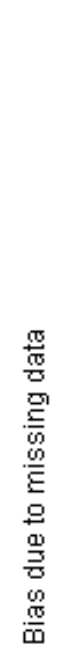 & 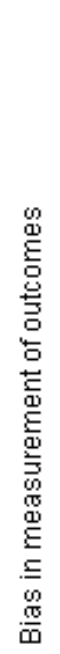 & 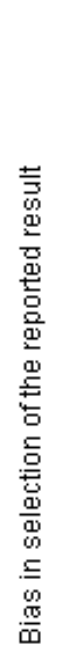 \\
\hline Berruyer 2015 & $?$ & $?$ & $\odot$ & $?$ & $?$ & $\odot$ & $\odot$ \\
\hline Chan 2016 & $?$ & + & $\odot$ & $?$ & + & $\odot$ & $\odot$ \\
\hline Chauchat 2017 & $?$ & $?$ & $\odot$ & $?$ & $\odot$ & - & - \\
\hline Edwards 2013 & $?$ & + & $\odot$ & $?$ & + & $\odot$ & $\odot$ \\
\hline Forges 2011 & $?$ & + & $\odot$ & $\odot$ & $?$ & $\odot$ & $\odot$ \\
\hline Guillemette 2014 & $?$ & $\odot$ & $\odot$ & $\odot$ & + & $\odot$ & $\odot$ \\
\hline Hama 2012 & $?$ & + & + & ? & $?$ & $\Theta$ & $\Theta$ \\
\hline Harrison 2006 & $?$ & + & + & $?$ & $?$ & - & - \\
\hline Janes 2015 & $?$ & $?$ & $\odot$ & $?$ & $?$ & $\odot$ & $\odot$ \\
\hline Juhasz 2016 & $?$ & + & + & $?$ & + & - & - \\
\hline Miyake 2013 & $?$ & + & + & 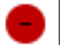 & + & $\Theta$ & + \\
\hline Mullot 2008 & $?$ & + & + & - & + & O & - \\
\hline Ozyaman 2016 & $?$ & + & + & $?$ & + & 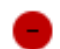 & 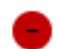 \\
\hline Poupeau 2016 & $?$ & $?$ & $\odot$ & $?$ & $?$ & - & O \\
\hline Roland 2017 & $?$ & $?$ & + & $?$ & + & $\Theta$ & $\Theta$ \\
\hline Sessink 2011 & $?$ & $?$ & + & ? & + & ค & $\Theta$ \\
\hline Sessink 2013 & $?$ & $?$ & + & $?$ & + & - & $\Theta$ \\
\hline Siderov 2010 & $?$ & $\odot$ & + & ? & + & 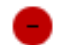 & + \\
\hline Simon 2016 & $?$ & + & + & - & + & ? & $\Theta$ \\
\hline Sottani 2012 & $?$ & $?$ & $\odot$ & $?$ & + & م & + \\
\hline Was 2016 & $?$ & + & + & - & + & 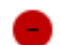 & - \\
\hline
\end{tabular}


Figure 2. (Continued)

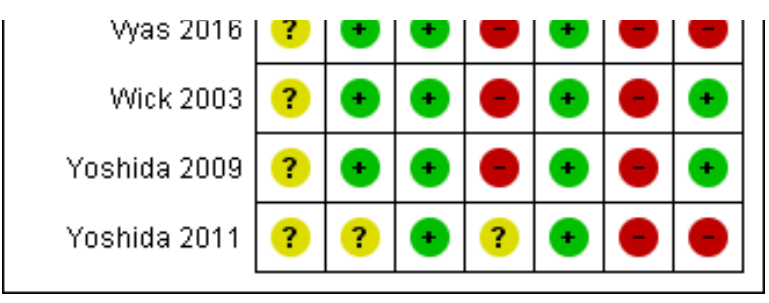

\section{Confounding bias}

There is insufficient information to assess the risk of confounding bias in all the studies (Berruyer 2015; Chan 2016; Chauchat 2017; Edwards 2013; Forges 2011; Guillemette 2014; Hama 2012; Harrison 2006; Janes 2015; Juhasz 2016; Miyake 2013; Mullot 2008; Ozyaman 2016; Poupeau 2016; Roland 2017; Sessink 2011; Sessink 2013; Siderov 2010; Simon 2016; Sottani 2012; Wick 2003; Yoshida 2009; Yoshida 2011). This is because none of the studies reported whether there were any baseline differences in any of the confounding factors.

\section{Selection bias}

Fourteen studies are at low risk of selection bias (Chan 2016; Edwards 2013; Forges 2011; Hama 2012; Harrison 2006; Juhasz 2016; Miyake 2013; Mullot 2008; Ozyaman 2016; Siderov 2010; Simon 2016; Vyas 2016; Wick 2003; Yoshida 2009). Nine studies are at moderate risk of selection bias, as the participating centres were probably selected or returned the questionnaire about CSTD use based on their safe handling practices (Berruyer 2015; Chauchat 2017; Janes 2015; Poupeau 2016; Roland 2017; Sessink 2011; Sessink 2013; Sottani 2012; Yoshida 2011). One study is at serious risk of bias as the sites of sampling differed between CSTD and control groups (Guillemette 2014). None of the studies are at critical risk of bias.

\section{Bias in classification of interventions}

All the studies are at low risk of bias since the classification of CSTD versus control was made clearly (Berruyer 2015; Chan 2016; Chauchat 2017; Edwards 2013; Forges 2011; Guillemette 2014; Hama 2012; Harrison 2006; Janes 2015; Juhasz 2016; Miyake 2013; Mullot 2008; Ozyaman 2016; Poupeau 2016; Roland 2017; Sessink 2011; Sessink 2013; Siderov 2010; Simon 2016; Sottani 2012; Vyas 2016; Wick 2003; Yoshida 2009; Yoshida 2011).

\section{Bias due to deviations from intended interventions}

There is insufficient information to assess the risk of bias due to deviations from intended interventions in 16 studies (Berruyer 2015; Chan 2016; Chauchat 2017; Edwards 2013; Hama 2012; Harrison 2006; Janes 2015; Juhasz 2016; Ozyaman 2016; Poupeau 2016; Roland 2017; Sessink 2011; Sessink 2013; Siderov 2010; Sottani 2012; Yoshida 2011), as they did not report whether the training periods and other co-interventions were similar in both groups. The remaining eight studies are at serious risk of bias, since it is clear that only CSTD groups received additional training while the control group did not receive an equivalent period of training in safe handling (Forges 2011; Guillemette 2014; Miyake 2013; Mullot 2008; Simon 2016; Vyas 2016; Wick 2003; Yoshida 2009).

\section{Bias due to missing data}

Eighteen studies are at low risk of bias due to missing data (Chan 2016; Chauchat 2017; Edwards 2013; Guillemette 2014; Juhasz 2016; Miyake 2013; Mullot 2008; Ozyaman 2016; Roland 2017; Sessink 2011; Sessink 2013; Siderov 2010; Simon 2016; Sottani 2012; Vyas 2016; Wick 2003; Yoshida 2009; Yoshida 2011). There is insufficient information to assess the risk of bias in the remaining six studies (Berruyer 2015; Forges 2011; Hama 2012; Harrison 2006; Janes 2015; Poupeau 2016), as there is either missing information, the impact of which on the effect estimates is not clear, or it is not clear whether there is missing information in the studies.

\section{Bias in measurement of outcomes}

All 24 studies are at serious risk of bias in measurement of outcomes as it appears that none of the studies used blinded assessment of outcomes (Berruyer 2015; Chan 2016; Chauchat 2017; Edwards 2013; Forges 2011; Guillemette 2014; Hama 2012; Harrison 2006; Janes 2015; Juhasz 2016; Miyake 2013; Mullot 2008; Ozyaman 2016; Poupeau 2016; Roland 2017; Sessink 2011; Sessink 2013; Siderov 2010; Simon 2016; Sottani 2012; Wick 2003; Yoshida 2009; Yoshida 2011).

\section{Bias in selection of the reported result}

Six studies are at low risk of bias in selection of the reported result (Forges 2011; Miyake 2013; Siderov 2010; Sottani 2012; Wick 2003; Yoshida 2009). The remaining 18 studies are at serious risk of bias in selection of the reported result: they report results partially (Berruyer 2015; Chan 2016; Chauchat 2017; Edwards 2013; Guillemette 2014; Hama 2012; Harrison 2006; Janes 2015; Juhasz 2016; Mullot 2008; Ozyaman 2016; Poupeau 2016; Roland 2017; Sessink 2011; Sessink 2013; Simon 2016; Vyas 2016; Yoshida 2011).

\section{Overall risk of bias}

All the studies are at serious risk of bias (Berruyer 2015; Chan 2016; Chauchat 2017; Edwards 2013; Forges 2011; Guillemette 2014; Hama 2012; Harrison 2006; Janes 2015; Juhasz 2016; Miyake 2013; Mullot 2008; Ozyaman 2016; Poupeau 2016; Roland 2017; Sessink 2011; Sessink 2013; Siderov 2010; Simon 2016; Sottani 2012; Vyas 2016; Wick 2003; Yoshida 2009; Yoshida 2011).

\section{Effects of interventions}

See: Summary of findings for the main comparison Closedsystem transfer device plus safe handling versus safe handling alone for reducing healthcare staff exposure to infusional hazardous drugs: exposure and surface contamination; Summary of findings 2 Closed-system transfer device plus safe handling versus safe handling alone for reducing healthcare staff exposure to infusional hazardous drugs: clinical outcomes 
The raw data used for analysis are available in Appendix 9 and Appendix 10.

\section{Primary outcomes}

\section{Exposure}

\section{Presence of hazardous drugs in urine}

Four studies (seven hospitals; 70 participants) report the proportion of people with positive urine tests for exposure (Miyake 2013; Sottani 2012; Wick 2003; Yoshida 2009). One study is a cross-sectional study involving four hospitals (Sottani 2012). The other studies are uncontrolled before-after studies, each involving a single hospital (Miyake 2013; Wick 2003; Yoshida 2009). The drugs measured in these trials are cyclophosphamide alone in two studies (Miyake 2013; Yoshida 2009), cyclophosphamide or ifosfamide in one study (Wick 2003), and cyclophosphamide, ifosfamide, or gemcitabine in one study (Sottani 2012). There are no considerable differences in the proportion of people with positive urine tests for exposure between the CSTD and control groups for cyclophosphamide alone (RR $0.83,95 \% \mathrm{Cl} 0.46$ to $1.52 ; \mathrm{I}^{2}=$ 0\%; 2 studies; 2 hospitals; 20 participants); cyclophosphamide or ifosfamide (RR $0.09,95 \% \mathrm{Cl} 0.00$ to $2.79 ; 1$ study; 1 hospital; 14 participants); and cyclophosphamide, ifosfamide, or gemcitabine (RR not estimable; 1 study; 4 hospitals; 36 participants) (Analysis 1.1). There is no alteration in the interpretation of results using the fixed-effect or the random-effects model.

Quality of evidence: the quality of evidence is very low because of the serious risk of bias in the studies (downgraded by one level), imprecision (small sample size (downgraded by one level) and wide confidence intervals (downgraded by one level)).

Subgroup analysis: since there is only one cross-sectional study and this is the only study examining cyclophosphamide, ifosfamide, or gemcitabine, we did not perform a subgroup analysis of uncontrolled before-after studies versus cross-sectional studies. PhaSeal was used in three studies (Miyake 2013; Wick 2003; Yoshida 2009). The authors of the fourth study did not report which device they used (Sottani 2012). There were no considerable differences in the proportion of people with positive urine tests for exposure between the PhaSeal and control groups (Analysis 2.1).

Sensitivity analysis: There is also no alteration in the interpretation of results using different intracluster correlation coefficients (ICC) (Analysis 3.1; Analysis 3.2; Analysis 3.3).

\section{Other measures of exposure}

None of the studies reported on blood tests or other measures of exposure to infusional hazardous drugs such as urine mutagenicity, chromosomal aberrations, sister chromatid exchanges, or micronuclei induction.

\section{Environmental contamination}

\section{Proportion of surfaces contaminated in pharmacy areas}

Fifteen studies (343 hospitals, 3156 surface samples) report the proportion of surface samples that were contaminated with various drugs in the pharmacy areas (Berruyer 2015; Chauchat 2017; Guillemette 2014; Janes 2015; Miyake 2013; Poupeau 2016; Roland 2017; Sessink 2011; Sessink 2013; Siderov 2010; Simon 2016; Sottani 2012; Vyas 2016; Wick 2003; Yoshida 2009). Seven are crosssectional studies involving 284 hospitals (Berruyer 2015; Chauchat
2017; Janes 2015; Poupeau 2016; Roland 2017; Simon 2016; Sottani 2012), and eight are uncontrolled before-after studies involving 59 hospitals (Guillemette 2014; Miyake 2013; Sessink 2011; Sessink 2013; Siderov 2010; Vyas 2016; Wick 2003; Yoshida 2009). There are no considerable differences in the proportion of surface samples that were contaminated between the CSTD and the control groups for any of the drugs in the pharmacy areas except 5-fluorouracil (Analysis 1.2).

- Cyclophosphamide: RR $0.89,95 \% \mathrm{Cl} 0.78$ to $1.01 ; \mathrm{I}^{2}=35 \%$ (13 studies: 7 uncontrolled before-after studies (Guillemette 2014; Miyake 2013; Sessink 2011; Sessink 2013; Siderov 2010; Wick 2003; Yoshida 2009); 6 cross-sectional studies (Berruyer 2015; Chauchat 2017; Janes 2015; Poupeau 2016; Roland 2017; Simon 2016); 338 hospitals, 2937 surface samples).

- Ifosfamide: RR $0.94,95 \% \mathrm{Cl} 0.74$ to $1.19 ; \mathrm{I}^{2}=8 \%$ (9 studies: 3 uncontrolled before-after studies (Guillemette 2014; Sessink 2011; Wick 2003); 6 cross-sectional studies (Berruyer 2015; Chauchat 2017; Janes 2015; Poupeau 2016; Roland 2017; Simon 2016); 304 hospitals, 2332 surface samples).

- Methotrexate: RR $0.84,95 \% \mathrm{Cl} 0.58$ to $1.22 ; \mathrm{I}^{2}=0 \%$ (6 studies: 1 uncontrolled before-after study (Guillemette 2014); 5 crosssectional studies (Berruyer 2015; Chauchat 2017; Janes 2015; Poupeau 2016; Roland 2017); 280 hospitals, 1781 surface samples).

- 5-fluorouracil: RR $0.63,95 \% \mathrm{Cl} 0.42$ to $0.94 ; \mathrm{I}^{2}=0 \%$ (4 studies: 2 uncontrolled before-after study (Sessink 2011; Vyas 2016); 2 cross-sectional studies (Chauchat 2017; Simon 2016); 107 hospitals, 1068 surface samples).

- Cytarabine: RR $0.72,95 \% \mathrm{Cl} 0.18$ to $2.86 ; \mathrm{I}^{2}=43 \%$ (2 studies: all cross-sectional studies (Chauchat 2017; Simon 2016); 84 hospitals, 780 surface samples).

- Gemcitabine: RR $0.96,95 \% \mathrm{Cl} 0.60$ to $1.54 ; \mathrm{I}^{2}=0 \%$ (2 crosssectional studies (Chauchat 2017; Simon 2016); 84 hospitals, 780 surface samples).

- Irinotecan: RR $0.36,95 \% \mathrm{Cl} 0.10$ to 1.33 (1 cross-sectional study (Chauchat 2017); 83 hospitals, 493 surface samples).

- Docetaxel: not estimable (1 cross-sectional study (Chauchat 2017); 83 hospitals, 493 surface samples).

- Paclitaxel: RR $0.57,95 \% \mathrm{Cl} 0.04$ to 9.06 (1 cross-sectional study (Chauchat 2017); 83 hospitals, 493 surface samples).

- Vinorelbine: RR $1.72,95 \% \mathrm{Cl} 0.16$ to 18.73 (1 cross-sectional study (Chauchat 2017); 83 hospitals, 493 surface samples).

- Ganciclovir: RR $0.01,95 \%$ Cl 0.00 to 27.11 (1 cross-sectional study (Simon 2016); 1 hospital, 287 surface samples).

- Epirubicin: RR 0.03, 95\% Cl 0.00 to 6.29 (1 uncontrolled beforeafter study (Vyas 2016); 1 hospital, 60 surface samples).

- Multiple drugs (data on each drug were not available): RR 0.87 , $95 \% \mathrm{Cl} 0.43$ to 1.77 (1 cross-sectional study (Sottani 2012); 4 hospitals, 109 surface samples).

There is no alteration in the interpretation of results using the fixedeffect or the random-effects model.

Quality of evidence: the quality of evidence is very low because of the serious risk of bias in all the studies (downgraded by one level); indirectness of the outcome, as all the outcomes reported are surrogate outcomes (downgraded by one level); and imprecision because of wide confidence intervals (downgraded by one level) or lack of evidence that the observed difference led to decreased 
exposure or tangible short-term or long-term health outcomes (downgraded by one level).

Subgroup analysis: there is no evidence of subgroup differences in the analyses that could be stratified by study design (uncontrolled before-after versus cross-sectional studies) (Analysis 2.2; Analysis 2.3; Analysis 2.4; Analysis 2.5). The device used in eight studies was PhaSeal (Guillemette 2014; Miyake 2013; Sessink 2011; Sessink 2013; Siderov 2010; Simon 2016; Wick 2003; Yoshida 2009). The devices used in five studies were variable (Berruyer 2015; Chauchat 2017; Janes 2015; Poupeau 2016; Roland 2017). The device used in one study was Tevadaptor (Vyas 2016). The last study did not report the device used in the study (Sottani 2012). There is no evidence of difference in proportion of surface samples that were contaminated between the PhaSeal and the control groups for any of the drugs other than cyclophosphamide (RR $0.88,95 \% \mathrm{Cl} 0.78$ to 0.99 ; 8 studies; 59 hospitals, 1278 surface samples; Analysis 2.6). There is no evidence of difference in proportion of surface samples that were contaminated between the Tevadaptor and the control groups for any of the drugs (Analysis 2.7)

Sensitivity analysis: there is also no alteration in the interpretation of results using different ICCS except for cyclophosphamide for intracluster coefficients of $0.05,0.01$, and 0.00 , and for ganciclovir and epirubicin for ICCs of 0.01 and 0.00 (Analysis 3.4; Analysis 3.5; Analysis 3.6).

\section{Proportion of surfaces contaminated in patient-care areas}

Six studies (283 hospitals, 1568 surface samples) reported the proportion of surface samples that were contaminated with various drugs in the patient-care areas (Berruyer 2015; Chauchat 2017; Janes 2015; Poupeau 2016; Roland 2017; Sottani 2012). There were no considerable differences in the proportion of surface samples that were contaminated with various drugs in the patient-care areas between the CSTD and control groups in the patient-care areas (Analysis 1.2).

- Cyclophosphamide: RR $1.01,95 \% \mathrm{Cl} 0.86$ to $1.18 ; \mathrm{I}^{2}=0 \%(5$ cross-sectional studies (Berruyer 2015; Chauchat 2017; Janes 2015; Poupeau 2016; Roland 2017); 279 hospitals, 1535 surface samples).

- Ifosfamide: RR $1.44,95 \% \mathrm{Cl} 0.91$ to $2.28 ; \mathrm{I}^{2}=20 \%$ (5 crosssectional studies (Berruyer 2015; Chauchat 2017; Janes 2015; Poupeau 2016; Roland 2017); 279 hospitals, 1535 surface samples).

- Methotrexate: RR $1.00,95 \% \mathrm{Cl} 0.55$ to $1.85 ; \mathrm{I}^{2}=0 \%$ (5 crosssectional studies (Berruyer 2015; Chauchat 2017; Janes 2015; Poupeau 2016; Roland 2017); 279 hospitals, 1535 surface samples).

- 5-fluorouracil: RR $1.09,95 \% \mathrm{Cl} 0.53$ to 2.23 (1cross-sectional study (Chauchat 2017); 83 hospitals, 460 surface samples).

- Cytarabine: RR 0.59, 95\% Cl 0.01 to 24.53 (1 cross-sectional study (Chauchat 2017); 83 hospitals, 460 surface samples).

- Gemcitabine: RR $1.13,95 \% \mathrm{Cl} 0.55$ to 2.33 (1 cross-sectional study (Chauchat 2017); 83 hospitals, 460 surface samples).

- Irinotecan: RR $0.44,95 \% \mathrm{Cl} 0.03$ to 6.15 (1 cross-sectional study (Chauchat 2017); 83 hospitals, 460 surface samples).

- Docetaxel: RR 0.59, 95\% Cl 0.01 to 24.53 (1 cross-sectional study (Chauchat 2017); 83 hospitals, 460 surface samples).

- Paclitaxel: RR $0.59,95 \% \mathrm{Cl} 0.01$ to 24.53 (1 cross-sectional study (Chauchat 2017); 83 hospitals, 460 surface samples).
- Vinorelbine: RR not estimable (1 cross-sectional study (Chauchat 2017); 83 hospitals, 460 surface samples).

- Multiple drugs (data on each drug were not available): RR 2.38, $95 \% \mathrm{Cl} 0.69$ to 8.23 (1 cross-sectional study (Sottani 2012); 4 hospitals, 33 surface samples).

Quality of evidence: the quality of evidence is very low because of the serious risk of bias in all the studies (downgraded by one level); indirectness, as all the reported outcomes are surrogate outcomes (downgraded by one level); and imprecision, as the confidence intervals are wide (downgraded by one level).

Subgroup analysis: all the analyses stratified by the drug measured in the samples included either uncontrolled before-after studies or cross-sectional studies. Therefore, a subgroup analysis based on study design is not possible. The devices used in five studies varied (Berruyer 2015; Chauchat 2017; Janes 2015; Poupeau 2016; Roland 2017), while one study did not report it (Sottani 2012).

Sensitivity analysis: there is also no alteration in the interpretation of results using ICCs of $0.05,0.01$, or 0.00 (Analysis 3.4; Analysis 3.4; Analysis 3.5).

\section{Quantity of contamination in surface samples from pharmacy areas}

Seven studies (282 hospitals, 1793 surface samples) report the quantity of contamination with cyclophosphamide from surface samples in pharmacy areas (Berruyer 2015; Chauchat 2017; Guillemette 2014; Janes 2015; Poupeau 2016; Roland 2017; Siderov 2010). Five are cross-sectional studies involving 279 hospitals using various types of CSTD (Berruyer 2015; Chauchat 2017; Janes 2015; Poupeau 2016; Roland 2017), and two are uncontrolled beforeafter studies involving three hospitals using PhaSeal (Guillemette 2014; Siderov 2010). The amount of cyclophosphamide is lower in pharmacy areas between the CSTD group and the control group (MD $-49.34 \mathrm{pg} / \mathrm{cm}^{2}, 95 \% \mathrm{Cl}-84.11$ to $-14.56, \mathrm{I}^{2}=0 \%$; Analysis 1.3 ). There is no alteration in the interpretation of results using the fixedeffect or the random-effects model.

In addition, one interrupted time-series study (3 hospitals; 342 samples) provides data on the quantity of contamination with cyclophosphamide from surface samples in pharmacy areas during three, three-week phases: initial phase of no CSTD, followed by CSTD, and then by no CSTD (Harrison 2006). Investigators took biweekly measurements in all three phases. Between the first two phases, the change in the slope between pre-CSTD and CSTD was $3.9439 \mathrm{pg} / \mathrm{cm}^{2}$ (95\% Cl 1.2303 to 6.6576; $\mathrm{P}=0.01$ ). Between the second and third phases, the slope and level were expected to rise again, but the change in the slope between CSTD and post-CSTD withdrawal was $-1.9331 \mathrm{pg} / \mathrm{cm}^{2}(95 \% \mathrm{Cl}-5.126$ to $1.2598 ; \mathrm{P}=0.200)$, and the level was $14.1670 \mathrm{pg} / \mathrm{cm}^{2}(\mathrm{SD}=10.6190)$.

Six studies (280 hospitals, 1749 surface samples) report the quantity of contamination with ifosfamide and methotrexate from surface samples in pharmacy areas (Berruyer 2015; Chauchat 2017; Guillemette 2014; Janes 2015; Poupeau 2016; Roland 2017). Five studies are cross-sectional studies involving 279 hospitals using various types of CSTD (Berruyer 2015; Chauchat 2017; Janes 2015; Poupeau 2016; Roland 2017), and one study is an uncontrolled before-after study involving one hospital using PhaSeal (Guillemette 2014). There are no considerable differences in the amount of ifosfamide and methotrexate in pharmacy areas between the CSTD group and the control group (MD $-0.32 \mathrm{pg} / \mathrm{cm}^{2}$, 
$95 \% \mathrm{Cl}-6.58$ to $5.94, \mathrm{I}^{2}=11 \%$ and $\mathrm{MD}-3.09 \mathrm{pg} / \mathrm{cm}^{2}, 95 \% \mathrm{Cl}-13.80$ to $7.61, \mathrm{I}^{2}=0 \%$, respectively; Analysis 1.3 ). There is no alteration in the interpretation of results using the fixed-effect or the randomeffects model.

Three studies (85 hospitals, 602 surface samples) report the quantity of contamination with 5-fluorouracil (Chauchat 2017; Forges 2011; Vyas 2016). Two were cross-sectional studies (Chauchat 2017; Forges 2011), while the third one was an uncontrolled before-after study (Vyas 2016). One study used variable CSTD (Chauchat 2017), one study used Spike Swan (Forges 2011), and the last study used Tevadaptor (Vyas 2016). There are no considerable differences in the amount of 5 -fluorouracil in pharmacy areas between the CSTD group and the control group ((MD $231.62 \mathrm{pg} / \mathrm{cm}^{2}, 95 \% \mathrm{Cl}-460.52$ to 923.76$)$.

One study (83 hospitals, 493 surface samples) reports the quantity of contamination with cytarabine, gemcitabine, and irinotecan from surface samples in pharmacy areas (Chauchat 2017). This is a cross-sectional study involving 83 hospitals using various types of CSTD (Chauchat 2017). There are no considerable differences in the amount of cytarabine, gemcitabine, and irinotecan in pharmacy areas between the CSTD group and the control group (cytarabine: $\mathrm{MD}-0.60 \mathrm{pg} / \mathrm{cm}^{2}, 95 \% \mathrm{Cl}-15.67$ to 14.47 ; gemcitabine: MD -32.70 $\mathrm{pg} / \mathrm{cm}^{2}, 95 \% \mathrm{Cl}-102.43$ to 37.03 ; and irinotecan: $\mathrm{MD}-18.27 \mathrm{pg} / \mathrm{cm}^{2}$, $95 \% \mathrm{Cl}-56.89$ to 20.35 ; Analysis 1.3 ).

One study (1 hospital, 60 surface samples) reports the quantity of contamination with epirubicin from surface samples in pharmacy areas (Vyas 2016). The amount of epirubicin is lower in pharmacy areas between the CSTD group and the control group (MD -110.00 $\mathrm{pg} / \mathrm{cm}^{2}, 95 \% \mathrm{Cl}-112.93$ to -107.07 ) (Analysis 1.3).

Quality of evidence: the quality of evidence is very low because of the serious risk of bias in all the studies (downgraded by one level); indirectness, as all the reported outcomes are surrogate outcomes (downgraded by one level); and imprecision, as the confidence intervals are wide (downgraded by one level) or there is no evidence that the observed difference led to decreased exposure or tangible short-term or long-term health outcomes (downgraded by one level).

Subgroup analysis: there is no evidence of subgroup differences based on study design for the drugs for which we could perform subgroup analyses (Analysis 2.8; Analysis 2.9; Analysis 2.10; Analysis 2.12). Two studies used PhaSeal (Guillemette 2014; Siderov 2010), one study used Spike Swan (Forges 2011), and one study used Tevadaptor (Vyas 2016). We could perform tests for subgroup differences for 5-fluorouracil only as there is no comparison using two different types of CSTD for the remaining comparisons. There is no evidence of subgroup differences based on device for 5fluorouracil. Only one study reports the use of a single type of CSTD (PhaSeal) before measuring ifosfamide and methotrexate in pharmacy areas. There is no evidence of difference in the amount of ifosfamide and methotrexate between PhaSeal and control groups (ifosfamide: MD $-2.59 \mathrm{pg} / \mathrm{cm}^{2}, 95 \% \mathrm{Cl}-26.75$ to 21.57; and methotrexate: MD $10.34 \mathrm{pg} / \mathrm{cm}^{2}, 95 \% \mathrm{Cl}-34.01$ to 54.69 ; Guillemette 2014; Analysis 2.11). All the studies that measured the quantity of contamination in patient-care areas used varied CSTDs, so we could not perform a subgroup analysis based on device.
Sensitivity analysis: there is also no alteration in the interpretation of results using ICCS of $0.05,0.01$, and 0.00 (Analysis 3.7; Analysis 3.8; Analysis 3.9).

\section{Quantity of contamination in surface samples from patient-care areas}

Five studies (279 hospitals, 1535 surface samples) report the quantity of contamination from surface samples in different drugs (cyclophosphamide, ifosfamide, and methotrexate) in patient-care areas (Berruyer 2015; Chauchat 2017; Janes 2015; Poupeau 2016; Roland 2017). All studies have a cross-sectional design and used various types of CSTD. There are no considerable differences in the amount of cyclophosphamide, ifosfamide, and methotrexate in patient-care areas between CSTD group and the control group (cyclophosphamide: MD $-13.34 \mathrm{pg} / \mathrm{cm}^{2}, 95 \% \mathrm{Cl}-36.01$ to $9.32, \mathrm{I}^{2}$ $=0 \%$; ifosfamide: $M D 3.59 \mathrm{pg} / \mathrm{cm}^{2}, 95 \% \mathrm{Cl}-3.45$ to $10.63, \mathrm{I}^{2}=0 \%$; and methotrexate: $\mathrm{MD} 0.10 \mathrm{pg} / \mathrm{cm}^{2}, 95 \% \mathrm{Cl}-0.57$ to $0.78, \mathrm{I}^{2}=0 \%$ ) (Analysis 1.3).

One cross-sectional study ( 83 hospitals, 460 surface samples) using various types of CSTD reports the quantity of contamination with 5-fluorouracil, cytarabine, gemcitabine, and irinotecan from surface samples in patient-care areas (Chauchat 2017). There are no considerable differences in the amount of 5-fluorouracil, cytarabine, gemcitabine, and irinotecan in patient-care areas between CSTD group and the control group (5-fluorouracil: MD $-43.90 \mathrm{pg} / \mathrm{cm}^{2}, 95 \% \mathrm{Cl}-141.51$ to 53.71 ; cytarabine: $\mathrm{MD}-0.20 \mathrm{pg} /$ $\mathrm{cm}^{2}, 95 \% \mathrm{Cl}-0.79$ to 0.39 ; gemcitabine: $\mathrm{MD} 0.47 \mathrm{pg} / \mathrm{cm}^{2}, 95 \% \mathrm{Cl}$ -1.77 to 2.71 ; and irinotecan: $\mathrm{MD}-0.05 \mathrm{pg} / \mathrm{cm}^{2}, 95 \% \mathrm{Cl}-0.15$ to 0.05 ; Analysis 1.3).

Quality of evidence: the quality of evidence is very low because of the serious risk of bias in all the studies (downgraded by one level); indirectness, as all the outcomes reported are surrogate outcomes (downgraded by one level); and imprecision, as the confidence intervals are wide (downgraded by one level). In addition, there is evidence of publication bias for the quantity of cyclophosphamide in patient areas (downgraded by one level).

Subgroup analysis: all studies used various types of CSTD.

Sensitivity analysis: there is also no alteration in the interpretation of results using ICCS of $0.05,0.01$, and 0.00 (Analysis 3.7; Analysis 3.8; Analysis 3.9).

\section{Atmospheric contamination}

None of the studies report atmospheric contamination.

\section{Short-term health outcomes}

None of the studies report short-term health outcomes such as skin rashes.

\section{Medium-term health outcomes}

None of the studies report medium-term health outcomes such as reproductive health effects (infertility or miscarriage).

\section{Long-term health outcomes}

None of the studies report long-term health outcomes such as development of any type of cancer. 


\section{Secondary outcomes}

\section{Adverse events}

None of the studies report adverse events.

\section{Potential cost savings due to reuse of multi-dose vials}

Five studies report on cost savings for drugs or the devices used for administration or both (Chan 2016; Edwards 2013; Juhasz 2016; Mullot 2008; Ozyaman 2016). None of the studies included personnel costs (i.e. the time spent by healthcare professionals on preparation or administration) while calculating the overall costs. Four studies are uncontrolled before-after studies conducted in a single hospital (Chan 2016; Edwards 2013; Mullot 2008; Ozyaman 2016), and one is an uncontrolled before-after study conducted in two hospitals (Juhasz 2016). Only three studies included the costs of CSTD in the calculation of cost differences (Chan 2016; Edwards 2013; Mullot 2008). The remaining two studies did not (Juhasz 2016; Ozyaman 2016). The cost savings due to CSTD are based on the potential of CSTD to maintain drug sterility for a longer period of time. However, only one study included the costs based on actual drug consumption (Mullot 2008); since this study also included the costs of CSTD, these cost savings are actual cost savings. Two studies calculated the actual drugs costs in CSTD group but calculated the potential cost savings based on the number of drug vials that would have been used if CSTD were not used (Chan 2016; Edwards 2013). The remaining two studies simulated cost savings based on the drug remaining in the vials (Juhasz 2016; Ozyaman 2016). Sufficient data for meta-analysis were available for only one study (Chan 2016). For these two reasons (variability in the calculation of costs and the lack of sufficient data to perform the meta-analysis), we have tabulated the data in Table 1, where we report the annual cost savings both as originally reported and after conversion to 2017 USD using the PPP conversion rates and GDP deflators reported in the October 2017 version of the World Economic Outlook Database.

As noted in Table 1, there is significant variability between the studies in terms of whether the use of CSTD results in cost savings (the point estimates of the average potential cost savings range between (2017) USD -642,656 and (2017) USD +221,818). Therefore, we cannot reach any conclusion on whether the use of CSTD in general or a particular type of CSTD results in cost savings. However, the study that reported actual cost savings reported higher costs in the CSTD group than the control group (Mullot 2008). The quality of evidence is very low for this outcome because of the serious risk of bias in all the studies (downgraded by one level) and the significant variability of the results between the studies both in magnitude and direction (downgraded by two levels).

\section{Subgroup analysis}

We will perform the following subgroup analyses given sufficient data in future updates of this review; the reasons for not performing these in this review are stated below.

- Study design (CBA studies versus other non-randomised study designs): there are no CBA studies.

- Study design (individual versus cluster unit of analysis): all studies are cluster studies.

- Professional role (pharmacy technician versus chemotherapy nurse versus other healthcare staff): no separate data were reported for different professional roles in the two studies that included nurses.

- Duration of possible exposure: the range of exposure to hazardous drugs is from two weeks to seven months in the studies that reported the presence of hazardous drugs in urine and the duration of exposure. Thus, all the studies included participants who had short-term exposure to hazardous drugs and short-term follow-up.

- Control (safe handling following UK HSE standards): none of the studies took place in the UK, and none of the studies report whether they followed UK HSE standards.

\section{Reporting bias}

There was is evidence of reporting bias or small study effects for the following outcomes measured in at least five studies either by visualisation or by Egger's test (Figure 3; Figure 4). 
Figure 3. Funnel plot of comparison: 1 Closed-system transfer device plus safe handling versus safe handling alone, outcome: 1.2 Proportion of surfaces contaminated.

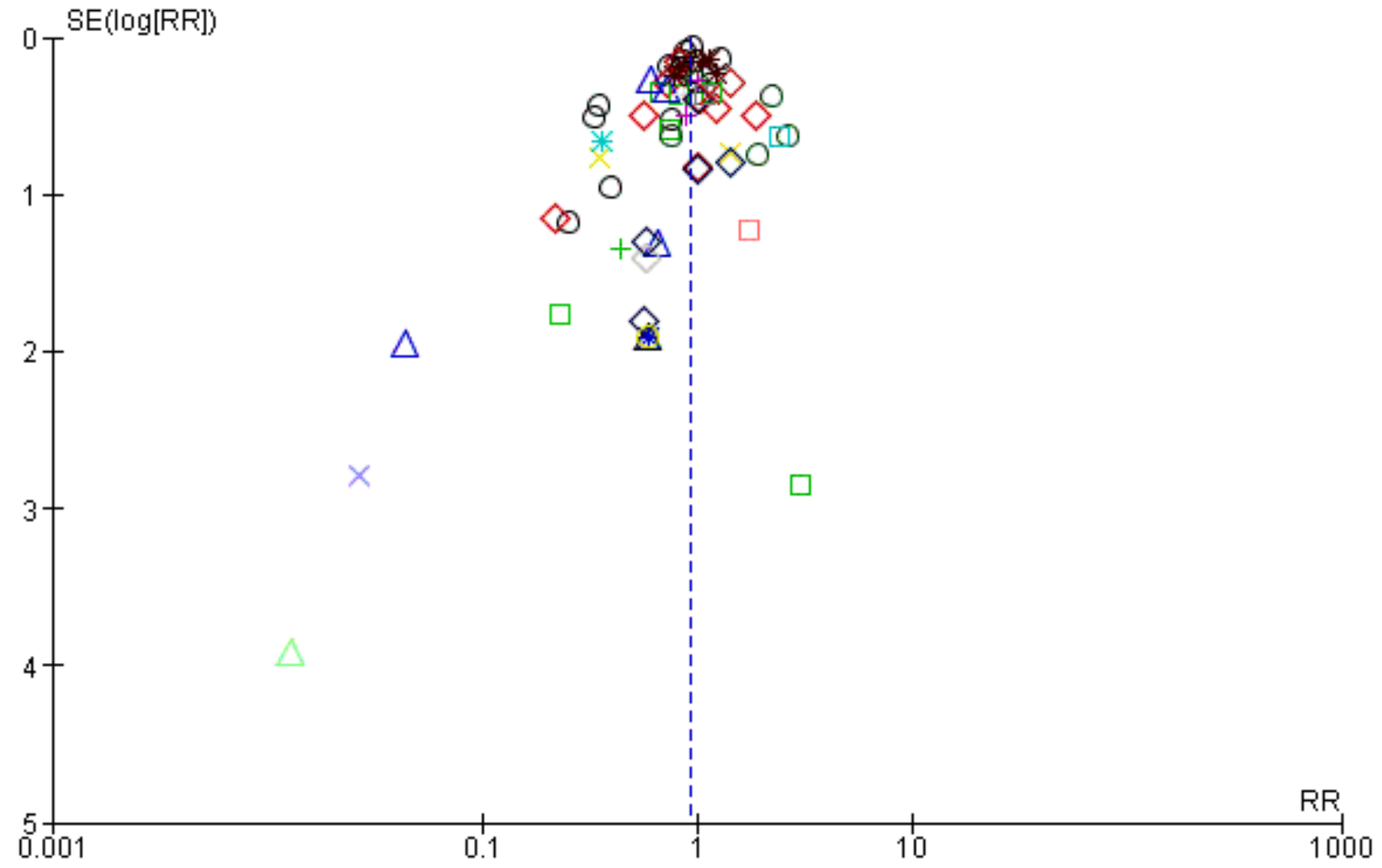

\section{Subgroups}

Cyclophosphamide (pharmacy areas)

$\diamond$ Ifosfamide (pharmacy areas)

Methotrexate (pharmacy areas)

$\triangle 5$-fluorouracil (pharmacy areas)

Cytarabine (pharmacy areas)

+ Gemcitabine (pharmacy areas)

* Irinotecan (pharmacy areas)

Docetaxel (pharmacy areas)

Paclitaxel (pharmacy areas)

Vinorelbine (pharmacy areas)

Ganciclovir (pharmacy areas)

Epirubicin (pharmacy areas)

Multiple drugs (pharmacy areas)

* Cyclophosphamide (patient-care areas)

$\bigcirc$ Ifosfamide (patient-care areas)

$>$ Methotrexate (patient-care areas)

5-fluorouracil (patient-care areas)

Cytarabine (patient-care areas)

Gemcitabine (patient-care areas)

+ Irinotecan (patient-care areas)

* Docetaxel (patient-care areas)

Paclitaxel (patient-care areas)

$\diamond$ Vinorelbine (patient-care areas)

$\square$ Multiple drugs (patient-care areas) 
Figure 4. Funnel plot of comparison: 1 Closed-system transfer device plus safe handling versus safe handling alone, outcome: 1.3 Quantity of surface contamination $\left(\mathrm{pg} / \mathrm{cm}^{2}\right)$.
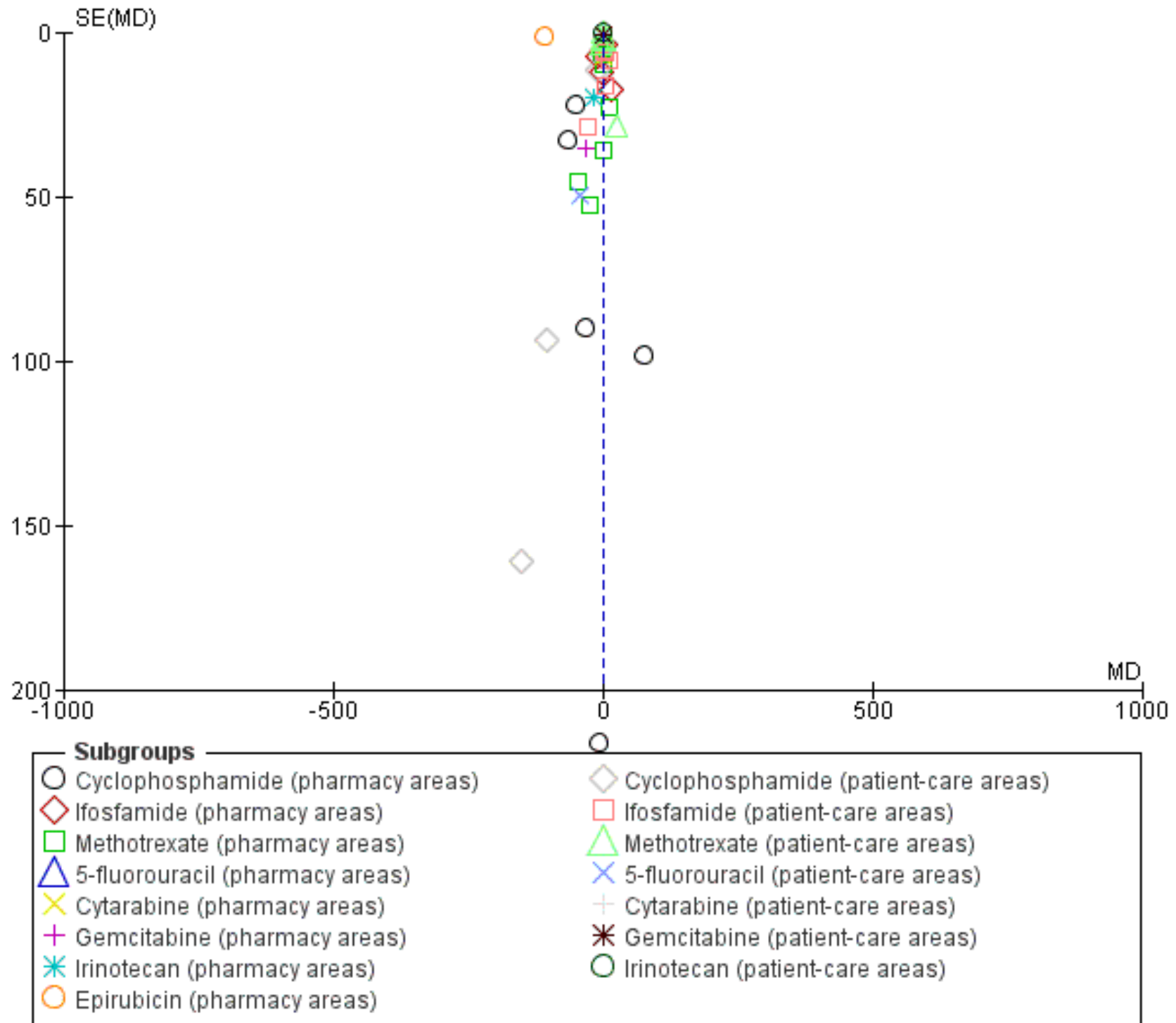

\begin{tabular}{|ll|}
\hline Subgroups & 0 \\
$\diamond$ Cyclophosphamide (pharmacy areas) & cyclophosphamide (patient-care areas) \\
$\triangleright$ Ifosfamide (pharmacy areas) & Ifosfamide (patient-care areas) \\
$\square$ Methotrexate (pharmacy areas) & Methotrexate (patient-care areas) \\
$\triangle$ 5-fluorouracil (pharmacy areas) & 5-fluorouracil (patient-care areas) \\
Cytarabine (pharmacy areas) & Cytarabine (patient-care areas) \\
+ Gemcitabine (pharmacy areas) & Gemcitabine (patient-care areas) \\
* Irinotecan (pharmacy areas) & $\bigcirc$ Irinotecan (patient-care areas) \\
Epirubicin (pharmacy areas) & \\
\hline
\end{tabular}

- Proportion of surfaces contaminated

- Ifosfamide (pharmacy areas): $P=0.929$

- Methotrexate (pharmacy areas): $P=0.768$

- Cyclophosphamide (patient-care areas): $\mathrm{P}=0.454$

- Ifosfamide (patient-care areas): $P=0.582$

- Methotrexate (patient-care areas): $P=0.438$

- Quantity of surface contamination

* Cyclophosphamide (pharmacy areas): $\mathrm{P}=0.662$

* Ifosfamide (pharmacy areas): $\mathrm{P}=0.509$

* Methotrexate (pharmacy areas): $P=0.479$

* Ifosfamide (patient-care areas): $\mathrm{P}=0.391$

* Methotrexate (patient-care areas): $\mathrm{P}=0.956$

The only exceptions for this are for differences in the proportion of surfaces contaminated with cyclophosphamide and quantity of cyclophosphamide in patient-care areas, which are statistically significant $(P=0.026$ and $P=0.002)$. This is because the point estimate of the difference between CSTD and control group is less in the studies with the least standard error (i.e. the studies that contributed more to the analysis) compared to the other studies (which contributed less to the meta-analysis), indicating potential small-study effects.

\section{DISCUSSION}

\section{Summary of main results}

In this systematic review, we included 24 observational studies comparing CSTD plus safe handling versus safe handling alone. There are no randomised controlled trials on this topic. Twenty-two studies report one or more outcomes for this review. However, the only outcomes reported in these 22 studies are exposure, surface contamination, and potential cost savings. None of the studies report important health outcomes relevant for healthcare staff 
exposed to infusional hazard drugs such as reduction in skin rashes, infertility, miscarriage, or the development of any type of cancer.

In terms of exposure, evidence of differences between CSTD plus safe handling versus safe handling alone is too uncertain for drawing conclusions. Decreased exposure, as defined by the presence of one or more hazardous drugs within the body (established via e.g. urine testing) or in the immediate vicinity (established via surface sampling), can result in beneficial shortterm or long-term health outcomes as exposure to hazardous drugs is probably associated with an increased risk of cancer, decreased fertility, congenital abnormalities, miscarriages, stillbirths, and low birthweight (Connor 2014; HSE 2017; NIOSH 2004).

There was a statistically significant reduction in the proportion of samples that were contaminated with 5 -fluorouracil (1/24 comparisons of proportion of surfaces contaminated in pharmacy or patient-care areas) and in the quantity of cyclophosphamide and epirubicin contamination in the CSTD plus safe handling group versus safe handling alone in pharmacy areas ( $2 / 15$ comparisons of quantity of contamination in pharmacy or patient-care areas). However, the quality of the evidence of differences in proportion of surfaces contaminated or quantity of surface contamination in pharmacy areas is too low to make a conclusion. Further, the quality of the evidence of differences in the proportion of surfaces contaminated or the quantity of surface contamination in patient areas is also too low to be certain about the presence or absence of a difference.

With regards to cyclophosphamide and epirubicin, the surface contamination in pharmacy areas is about $50 \mathrm{pg} / \mathrm{cm}^{2}$ and $110 \mathrm{pg} /$ $\mathrm{cm}^{2}$ less in the intervention group than in the control. There are multiple issues with this small difference. Firstly, the difference in quantity of contamination was found only for two drugs in the pharmacy area (and did not extend to patient-care areas or other drugs), that is, the healthcare staff are still exposed to cyclophosphamide or epirubicin in other areas and other hazardous drugs in pharmacy and patient-care areas. Moreover, by design, CSTDs do not protect healthcare staff from hazardous orally administered drugs. Therefore, the healthcare staff may be exposed to hazardous oral drugs, which can lead to the same ill effects of infusional hazardous drugs. However, hazardous oral drugs were not typically reported in the studies comparing CSTD plus safe handling versus safe handling alone, making it difficult to assess the potential effect of reducing some specific infusional hazardous drugs. Because of the many hazardous drugs to which healthcare professionals are exposed, any assessment of surface contamination and exposure by measuring a limited number of hazardous drugs can only be an estimation of the overall exposure (Connor 2006). A correlation between two outcomes does not make one outcome a good surrogate of another (Bucher 1999; Fleming 1996; Kim 2015; Prentice 1989; Rupp 2017a; Yudkin 2011). A reduction in the surface contamination by CSTD should result in decreased exposure or increased short or long-term health outcomes for it to be called a good surrogate outcome. To summarise, the clinical relevance of this small reduction in the quantity of cyclophosphamide or epirubicin in terms of reducing overall exposure and improving short-term or long-term health outcomes is not known.

With regards to 5 -fluorouracil, the evidence is too uncertain to conclude there is a reduction in quantity of 5 -fluorouracil, though we note a reduction in the proportion of surfaces contaminated with 5-fluorouracil.There are several possible explanations for this. One possibility is that there was insufficient power to detect a reduction in quantity of 5-fluorouracil. Even if this were the case (and there was an actual reduction in 5-fluorouracil), the same issues arise that did for a reduction in cyclophosphamide: does this reduction decrease overall exposure or does it lead to short or long-term health outcomes. A second possibility is that despite a reduction in the surfaces contaminated with 5 -fluorouracil, the overall quantity of contamination with 5 -fluorouracil is the same. A third possibility is that the differences may be due to different studies included under the outcome, which may reflect selective outcome reporting, which may in turn indicate that there is actually no reduction in the quantity of 5-fluorouracil. In the second and third possibilities, it is unknown whether reducing the proportion of surfaces contaminated with 5-fluorouracil without reducing its overall quantity leads to a decrease in overall exposure or to an improvement in health.

All things considered, there is substantial uncertainty in whether the addition of CSTD to safe handling practices decreases exposure or has any reduction in exposure or provides short or long-term health outcomes in healthcare staff using infusional hazardous drugs.

There in significant variability in the potential cost savings. The way that the cost savings were calculated varied significantly between the studies. A meta-analysis is not possible because of the variability in the methods used in calculating potential cost savings and the lack of sufficient information to perform the metaanalysis. Only one study includes the costs based on actual drug consumption and costs of CSTD (Mullot 2008). This study reports higher costs. The other studies simulated cost savings, which is likely to overestimate them. None of the studies include personnel costs (costs involved in preparing the drugs and administration of the drugs) when evaluating the cost savings. Overall, there is great uncertainty in whether CSTD saves any money. Future studies should include the total actual drug costs (based on actual drug consumption rather than potential drug consumption), CSTD costs, and personnel costs (costs involved in preparing the drugs and administration of the drugs).

Based on the above observations, there is currently significant uncertainty on whether the routine use of CSTD in addition to safe handling of infusional hazardous drugs leads either to decreased exposure, short-term or long-term health outcomes, or financial benefits.

\section{Overall completeness and applicability of evidence}

Although we did not restrict the inclusion of studies based on the hospital size, all the studies that provide information on the size of the hospitals included only hospitals with at least 50 beds. Therefore, the evidence is applicable only to such hospitals. Most of the information for this review comes from pharmacy areas; therefore the evidence is applicable only for these areas. However, patient-care areas are equally important, as healthcare staff are also exposed to residual hazardous drugs in these settings. Again, if studies use surrogate measures such as surface contamination to estimate the potential short-term or long-term health outcome of CSTD, they should measure surface contamination in patientcare areas in order to provide a reasonable estimate of the health outcomes of using CSTD. The healthcare professionals in the studies that provide data were mostly pharmacists or 
pharmacy technicians. Therefore, the evidence is mainly applicable for pharmacists and pharmacy technicians. Most of the studies that provide information for this review evaluated the use of PhaSeal; therefore the findings are mostly applicable to PhaSeal.

\section{Quality of the evidence}

The overall quality of evidence is very low. The major reasons for this are as follows.

Risk of bias: all the studies are at serious risk of bias. The main reasons for this are the use of co-interventions (for example, additional training of staff in CSTD without the control group receiving the same amount of training in safe handling) and lack of blinded measurement of outcomes. None of the studies report using an independent person (blinded to the groups) for obtaining surface samples. In addition, we assigned a 'no information' label for confounding bias on all the studies due to inadequate information regarding details such as the surfaces being clean prior to the start of the exposure. This is a particularly important problem with uncontrolled before-after studies since standard cleaning techniques may not be sufficient to get rid of the surface contamination, which might mean that the surfaces might have had several years of exposure to contamination in the 'safe handling alone' group, while those in the 'CSTD group plus safe handling' group are exposed to only a short period of exposure to contamination (a few months typically) because of thorough cleaning prior to start of CSTD. Even when the exposure outcome was measured objectively, such as with a urine test where the levels can be measured using automated equipment, we found the risk of bias to be serious.

Future studies should try to address these issues by using appropriate study designs that ensure that the only difference between CSTD and control is the use of CSTD, and that an independent person (blinded to the groups) obtains surface samples. Another major issue is selective reporting bias, as in many instances study authors did not report their results fully. While we acknowledge that it is not mandatory to register observational studies, future studies should publish a protocol prior to conducting the study and report all the results so that it is clear that results are not reported based on the observations.

Inconsistency: there is no evidence of inconsistency in the results for exposure; however, there is major inconsistency in the methodology and results of potential cost savings by CSTD. In particular, we noted major differences in the results between studies that used actual cost savings and simulated cost savings. Future studies should report the actual cost savings rather than simulated cost savings.

Indirectness of evidence: because of the many hazardous drugs to which healthcare professionals are exposed, any assessment of exposure by measuring a limited number of hazardous drugs can only be an estimation of the overall exposure (Connor 2006). In addition, surface contamination can be considered a surrogate for exposure since there is an association between the two variables (Connor 2006).

Imprecision: as shown in the sample size calculations below, the sample size included in this review is too small to detect a difference in urinary exposure. In the absence of information on how much difference in proportion of samples contaminated or in quantity of contamination is clinically beneficial, it was not easy to assess whether the overall sample size was sufficient to detect differences between CSTD and control for surface contamination.

Publication bias: visualisation of funnel plots and Egger's test did not reveal any publication bias for most of the outcomes in which at least five studies were included. Registration of studies prior to conducting them allows better assessment of both selective reporting and publication bias.

\section{Potential biases in the review process}

We followed the protocol we formulated before we started conducting this Cochrane systematic review (Gurusamy 2017). The only major deviation is the sensitivity analysis using different intracluster correlation coefficients (ICCS). However, we performed this only to assess the reason for the differences in the conclusions reached by us and a number the study authors; in particular, we did not use these post hoc sensitivity analyses to make any inferences about the effect of CSTD.

While we have minimised the errors in study selection and data extraction by independent, duplicate performance of these processes, we may have missed studies that do not mention CSTD in the title or abstract. It is impractical to review the full text of all references (we identified 7321 unique references using our search strategy). In this regard, we followed our protocol of screening the title and abstract and obtaining full texts for references considered relevant based on the full text. Besides, these studies (which do not mention CSTD in the title or abstract) are likely to show no evidence of benefit of CSTD (the probable reason for not mentioning CSTD in the title or abstract); therefore, our conclusions are unlikely to change.

None of the studies reported an ICC. Therefore, we used the value of 0.10 decided a priori based on studies about implementation research (Campbell 2001). The results were robust in a sensitivity analysis using 0.05 for the ICC (i.e. half the correlation noted in similar studies) for most analyses; therefore, our conclusions would probably not change even if the studies had reported the intracluster correlation. However, we recommend that study authors report intracluster correlations in the future to enable accurate estimation of their results.

\section{Agreements and disagreements with other studies or reviews}

This is the first systematic review on the topic. We disagree with the study authors who concluded that routine CSTD use is beneficial (Edwards 2013; Hama 2012; Juhasz 2016; Miyake 2013; Ozyaman 2016; Sessink 2011; Sessink 2013; Siderov 2010; Simon 2016; Wick 2003; Yoshida 2011). Ignoring the design effect by not adjusting the effect estimates for intracluster correlation can lead to an underestimation of random errors (Killip 2004); consequently this could lead to erroneous conclusions. Many study authors concluded that CSDTs decrease contamination or exposure in contrast to our conclusion that this is uncertain. The reason for this discrepancy is that the study authors appear to have ignored the clustering of participants and the risk of bias in their studies. 


\section{AUTHORS' CONCLUSIONS}

\section{Implications for practice}

The available evidence does not support or refute the routine use of closed-system drug transfer devices in addition to safe handling of infusional hazardous drugs, as the evidence is too uncertain to conclude that there are differences in exposure or financial benefits between CSTD plus safe handling versus safe handling alone. None of the studies report health benefits.

\section{Implications for research}

Future studies should be designed in such a way as to decrease the risk of bias.

\section{Study design}

Well-designed multicentre randomised controlled trials may be feasible if the exposure, as measured by urine samples, is high (please see sample size calculations below). The next best study design is interrupted time-series, which is likely to provide a better estimate than uncontrolled before-after studies or cross-sectional studies. In all types of study designs, investigators should take steps to ensure that there are no other differences between CSTD and control groups, so that they can obtain a reasonable estimate of decrease in exposure and the short-term or long-term health effects of using CSTD. This includes measures such as proper cleaning of the surfaces prior to exposure of both the intervention and control groups (i.e. all surfaces should be cleaned and samples taken to ensure that they are clean, followed by exposure to an equivalent period of time in the safe handling alone group as in the CSTD plus safe handling group), so that there is no residual contamination. Likewise, staff in both groups should receive an equal period of training for CSTD plus safe handling and safe handling alone of infusional hazardous drugs. This will ensure that the effect observed is the true effect due to CSTD. Other information of interest includes the annual drug use within the centre, description of the tasks performed by the staff, and the safe handling practices used, so that it is possible to estimate the effect of CSTD in different situations. Studies should register their protocol prospectively, for example in journal publications, ClinicalTrials.gov, or scientific repositories such as zenodo.org.

\section{Population}

Staff exposed to infusional hazardous drugs.

\section{Study arms}

Intervention: CSTD plus safe handling.

Control: safe handling alone or other measures such as central priming of intravenous tubes, cleaning of vials, cleaning of surfaces, management of patient excreta and storage in addition to safe handling (multi-arm randomised controlled trials or factorial trial design).

\section{Outcomes}

Primary outcome: exposure to an appropriate selection of hazardous drugs used in the hospitals.

Secondary outcomes: short-term or long-term health outcomes and cost-effectiveness.
In the future, studies using exposure as an outcome should measure exposure to a relevant selection of hazardous drugs in order to provide a reasonable estimate of the short-term or long-term health effects of using CSTD. Surface contamination should be considered less important than exposure. This is because the staff are exposed to other unmeasured hazardous drugs and contamination in patient-care areas. Using surface contamination as the primary outcome has the potential to lead to complacency in handling drugs.

\section{Sample size calculations}

The baseline risk of cancers in people exposed to hazardous drugs is $0.3 \%$ (Ratner 2010). Using an alpha error of $5 \%$, power of $80 \%$, and a relative risk reduction of $20 \%$, the unadjusted sample size required is 234,830 . Using an ICC of 0.10 and the median cluster size of 13 observed in the studies that report on exposure, the sample size adjusted for clustering is 516,626.

The baseline risk of congenital anomalies in women who were exposed to hazardous drugs is $0.1 \%$ to $6.0 \%$ (Connor 2014). Using the median baseline risk of congenital anomalies and the same parameters as for the previous sample size calculation, the unadjusted sample size required is 30,078 and the adjusted sample size is 66,172 .

The risk of stillbirths, miscarriages, and tubal pregnancies in women exposed to hazardous drugs is $0.1 \%$ to $25.9 \%$, depending on the methods used to calculate the risk (Connor 2014). This results in an unadjusted sample size of 31,474 and an adjusted sample size of 69,243 using the median baseline risk of $2.2 \%$ and the same parameters of above.

The true incidence of acute ill health effects due to exposure to infusional hazardous drugs is not known. Using an estimate of $5 \%$ of people using safe handling practices with the remaining parameters remaining the same as above, an unadjusted sample size of 13,492 and adjusted sample size of 29,682 is required.

None of these outcomes can be explored in randomised controlled settings because these sample sizes are impractical, even if the ICC were much smaller than 0.10 . About $77 \%$ of people using safe handling alone had hazardous drugs in their urine, based on the median baseline risk in the studies included in this systematic review. Using a relative risk reduction of $44 \%$ (median risk reduction in the three studies in which one or more people in the safe handling group had hazardous drugs in the urine), an alpha error of $5 \%$, power of $80 \%$, an ICC of 0.10 , and a cluster size of 13 , the unadjusted sample size required is 66 and the adjusted sample size is 145 . This can be achieved, but requires multicentre studies. However, other studies have indicated that none of the healthcare staff had positive urine samples (Poupeau 2017; Sottani 2012), which may reflect high quality safety handling practices or differences in methodology used to collect urine (spot urine sample versus 24-hour urine sample). If the rates of urinary exposure are low, then it will be difficult to conduct a randomised controlled trial, and interrupted time-series may be a good alternative.

\section{ACKN OWLEDGEMENTS}

We thank Jani Ruotsalainen, Managing Editor, and Jos Verbeek, Coordinating Editor from Cochrane Work Review Group for their help in all stages of the protocol and current review. We also thank the editors Alex Burdorf and Nicole Skoetz and external peer referee

Closed-system drug-transfer devices plus safe handling of hazardous drugs versus safe handling alone for reducing exposure to 

the text of the review. 


\section{R E F E R E N C E S}

\section{References to studies included in this review}

Berruyer 2015 \{published data only\}

* Berruyer M, Tanguay C, Caron NJ, Lefebvre M, Bussieres JF. Multicenter study of environmental contamination with antineoplastic drugs in 36 Canadian hospitals: A 2013 followup study. Journal of Occupational and Environmental Hygiene 2015;12(2):87-94.

Tanguay C, Bussieres JF. Additional information on study methods and data related to study. Bussieres JF August 2017.

\section{Chan 2016 \{published data only\}}

$\mathrm{Chan} \mathrm{H}$, Hassali MA. Additional information on study methods and data related to study. Hassali MA August 2017.

Chan H, Lim CJ, Hassali MA, Saleem F. Closed-system transfer device for preparation of antineoplastic drugs in a Malaysian public hospital: is it truly cost saving?. Value in Health 2016;19(7):A860.

* Chan HK, Lim YM. Cost analysis of using a closed-system transfer device (CSTD) for antineoplastic drug preparation in a Malaysian government-funded hospital. Asian Pacific Journal of Cancer Prevention 2016;17(11):4951-7.

\section{Chauchat 2017 \{unpublished data only\}}

* Chauchat L, Tanguay C, Caron N, Gagné S, Labrèche F, Bussières JF. Multicenter study of the surface contamination with ten antineoplastics in 81 Canadian hospitals in 2017. www.gerpac.eu/multicenter-study-of-the-surfacecontamination-with-ten-antineoplastics-in-81-canadianhospitals-in-2017 (accessed on 29 November 2017).

Tanguay C, Bussieres JF. Additional information on study methods and data related to study. Bussieres JF August 2017.

\section{Edwards 2013 \{published data only\}}

Edwards M. Cost savings realized by use of a closed-system transfer device (CSTD) for preparation of antineoplastic agents. Journal of Oncology Pharmacy Practice 2013;19(1 Suppl):5.

Edwards M, Solimando D, Grollman F, Pang J, Preston L, Johnson A, et al. Cost savings realized by use of a closed-system transfer device for preparation of antineoplastic agents. Journal of the American Pharmacists Association 2013;53(5):e153.

Edwards MS. Additional information on study methods and data related to study. Edwards MS August 2017.

* Edwards MS, Solimando DA, Grollman FR, Pang JL, Chasick AH, Hightman CM, et al. Cost savings realized by use of the Phaseal closed-system transfer device for preparation of antineoplastic agents. Journal of Oncology Pharmacy Practice 2013;19(4):338-47.

\section{Forges 2011 \{published data only\}}

Forges F, Simoens X, Chauvin F. Comparative parallel assessment of a transfer device in reducing 5 -fluorouracil environmental contamination inside positive air pressure isolators. Journal of Oncology Pharmacy Practice 2011;17(1):61-7.

\section{Guillemette 2014 \{published data only\}}

* Guillemette A, Langlois H, Voisine M, Merger D, Therrien R, Mercier $\mathrm{G}$, et al. Impact and appreciation of two methods aiming at reducing hazardous drug environmental contamination: the centralization of the priming of IV tubing in the pharmacy and use of a closed-system transfer device. Journal of Oncology Pharmacy Practice 2014;20(6):426-32.

Tanguay C, Bussieres JF. Additional information on study methods and data related to study. Bussieres JF August 2017.

Hama 2012 \{published data only\}

Hama T. Issues occurring in preparation of anticancer agents. Annals of Oncology 2012;23(Suppl 11):xi68.

Harrison 2006 \{published data only\}

Harrison BR, Peters BG, Bing MR. Comparison of surface contamination with cyclophosphamide and fluorouracil using a closed-system drug transfer device versus standard preparation techniques. American Journal of Health-System Pharmacy 2006;63(18):1736-44

\section{Janes 2015 \{published data only\}}

* Janes A, Tanguay C, Caron NJ, Bussieres JF. Environmental contamination with cyclophosphamide, ifosfamide, and methotrexate: a study of 51 Canadian centres. Canadian Journal of Hospital Pharmacy 2015;68(4):279-89.

Tanguay C, Bussieres JF. Additional information on study methods and data related to study. Bussieres JF August 2017.

\section{Juhasz 2016 \{published data only\}}

Juhasz A, Batka G, Szucs A. Responding to drug shortages and rising costs: IV chemotherapy drug use optimization achieved by closed safety devices in hospital pharmacies. Drugs and Therapy Perspectives 2016;32(4):170-6.

Miyake 2013 \{published data only\}

Miyake T, Iwamoto T, Tanimura M, Okuda M. Impact of closedsystem drug transfer device on exposure of environment and healthcare provider to cyclophosphamide in Japanese hospital. Springerplus 2013;2:273.

\section{Mullot 2008 \{published data only\}}

Mullot H, Blondeel S, Escalup L, Negellen S, Chenailler C, Pelloquin $A$, et al. Intérêt et faisabilité des systèmes Tevadaptor et Phasea ${ }^{\circledR}$ dans une unité centralisée de préparation des anticancéreux. Le Pharmacien Hospitalier 2008;43(175):189-99.

Ozyaman 2016 \{published data only\}

Ozyaman A, Birli E, Sarikaya MA. Drug savings realised by use of a right closed system transfer device in the preparation of antineoplastic drugs. European Journal of Hospital Pharmacy 2016;23:A202. 
Poupeau 2016 \{published data only\}

* Poupeau C, Tanguay C, Caron NJ, Bussieres JF. Multicenter study of environmental contamination with cyclophosphamide, ifosfamide, and methotrexate in 48 Canadian hospitals. Journal of Oncology Pharmacy Practice 2018;24(1):9-17.

Tanguay C, Bussieres JF. Additional information on study methods and data related to study. Bussieres JF August 2017.

Roland 2017 \{published data only\}

* Roland C, Caron N, Bussieres JF. Multicenter study of environmental contamination with cyclophosphamide, ifosfamide and methotrexate in 66 Canadian hospitals: a 2016 follow-up study. Journal of Occupational and Environmental Hygiene 2017;14(8):661-9.

Tanguay C, Bussieres JF. Additional information on study methods and data related to study. Bussieres JF August 2017.

\section{Sessink 2011 \{published data only\}}

Sessink PJ. Additional information on study methods and data related to study. Sessink PJ August 2017.

* Sessink PJ, Connor TH, Jorgenson JA, Tyler TG. Reduction in surface contamination with antineoplastic drugs in 22 hospita pharmacies in the US following implementation of a closedsystem drug transfer device. Journal of Oncology Pharmacy Practice 2011;17(1):39-48.

\section{Sessink 2013 \{published data only\}}

Sessink PJ. Additional information on study methods and data related to study. Sessink PJ August 2017.

* Sessink PJ, Trahan J, Coyne JW. Reduction in surface contamination with cyclophosphamide in 30 us hospital pharmacies following implementation of a closed-system drug transfer device. Hospital Pharmacy 2013;48(3):204-12.

\section{Siderov 2010 \{published data only\}}

Siderov J, Kirsa S, McLauchlan R. Reducing workplace cytotoxic surface contamination using a closed-system drug transfer device. Journal of Oncology Pharmacy Practice 2010;16(1):19-25.

\section{Simon 2016 \{published data only\}}

* Simon N, Vasseur M, Pinturaud M, Soichot M, Richeval C, Humbert $L$, et al. Effectiveness of a closed-system transfer device in reducing surface contamination in a new antineoplastic drug-compounding unit: a prospective, controlled, parallel study. PLOS ONE 2016;11(7):e0159052.

Simon N, Vasseur M, Pinturaud M, Soichot M, Richeval C, Humbert $L$, et al. Using a closed-system transfer device leads to better control of occupational exposure in routine practice. European Journal of Hospital Pharmacy 2015;22(Suppl 1):A122-3.

\section{Sottani 2012 \{published data only\}}

Sottani C, Porro B, Imbriani M, Minoia C. Occupational exposure to antineoplastic drugs in four Italian health care settings.

Toxicology Letters 2012;213(1):107-15.

\section{Vyas 2016 \{published data only\}}

Vyas N, Turner A, Clark JM, Sewell GJ. Evaluation of a closedsystem cytotoxic transfer device in a pharmaceutical isolator Journal of Oncology Pharmacy Practice 2016;22(1):10-9.

\section{Wick 2003 \{published data only\}}

Wick C, Slawson MH, Jorgenson JA, Tyler LS. Using a closedsystem protective device to reduce personnel exposure to antineoplastic agents. American Journal of Health-System Pharmacy 2003;60(22):2314-20.

Yoshida 2009 \{published data only\}

Yoshida J, Tei G, Mochizuki C, Masu Y, Koda S, Kumagai S. Use of a closed system device to reduce occupational contamination and exposure to antineoplastic drugs in the hospital work environment. Annals of Occupational Hygiene 2009;53(2):153-60.

\section{Yoshida 2011 \{published data only\}}

Yoshida J, Koda S, Nishida S, Yoshida T, Miyajima K, Kumagai S. Association between occupational exposure levels of antineoplastic drugs and work environment in five hospitals in Japan. Journal of Oncology Pharmacy Practice 2011;17(1):29-38.

\section{References to studies excluded from this review}

\section{Amos 2012 \{published data only\}}

Amos C. A human factors usability comparison of three closed drug-transfer systems. Journal of Oncology Pharmacy Practice 2012;18:18-9.

\section{Blazawski 2013 \{published data only\}}

Blazawski J, De Freitas E. Testing the sterility of single-use vials of bevacizumab and cetuximab after entry with the Phaseal closed-system transfer device. Journal of the American Pharmacists Association 2013;53(5):e164.

\section{Chantry 2015 \{published data only\}}

Chantry A, Fanton d'Andon C, Gouillet A, Garrigue P, Guillet B. A specific fluorescein-combined media fill test for validation of aseptic radiopharmaceutical preparations and assessment of good radiopharmacy practice. European Journal of Nuclear Medicine and Molecular Imaging 2015;42(Suppl 1):S484.

\section{Clark 2013 \{published data only\}}

Clark BA, Sessink PJ. Use of a closed system drug-transfer device eliminates surface contamination with antineoplastic agents. Journal of Oncology Pharmacy Practice 2013;19(2):99-104.

\section{Connor 2010 \{published data only\}}

Connor TH, DeBord DG, Pretty JR, Oliver MS, Roth TS, Lees PS, et al. Evaluation of antineoplastic drug exposure of health care workers at three university-based us cancer centers. Journal of Occupational and Environmental Medicine 2010;52(10):1019-27.

\section{Contractor 2015 \{published data only\}}

Contractor S, Thomas J, Shahid U. Use of the Phaseal transfer system during chemoembolization to prevent unintentional leakage of chemotherapeutic agents during preparation and 
delivery. Journal of Vascular and Interventional Radiology 2015;26(5):e93.

\section{Cox 2017 \{published data only\}}

Cox J, Speed V, O'Neal S, Hasselwander T, Sherwood C, Eckel SF, et al. Development and evaluation of a novel product to remove surface contamination of hazardous drugs. Journal of Oncology Pharmacy Practice 2017;23(2):103-15.

\section{De Ausen 2013 \{published data only\}}

De Ausen L, DeFreitas EF, Littleton L, Lustik M. Leakage from closed-system transfer devices as detected by a radioactive tracer. American Journal of Health-System Pharmacy 2013;70(7):619-23.

\section{DeFreitas 2012 \{published data only\}}

DeFreitas E. Comparison of closed systems drug transfer devices (CSTDs) using technetium (Tc99m) as a radioactive tracer. Journal of Oncology Pharmacy Practice 2012;18(2 Suppl):11-2.

\section{De Prijck 2008 \{published data only\}}

De Prijck K, D'Haese E, Vandenbroucke J, Coucke W, Robays H, Nelis HJ. Microbiological challenge of four protective devices for the reconstitution of cytotoxic agents. Letters in Applied Microbiology 2008;47(6):543-8.

\section{Enciso-Zarate 2016 \{published data only\}}

Enciso-Zarate A, Guzman-Oviedo J, Sanchez-Cardona F, Martinez-Rohenes D, Rodriguez-Palomino JC, AlvarezRisco A, et al. Evaluation of contamination by cytotoxic agents in Colombian hospitals. Pharmaceutical Care España 2016;18(6):241-50.

\section{Favier 2012 \{published data only\}}

Favier B, Labrosse H, Gilles-Afchain L, Cropet C, Perol D, Chaumard N, et al. The Phaseal ${ }^{\circledR}$ system: impact of its use on workplace contamination and duration of chemotherapy preparation. Journal of Oncology Pharmacy Practice 2012;18(1):37-45.

\section{Fernandez 2013 \{published data only\}}

Fernandez JSR, Del Carmen Lozano Iglesias M, Peinado II. Microbiological stability of drugs elaborated in a biological safety cabinet using a closed-system drug transfer device. Anales de la Real Academia Nacional de Farmacia 2013;79(3):465-80.

\section{Garrigue 2016 \{published data only\}}

Garrigue P, Montana M, Ventre C, Savry A, Gauthier-Villano L, Pisano $P$, et al. Safe cytotoxic drug preparation using closedsystem transfer device: Technical and practical evaluation of a new device (Vialshield/Texium) comparatively to a reference one (Phaseal). International Journal of Pharmaceutical Compound 2016;20(2):148-54.

Gebel 2015 \{published data only\}

Gebel J. Evaluation of the microbial tightness of closed system transfer devices by simulating airborne and touch contamination. Critical Care 2015;19(Suppl 1):S29-30.
Gilles 2009 \{published data only\}

Gilles L, Favier B, Catillon F, Dussart C, Peyron F, Simoens X, et al. Improvement of quality of practices for the preparation of cytotoxic drugs: results of a "before-after" study. Bulletin du Cancer 2009;96(9):839-49.

\section{Gomez-Alvarez 2016 \{published data only\}}

Gomez-Alvarez S, Porta-Oltra B, Hernandez-Griso M, PerezLabana F, Climente-Marti M. Evaluation of two closed-system drug transfer device in the antineoplastic drug elaboration process. Farmacia Hospitalaria 2016;40(1):36-43.

\section{Gonzalez-Haba Pena 2016 \{published data only\}} Gonzalez-Haba Pena E, Manrique Rodriguez S, Herranz Alonso AM, Perez Castan P, Moreno Galvez M, Iglesias Peinado I, et al. Comparative study of preparation of hazardous drugs with different closed-system drug transfer devices by means of simulation with fluorescein. Farmacia Hospitalaria 2016;40(n06):496-503.

Hama 2011 \{published data only\}

Hama K, Kitada N, Fukushima K, Hashida T, Kataoka K. Investigation on residual-related error and the effect of solution properties using protective devices for the reconstitution of cytotoxic agents in actual situations. Journal of Oncology Pharmacy Practice 2011;17(1):55-60.

\section{Hong 2017 \{published data only\}}

Hong MY, Lin YS, Hwang YJ, Lai YH. Nurses' perceptions and satisfaction to the use of a closed-system drug transfer device for chemotherapy administration. Oncology Nursing Forum 2017;44(2 (2017 Oncology Nursing Society Annual Congress: Podium Abstracts)):182.

\section{Hospital Employee Health 2005 \{published data only\}}

New needleless valves leading to spike in BSIs: solving one problem and creating another... bloodstream infections. Hospital Employee Health 2005;24(8):97-9.

\section{Hospital Infection Control 2005 \{published data only\}}

New needleless valves leading to spike in BSIs: solving one problem and creating another. Hospital Infection Control \& Prevention 2005;32(7):89-91.

\section{Idell 2009 \{published data only\}}

Idell C, Yost B, Bearman B, Gallardo M. Strategies to increase staff compliance with use of closed-system drug transfer devices (CSTD). Oncology Nursing Forum 2009;36(3):75-6.

\section{Ikeno 2014 \{published data only\}}

Ikeno Y, Arii D, Nakajima H, Murooka K, Nojima M, Kidokoro A. Verification of reduction in preparation time and cost of cyclophosphamide when using the closed-system drug transfer device. Gan to Kagaku Ryoho 2014;41(5):611-5.

\section{Jorgenson 2008 \{published data only\}}

Jorgenson JA, Spivey SM, Au C, Canann D, Ritter H, Smith B. Contamination comparison of transfer devices intended for handling hazardous drugs. Hospital Pharmacy 2008;43(9):723-7. 


\section{Kopp 2013 \{published data only\}}

Kopp B, Schierl R, Nowak D. Evaluation of working practices and surface contamination with antineoplastic drugs in outpatient oncology health care settings. International Archives of Occupational and Environmental Health 2013;86(1):47-55.

Kunneva 2016 \{published data only\}

Kunneva L. Closed system drug transfer devices for chemotherapy. Nursing 2016;46(1):67-8.

\section{Kurihara 2017 \{published data only\}}

Kurihara T, Uchida T. Investigation in reduction of occupational exposures from anti-cancer agents using the infusion set which incorporated bd Phasealtm system. Journal of Oncology Pharmacy Practice 2017;23(4 Suppl):19-20.

\section{Laws 2016 \{published data only\}}

Laws J. Checking the safety of closed system transfer devices. Occupational Health \& Safety 2016;85(11):4.

\section{Ledford 2010 \{published data only\}}

Ledford A, Maliakal P, Rogers T, Mackey M. Evaluation of two closed system transfer devices in an outpatient community cancer center. Journal of Oncology Pharmacy Practice 2010;16(1 Suppl):16-7.

\section{Le Garlantezec 2011 \{published data only\}}

Le Garlantezec P, Rizzo-Padoin N, Aupee O, Lamand V, Broto H, Almeras D. Evaluation of the performance of transfer devices in a closed system using a radioactive solution of [99mTC] [Évaluation de la performance de dispositifs de transfert en système clos au moyen d'une solution radioactive de [99mTC]]. Annales Pharmaceutiques Françaises 2011;69(3):182-91.

\section{Lennan 2017 \{published data only\}}

Lennan E. Considering closed-system transfer devices for safe handling of drugs. British Journal of Nursing 2017;26(10):S26-8.

\section{Lin 2017 \{published data only\}}

Lin C, Chiang SC. Challenge the compatibility of closed system transfer devices with multiple chemotherapy drugs. Journal of Oncology Pharmacy Practice 2017;23(4 Suppl):3.

\section{McDiarmid 2010 \{published data only\}}

McDiarmid MA, Oliver MS, Roth TS, Rogers B, Escalante C. Chromosome 5 and 7 abnormalities in oncology personnel handling anticancer drugs. Journal of Occupational and Environmental Medicine 2010;52(10):1028-34.

\section{McMichael 2011 \{published data only\}}

McMichael DM, Jefferson DM, Carey ET, Forrey RA, Spivey SM, Mulvaney JM, et al. Utility of the Phaseal closed system drug transfer device. American Journal of Pharmacy Benefits 2011;3(1):9-16.

\section{Meade 2015 \{published data only\}}

Meade E. Use of closed-system drug transfer devices in the handling and administration of MABs. British Journal of Nursing 2015;24(16 Suppl 1):S21-7.
Nishigaki 2010 \{published data only\}

Nishigaki R, Konno E, Sugiyasu M, Yonemura M, Otsuka T, Watanabe $Y$, et al. The usefulness of a closed-system device for the mixing of injections to prevent occupational exposure to anticancer drugs. Journal of Japanese Society of Hospital Pharmacists 2010;46(1):113-7.

Nygren 2005 \{published data only\}

Nygren O, Gustavsson B, Eriksson R. A test method for assessment of spill and leakage from drug preparation systems. Annals of Occupational Hygiene 2005;49(8):711-8.

\section{Nygren 2008 \{published data only\}}

Nygren O, Olofsson E, Johansson L. Spill and leakage using a drug preparation system based on double-filter technology. Annals of Occupational Hygiene 2008;52(2):95-8.

Nyman 2007 \{published data only\}

Nyman HA, Jorgenson JA, Slawson MH. Workplace contamination with antineoplastic agents in a new cancer hospital using a closed-system drug transfer device. Hospital Pharmacy 2007;42(3):219-25.

Odraska 2013 \{published data only\}

Odraska P, Dolezalova L, Kuta J, Oravec M, Piler P, Blaha L. Evaluation of the efficacy of additional measures introduced for the protection of healthcare personnel handling antineoplastic drugs. Annals of Occupational Hygiene 2013;57(2):240-50.

Oncology Nurse Advisor 2017 \{published data only\} Closed system drug transfer device reduces nurse exposure to hazardous drugs. Oncology Nurse Advisor 2017;8(3):20-1.

Perlo 2015 \{published data only\}

Perlo G, Davit A, Viglietti AL, Biggi A. Use of needle free closed system devices in the radio labelled white blood cells (wbc) procedure. Clinical and Translational Imaging 2015;3(Suppl 1):S131.

\section{Queruau Lamerie 2012 \{published data only\}}

Queruau Lamerie T, Carrez L, Decaudin B, Bouchoud L, Goossens JF, Barthelemy C, et al. Multiple-test assessment of devices to protect healthcare workers when administering cytotoxic drugs to patients. Journal of Oncology Pharmacy Practice 2012;18(2):191-200.

\section{Rupp 2017 \{published data only\}}

Rupp K, Tyler T. Assessment of a new closed system drugtransfer device at 17 us cancer centers. Oncology Nursing Forum 2017;44(2 (2017 Oncology Nursing Society Annual Congress: Podium Abstracts)):29.

\section{Sanchez-Rubio Ferrandez 2012 \{published data only\}}

Sanchez-Rubio Ferrandez J, Lozano Esteban MC, Iglesias Peinado I, Fernandez Alonso JM, Bautista Sanz MP, Matilla Garcia E, et al. Microbiological stability of vials used in cytostatic compounding. European Journal of Hospital Pharmacy: Science and Practice 2012;19(2):144-5. 


\section{Sanchez-Rubio Ferrandez 2012a \{published data only\}}

Sanchez-Rubio Ferrandez J, Lozano MC, Iglesias I, SanchezRubio Ferrandez L, Rodriguez Vargas B, Moreno Diaz R. Use of a closed-system drug transfer device (Phaseal) and impact on preparation time. International Journal of Pharmaceutical Compound 2012;16(5):431-3.

\section{Sato 2010 \{published data only\}}

Sato J, Odagiri N, Terui K, Iwasaki Y, Hosoya E, Hayakari M. Availability evaluation of closed systems by using practical training kits for preparation of antitumor drugs. Japanese Journal of Cancer and Chemotherapy 2010;37(9):1753-7.

\section{Sessink 1999 \{published data only\}}

Sessink PJM, Rolf MAE, Ryden NS. Evaluation of the Phaseal hazardous drug containment system. Hospital Pharmacy 1999;34(11):1311-7.

\section{Simon 2010 \{published data only\}}

Simon N, Decaudin B, Lannoy D, Danicourt F, Barthelemy C, Odou P. Technical evaluation of a new sterile medical device to improve anticancer chemotherapy administration. Oncology Nursing Forum 2010;37(6):E370-6.

\section{Smith 2014 \{published data only\}}

Smith ST, Szlaczky MC. Syringe plunger contamination by hazardous drugs: a comparative study. Journal of Oncology Pharmacy Practice 2014;20(5):381-5.

\section{Talsmar 2015 \{published data only\}}

Talsmar J. FDA warns against use of certain closed system transfer devices with Treanda injection. Drug Topics 2015;10 April:36.

\section{Thomas Carey 2011 \{published data only\}}

Thomas Carey E, Forrey RA, Haughs D, Jefferson DM, Jorgenson JA, McMichael DM, et al. Second look at utilization of a closed-system transfer device (Phaseal). American Journal of Pharmacy Benefits 2011;3(6):311-8.

\section{Tyler 2017 \{published data only\}}

Tyler TG, Power LA. Assessment of a new closed system drug transfer device (CSTD) at 13 U.S. cancer centers. Journal of Oncology Pharmacy Practice 2017;23(4 Suppl):21.

\section{Yoshida 2013 \{published data only\}}

Yoshida J, Koda S, Nishida S, Nakano H, Tei G, Kumagai S. Association between occupational exposure and control measures for antineoplastic drugs in a pharmacy of a hospital. Annals of Occupational Hygiene 2013;57(2):251-60.

\section{Additional references}

\section{ASHP 2006}

American Society of Health-System Pharmacists. ASHP guidelines on handling hazardous drugs. American Journal of Health-System Pharmacy 2006;63(12):1172-91.

\section{ASSTSAS 2008}

ASSTSAS. Prevention Guide Safe Handling of Hazardous Drugs, 2008. asstsas.qc.ca/sites/default/files/publications/documents/ Guides_Broch_Depl/GP65A_hazardous_drugs.pdf (accessed 27 June 2017)

\section{Awad 2009}

Awad A, Stuve O. Cyclophosphamide in multiple sclerosis: scientific rationale, history and novel treatment paradigms. Therapeutic Advances in Neurological Disorders 2009;2(6):50-61.

\section{B Braun 2017a}

B Braun. Onguard ${ }^{\circledR}$ closed system transfer device (CSTD), 2017. www.bbraunusa.com/products.html?prid=PRID00006969 (accessed 7 June 2017)

\section{B Braun 2017b}

B Braun. 0.2 micron air venting filter, hydrophobic, 2017. us.bbraunoem.com/cps/rde/xchg/oem-bbraunoem-en-us/ hs.xsl/products.html?prid=S4001002 (accessed 23 June 2017).

\section{Bateman 2015}

Bateman R, Santillo M, Hardy L, Lennan E (NHS Pharmaceutical Quality Assurance Committee). Guidance on the safe handling of monoclonal antibody (mAb) products, 5th edition, 2015. ukons.org/downloads/ Proposed_national_requirements_for_overlabelling_of_foreign \%28non-English_language\%29_imported_medicines.pdf (accessed 27 June 2017).

\section{BD 2017a}

Becton Dickinson. BD PhaSeal system for hazardous drug handling. System components, 2017. www.bd.com/pharmacy/ phaseal/components.asp (accessed 7 June 2017).

\section{BD 2017b}

Becton Dickinson. Chemo Safety system, 2017. www.carefusion.com/our-products/infusion/iv-therapy/chemosafety-system (accessed 7 June 2017).

\section{BNF 2017}

British National Formulary. Cytotoxic drugs, 2017. bnf.nice.org.uk/treatment-summary/cytotoxic-drugs.html (accessed 7 June 2017).

\section{Brogan 2000}

Brogan PA, Dillon MJ. The use of immunosuppressive and cytotoxic drugs in non-malignant disease. Archives of Disease in Childhood 2000;83(3):259-64.

\section{Bucher 1999}

Bucher HC, Guyatt GH, Cook DJ, Holbrook A, McAlister FA. Users' guides to the medical literature: Xix. Applying clinical trial results. A. How to use an article measuring the effect of an intervention on surrogate end points. Evidence-based medicine working group. JAMA 1999;282(8):771-8.

\section{Campbell 2001}

Campbell MK, Mollison J, Grimshaw JM. Cluster trials in implementation research: estimation of intracluster 
correlation coefficients and sample size. Statistics in Medicine 2001;20(3):391-9.

\section{Cassidy 2011}

Cassidy J, Saltz L, Twelves C, Van Cutsem E, Hoff P, Kang Y, et al. Efficacy of capecitabine versus 5-fluorouracil in colorectal and gastric cancers: a meta-analysis of individual data from 6171 patients. Annals of Oncology 2011;22(12):2604-9.

\section{Chu 2012}

Chu WC, Hon CY, Danyluk Q, Chua PP, Astrakianakis G. Pilot assessment of the antineoplastic drug contamination levels in British Columbian hospitals pre- and post-cleaning. Journal of Oncology Pharmacy Practice 2012;18(1):46-51.

\section{Connor 2005}

Connor TH, Sessink PJ, Harrison BR, Pretty JR, Peters BG, Alfaro RM, et al. Surface contamination of chemotherapy drug vials and evaluation of new vial-cleaning techniques: results of three studies. American Journal of Health-System Pharmacy 2005;62(5):475-84.

\section{Connor 2006}

Connor TH. Hazardous anticancer drugs in health care: environmental exposure assessment. Annals of the New York Academy of Sciences 2006;1076:615-23.

\section{Connor 2014}

Connor TH, Lawson CC, Polovich M, McDiarmid MA. Reproductive health risks associated with occupational exposures to antineoplastic drugs in health care settings: a review of the evidence. Journal of Occupational and Environmental Medicine 2014;56(9):901-10.

\section{Easty 2015}

Easty AC, Coakley N, Cheng R, Cividino M, Savage P, Tozer R, et al. Safe handling of cytotoxics: guideline recommendations. Current Oncology 2015;22(1):e27-37.

\section{Egger 1997}

Egger M, Davey SG, Schneider M, Minder C. Bias in meta-analysis detected by a simple, graphical test. $B M J$ 1997;315(7109):629-34.

\section{Equashield 2017}

Equashield LLC. Equashield, 2017. www.equashield.com/ (accessed 7 June 2017).

\section{Evers 2005}

Evers S, Goossens M, de Vet H, van Tulder M, Ament A. Criteria list for assessment of methodological quality of economic evaluations: consensus on health economic criteria. International Journal of Technology Assessment in Health Care 2005;21(2):240-5.

\section{Favier 2003}

Favier B, Gilles L, Ardiet C, Latour JF. External contamination of vials containing cytotoxic agents supplied by pharmaceutical manufacturers. Journal of Oncology Pharmacy Practice 2003;9(1):15-20.

\section{Fernandes Moca Trevisani 2013}

Fernandes Moca Trevisani V, Castro AA, Ferreira Neves Neto J, Atallah AN. Cyclophosphamide versus methylprednisolone for treating neuropsychiatric involvement in systemic lupus erythematosus. Cochrane Database of Systematic Reviews 2013, Issue 2. [DOI: 10.1002/14651858.CD002265.pub3]

\section{Fleming 1996}

Fleming TR, DeMets DL. Surrogate end points in clinical trials: are we being misled?. Annals of Internal Medicine 1996;125(7):605-13.

\section{Fleury-Souverain 2014}

Fleury-Souverain S, Nussbaumer S, Mattiuzzo M, Bonnabry P. Determination of the external contamination and crosscontamination by cytotoxic drugs on the surfaces of vials available on the Swiss market. Journal of Oncology Pharmacy Practice 2014;20(2):100-1.

\section{Ge 2015}

Ge Y, Peng Q, Zhang S, Zhou H, Lu X, Wang G. Cyclophosphamide treatment for idiopathic inflammatory myopathies and related interstitial lung disease: a systematic review. Clinical Rheumatology 2015;34(1):99-105.

\section{GRADEpro GDT [Computer program]}

McMaster University (developed by Evidence Prime). GRADEpro GDT. Version accessed prior to 22 March 2018. Hamilton (ON): McMaster University (developed by Evidence Prime), 2015.

\section{Hartman 2001}

Hartman AR, Fleming GF, Dillon JJ. Meta-analysis of adjuvant cyclophosphamide/methotrexate/5-fluorouracil chemotherapy in postmenopausal women with estrogen receptor-positive, node-positive breast cancer. Clinical Breast Cancer 2001;2(2):138-43.

\section{Hazlewood 2016}

Hazlewood GS, Barnabe C, Tomlinson G, Marshall D, Devoe DJ, Bombardier C. Methotrexate monotherapy and methotrexate combination therapy with traditional and biologic disease modifying anti-rheumatic drugs for rheumatoid arthritis: A network meta-analysis. Cochrane Database of Systematic Reviews 2016, Issue 8. [DOI: 10.1002/14651858.CD010227.pub2]

\section{Healthmark 2017}

Healthmark. Chemo spikes: chemotherapy reconstitution spikes, 2017. www.healthmark.ca/2-36-10-ChemoSpikes_en.html?ProduitID=21 (accessed 23 June 2017).

\section{Hedmer 2005}

Hedmer M, Georgiadi A, Bremberg ER, Jonsson BA, Eksborg S. Surface contamination of cyclophosphamide packaging and surface contamination with antineoplastic drugs in a hospital pharmacy in Sweden. Annals of Occupational Hygiene 2005;49(7):629-37.

\section{Higgins 2011}

Higgins JP, Green S, editor(s). Cochrane Handbook for Systematic Reviews of Interventions Version 5.1.0 (updated 
March 2011). The Cochrane Collaboration, 2011. Available from handbook.cochrane.org.

\section{Hon 2014}

Hon CY, Teschke K, Demers PA, Venners S. Antineoplastic drug contamination on the hands of employees working throughout the hospital medication system. Annals of Occupational Hygiene 2014;58(6):761-70.

\section{HSE 2017}

Health and Safety Executive. Safe handling of cytotoxic drugs in the workplace, 2017. www.hse.gov.uk/healthservices/safe-usecytotoxic-drugs.htm (accessed 7 June 2017).

\section{ICUMED 2017}

ICU Medical Inc. ChemoClave needlefree closed systems and closed system transfer devices (CSTDs), 2017. www.icumed.com/products/oncology/hazardous-drug-closedsystems-and-cstds/chemoclave.aspx (accessed 7 June 2016).

\section{ljaz 2014}

ljaz S, Verbeek JH, Mischke C, Ruotsalainen J. Inclusion of nonrandomized studies in Cochrane systematic reviews was found to be in need of improvement. Journal of Clinical Epidemiology 2014;67(6):645-53.

\section{ISOPP 2007}

International Society of Oncology Pharmacy Practitioners Standards Committee. ISOPP standards of practice. Safe handling of cytotoxics. Journal of Oncology Pharmacy Practice 2007;13(Suppl):1-81.

\section{Killip 2004}

Killip S, Mahfoud Z, Pearce K. What is an intracluster correlation coefficient? Crucial concepts for primary care researchers. Annals of Family Medicine 2004;2(3):204-8.

\section{Kim 2015}

Kim C, Prasad V. Cancer drugs approved on the basis of a surrogate end point and subsequent overall survival: an analysis of 5 years of US Food and Drug Administration approvals. JAMA Internal Medicine 2015;175(12):1992-4.

\section{Mahmoodi 2017}

Mahmoodi M, Soleyman-Jahi S, Zendehdel K, Mozdarani H, Azimi C, Farzanfar F, et al. Chromosomal aberrations, sister chromatid exchanges, and micronuclei in lymphocytes of oncology department personnel handling anti-neoplastic drugs. Drug and Chemical Toxicology 2017;40(2):235-40.

\section{Mason 2003}

Mason HJ, Morton J, Garfitt SJ, Iqbal S, Jones K. Cytotoxic drug contamination on the outside of vials delivered to a hospital pharmacy. Annals of Occupational Hygiene 2003;47(8):681-5.

\section{McDiarmid 2014}

McDiarmid MA, Rogers B, Oliver MS. Chromosomal effects of non-alkylating drug exposure in oncology personnel. Environmental and Molecular Mutagenesis 2014;55(4):369-74.

\section{Moretti 2015}

Moretti M, Grollino MG, Pavanello S, Bonfiglioli R, Villarini M, Appolloni M, et al. Micronuclei and chromosome aberrations in subjects occupationally exposed to antineoplastic drugs: a multicentric approach. International Archives of Occupational and Environmental Health 2015;88(6):683-95.

\section{Mulder 2015}

Mulder RL, Paulides M, Langer T, Kremer LC, van Dalen EC. Cyclophosphamide versus ifosfamide for paediatric and young adult bone and soft tissue sarcoma patients. Cochrane Database of Systematic Reviews 2015, Issue 9. [DOI: 10.1002/14651858.CD006300.pub2]

\section{Naito 2012}

Naito T, Osawa T, Suzuki N, Goto T, Takada A, Nakamichi H, et al. Comparison of contamination levels on the exterior surfaces of vials containing platinum anticancer drugs in Japan. Biological \& Pharmaceutical Bulletin 2012;35(11):2043-9.

\section{NCBI 1978}

National Center for Biotechnology Information. Cytotoxins, 1978. www.ncbi.nlm.nih.gov/mesh/68003603 (accessed 7 June 2017).

\section{NIOSH 2004}

National Institute for Occupational Safety and Health. Preventing occupational exposures to antineoplastic and other hazardous drugs in health care settings, 2004. www.cdc.gov/ niosh/docs/2004-165/pdfs/2004-165.pdf (accessed 7 June 2017).

\section{Nunes 2015}

Nunes AA, da Silva AS, Souza KM, Koury Cde N, de Mello LM. Rituximab, fludarabine, and cyclophosphamide versus fludarabine and cyclophosphamide for treatment of chronic lymphocytic leukemia: a systematic review with meta-analysis. Critical Reviews in Oncology/Hematology 2015;94(3):261-9.

\section{Philips 2004}

Philips Z, Ginnelly L, Sculpher M, Claxton K, Golder S, Riemsma R, et al. Review of guidelines for good practice in decision-analytic modelling in health technology assessment. Health Technology Assessment 2004;8(36):1-158.

\section{Poormoghim 2012}

Poormoghim H, Moradi Lakeh M, Mohammadipour M, Sodagari F, Toofaninjed N. Cyclophosphamide for scleroderma lung disease: a systematic review and meta-analysis. Rheumatology International 2012;32(8):2431-44.

\section{Poupeau 2017}

Poupeau C, Tanguay C, Plante C, Gagne S, Caron N, Bussieres JF. Pilot study of biological monitoring of four antineoplastic drugs among Canadian healthcare workers. Journal of Oncology Pharmacy Practice 2017;23(5):323-32.

\section{Power 2014}

Power LA, Sessink PJ, Gesy K, Charbonneau F. Hazardous drug residue on exterior vial surfaces: evaluation of a commercial manufacturing process. Hospital Pharmacy 2014;49(4):355-62. 


\section{Prentice 1989}

Prentice RL. Surrogate endpoints in clinical trials: definition and operational criteria. Statistics in Medicine 1989;8(4):431-40.

\section{Ramphal 2014}

Ramphal R, Bains T, Vaillancourt R, Osmond MH, Barrowman N. Occupational exposure to cyclophosphamide in nurses at a single center. Journal of Occupational and Environmental Medicine/American College of Occupational and Environmental Medicine 2014;56(3):304-12.

\section{Ramsay 2003}

Ramsay CR, Matowe L, Grilli R, Grimshaw JM, Thomas RE. Interrupted time series designs in health technology assessment: lessons from two systematic reviews of behavior change strategies. International Journal of Technology Assessment in Health Care 2003;19(4):613-23.

\section{Ratner 2010}

Ratner PA, Spinelli JJ, Beking K, Lorenzi M, Chow Y, Teschke K, et al. Cancer incidence and adverse pregnancy outcome in registered nurses potentially exposed to antineoplastic drugs. BMC Nursing 2010;9:15.

\section{RevMan 2014 [Computer program]}

The Nordic Cochrane Centre, The Cochrane Collaboration. Review Manager (RevMan). Version 5.3. Copenhagen: The Nordic Cochrane Centre, The Cochrane Collaboration, 2014.

\section{Rodriguez-Peralvarez 2017}

Rodriguez-Peralvarez M, Guerrero-Misas M, Thorburn D, Davidson BR, Tsochatzis E, Gurusamy KS. Maintenance immunosuppression for adults undergoing liver transplantation: a network meta-analysis. Cochrane Database of Systematic Reviews 2017, Issue 3. [DOI: 10.1002/14651858.CD011639.pub2]

\section{Rupp 2017a}

Rupp T, Zuckerman D. Quality of life, overall survival, and costs of cancer drugs approved based on surrogate endpoints. JAMA Internal Medicine 2017;177(2):276-7.

\section{Schierl 2016}

Schierl R, Masini C, Groeneveld S, Fischer E, Bohlandt A, Rosini V, et al. Environmental contamination by cyclophosphamide preparation: comparison of conventional manual production in biological safety cabinet and robotassisted production by APOTECAchemo. Journal of Oncology Pharmacy Practice 2016;22(1):37-45.

\section{Sessink 2015}

Sessink PJ, Leclercq GM, Wouters DM, Halbardier L, Hammad C, Kassoul N. Environmental contamination, product contamination and workers exposure using a robotic system for

\section{CHARACTERISTICS OF STUDIES}

\section{Characteristics of included studies [ordered by study ID]}

antineoplastic drug preparation. Journal of Oncology Pharmacy Practice 2015;21(2):118-27.

\section{Skov 1992}

Skov T, Maarup B, Olsen J, Rorth M, Winthereik H, Lynge E. Leukaemia and reproductive outcome among nurses handling antineoplastic drugs. British Journal of Industrial Medicine 1992;49(12):855-61.

\section{Sterne 2016}

Sterne JA, Hernán MA, Reeves BC, Savović J, Berkman ND, Viswanathan M, et al. ROBINS-I: a tool for assessing risk of bias in non-randomised studies of interventions. $B M J$ 2016;355:i4919.

\section{Sugiura 2011}

Sugiura S, Asano M, Kinoshita K, Tanimura M, Nabeshima T. Risks to health professionals from hazardous drugs in Japan: a pilot study of environmental and biological monitoring of occupational exposure to cyclophosphamide. Journal of Oncology Pharmacy Practice 2011;17(1):14-9.

\section{USP 2017}

US Pharmacopeial Convention (USP). General chapter $<800>$ Hazardous drugs - handling in healthcare settings, 2017. www.usp.org/compounding/general-chapter-hazardous-drugshandling-healthcare (accessed 14 October 2017).

\section{Viegas 2014}

Viegas S, Padua M, Veiga AC, Carolino E, Gomes M. Antineoplastic drugs contamination of workplace surfaces in two Portuguese hospitals. Environmental Monitoring and Assessment 2014;186(11):7807-18.

\section{Yudkin 2011}

Yudkin JS, Lipska KJ, Montori VM. The idolatry of the surrogate. BMJ 2011;343:d7995.

\section{Zhu 2017}

Zhu LB, Liu LL, Yao L, Wang LN. Efficacy and safety of tacrolimus versus cyclophosphamide for primary membranous nephropathy: a meta-analysis. Drugs 2017;77(2):187-99.

\section{References to other published versions of this review Gurusamy 2017}

Gurusamy KS, Best LMJ, Tanguay C, Lennan E, Korva M, Bussières JF. Closed-system drug-transfer devices in addition to safe handling of hazardous drugs versus safe handling alone for reducing healthcare staff exposure to infusional hazardous drugs. Cochrane Database of Systematic Reviews 2017, Issue 11. [DOI: 10.1002/14651858.CD012860]

* Indicates the major publication for the study 
Berruyer 2015

\begin{tabular}{ll}
\hline Methods & Cross-sectional study; cluster study \\
\hline Participants & Country: Canada \\
& Number of clusters: 36 \\
& Number excluded: $1(2.8 \%)$ \\
& Reason for exclusion: one hospital did not provide reply to the CSTD status \\
& Number included: 35 \\
& Chemotherapy agents tested for contamination: cyclophosphamide, ifosfamide, and methotrexate \\
& Professional role: pharmacy technician/pharmacist \\
& Size of the hospitals/wards: at least 50 beds \\
\hline Interventions & $\begin{array}{l}\text { Group 1: CSTD + standard care (variable) (N = 7) } \\
\text { Group 2: standard care (variable including removal of outer packaging and cleaned vials after receipt } \\
\text { in some hospitals) (N = 28) }\end{array}$ \\
\hline Outcomes & Outcomes reported: surface contamination \\
\hline Notes & Authors provided additional information. \\
& Source of funding: No special funding. \\
\hline
\end{tabular}

\section{Risk of bias}

\begin{tabular}{|c|c|c|}
\hline Bias & Authors' judgement & Support for judgement \\
\hline Confounding bias & Unclear risk & $\begin{array}{l}\text { Risk of bias: no information } \\
\text { Comment: no information to judge whether the confounding factors were bal- } \\
\text { anced across groups }\end{array}$ \\
\hline Selection bias & Unclear risk & $\begin{array}{l}\text { Risk of bias: moderate } \\
\text { Comment: the participating centres may have done so based on their pharma- } \\
\text { cological practices }\end{array}$ \\
\hline $\begin{array}{l}\text { Bias in classification of in- } \\
\text { terventions }\end{array}$ & Low risk & $\begin{array}{l}\text { Risk of bias: low } \\
\text { Comment: the intervention and control were well defined }\end{array}$ \\
\hline $\begin{array}{l}\text { Bias due to deviations } \\
\text { from intended interven- } \\
\text { tions }\end{array}$ & Unclear risk & $\begin{array}{l}\text { Risk of bias: no information } \\
\text { Comment: no information to judge whether the co-interventions were similar } \\
\text { across the groups }\end{array}$ \\
\hline Bias due to missing data & Unclear risk & $\begin{array}{l}\text { Risk of bias: no information } \\
\text { Comment: insufficient information to judge whether there was bias due to } \\
\text { missing data (i.e. the hospital which did not reply about CSTD status may have } \\
\text { done so because of the intervention or the outcome) }\end{array}$ \\
\hline $\begin{array}{l}\text { Bias in measurement of } \\
\text { outcomes }\end{array}$ & High risk & $\begin{array}{l}\text { Risk of bias: serious } \\
\text { Comment: the outcome assessors do not seem to be blinded to the groups }\end{array}$ \\
\hline $\begin{array}{l}\text { Bias in selection of the re- } \\
\text { ported result }\end{array}$ & High risk & $\begin{array}{l}\text { Risk of bias: serious } \\
\text { Comment: only selected results were reported }\end{array}$ \\
\hline
\end{tabular}

Chan 2016

\begin{tabular}{ll}
\hline Methods & Uncontrolled before-after cohort study; cluster study \\
\hline Participants & Country: Malaysia \\
\hline
\end{tabular}

Closed-system drug-transfer devices plus safe handling of hazardous drugs versus safe handling alone for reducing exposure to 
Chan 2016 (Continued)

Number of clusters: 2

Number excluded: 0 (0\%)

Number included: 2

Chemotherapy agents tested for contamination: not measured

Professional role: pharmacists or pharmacy technicians

Size of the hospitals/wards: 852 beds

\begin{tabular}{ll}
\hline Interventions & $\begin{array}{l}\text { Group 1: CSTD + standard care (PhaSeal) }(\mathrm{N}=1) \\
\text { Group 2: Standard care (not stated) }(\mathrm{N}=1)\end{array}$ \\
\hline Outcomes & Outcomes reported: potential cost savings \\
\hline Notes & Authors provided additional information. \\
& Source of funding: Not reported.
\end{tabular}

\section{Risk of bias}

\begin{tabular}{lll}
\hline Bias & Authors' judgement & Support for judgement \\
\hline Confounding bias & Unclear risk & $\begin{array}{l}\text { Risk of bias: no information } \\
\text { Comment: no information to judge whether the confounding factors were bal- } \\
\text { anced across groups }\end{array}$ \\
\hline Selection bias & Low risk & $\begin{array}{l}\text { Risk of bias: low } \\
\text { Comment: the research was performed in the same centre }\end{array}$ \\
\hline $\begin{array}{l}\text { Bias in classification of in- } \\
\text { terventions }\end{array}$ & Low risk & $\begin{array}{l}\text { Risk of bias: low } \\
\text { Comment: the intervention and control were well defined }\end{array}$ \\
\hline $\begin{array}{l}\text { Bias due to deviations } \\
\text { from intended interven- } \\
\text { tions }\end{array}$ & Unclear risk & $\begin{array}{l}\text { Risk of bias: no information } \\
\text { Comment: no information to judge whether the co-interventions were similar } \\
\text { across the groups }\end{array}$ \\
\hline $\begin{array}{l}\text { Bias due to missing data } \\
\text { Bias in measurement of }\end{array}$ & Low risk & $\begin{array}{l}\text { Righ of bias: low } \\
\text { Comment: all samples were probably included in the analysis }\end{array}$ \\
\hline $\begin{array}{l}\text { Bias in selection of the re- } \\
\text { ported result }\end{array}$ & High risk & $\begin{array}{l}\text { Risk of bias: serious } \\
\text { Comment: the outcome assessors do not seem to be blinded to the groups }\end{array}$ \\
\hline
\end{tabular}

\section{Chauchat 2017}

\begin{tabular}{ll}
\hline Methods & Cross-sectional study; cluster study \\
\hline Participants & Country: Canada \\
& Number of clusters: 83 \\
& Number excluded: $0(0 \%)$ \\
& Number included: 83 \\
& Chemotherapy agents tested for contamination: cyclophosphamide, ifosfamide, methotrexate, 5-fluo- \\
& rouracil, cytarabine, gemcitabine, irinotecan, and other drugs \\
& Professional role: pharmacy technician/pharmacist \\
& Size of the hospitals/wards: $>50$ beds \\
\hline
\end{tabular}

Closed-system drug-transfer devices plus safe handling of hazardous drugs versus safe handling alone for reducing exposure to 
Chauchat 2017 (Continued)

\begin{tabular}{ll} 
Interventions & Group 1: CSTD + standard care (variable) $(\mathrm{N}=$ \\
& Group 2: standard care (not stated) $(\mathrm{N}=52)$ \\
\hline Outcomes & Outcomes reported: surface contamination \\
\hline Notes & Unpublished data \\
& Source of funding: No special funding.
\end{tabular}

Risk of bias

\begin{tabular}{lll}
\hline Bias & Authors' judgement & Support for judgement \\
\hline Confounding bias & Unclear risk & $\begin{array}{l}\text { Risk of bias: no information } \\
\text { Comment: no information to judge whether the confounding factors were bal- } \\
\text { anced across groups }\end{array}$ \\
\hline Selection bias & Unclear risk & $\begin{array}{l}\text { Risk of bias: moderate } \\
\text { Comment: the participating centres may have done so based on their pharma- } \\
\text { cological practices }\end{array}$ \\
\hline $\begin{array}{l}\text { Bias in classification of in- } \\
\text { terventions }\end{array}$ & Low risk & $\begin{array}{l}\text { Risk of bias: low } \\
\text { Comment: the intervention and control were well defined }\end{array}$ \\
\hline $\begin{array}{l}\text { Bias due to deviations } \\
\text { from intended interven- } \\
\text { tions }\end{array}$ & Unclear risk & $\begin{array}{l}\text { Risk of bias: no information } \\
\text { Comment: no information to judge whether the co-interventions were similar } \\
\text { across the groups }\end{array}$ \\
\hline $\begin{array}{l}\text { Bias due to missing data } \\
\text { Bias in measurement of }\end{array}$ & Low risk & High risk \\
$\begin{array}{l}\text { Rias in selection of the re- } \\
\text { ported result }\end{array}$ & High risk & $\begin{array}{l}\text { Comment: all samples were included in the analysis } \\
\text { Comment: the outcome assessors do not seem to be blinded to the groups }\end{array}$ \\
\hline
\end{tabular}

\section{Edwards 2013}

\begin{tabular}{ll}
\hline Methods & Uncontrolled before-after cohort study; cluster study \\
\hline Participants & Country: USA \\
& Number of clusters: 2 \\
& Number excluded: $0(0 \%)$ \\
& $\begin{array}{l}\text { Number included: } 2 \\
\text { Chemotherapy agents tested for contamination: not measured } \\
\text { Professional role: pharmacy (not clear whether pharmacist or pharmacy technician) } \\
\text { Size of the hospitals/wards: } 335 \text { beds }\end{array}$ \\
\hline Interventions & Group 1: CSTD + standard care (PhaSeal) ( $=1)$ \\
& Group 2: standard care (not stated) ( $=1)$ \\
\hline Outcomes & Outcomes reported: potential cost savings \\
\hline Notes & Authors provided additional information.
\end{tabular}


Edwards 2013 (Continued)

Source of funding: No special funding.

\section{Risk of bias}

\begin{tabular}{|c|c|c|}
\hline Bias & Authors' judgement & Support for judgement \\
\hline Confounding bias & Unclear risk & $\begin{array}{l}\text { Risk of bias: no information } \\
\text { Comment: no information to judge whether the confounding factors were bal- } \\
\text { anced across groups }\end{array}$ \\
\hline Selection bias & Low risk & $\begin{array}{l}\text { Risk of bias: low } \\
\text { Comment: the research was performed in the same centre }\end{array}$ \\
\hline $\begin{array}{l}\text { Bias in classification of in- } \\
\text { terventions }\end{array}$ & Low risk & $\begin{array}{l}\text { Risk of bias: low } \\
\text { Comment: the intervention and control were well defined }\end{array}$ \\
\hline $\begin{array}{l}\text { Bias due to deviations } \\
\text { from intended interven- } \\
\text { tions }\end{array}$ & Unclear risk & $\begin{array}{l}\text { Risk of bias: no information } \\
\text { Comment: no information to judge whether the co-interventions were similar } \\
\text { across the groups }\end{array}$ \\
\hline Bias due to missing data & Low risk & $\begin{array}{l}\text { Risk of bias: low } \\
\text { Comment: all samples were probably included in the analysis }\end{array}$ \\
\hline $\begin{array}{l}\text { Bias in measurement of } \\
\text { outcomes }\end{array}$ & High risk & $\begin{array}{l}\text { Risk of bias: serious } \\
\text { Comment: the outcome assessors do not seem to be blinded to the groups }\end{array}$ \\
\hline $\begin{array}{l}\text { Bias in selection of the re- } \\
\text { ported result }\end{array}$ & High risk & $\begin{array}{l}\text { Risk of bias: serious } \\
\text { Comment: actual savings based on the reuse of the drug were not reported } \\
\text { despite being probably collected }\end{array}$ \\
\hline
\end{tabular}

Forges 2011

\begin{tabular}{ll}
\hline Methods & Cross-sectional study; cluster study \\
\hline Participants & $\begin{array}{l}\text { Country: France } \\
\text { Number of clusters: } 2 \\
\text { Number excluded: not stated } \\
\text { Number included: } 2 \\
\text { Chemotherapy agents tested for contamination: 5-fluorouracil } \\
\text { Professional role: pharmacy technician } \\
\text { Size of the hospitals/wards: not stated }\end{array}$ \\
\hline Interventions & $\begin{array}{l}\text { Group 1: CSTD + standard care (Spike Swan) (N }=1) \\
\text { Group 2: standard care (isolators, gloves, and daily washing) }(\mathrm{N}=1)\end{array}$ \\
\hline Outcomes & Outcomes reported: surface contamination \\
\hline Notes & Source of funding: Not reported.
\end{tabular}

\section{Risk of bias}

\begin{tabular}{lll}
\hline Bias & Authors' judgement & Support for judgement \\
\hline Confounding bias & Unclear risk & $\begin{array}{l}\text { Risk of bias: no information } \\
\text { Comment: no information to judge whether the confounding factors were bal- } \\
\text { anced across groups }\end{array}$ \\
\end{tabular}

Closed-system drug-transfer devices plus safe handling of hazardous drugs versus safe handling alone for reducing exposure to 
Forges 2011 (Continued)

$\begin{array}{ll}\text { Selection bias } \quad \text { Low risk } & \text { Risk of bias: low } \\ \text { Comment: the is }\end{array}$

Comment: the isolators were all in the same centre and some preparations were made with CSTD while others were not made with CSTD

\begin{tabular}{ll}
\hline $\begin{array}{l}\text { Bias in classification of in- } \\
\text { terventions }\end{array}$ & Low risk \\
& Comment: the intervention and control were well defined
\end{tabular}

\begin{tabular}{|c|c|c|}
\hline $\begin{array}{l}\text { Bias due to deviations } \\
\text { from intended interven- } \\
\text { tions }\end{array}$ & High risk & $\begin{array}{l}\text { Risk of bias: serious } \\
\text { Comment: only the intervention group received additional training and super- } \\
\text { vision }\end{array}$ \\
\hline
\end{tabular}

\begin{tabular}{ll}
\hline Bias due to missing data $\quad$ Unclear risk & Risk of bias: no information \\
& Comment: insufficient information to judge whether there was bias due to \\
& missing data
\end{tabular}

\begin{tabular}{lll}
\hline $\begin{array}{l}\text { Bias in measurement of } \\
\text { outcomes }\end{array}$ & High risk & $\begin{array}{l}\text { Risk of bias: serious } \\
\text { Comment: the outcome assessors do not seem to be blinded to the groups }\end{array}$ \\
\hline $\begin{array}{l}\text { Bias in selection of the re- } \\
\text { ported result }\end{array}$ & Low risk & $\begin{array}{l}\text { Risk of bias: low } \\
\text { Comment: the authors appear to have reported all the results }\end{array}$ \\
\hline
\end{tabular}

Guillemette 2014

\begin{tabular}{ll}
\hline Methods & Uncontrolled before-after cohort study; cluster study \\
\hline Participants & $\begin{array}{l}\text { Country: Canada } \\
\text { Number of clusters: } 2 \\
\text { Number excluded: } 0 \text { ( } 0 \%) \\
\text { Number included: } 2 \\
\text { Chemotherapy agents tested for contamination: cyclophosphamide, ifosfamide, and methotrexate } \\
\text { Professional role: pharmacy technician } \\
\text { Size of the hospitals/wards: }>500 \text { beds }\end{array}$ \\
\hline Interventions & $\begin{array}{l}\text { Group 1: CSTD + standard care (PhaSeal) ( }=1) \\
\text { Group 2: standard care (biological safety cabinets) }(\mathrm{N}=1)\end{array}$ \\
\hline Outcomes & Outcomes reported: surface contamination \\
\hline Notes & Authors provided additional information. \\
& Source of funding: No special funding. \\
\hline
\end{tabular}

\section{Risk of bias}

\begin{tabular}{lll}
\hline Bias & Authors' judgement & Support for judgement \\
\hline Confounding bias & Unclear risk & $\begin{array}{l}\text { Risk of bias: no information } \\
\text { Comment: no information to judge whether the confounding factors were bal- } \\
\text { anced across groups }\end{array}$ \\
\hline Selection bias & High risk & $\begin{array}{l}\text { Risk of bias: serious } \\
\text { Comment: although the research was performed in the same centre, different } \\
\text { sites were chosen for sampling from the intervention and control }\end{array}$ \\
\hline
\end{tabular}


Guillemette 2014 (Continued)

$\begin{array}{ll}\begin{array}{l}\text { Bias in classification of in- } \\ \text { terventions }\end{array} & \text { Low risk of bias: low } \\ & \text { Comment: the intervention and control were well defined }\end{array}$

\begin{tabular}{lll}
\hline $\begin{array}{l}\text { Bias due to deviations } \\
\text { from intended interven- } \\
\text { tions }\end{array}$ & High risk & $\begin{array}{l}\text { Risk of bias: serious } \\
\text { Comment: the technicians received additional training prior to the interven- } \\
\text { tion }\end{array}$ \\
\hline Bias due to missing data & Low risk & $\begin{array}{l}\text { Risk of bias: low } \\
\text { Comment: all samples were included in the analysis }\end{array}$ \\
\hline $\begin{array}{l}\text { Bias in measurement of } \\
\text { outcomes }\end{array}$ & High risk & $\begin{array}{l}\text { Risk of bias: serious } \\
\text { Comment: the outcome assessors do not seem to be blinded to the groups }\end{array}$ \\
$\begin{array}{l}\text { Bias in selection of the re- } \\
\text { ported result }\end{array}$ & High risk & $\begin{array}{l}\text { Risk of bias: serious } \\
\text { Comment: only selected results were reported }\end{array}$ \\
\hline
\end{tabular}

Hama 2012

\begin{tabular}{ll}
\hline Methods & Uncontrolled before-after cohort study; cluster study \\
\hline Participants & Country: Japan \\
& Number of clusters: 2 \\
& Number excluded: $0(0 \%)$ \\
& $\begin{array}{l}\text { Number included: } 2 \\
\text { Chemotherapy agents tested for contamination: cyclophosphamide } \\
\text { Professional role: pharmacists } \\
\text { Size of the hospitals/wards: }>150 \text { patients per day }\end{array}$ \\
\hline Interventions & Group 1: CSTD + standard care (PhaSeal) ( $=1)$ \\
& Group 2: standard care (personal protective equipment) $(\mathrm{N}=1)$ \\
\hline Outcomes & None of the outcomes of interest were reported. \\
\hline Notes & Source of funding: Not reported.
\end{tabular}

\section{Risk of bias}

\begin{tabular}{lll}
\hline Bias & Authors' judgement & Support for judgement \\
\hline Confounding bias & Unclear risk & $\begin{array}{l}\text { Risk of bias: no information } \\
\text { Comment: no information to judge whether the confounding factors were bal- } \\
\text { anced across groups }\end{array}$ \\
\hline Selection bias & Low risk & $\begin{array}{l}\text { Risk of bias: low } \\
\text { Comment: the research was performed in the same centre }\end{array}$ \\
\hline $\begin{array}{l}\text { Bias in classification of in- } \\
\text { terventions }\end{array}$ & Low risk & $\begin{array}{l}\text { Risk of bias: low } \\
\text { Comment: the intervention and control were well defined }\end{array}$ \\
\hline $\begin{array}{l}\text { Bias due to deviations } \\
\text { from intended interven- } \\
\text { tions }\end{array}$ & Unclear risk & $\begin{array}{l}\text { Risk of bias: no information } \\
\text { Comment: no information to judge whether the co-interventions were similar } \\
\text { across the groups }\end{array}$ \\
\hline $\begin{array}{l}\text { Bias due to missing data } \\
\text { and }\end{array}$ & Unclear risk & \begin{tabular}{l} 
Risk of bias: no information \\
\hline
\end{tabular}
\end{tabular}


Hama 2012 (Continued)

Comment: insufficient information to judge whether there was bias due to missing data

\begin{tabular}{lll}
\hline $\begin{array}{l}\text { Bias in measurement of } \\
\text { outcomes }\end{array}$ & High risk & $\begin{array}{l}\text { Risk of bias: serious } \\
\text { Comment: the outcome assessors do not seem to be blinded to the groups }\end{array}$ \\
\hline $\begin{array}{l}\text { Bias in selection of the re- } \\
\text { ported result }\end{array}$ & High risk & $\begin{array}{l}\text { Risk of bias: serious } \\
\text { Comment: only selected results were reported, but even these were not re- } \\
\text { ported in a format from which inferences could be made }\end{array}$ \\
\hline
\end{tabular}

Harrison 2006

\begin{tabular}{ll}
\hline Methods & interrupted time-series; cluster study \\
\hline Participants & Country: USA \\
& Number of clusters: 6 \\
& Number excluded: $0(0 \%)$ \\
& Number included: 6 \\
Chemotherapy agents tested for contamination: cyclophosphamide, fluorouracil & Professional role: pharmacists \\
& Size of the hospitals/wards: not stated \\
\hline
\end{tabular}

\begin{tabular}{ll}
\hline Interventions & Group 1: CSTD + standard care (PhaSeal) $(\mathrm{N}=3)$ \\
& Group 2: standard care (biological safety cabinets, latex rubber chemoprotective gloves, disposable \\
& gowns, and aseptic and negative-pressure mixing techniques) $(\mathrm{N}=3)$
\end{tabular}

\begin{tabular}{ll}
\hline Outcomes & Outcomes reported: surface contamination \\
\hline Notes & Source of funding: PhaSeal manufacturers. \\
\hline
\end{tabular}

\section{Risk of bias}

\begin{tabular}{|c|c|c|}
\hline Bias & Authors' judgement & Support for judgement \\
\hline Confounding bias & Unclear risk & $\begin{array}{l}\text { Risk of bias: no information } \\
\text { Comment: no information to judge whether the confounding factors were bal- } \\
\text { anced across groups }\end{array}$ \\
\hline Selection bias & Low risk & $\begin{array}{l}\text { Risk of bias: low } \\
\text { Comment: the research was performed in the same centre }\end{array}$ \\
\hline $\begin{array}{l}\text { Bias in classification of in- } \\
\text { terventions }\end{array}$ & Low risk & $\begin{array}{l}\text { Risk of bias: low } \\
\text { Comment: the intervention and control were well defined }\end{array}$ \\
\hline $\begin{array}{l}\text { Bias due to deviations } \\
\text { from intended interven- } \\
\text { tions }\end{array}$ & Unclear risk & $\begin{array}{l}\text { Risk of bias: no information } \\
\text { Comment: no information to judge whether the co-interventions were similar } \\
\text { across the groups }\end{array}$ \\
\hline Bias due to missing data & Unclear risk & $\begin{array}{l}\text { Risk of bias: no information } \\
\text { Comment: insufficient information to judge whether there was bias due to } \\
\text { missing data }\end{array}$ \\
\hline $\begin{array}{l}\text { Bias in measurement of } \\
\text { outcomes }\end{array}$ & High risk & $\begin{array}{l}\text { Risk of bias: serious } \\
\text { Comment: the outcome assessors do not seem to be blinded to the groups }\end{array}$ \\
\hline
\end{tabular}


Harrison 2006 (Continued)

Bias in selection of the re- High risk ported result
Risk of bias: serious

Comment: the authors have not reported the results fully and this seems to be dependent upon the results

Janes 2015

\begin{tabular}{ll}
\hline Methods & Cross-sectional study; cluster study \\
\hline Participants & $\begin{array}{l}\text { Country: Canada } \\
\text { Number of clusters: } 51 \\
\text { Number excluded: } 2 \text { (3.9\%) } \\
\text { Reason for exclusion: } 2 \text { hospitals did not provide reply to the CSTD status } \\
\text { Number included: } 49 \\
\text { Chemotherapy agents tested for contamination: cyclophosphamide, ifosfamide, and methotrexate } \\
\text { Professional role: pharmacy technician/pharmacist } \\
\text { Size of the hospitals/wards: at least 50 beds }\end{array}$ \\
\hline Interventions & $\begin{array}{l}\text { Group } 1: \text { CSTD }+ \text { standard care (variable) (N = 12) } \\
\text { Group 2: standard care (variable including removal of outer packaging and cleaned vials after receipt } \\
\text { in some hospitals) (N = 37) }\end{array}$ \\
\hline Outcomes & Outcomes reported: surface contamination \\
\hline Notes & Authors provided additional information. \\
& Source of funding: No special funding. \\
\hline
\end{tabular}

\section{Risk of bias}

\begin{tabular}{|c|c|c|}
\hline Bias & Authors' judgement & Support for judgement \\
\hline Confounding bias & Unclear risk & $\begin{array}{l}\text { Risk of bias: no information } \\
\text { Comment: no information to judge whether the confounding factors were bal- } \\
\text { anced across groups }\end{array}$ \\
\hline Selection bias & Unclear risk & $\begin{array}{l}\text { Risk of bias: moderate } \\
\text { Comment: the participating centres may have done so based on their pharma- } \\
\text { cological practices }\end{array}$ \\
\hline $\begin{array}{l}\text { Bias in classification of in- } \\
\text { terventions }\end{array}$ & Low risk & $\begin{array}{l}\text { Risk of bias: low } \\
\text { Comment: the intervention and control were well defined }\end{array}$ \\
\hline $\begin{array}{l}\text { Bias due to deviations } \\
\text { from intended interven- } \\
\text { tions }\end{array}$ & Unclear risk & $\begin{array}{l}\text { Risk of bias: no information } \\
\text { Comment: no information to judge whether the co-interventions were similar } \\
\text { across the groups }\end{array}$ \\
\hline Bias due to missing data & Unclear risk & $\begin{array}{l}\text { Risk of bias: no information } \\
\text { Comment: insufficient information to judge whether there was bias due to } \\
\text { missing data (i.e. the hospitals which did not reply about CSTD status may } \\
\text { have done so because of the intervention or the outcome) }\end{array}$ \\
\hline $\begin{array}{l}\text { Bias in measurement of } \\
\text { outcomes }\end{array}$ & High risk & $\begin{array}{l}\text { Risk of bias: serious } \\
\text { Comment: the outcome assessors do not seem to be blinded to the groups }\end{array}$ \\
\hline $\begin{array}{l}\text { Bias in selection of the re- } \\
\text { ported result }\end{array}$ & High risk & $\begin{array}{l}\text { Risk of bias: serious } \\
\text { Comment: only selected results were reported }\end{array}$ \\
\hline
\end{tabular}

Closed-system drug-transfer devices plus safe handling of hazardous drugs versus safe handling alone for reducing exposure to 
Juhasz 2016

\begin{tabular}{|c|c|c|}
\hline Methods & \multicolumn{2}{|c|}{ Uncontrolled before-after cohort study; cluster study } \\
\hline Participants & \multicolumn{2}{|c|}{$\begin{array}{l}\text { Country: Hungary } \\
\text { Number of clusters: } 4 \\
\text { Number excluded: } 0(0 \%) \\
\text { Number included: } 4 \\
\text { Chemotherapy agents tested for contamination: not measured } \\
\text { Professional role: pharmacy (not clear whether pharmacist or pharmacy technician) } \\
\text { Size of the hospitals/wards: } 335 \text { beds }\end{array}$} \\
\hline Interventions & \multicolumn{2}{|c|}{$\begin{array}{l}\text { Group 1: CSTD + standard care (Tevadaptor) }(\mathrm{N}=2) \\
\text { Group 2: standard care (not stated) }(\mathrm{N}=2)\end{array}$} \\
\hline Outcomes & \multicolumn{2}{|c|}{ Outcomes reported: potential cost savings } \\
\hline Notes & \multicolumn{2}{|c|}{ Source of funding: No special funding. } \\
\hline \multicolumn{3}{|l|}{ Risk of bias } \\
\hline Bias & Authors' judgement & Support for judgement \\
\hline Confounding bias & Unclear risk & $\begin{array}{l}\text { Risk of bias: no information } \\
\text { Comment: no information to judge whether the confounding factors were bal- } \\
\text { anced across groups }\end{array}$ \\
\hline Selection bias & Low risk & $\begin{array}{l}\text { Risk of bias: low } \\
\text { Comment: the research was performed in the same centres }\end{array}$ \\
\hline $\begin{array}{l}\text { Bias in classification of in- } \\
\text { terventions }\end{array}$ & Low risk & $\begin{array}{l}\text { Risk of bias: low } \\
\text { Comment: the intervention and control were well defined }\end{array}$ \\
\hline $\begin{array}{l}\text { Bias due to deviations } \\
\text { from intended interven- } \\
\text { tions }\end{array}$ & Unclear risk & $\begin{array}{l}\text { Risk of bias: no information } \\
\text { Comment: no information to judge whether the co-interventions were similar } \\
\text { across the groups }\end{array}$ \\
\hline Bias due to missing data & Low risk & $\begin{array}{l}\text { Risk of bias: low } \\
\text { Comment: all samples were probably included in the analysis }\end{array}$ \\
\hline $\begin{array}{l}\text { Bias in measurement of } \\
\text { outcomes }\end{array}$ & High risk & $\begin{array}{l}\text { Risk of bias: serious } \\
\text { Comment: the outcome assessors do not seem to be blinded to the groups }\end{array}$ \\
\hline $\begin{array}{l}\text { Bias in selection of the re- } \\
\text { ported result }\end{array}$ & High risk & $\begin{array}{l}\text { Risk of bias: serious } \\
\text { Comment: actual savings based on the reuse of the drug were not reported } \\
\text { despite being probably collected }\end{array}$ \\
\hline
\end{tabular}

Miyake 2013

\begin{tabular}{ll}
\hline Methods & Uncontrolled before-after cohort study; cluster study \\
\hline Participants & Country: Japan \\
& Number of clusters: 2 \\
& Number excluded: $0(0 \%)$ \\
& Number included: 2 \\
& Chemotherapy agents tested for contamination: cyclophosphamide \\
\hline
\end{tabular}

Closed-system drug-transfer devices plus safe handling of hazardous drugs versus safe handling alone for reducing exposure to 
Miyake 2013 (Continued)

Professional role: pharmacist

Size of the hospitals/wards: 655 beds

\begin{tabular}{|c|c|c|}
\hline Interventions & \multicolumn{2}{|c|}{$\begin{array}{l}\text { Group 1: CSTD + standard care (PhaSeal) }(\mathrm{N}=1) \\
\text { Group 2: standard care (not stated) }(\mathrm{N}=1)\end{array}$} \\
\hline Outcomes & \multicolumn{2}{|c|}{ Outcomes reported: exposure and surface contamination } \\
\hline Notes & \multicolumn{2}{|c|}{ Source of funding: Not reported. } \\
\hline \multicolumn{3}{|l|}{ Risk of bias } \\
\hline Bias & Authors' judgement & Support for judgement \\
\hline Confounding bias & Unclear risk & $\begin{array}{l}\text { Risk of bias: no information } \\
\text { Comment: no information to judge whether the confounding factors were bal- } \\
\text { anced across groups }\end{array}$ \\
\hline Selection bias & Low risk & $\begin{array}{l}\text { Risk of bias: low } \\
\text { Comment: the research was performed in the same centre }\end{array}$ \\
\hline $\begin{array}{l}\text { Bias in classification of in- } \\
\text { terventions }\end{array}$ & Low risk & $\begin{array}{l}\text { Risk of bias: low } \\
\text { Comment: the intervention and control were well defined }\end{array}$ \\
\hline $\begin{array}{l}\text { Bias due to deviations } \\
\text { from intended interven- } \\
\text { tions }\end{array}$ & High risk & $\begin{array}{l}\text { Risk of bias: serious } \\
\text { Comment: the pharmacists received training prior to use of CSTD. No such } \\
\text { training was provided in the control group }\end{array}$ \\
\hline Bias due to missing data & Low risk & $\begin{array}{l}\text { Risk of bias: low } \\
\text { Comment: all samples were included in the analysis }\end{array}$ \\
\hline $\begin{array}{l}\text { Bias in measurement of } \\
\text { outcomes }\end{array}$ & High risk & $\begin{array}{l}\text { Risk of bias: serious } \\
\text { Comment: the outcome assessors do not seem to be blinded to the groups }\end{array}$ \\
\hline $\begin{array}{l}\text { Bias in selection of the re- } \\
\text { ported result }\end{array}$ & Low risk & $\begin{array}{l}\text { Risk of bias: low } \\
\text { Comment: all results seem to be reported }\end{array}$ \\
\hline
\end{tabular}

Mullot 2008

\begin{tabular}{ll}
\hline Methods & Uncontrolled before-after cohort study; cluster study \\
\hline Participants & Country: France \\
& Number of clusters: 2 \\
& Number excluded: 0 ( $0 \%)$ \\
& $\begin{array}{l}\text { Number included: } 2 \\
\text { Chemotherapy agents tested for contamination: not measured } \\
\text { Professional role: pharmacist, pharmacy technician, nurse } \\
\text { Size of the hospitals/wards: not stated, but about } 150 \text { preparations per day }\end{array}$ \\
\hline Interventions & $\begin{array}{l}\text { Group 1: CSTD + standard care (PhaSeal/Tevadaptor) ( } \mathrm{N}=1 \text { ) } \\
\text { Group 2: standard care (hood with laminar flow, isolators, neoprene gloves, air intake with standard } \\
\text { needles (no spike use) ( } \mathrm{N}=1 \text { ) }\end{array}$ \\
\hline Outcomes & Outcomes reported: potential cost savings \\
\hline Notes & Source of funding: Not reported.
\end{tabular}

Closed-system drug-transfer devices plus safe handling of hazardous drugs versus safe handling alone for reducing exposure to 
Mullot 2008 (Continued)

Risk of bias

\begin{tabular}{lll}
\hline Bias & Authors' judgement & Support for judgement \\
\hline Confounding bias & Unclear risk & $\begin{array}{l}\text { Risk of bias: no information } \\
\text { Comment: no information to judge whether the confounding factors were bal- } \\
\text { anced across groups }\end{array}$ \\
\hline Selection bias & Low risk & $\begin{array}{l}\text { Risk of bias: low } \\
\text { Comment: the research was performed in the same centre }\end{array}$ \\
\hline $\begin{array}{l}\text { Bias in classification of in- } \\
\text { terventions }\end{array}$ & Low risk & $\begin{array}{l}\text { Risk of bias: low } \\
\text { Comment: the intervention and control were well defined }\end{array}$ \\
\hline $\begin{array}{l}\text { Bias due to deviations } \\
\text { from intended interven- } \\
\text { tions }\end{array}$ & High risk & $\begin{array}{l}\text { Risk of bias: serious } \\
\text { Comment: the personnel received training prior to use of CSTD. No such train- } \\
\text { ing was provided in the control group }\end{array}$ \\
\hline $\begin{array}{l}\text { Bias due to missing data } \\
\text { Bias in measurement of }\end{array}$ & Low risk & High risk \\
\hline $\begin{array}{l}\text { Bias in selection of the re- } \\
\text { ported result }\end{array}$ & High risk & $\begin{array}{l}\text { Risk of bias: low } \\
\text { Comment: all samples were probably included in the analysis }\end{array}$ \\
\hline
\end{tabular}

Ozyaman 2016

\begin{tabular}{ll}
\hline Methods & Uncontrolled before-after cohort study; cluster study \\
\hline Participants & Country: Turkey \\
Number of clusters: 2 \\
Number excluded: $0(0 \%)$ \\
Number included: 2 \\
Chemotherapy agents tested for contamination: not measured \\
Professional role: pharmacy (not clear whether pharmacist or pharmacy technician) \\
Size of the hospitals/wards: not stated
\end{tabular}

\begin{tabular}{ll}
\hline Interventions & Group 1: CSTD + standard care $($ PhaSeal) $(\mathrm{N}=1)$ \\
& Group 2: standard care $($ not stated $)(\mathrm{N}=1)$
\end{tabular}

\begin{tabular}{ll}
\hline Outcomes & Outcomes reported: potential cost savings \\
\hline Notes & Source of funding: Not reported. \\
\hline
\end{tabular}

\section{Risk of bias}

\begin{tabular}{lll}
\hline Bias & Authors' judgement & Support for judgement \\
\hline Confounding bias & Unclear risk & $\begin{array}{l}\text { Risk of bias: no information } \\
\text { Comment: no information to judge whether the confounding factors were bal- } \\
\text { anced across groups }\end{array}$ \\
\hline Selection bias & Low risk & Risk of bias: low
\end{tabular}




\begin{tabular}{ll}
\hline $\begin{array}{l}\text { Bias in classification of in- } \\
\text { terventions }\end{array}$ & Low risk \\
\end{tabular}

\begin{tabular}{lll}
\hline $\begin{array}{l}\text { Bias due to deviations } \\
\text { from intended interven- } \\
\text { tions }\end{array}$ & Unclear risk & $\begin{array}{l}\text { Risk of bias: no information } \\
\text { Comment: no information to judge whether the co-interventions were similar } \\
\text { across the groups }\end{array}$ \\
\hline Bias due to missing data & Low risk & $\begin{array}{l}\text { Risk of bias: low } \\
\text { Comment: all samples were probably included in the analysis }\end{array}$ \\
\hline $\begin{array}{l}\text { Bias in measurement of } \\
\text { outcomes }\end{array}$ & High risk & $\begin{array}{l}\text { Risk of bias: serious } \\
\text { Comment: the outcome assessors do not seem to be blinded to the groups }\end{array}$ \\
\hline $\begin{array}{l}\text { Bias in selection of the re- } \\
\text { ported result }\end{array}$ & High risk & $\begin{array}{l}\text { Risk of bias: serious } \\
\text { Comment: actual savings based on the reuse of the drug were not reported } \\
\text { despite being probably collected }\end{array}$ \\
\hline
\end{tabular}

\section{Poupeau 2016}

\begin{tabular}{ll}
\hline Methods & Cross-sectional study; cluster study \\
\hline Participants & Country: Canada \\
& Number of clusters: 48 \\
& Number excluded: 2 (4.2\%) \\
& Reason for exclusion: Two hospitals did not provide reply to the CSTD status \\
& Number included: 46 \\
& Chemotherapy agents tested for contamination: cyclophosphamide, ifosfamide, and methotrexate \\
& Professional role: pharmacy technician/pharmacist \\
& Size of the hospitals/wards: at least 50 beds \\
\hline Interventions & $\begin{array}{l}\text { Group 1: CSTD + standard care (variable) ( } \mathrm{N}=12 \text { ) } \\
\text { Group 2: standard care (variable including removal of outer packaging and cleaned vials after receipt } \\
\text { in some hospitals) ( } \mathrm{N}=34)\end{array}$ \\
\hline Outcomes & Outcomes reported: surface contamination \\
\hline Notes & Authors provided additional information. \\
& Source of funding: No special funding. \\
\hline
\end{tabular}

\section{Risk of bias}

\begin{tabular}{lll}
\hline Bias & Authors' judgement & Support for judgement \\
\hline Confounding bias & Unclear risk & $\begin{array}{l}\text { Risk of bias: no information } \\
\text { Comment: no information to judge whether the confounding factors were bal- } \\
\text { anced across groups }\end{array}$ \\
\hline Selection bias & Unclear risk & $\begin{array}{l}\text { Risk of bias: moderate } \\
\text { Comment: the participating centres may have done so based on their pharma- } \\
\text { cological practices }\end{array}$ \\
\hline Bias in classification of in- & Low risk & $\begin{array}{l}\text { Risk of bias: low } \\
\text { Comentions }\end{array}$ \\
\hline
\end{tabular}


Poupeau 2016 (Continued)

Bias due to deviations from intended interventions
Unclear risk Risk of bias: no information

Comment: no information to judge whether the co-interventions were similar across the groups
Risk of bias: no information

Comment: insufficient information to judge whether there was bias due to missing data (i.e. the hospitals which did not reply about CSTD status may have done so because of the intervention or the outcome)

\begin{tabular}{lll}
\hline $\begin{array}{l}\text { Bias in measurement of } \\
\text { outcomes }\end{array}$ & High risk & $\begin{array}{l}\text { Risk of bias: serious } \\
\text { Comment: the outcome assessors do not seem to be blinded to the groups }\end{array}$ \\
\hline $\begin{array}{l}\text { Bias in selection of the re- } \\
\text { ported result }\end{array}$ & High risk & $\begin{array}{l}\text { Risk of bias: serious } \\
\text { Comment: only selected results were reported }\end{array}$ \\
\hline
\end{tabular}

Roland 2017

\begin{tabular}{ll}
\hline Methods & Cross-sectional study; cluster study \\
\hline Participants & $\begin{array}{l}\text { Country: Canada } \\
\text { Number of clusters: } 66 \\
\text { Number excluded: } 0(0 \%) \\
\text { Number included: } 66 \\
\text { Chemotherapy agents tested for contamination: cyclophosphamide, ifosfamide, and methotrexate } \\
\text { Professional role: pharmacy technician/pharmacist } \\
\text { Size of the hospitals/wards: at least } 50 \text { beds }\end{array}$ \\
\hline Interventions & $\begin{array}{l}\text { Group 1: CSTD + standard care (variable) ( } \mathrm{N}=23) \\
\text { Group 2: standard care (variable including removal of outer packaging and cleaned vials after receipt } \\
\text { in some hospitals) (N = 43) }\end{array}$ \\
\hline Outcomes & Outcomes reported: surface contamination \\
\hline Notes & Authors provided additional information. \\
& Source of funding: No special funding. \\
\hline
\end{tabular}

\section{Risk of bias}

\begin{tabular}{lll}
\hline Bias & Authors' judgement & Support for judgement \\
\hline Confounding bias & Unclear risk & $\begin{array}{l}\text { Risk of bias: no information } \\
\text { Comment: no information to judge whether the confounding factors were bal- } \\
\text { anced across groups }\end{array}$ \\
\hline Selection bias & Unclear risk & $\begin{array}{l}\text { Risk of bias: moderate } \\
\text { Comment: the participating centres may have done so based on their pharma- } \\
\text { cological practices }\end{array}$ \\
\hline $\begin{array}{l}\text { Bias in classification of in- } \\
\text { terventions }\end{array}$ & Low risk & $\begin{array}{l}\text { Risk of bias: low } \\
\text { Comment: the intervention and control were well defined }\end{array}$ \\
\hline $\begin{array}{l}\text { Bias due to deviations } \\
\text { from intended interven- } \\
\text { tions }\end{array}$ & Unclear risk & $\begin{array}{l}\text { Risk of bias: no information } \\
\text { Comment: no information to judge whether the co-interventions were similar } \\
\text { across the groups }\end{array}$ \\
\hline
\end{tabular}

Closed-system drug-transfer devices plus safe handling of hazardous drugs versus safe handling alone for reducing exposure to 
Roland 2017 (Continued)

$\begin{array}{ll}\text { Bias due to missing data Low risk } & \text { Risk of bias: low } \\ & \text { Comment: all samples were included in the analysis }\end{array}$

\section{Bias in measurement of High risk} outcomes
Risk of bias: serious

Comment: the outcome assessors do not seem to be blinded to the groups

$\begin{array}{lll}\begin{array}{l}\text { Bias in selection of the re- } \\ \text { ported result }\end{array} & \text { High risk } & \begin{array}{l}\text { Risk of bias: serious } \\ \text { Comment: only selected results were reported }\end{array}\end{array}$

Sessink 2011

\begin{tabular}{ll}
\hline Methods & Uncontrolled before-after cohort study; cluster study \\
\hline Participants & Country: USA \\
Number of clusters: 44 \\
Number excluded: $0(0 \%)$ \\
Number included: 44 \\
Chemotherapy agents tested for contamination: cyclophosphamide, ifosfamide, and 5-fluorouracil \\
Professional role: pharmacist \\
Size of the hospitals/wards: not stated
\end{tabular}

\begin{tabular}{ll}
\hline Interventions & Group 1: CSTD + standard care (PhaSeal) $(\mathrm{N}=22)$ \\
& Group 2: standard care (class II BSCs, protective gloves, disposable gowns, and aseptic and nega- \\
& tive-pressure mixing techniques using needle syringes) $(\mathrm{N}=22)$
\end{tabular}

\begin{tabular}{ll}
\hline Outcomes & Outcomes reported: surface contamination \\
\hline Notes & Authors provided additional information. \\
& Source of funding: PhaSeal manufacturers.
\end{tabular}

\section{Risk of bias}

\begin{tabular}{lll}
\hline Bias & Authors' judgement & Support for judgement \\
\hline Confounding bias & Unclear risk & $\begin{array}{l}\text { Risk of bias: no information } \\
\text { Comment: no information to judge whether the confounding factors were bal- } \\
\text { anced across groups }\end{array}$ \\
\hline Selection bias & Unclear risk & $\begin{array}{l}\text { Risk of bias: moderate } \\
\text { Comment: the participating centres were probably selected based on their } \\
\text { pharmacological practices }\end{array}$ \\
\hline $\begin{array}{l}\text { Bias in classification of in- } \\
\text { terventions }\end{array}$ & Low risk & $\begin{array}{l}\text { Risk of bias: low } \\
\text { Comment: the intervention and control were well defined }\end{array}$ \\
\hline $\begin{array}{l}\text { Bias due to deviations } \\
\text { from intended interven- } \\
\text { tions }\end{array}$ & Unclear risk & $\begin{array}{l}\text { Risk of bias: no information } \\
\text { Comment: no information to judge whether the co-interventions were similar } \\
\text { across the groups }\end{array}$ \\
\hline Bias due to missing data & Low risk & $\begin{array}{l}\text { Risk of bias: low } \\
\text { Comment: all samples were included in the analysis }\end{array}$ \\
\hline $\begin{array}{l}\text { Bias in measurement of } \\
\text { outcomes }\end{array}$ & High risk & $\begin{array}{l}\text { Risk of bias: serious } \\
\text { Comment: the outcome assessors do not seem to be blinded to the groups }\end{array}$ \\
\hline
\end{tabular}

Closed-system drug-transfer devices plus safe handling of hazardlous drugs versus safe handling alone for reducing exposure to 
Sessink 2011 (Continued)

$\begin{array}{ll}\begin{array}{l}\text { Bias in selection of the re- } \quad \text { High risk } \\ \text { ported result }\end{array} & \begin{array}{l}\text { Risk of bias: serious } \\ \text { Comment: only selected results were reported and none could be used for the } \\ \text { systematic review }\end{array}\end{array}$

Sessink 2013

\begin{tabular}{|c|c|}
\hline Methods & Uncontrolled before-after cohort study; cluster study \\
\hline Participants & $\begin{array}{l}\text { Country: USA } \\
\text { Number of clusters: } 60 \\
\text { Number excluded: } 0 \text { (0\%) } \\
\text { Number included: } 60 \\
\text { Chemotherapy agents tested for contamination: cyclophosphamide } \\
\text { Professional role: pharmacist } \\
\text { Size of the hospitals/wards: not stated }\end{array}$ \\
\hline Interventions & $\begin{array}{l}\text { Group 1: CSTD + standard care }(\text { PhaSeal })(\mathrm{N}=30) \\
\text { Group 2: standard care (not stated) }(\mathrm{N}=30)\end{array}$ \\
\hline Outcomes & Outcomes reported: surface contamination \\
\hline Notes & $\begin{array}{l}\text { Authors provided additional information. } \\
\text { Source of funding: PhaSeal manufacturers. }\end{array}$ \\
\hline
\end{tabular}

\section{Risk of bias}

\begin{tabular}{|c|c|c|}
\hline Bias & Authors' judgement & Support for judgement \\
\hline Confounding bias & Unclear risk & $\begin{array}{l}\text { Risk of bias: no information } \\
\text { Comment: no information to judge whether the confounding factors were bal- } \\
\text { anced across groups }\end{array}$ \\
\hline Selection bias & Unclear risk & $\begin{array}{l}\text { Risk of bias: moderate } \\
\text { Comment: the participating centres were probably selected based on their } \\
\text { pharmacological practices }\end{array}$ \\
\hline $\begin{array}{l}\text { Bias in classification of in- } \\
\text { terventions }\end{array}$ & Low risk & $\begin{array}{l}\text { Risk of bias: low } \\
\text { Comment: the intervention and control were well defined }\end{array}$ \\
\hline $\begin{array}{l}\text { Bias due to deviations } \\
\text { from intended interven- } \\
\text { tions }\end{array}$ & Unclear risk & $\begin{array}{l}\text { Risk of bias: no information } \\
\text { Comment: no information to judge whether the co-interventions were similar } \\
\text { across the groups }\end{array}$ \\
\hline Bias due to missing data & Low risk & $\begin{array}{l}\text { Risk of bias: low } \\
\text { Comment: all samples were included in the analysis }\end{array}$ \\
\hline $\begin{array}{l}\text { Bias in measurement of } \\
\text { outcomes }\end{array}$ & High risk & $\begin{array}{l}\text { Risk of bias: serious } \\
\text { Comment: the outcome assessors do not seem to be blinded to the groups }\end{array}$ \\
\hline $\begin{array}{l}\text { Bias in selection of the re- } \\
\text { ported result }\end{array}$ & High risk & $\begin{array}{l}\text { Risk of bias: serious } \\
\text { Comment: only selected results were reported and none could be used for the } \\
\text { systematic review }\end{array}$ \\
\hline
\end{tabular}


Siderov 2010

\begin{tabular}{|c|c|c|}
\hline Methods & \multicolumn{2}{|c|}{ Uncontrolled before-after cohort study; cluster study } \\
\hline Participants & \multicolumn{2}{|c|}{$\begin{array}{l}\text { Country: Australia } \\
\text { Number of clusters: } 4 \\
\text { Number excluded: } 0(0 \%) \\
\text { Number included: } 4 \\
\text { Chemotherapy agents tested for contamination: cyclophosphamide } \\
\text { Professional role: pharmacist } \\
\text { Size of the hospitals/wards: not stated }\end{array}$} \\
\hline Interventions & \multicolumn{2}{|c|}{$\begin{array}{l}\text { Group 1: CSTD + standard care (PhaSeal) }(\mathrm{N}=2) \\
\text { Group 2: standard care (not stated) }(\mathrm{N}=2)\end{array}$} \\
\hline Outcomes & \multicolumn{2}{|c|}{ Outcomes reported: surface contamination } \\
\hline Notes & \multicolumn{2}{|c|}{ Source of funding: PhaSeal manufacturers. } \\
\hline \multicolumn{3}{|l|}{ Risk of bias } \\
\hline Bias & Authors' judgement & Support for judgement \\
\hline Confounding bias & Unclear risk & $\begin{array}{l}\text { Risk of bias: no information } \\
\text { Comment: no information to judge whether the confounding factors were bal- } \\
\text { anced across groups }\end{array}$ \\
\hline Selection bias & Low risk & $\begin{array}{l}\text { Risk of bias: low } \\
\text { Comment: the research was performed in the same centre }\end{array}$ \\
\hline $\begin{array}{l}\text { Bias in classification of in- } \\
\text { terventions }\end{array}$ & Low risk & $\begin{array}{l}\text { Risk of bias: low } \\
\text { Comment: the intervention and control were well defined }\end{array}$ \\
\hline $\begin{array}{l}\text { Bias due to deviations } \\
\text { from intended interven- } \\
\text { tions }\end{array}$ & Unclear risk & $\begin{array}{l}\text { Risk of bias: no information } \\
\text { Comment: no information to judge whether the co-interventions were similar } \\
\text { across the groups }\end{array}$ \\
\hline Bias due to missing data & Low risk & $\begin{array}{l}\text { Risk of bias: low } \\
\text { Comment: all samples were included in the analysis }\end{array}$ \\
\hline $\begin{array}{l}\text { Bias in measurement of } \\
\text { outcomes }\end{array}$ & High risk & $\begin{array}{l}\text { Risk of bias: serious } \\
\text { Comment: the outcome assessors do not seem to be blinded to the groups }\end{array}$ \\
\hline $\begin{array}{l}\text { Bias in selection of the re- } \\
\text { ported result }\end{array}$ & Low risk & $\begin{array}{l}\text { Risk of bias: low } \\
\text { Comment: all results seem to be reported }\end{array}$ \\
\hline
\end{tabular}

\section{Simon 2016}

\begin{tabular}{ll}
\hline Methods & Cross-sectional study; cluster study \\
\hline Participants & Country: France \\
& Number of clusters: 2 \\
& Number excluded: $0(0 \%)$ \\
& Number included: 2 \\
Chemotherapy agents tested for contamination: cyclophosphamide; cytarabine; cytarabine; dacar- \\
bazine; doxorubicin; fluorouracil; ganciclovir; gemcitabine; ifosfamide; irinotecan \\
Professional role: pharmacist
\end{tabular}

Closed-system drug-transfer devices plus safe handling of hazardous drugs versus safe handling alone for reducing exposure to 
Simon 2016 (Continued)

Size of the hospitals/wards: not stated

Interventions Group 1: CSTD + standard care (PhaSeal) $(\mathrm{N}=1)$

Group 2: standard care (isolators and personal protective equipment (gloves, sterile drapes, compresses)) $(\mathrm{N}=1)$

\begin{tabular}{ll}
\hline Outcomes & Outcomes reported: surface contamination \\
\hline Notes & Source of funding: PhaSeal manufacturers.
\end{tabular}

\section{Risk of bias}

\begin{tabular}{lll}
\hline Bias & Authors' judgement & Support for judgement \\
\hline Confounding bias & Unclear risk & $\begin{array}{l}\text { Risk of bias: no information } \\
\text { Comment: no information to judge whether the confounding factors were bal- } \\
\text { anced across groups }\end{array}$ \\
& &
\end{tabular}

\begin{tabular}{|c|c|c|}
\hline Selection bias & Low risk & $\begin{array}{l}\text { Risk of bias: low } \\
\text { Comment: the research was performed in } 2 \text { isolators in the same centre: in } 1 \\
\text { isolator, CSTD was used; in the other it was not }\end{array}$ \\
\hline $\begin{array}{l}\text { Bias in classification of in- } \\
\text { terventions }\end{array}$ & Low risk & $\begin{array}{l}\text { Risk of bias: low } \\
\text { Comment: the intervention and control were well defined }\end{array}$ \\
\hline $\begin{array}{l}\text { Bias due to deviations } \\
\text { from intended interven- } \\
\text { tions }\end{array}$ & High risk & $\begin{array}{l}\text { Risk of bias: serious } \\
\text { Comment: the pharmacists received training prior to use of CSTD. No such } \\
\text { training was provided in the control group }\end{array}$ \\
\hline Bias due to missing data & Low risk & $\begin{array}{l}\text { Risk of bias: low } \\
\text { Comment: almost all samples were included in the analysis }\end{array}$ \\
\hline $\begin{array}{l}\text { Bias in measurement of } \\
\text { outcomes }\end{array}$ & High risk & $\begin{array}{l}\text { Risk of bias: serious } \\
\text { Comment: the outcome assessors do not seem to be blinded to the groups } \\
\text { (although the authors say 'To avoid any evaluation bias, the measurement of } \\
\text { occupational exposure was carried out in blind conditions. The results were } \\
\text { interpreted after the last sampling day', it appears that they mean laboratory } \\
\text { measurements rather than the person sampling since the compounding units } \\
\text { were different in the intervention group and wipe samples were taken before } \\
\text { and after the daily cleaning process). }\end{array}$ \\
\hline $\begin{array}{l}\text { Bias in selection of the re- } \\
\text { ported result }\end{array}$ & High risk & $\begin{array}{l}\text { Risk of bias: serious } \\
\text { Comment: only selected results were reported and none could be used for the } \\
\text { systematic review }\end{array}$ \\
\hline
\end{tabular}

\section{Sottani 2012}

\begin{tabular}{ll}
\hline Methods & Cross-sectional study; cluster study \\
\hline Participants & Country: Italy \\
& Number of clusters: 4 \\
& Number excluded: $0(0 \%)$ \\
& Number included: 4 \\
& Chemotherapy agents tested for contamination: cyclophosphamide, ifosfamide, and gemcitabine \\
& Professional role: pharmacy technician \\
& Size of the hospitals/wards: not stated \\
\hline
\end{tabular}

Closed-system drug-transfer devices plus safe handling of hazardous drugs versus safe handling alone for reducing exposure to 
Sottani 2012 (Continued)

\begin{tabular}{ll} 
Interventions & $\begin{array}{l}\text { Group 1: } \text { CSTD + standard care (not stated) }(\mathrm{N}=3) \\
\text { Group 2: standard care (not stated) }(\mathrm{N}=1)\end{array}$ \\
\hline Outcomes & Outcomes reported: exposure and surface contamination \\
\hline Notes & Source of funding: Not reported.
\end{tabular}

\section{Risk of bias}

\begin{tabular}{|c|c|c|}
\hline Bias & Authors' judgement & Support for judgement \\
\hline Confounding bias & Unclear risk & $\begin{array}{l}\text { Risk of bias: no information } \\
\text { Comment: no information to judge whether the confounding factors were bal- } \\
\text { anced across groups }\end{array}$ \\
\hline Selection bias & Unclear risk & $\begin{array}{l}\text { Risk of bias: moderate } \\
\text { Comment: the participating centres were probably selected based on their } \\
\text { pharmacological practices }\end{array}$ \\
\hline $\begin{array}{l}\text { Bias in classification of in- } \\
\text { terventions }\end{array}$ & Low risk & $\begin{array}{l}\text { Risk of bias: low } \\
\text { Comment: the intervention and control were well defined }\end{array}$ \\
\hline $\begin{array}{l}\text { Bias due to deviations } \\
\text { from intended interven- } \\
\text { tions }\end{array}$ & Unclear risk & $\begin{array}{l}\text { Risk of bias: no information } \\
\text { Comment: no information to judge whether the co-interventions were similar } \\
\text { across the groups }\end{array}$ \\
\hline Bias due to missing data & Low risk & $\begin{array}{l}\text { Risk of bias: low } \\
\text { Comment: all samples were included in the analysis }\end{array}$ \\
\hline $\begin{array}{l}\text { Bias in measurement of } \\
\text { outcomes }\end{array}$ & High risk & $\begin{array}{l}\text { Risk of bias: serious } \\
\text { Comment: the outcome assessors do not seem to be blinded to the groups }\end{array}$ \\
\hline $\begin{array}{l}\text { Bias in selection of the re- } \\
\text { ported result }\end{array}$ & Low risk & $\begin{array}{l}\text { Risk of bias: low } \\
\text { Comment: all results seem to be reported }\end{array}$ \\
\hline
\end{tabular}

Vyas 2016

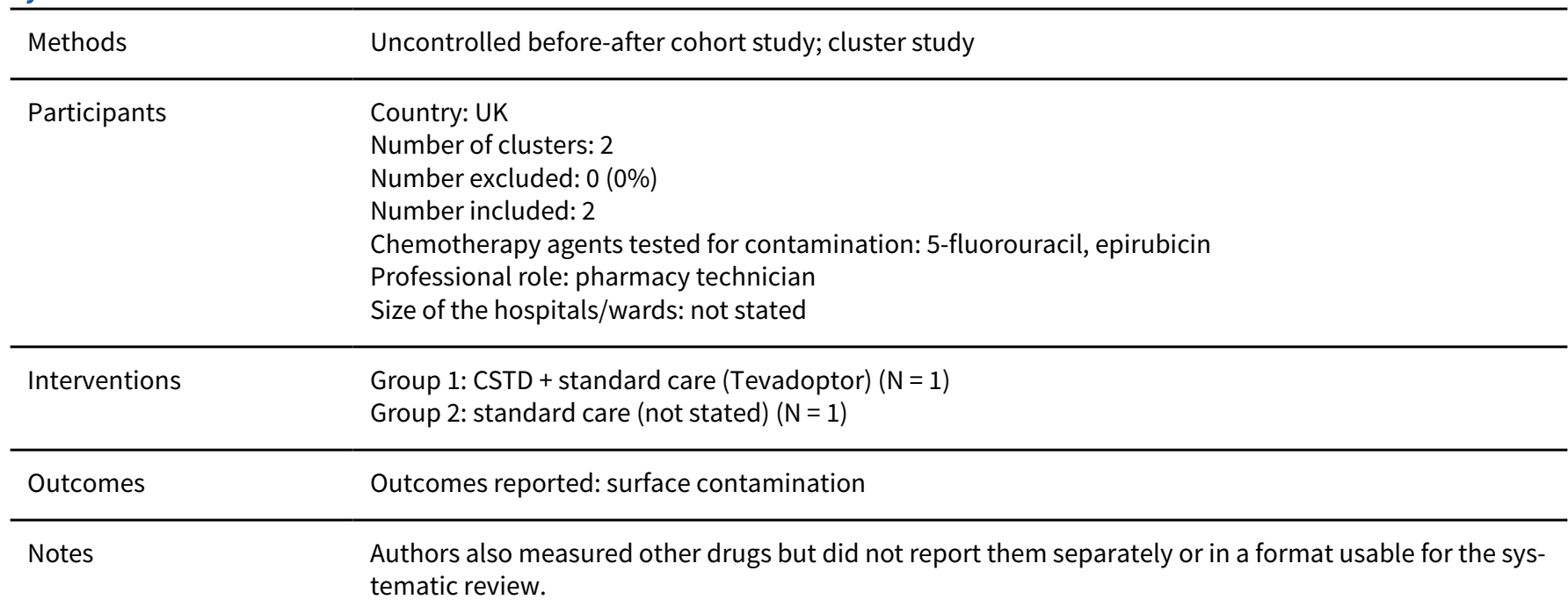


Vyas 2016 (Continued)

Source of funding: Not reported.

\section{Risk of bias}

\begin{tabular}{lll}
\hline Bias & Authors' judgement & Support for judgement \\
\hline Confounding bias & Unclear risk & $\begin{array}{l}\text { Risk of bias: no information } \\
\text { Comment: no information to judge whether the confounding factors were bal- } \\
\text { anced across groups }\end{array}$ \\
\hline Selection bias & Low risk & $\begin{array}{l}\text { Risk of bias: low } \\
\text { Comment: the research was performed in the same centre }\end{array}$ \\
\hline $\begin{array}{l}\text { Bias in classification of in- } \\
\text { terventions }\end{array}$ & Low risk & $\begin{array}{l}\text { Risk of bias: low } \\
\text { Comment: the intervention and control were well defined }\end{array}$ \\
\hline $\begin{array}{l}\text { Bias due to deviations } \\
\text { from intended interven- } \\
\text { tions }\end{array}$ & High risk & $\begin{array}{l}\text { Risk of bias: serious } \\
\text { Comment: the pharmacy technicians received training prior to use of CSTD. } \\
\text { No such training was probably provided in the control group }\end{array}$ \\
\hline $\begin{array}{l}\text { Bias due to missing data } \\
\text { Bias in measurement of }\end{array}$ & Low risk & High risk \\
$\begin{array}{l}\text { Bias in selection of the re- } \\
\text { ported result }\end{array}$ & High risk & $\begin{array}{l}\text { Risk of bias: low } \\
\text { Comment: all samples were included in the analysis }\end{array}$ \\
\hline
\end{tabular}

Wick 2003

\begin{tabular}{ll}
\hline Methods & Uncontrolled before-after cohort study; cluster study \\
\hline Participants & Country: USA \\
& Number of clusters: 2 \\
& Number excluded: 0 ( $0 \%)$ \\
& $\begin{array}{l}\text { Chmber included: } 2 \\
\text { Professional role: pharmacist, pharmacy technician, nurse } \\
\text { Size of the hospitals/wards: not stated }\end{array}$ \\
\hline Interventions & Group 1: CSTD + standard care (PhaSeal) ( $=1)$ \\
\hline Outcomes & Group 2: standard care (not stated) ( $=1)$ \\
\hline Notes & Outcomes reported: exposure and surface contamination \\
\hline
\end{tabular}

\section{Risk of bias}

\begin{tabular}{lll}
\hline Bias & Authors' judgement & Support for judgement \\
\hline Confounding bias & Unclear risk & $\begin{array}{l}\text { Risk of bias: no information } \\
\text { Comment: no information to judge whether the confounding factors were bal- } \\
\text { anced across groups }\end{array}$ \\
\hline
\end{tabular}

Closed-system drug-transfer devices plus safe handling of hazardous drugs versus safe handling alone for reducing exposure to 
Wick 2003 (Continued)

\begin{tabular}{lll} 
Selection bias & Low risk & $\begin{array}{l}\text { Risk of bias: low } \\
\text { Comment: the research was performed in the same centre }\end{array}$ \\
\hline $\begin{array}{l}\text { Bias in classification of in- } \\
\text { terventions }\end{array}$ & Low risk & $\begin{array}{l}\text { Risk of bias: low } \\
\text { Comment: the intervention and control were well defined }\end{array}$ \\
\hline $\begin{array}{l}\text { Bias due to deviations } \\
\text { from intended interven- } \\
\text { tions }\end{array}$ & High risk & $\begin{array}{l}\text { Risk of bias: serious } \\
\text { Comment: the pharmacists/technicians/nurses received training prior to use } \\
\text { of CSTD. No such training was probably provided in the control group }\end{array}$ \\
\hline $\begin{array}{l}\text { Bias due to missing data } \\
\text { Bias in measurement of }\end{array}$ & Low risk & $\begin{array}{l}\text { Risk of bias: low } \\
\text { Comment: all samples were included in the analysis }\end{array}$ \\
\hline $\begin{array}{l}\text { Bias in selection of the re- } \\
\text { ported result }\end{array}$ & Low risk & $\begin{array}{l}\text { Risk of bias: serious } \\
\text { Comment: the outcome assessors do not seem to be blinded to the groups }\end{array}$ \\
\hline
\end{tabular}

Yoshida 2009

\begin{tabular}{|c|c|}
\hline Methods & Uncontrolled before-after cohort study; cluster study \\
\hline Participants & $\begin{array}{l}\text { Country: Japan } \\
\text { Number of clusters: } 2 \\
\text { Number excluded: } 0(0 \%) \\
\text { Number included: } 2 \\
\text { Chemotherapy agents tested for contamination: cyclophosphamide } \\
\text { Professional role: pharmacist } \\
\text { Size of the hospitals/wards: not stated }\end{array}$ \\
\hline Interventions & $\begin{array}{l}\text { Group 1: CSTD + standard care (PhaSeal) }(\mathrm{N}=1) \\
\text { Group 2: standard care (Biological safety cabinet and personal protection equipment) }(\mathrm{N}=1)\end{array}$ \\
\hline Outcomes & Outcomes reported: exposure and surface contamination \\
\hline Notes & Source of funding: Not reported. \\
\hline
\end{tabular}

\section{Risk of bias}

\begin{tabular}{|c|c|c|}
\hline Bias & Authors' judgement & Support for judgement \\
\hline Confounding bias & Unclear risk & $\begin{array}{l}\text { Risk of bias: no information } \\
\text { Comment: no information to judge whether the confounding factors were bal- } \\
\text { anced across groups }\end{array}$ \\
\hline Selection bias & Low risk & $\begin{array}{l}\text { Risk of bias: low } \\
\text { Comment: the research was performed in the same centre }\end{array}$ \\
\hline $\begin{array}{l}\text { Bias in classification of in- } \\
\text { terventions }\end{array}$ & Low risk & $\begin{array}{l}\text { Risk of bias: low } \\
\text { Comment: the intervention and control were well defined }\end{array}$ \\
\hline $\begin{array}{l}\text { Bias due to deviations } \\
\text { from intended interven- } \\
\text { tions }\end{array}$ & High risk & $\begin{array}{l}\text { Risk of bias: serious } \\
\text { Comment: the pharmacists received training prior to use of CSTD. No such } \\
\text { training was probably provided in the control group }\end{array}$ \\
\hline
\end{tabular}

Closed-system drug-transfer devices plus safe handling of hazardous drugs versus safe handling alone for reducing exposure to 
Yoshida 2009 (Continued)

$\begin{array}{ll}\text { Bias due to missing data Low risk } & \text { Risk of bias: low } \\ \text { Comment: all samples were included in the analysis }\end{array}$

\section{Bias in measurement of High risk} outcomes
Risk of bias: serious

Comment: the outcome assessors do not seem to be blinded to the groups

$\begin{array}{lll}\begin{array}{l}\text { Bias in selection of the re- } \\ \text { ported result }\end{array} & \text { Low risk } & \begin{array}{l}\text { Risk of bias: low } \\ \text { Comment: all results seem to be reported }\end{array}\end{array}$

Yoshida 2011

\begin{tabular}{ll}
\hline Methods & Cross-sectional study; cluster study \\
\hline Participants & $\begin{array}{l}\text { Country: Japan } \\
\text { Number of clusters: } 5 \\
\text { Number excluded: not stated } \\
\text { Number included: } 5 \\
\text { Chemotherapy agents tested for contamination: cyclophosphamide; 5-fluorouracil, gemcitabine, and } \\
\text { platinum-containing drugs } \\
\text { Professional role: pharmacist } \\
\text { Size of the hospitals/wards: not stated }\end{array}$ \\
\hline Interventions & $\begin{array}{l}\text { Group 1: CSTD + standard care (not stated) (N=3) } \\
\text { Group 2: standard care (variable) ( }=2)\end{array}$ \\
\hline Outcomes & None of the outcomes of interest were reported. \\
\hline Notes & Source of funding: Not reported. \\
\hline
\end{tabular}

\section{Risk of bias}

\begin{tabular}{lll}
\hline Bias & Authors' judgement & Support for judgement \\
\hline Confounding bias & Unclear risk & $\begin{array}{l}\text { Risk of bias: no information } \\
\text { Comment: no information to judge whether the confounding factors were bal- } \\
\text { anced across groups }\end{array}$ \\
\hline Selection bias & Unclear risk & $\begin{array}{l}\text { Risk of bias: moderate } \\
\text { Comment: the participating centres were probably selected based on their } \\
\text { pharmacological practices }\end{array}$ \\
\hline $\begin{array}{l}\text { Bias in classification of in- } \\
\text { terventions }\end{array}$ & Low risk & $\begin{array}{l}\text { Risk of bias: low } \\
\text { Comment: the intervention and control were well defined }\end{array}$ \\
\hline $\begin{array}{l}\text { Bias due to deviations } \\
\text { from intended interven- } \\
\text { tions }\end{array}$ & Unclear risk & $\begin{array}{l}\text { Risk of bias: no information } \\
\text { Comment: no information to judge whether the co-interventions were similar } \\
\text { across the groups }\end{array}$ \\
\hline $\begin{array}{l}\text { Bias due to missing data } \\
\text { Bias in measurement of }\end{array}$ & Low risk & High risk \\
$\begin{array}{l}\text { Bias in selection of the re- } \\
\text { ported result }\end{array}$ & High risk & $\begin{array}{l}\text { Risk of bias: low } \\
\text { Comment: all samples were included in the analysis }\end{array}$ \\
\hline
\end{tabular}

Closed-system drug-transfer devices plus safe handling of hazardous drugs versus safe handling alone for reducing exposure to 
Yoshida 2011 (Continued)

Comment: the authors have not reported the results in a format from which inferences could be made

CSTD: closed-system transfer device.

Characteristics of excluded studies [ordered by study ID]

\begin{tabular}{|c|c|}
\hline Study & Reason for exclusion \\
\hline Amos 2012 & Comparison of different CSTDs \\
\hline Blazawski 2013 & Simulation study \\
\hline Chantry 2015 & Simulation study \\
\hline Clark 2013 & Not a study comparing CSTD versus standard care \\
\hline Connor 2010 & Not a study comparing CSTD versus standard care \\
\hline Contractor 2015 & Not a study comparing CSTD versus standard care \\
\hline Cox 2017 & Not a study comparing CSTD versus standard care \\
\hline De Ausen 2013 & Simulation study \\
\hline De Prijck 2008 & Simulation study \\
\hline DeFreitas 2012 & Simulation study \\
\hline Enciso-Zarate 2016 & Not a study comparing CSTD versus standard care \\
\hline Favier 2012 & Simulation study \\
\hline Fernandez 2013 & Simulation study \\
\hline Garrigue 2016 & Simulation study \\
\hline Gebel 2015 & Simulation study \\
\hline Gilles 2009 & Not a study comparing CSTD versus standard care \\
\hline Gomez-Alvarez 2016 & Simulation study \\
\hline Gonzalez-Haba Pena 2016 & Simulation study \\
\hline Hama 2011 & Simulation study \\
\hline Hong 2017 & Not a study comparing CSTD versus standard care \\
\hline Hospital Employee Health 2005 & Not a primary research study \\
\hline Hospital Infection Control 2005 & Not a primary research study \\
\hline Idell 2009 & Not a study comparing CSTD versus standard care \\
\hline
\end{tabular}




\begin{tabular}{|c|c|}
\hline Study & Reason for exclusion \\
\hline Ikeno 2014 & Simulation study \\
\hline Jorgenson 2008 & Simulation study \\
\hline Kopp 2013 & Not a study comparing CSTD versus standard care \\
\hline Kunneva 2016 & Not a primary research study \\
\hline Kurihara 2017 & Not a study comparing CSTD versus standard care \\
\hline Laws 2016 & Not a primary research study \\
\hline Le Garlantezec 2011 & Simulation study \\
\hline Ledford 2010 & Comparison of different CSTDs \\
\hline Lennan 2017 & Not a primary research study \\
\hline Lin 2017 & Simulation study \\
\hline McDiarmid 2010 & $\begin{array}{l}\text { Intermittent use of CSTD (not possible to determine whether the outcomes are for CSTD } \\
\text { or standard care) }\end{array}$ \\
\hline McMichael 2011 & Simulation study \\
\hline Meade 2015 & Not a primary research study \\
\hline Nishigaki 2010 & Simulation study \\
\hline Nygren 2005 & Not a study comparing CSTD versus standard care \\
\hline Nygren 2008 & Simulation study \\
\hline Nyman 2007 & Not a study comparing CSTD versus standard care \\
\hline Odraska 2013 & Not a study comparing CSTD versus standard care \\
\hline Oncology Nurse Advisor 2017 & Not a primary research study \\
\hline Perlo 2015 & Simulation study \\
\hline Queruau Lamerie 2012 & Simulation study \\
\hline Rupp 2017 & Simulation study \\
\hline Sanchez-Rubio Ferrandez 2012 & Simulation study \\
\hline Sanchez-Rubio Ferrandez 2012a & Simulation study \\
\hline Sato 2010 & Simulation study \\
\hline Sessink 1999 & Not a study comparing CSTD versus standard care \\
\hline Simon 2010 & Simulation study \\
\hline
\end{tabular}




\begin{tabular}{ll}
\hline Study & Reason for exclusion \\
\hline Smith 2014 & Simulation study \\
\hline Talsmar 2015 & Not a primary research study \\
\hline Thomas Carey 2011 & Simulation study \\
\hline Tyler 2017 & Not a study comparing CSTD versus standard care \\
\hline Yoshida 2013 & Not a study comparing CSTD versus standard care \\
\hline
\end{tabular}

CSTD: closed-system transfer device.

\section{DATA AND ANALYSES}

Comparison 1. Closed-system transfer device plus safe handling versus safe handling alone

\begin{tabular}{|c|c|c|c|c|}
\hline Outcome or subgroup title & No. of studies & $\begin{array}{l}\text { No. of partici- } \\
\text { pants }\end{array}$ & Statistical method & Effect size \\
\hline 1 Urine tests for exposure & 4 & & Risk Ratio (Random, 95\% Cl) & Subtotals only \\
\hline 1.1 Cyclophoshamide & 2 & & Risk Ratio (Random, 95\% Cl) & $0.83[0.46,1.52]$ \\
\hline $\begin{array}{l}1.2 \text { Cyclophosphamide or ifos- } \\
\text { famide }\end{array}$ & 1 & & Risk Ratio (Random, 95\% Cl) & $0.09[0.00,2.79]$ \\
\hline $\begin{array}{l}1.3 \text { Cyclophosphamide, ifos- } \\
\text { famide, or gemcitabine }\end{array}$ & 1 & & Risk Ratio (Random, 95\% Cl) & $0.0[0.0,0.0]$ \\
\hline $\begin{array}{l}2 \text { Proportion of surfaces contam- } \\
\text { inated }\end{array}$ & 15 & & Risk Ratio (Random, 95\% Cl) & Subtotals only \\
\hline $\begin{array}{l}2.1 \text { Cyclophosphamide (pharma- } \\
\text { cy areas) }\end{array}$ & 13 & & Risk Ratio (Random, 95\% Cl) & $0.89[0.78,1.01]$ \\
\hline 2.2 Ifosfamide (pharmacy areas) & 9 & & Risk Ratio (Random, 95\% Cl) & $0.94[0.74,1.19]$ \\
\hline $\begin{array}{l}2.3 \text { Methotrexate (pharmacy ar- } \\
\text { eas) }\end{array}$ & 6 & & Risk Ratio (Random, 95\% Cl) & $0.84[0.58,1.22]$ \\
\hline $\begin{array}{l}2.45 \text {-fluorouracil (pharmacy ar- } \\
\text { eas) }\end{array}$ & 4 & & Risk Ratio (Random, 95\% Cl) & $0.63[0.42,0.94]$ \\
\hline 2.5 Cytarabine (pharmacy areas) & 2 & & Risk Ratio (Random, 95\% Cl) & $0.72[0.18,2.86]$ \\
\hline $\begin{array}{l}2.6 \text { Gemcitabine (pharmacy ar- } \\
\text { eas) }\end{array}$ & 2 & & Risk Ratio (Random, 95\% Cl) & $0.96[0.60,1.54]$ \\
\hline 2.7 Irinotecan (pharmacy areas) & 1 & & Risk Ratio (Random, 95\% Cl) & $0.36[0.10,1.33]$ \\
\hline 2.8 Docetaxel (pharmacy areas) & 1 & & Risk Ratio (Random, 95\% Cl) & $0.0[0.0,0.0]$ \\
\hline
\end{tabular}




\begin{tabular}{|c|c|c|c|c|}
\hline Outcome or subgroup title & No. of studies & $\begin{array}{l}\text { No. of partici- } \\
\text { pants }\end{array}$ & Statistical method & Effect size \\
\hline 2.9 Paclitaxel (pharmacy areas) & 1 & & Risk Ratio (Random, 95\% Cl) & $0.57[0.04,9.06]$ \\
\hline $\begin{array}{l}2.10 \text { Vinorelbine (pharmacy ar- } \\
\text { eas) }\end{array}$ & 1 & & Risk Ratio (Random, 95\% Cl) & $1.72[0.16,18.73]$ \\
\hline $\begin{array}{l}2.11 \text { Ganciclovir (pharmacy ar- } \\
\text { eas) }\end{array}$ & 1 & & Risk Ratio (Random, 95\% Cl) & $0.01[0.00,27.11]$ \\
\hline 2.12 Epirubicin (pharmacy areas) & 1 & & Risk Ratio (Random, 95\% Cl) & $0.03[0.00,6.29]$ \\
\hline $\begin{array}{l}2.13 \text { Multiple drugs (pharmacy ar- } \\
\text { eas) }\end{array}$ & 1 & & Risk Ratio (Random, 95\% Cl) & $0.87[0.43,1.77]$ \\
\hline $\begin{array}{l}2.14 \text { Cyclophosphamide (pa- } \\
\text { tient-care areas) }\end{array}$ & 5 & & Risk Ratio (Random, 95\% Cl) & $1.01[0.86,1.18]$ \\
\hline $\begin{array}{l}2.15 \text { Ifosfamide (patient-care ar- } \\
\text { eas) }\end{array}$ & 5 & & Risk Ratio (Random, 95\% Cl) & $1.44[0.91,2.28]$ \\
\hline $\begin{array}{l}2.16 \text { Methotrexate (patient-care } \\
\text { areas) }\end{array}$ & 5 & & Risk Ratio (Random, 95\% Cl) & $1.00[0.55,1.85]$ \\
\hline $\begin{array}{l}2.175 \text {-fluorouracil (patient-care } \\
\text { areas) }\end{array}$ & 1 & & Risk Ratio (Random, 95\% Cl) & $1.09[0.53,2.23]$ \\
\hline $\begin{array}{l}2.18 \text { Cytarabine (patient-care ar- } \\
\text { eas) }\end{array}$ & 1 & & Risk Ratio (Random, 95\% Cl) & $0.59[0.01,24.53]$ \\
\hline $\begin{array}{l}2.19 \text { Gemcitabine (patient-care } \\
\text { areas) }\end{array}$ & 1 & & Risk Ratio (Random, 95\% Cl) & $1.13[0.55,2.33]$ \\
\hline $\begin{array}{l}2.20 \text { Irinotecan (patient-care ar- } \\
\text { eas) }\end{array}$ & 1 & & Risk Ratio (Random, 95\% Cl) & $0.44[0.03,6.15]$ \\
\hline $\begin{array}{l}\text { 2.21 Docetaxel (patient-care ar- } \\
\text { eas) }\end{array}$ & 1 & & Risk Ratio (Random, 95\% Cl) & $0.59[0.01,24.53]$ \\
\hline $\begin{array}{l}\text { 2.22 Paclitaxel (patient-care ar- } \\
\text { eas) }\end{array}$ & 1 & & Risk Ratio (Random, 95\% Cl) & $0.59[0.01,24.53]$ \\
\hline $\begin{array}{l}2.23 \text { Vinorelbine (patient-care ar- } \\
\text { eas) }\end{array}$ & 1 & & Risk Ratio (Random, 95\% Cl) & $0.0[0.0,0.0]$ \\
\hline $\begin{array}{l}2.24 \text { Multiple drugs (patient-care } \\
\text { areas) }\end{array}$ & 1 & & Risk Ratio (Random, 95\% Cl) & $2.38[0.69,8.23]$ \\
\hline $\begin{array}{l}3 \text { Quantity of surface contamina- } \\
\text { tion }\left(\mathrm{pg} / \mathrm{cm}^{2}\right)\end{array}$ & 9 & & $\begin{array}{l}\text { Mean Difference (Random, } \\
95 \% \mathrm{Cl} \text { ) }\end{array}$ & Subtotals only \\
\hline $\begin{array}{l}3.1 \text { Cyclophosphamide (pharma- } \\
\text { cy areas) }\end{array}$ & 7 & & $\begin{array}{l}\text { Mean Difference (Random, } \\
95 \% \mathrm{Cl} \text { ) }\end{array}$ & $-49.34[-84.11,-14.56]$ \\
\hline 3.2 Ifosfamide (pharmacy areas) & 6 & & $\begin{array}{l}\text { Mean Difference (Random, } \\
95 \% \mathrm{Cl} \text { ) }\end{array}$ & $-0.32[-6.58,5.94]$ \\
\hline
\end{tabular}




\begin{tabular}{|c|c|c|c|c|}
\hline Outcome or subgroup title & No. of studies & $\begin{array}{l}\text { No. of partici- } \\
\text { pants }\end{array}$ & Statistical method & Effect size \\
\hline $\begin{array}{l}\text { 3.3 Methotrexate (pharmacy ar- } \\
\text { eas) }\end{array}$ & 6 & & $\begin{array}{l}\text { Mean Difference (Random, } \\
95 \% \mathrm{Cl} \text { ) }\end{array}$ & $-3.09[-13.80,7.61]$ \\
\hline $\begin{array}{l}3.45 \text {-fluorouracil (pharmacy ar- } \\
\text { eas) }\end{array}$ & 3 & & $\begin{array}{l}\text { Mean Difference (Random, } \\
95 \% \mathrm{Cl} \text { ) }\end{array}$ & $\begin{array}{l}231.62[-460.52 \\
923.76]\end{array}$ \\
\hline 3.5 Cytarabine (pharmacy areas) & 1 & & $\begin{array}{l}\text { Mean Difference (Random, } \\
95 \% \mathrm{Cl} \text { ) }\end{array}$ & $-0.6[-15.67,14.47]$ \\
\hline $\begin{array}{l}\text { 3.6 Gemcitabine (pharmacy ar- } \\
\text { eas) }\end{array}$ & 1 & & $\begin{array}{l}\text { Mean Difference (Random, } \\
95 \% \mathrm{Cl} \text { ) }\end{array}$ & $-32.7[-102.43,37.03]$ \\
\hline 3.7 Irinotecan (pharmacy areas) & 1 & & $\begin{array}{l}\text { Mean Difference (Random, } \\
95 \% \mathrm{Cl} \text { ) }\end{array}$ & $-18.27[-56.89,20.35]$ \\
\hline 3.8 Epirubicin (pharmacy areas) & 1 & & $\begin{array}{l}\text { Mean Difference (Random, } \\
95 \% \mathrm{Cl} \text { ) }\end{array}$ & $\begin{array}{l}-110.0[-112.93 \\
-107.07]\end{array}$ \\
\hline $\begin{array}{l}3.9 \text { Cyclophosphamide (pa- } \\
\text { tient-care areas) }\end{array}$ & 5 & & $\begin{array}{l}\text { Mean Difference (Random, } \\
95 \% \mathrm{Cl} \text { ) }\end{array}$ & $-13.34[-36.01,9.32]$ \\
\hline $\begin{array}{l}3.10 \text { Ifosfamide (patient-care ar- } \\
\text { eas) }\end{array}$ & 5 & & $\begin{array}{l}\text { Mean Difference (Random, } \\
95 \% \mathrm{Cl} \text { ) }\end{array}$ & $3.59[-3.45,10.63]$ \\
\hline $\begin{array}{l}3.11 \text { Methotrexate (patient-care } \\
\text { areas) }\end{array}$ & 5 & & $\begin{array}{l}\text { Mean Difference (Random, } \\
95 \% \mathrm{Cl} \text { ) }\end{array}$ & $0.10[-0.57,0.78]$ \\
\hline $\begin{array}{l}3.125 \text {-fluorouracil (patient-care } \\
\text { areas) }\end{array}$ & 1 & & $\begin{array}{l}\text { Mean Difference (Random, } \\
95 \% \mathrm{Cl} \text { ) }\end{array}$ & $-43.9[-141.51,53.71]$ \\
\hline $\begin{array}{l}3.13 \text { Cytarabine (patient-care ar- } \\
\text { eas) }\end{array}$ & 1 & & $\begin{array}{l}\text { Mean Difference (Random, } \\
95 \% \mathrm{Cl} \text { ) }\end{array}$ & $-0.20[-0.79,0.39]$ \\
\hline $\begin{array}{l}3.14 \text { Gemcitabine (patient-care } \\
\text { areas) }\end{array}$ & 1 & & $\begin{array}{l}\text { Mean Difference (Random, } \\
95 \% \mathrm{Cl} \text { ) }\end{array}$ & $0.47[-1.77,2.71]$ \\
\hline $\begin{array}{l}3.15 \text { Irinotecan (patient-care ar- } \\
\text { eas) }\end{array}$ & 1 & & $\begin{array}{l}\text { Mean Difference (Random, } \\
95 \% \mathrm{Cl} \text { ) }\end{array}$ & $-0.05[-0.15,0.05]$ \\
\hline
\end{tabular}

Analysis 1.1. Comparison 1 Closed-system transfer device plus safe handling versus safe handling alone, Outcome 1 Urine tests for exposure.

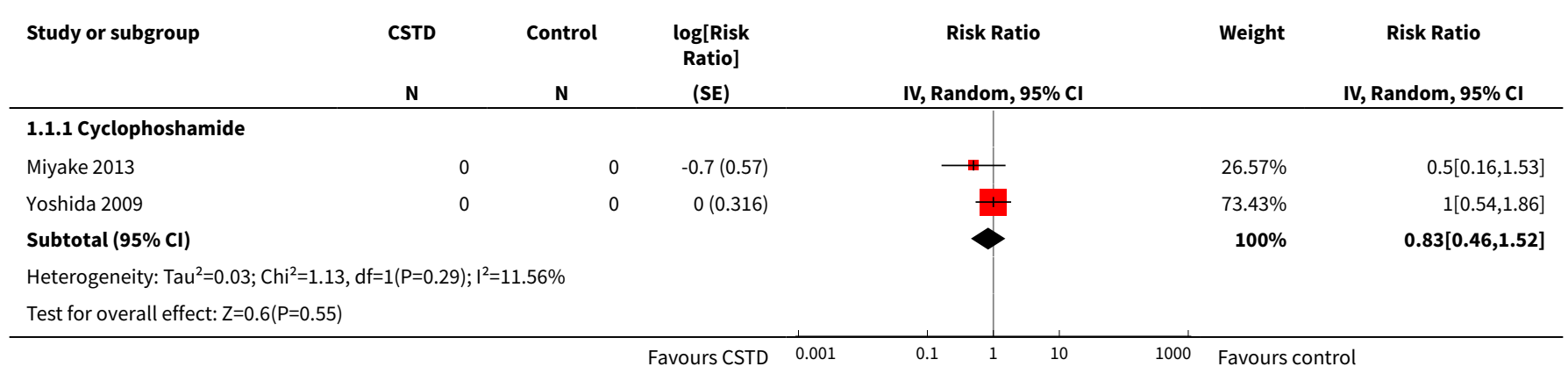

Closed-system drug-transfer devices plus safe handling of hazardous drugs versus safe handling alone for reducing exposure to 


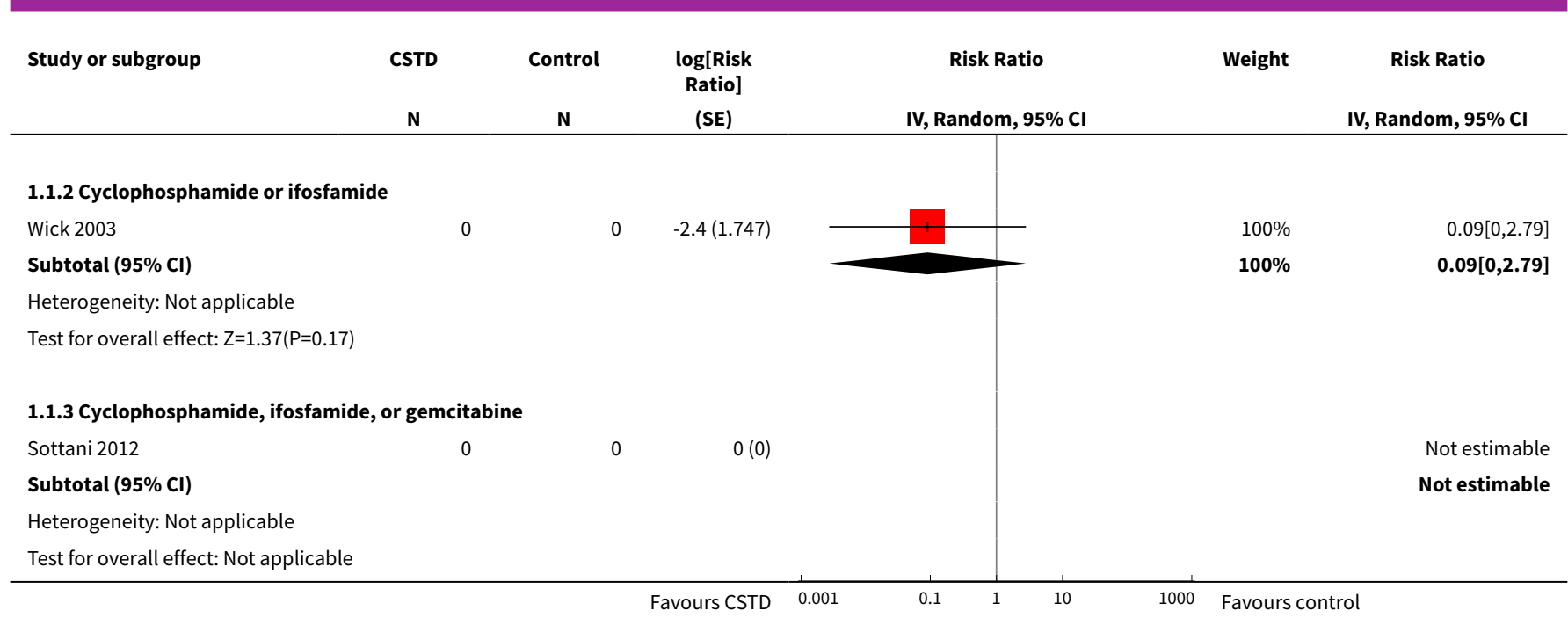

Analysis 1.2. Comparison 1 Closed-system transfer device plus safe handling versus safe handling alone, Outcome 2 Proportion of surfaces contaminated.

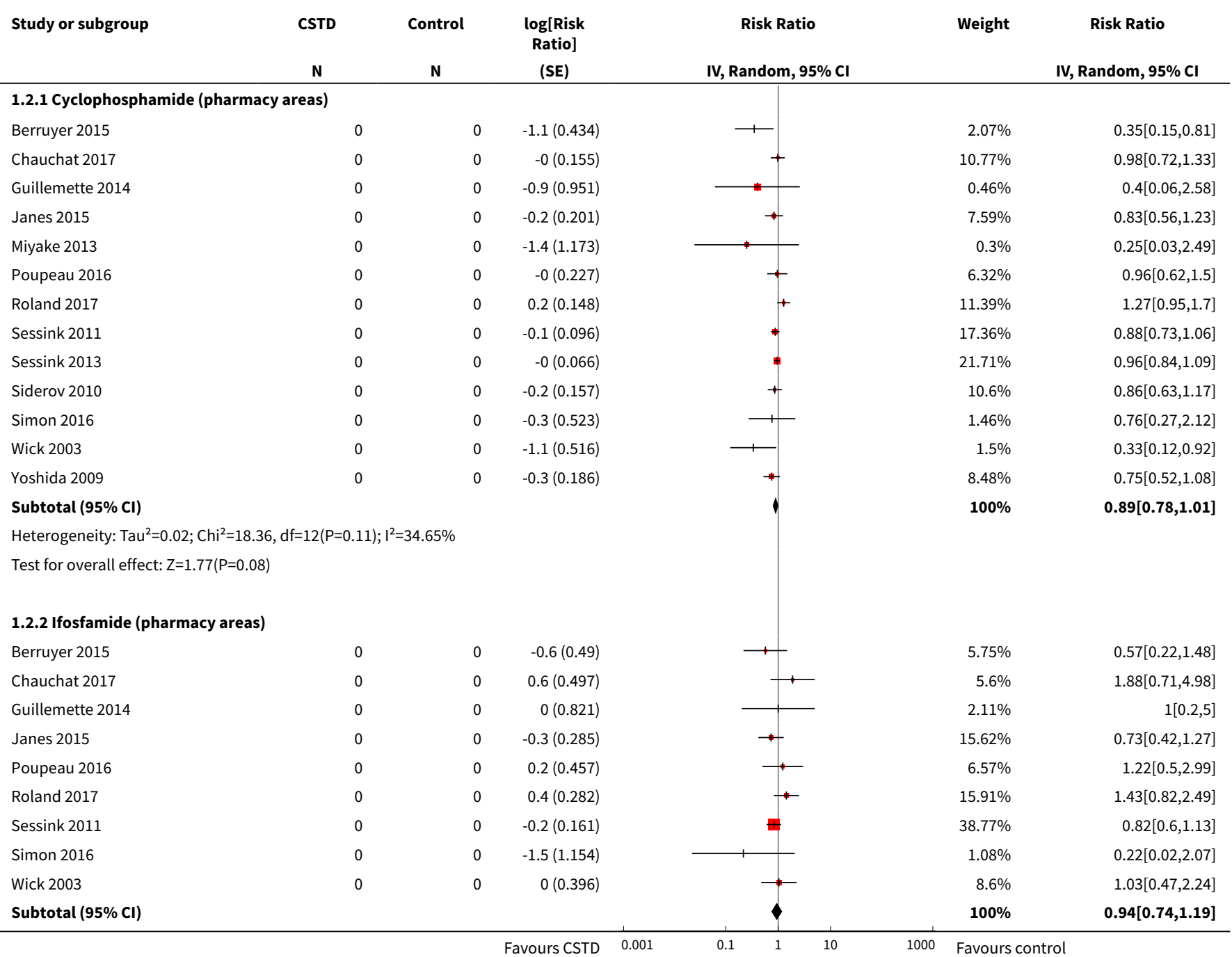

Closed-system drug-transfer devices plus safe handling of hazardous drugs versus safe handling alone for reducing exposure to 


\begin{tabular}{lcccc} 
Study or subgroup & CSTD & Control & $\begin{array}{c}\text { log[Risk } \\
\text { Ratio] }\end{array}$ & Risk Ratio \\
& N & N & (SE) & IV, Random, $95 \% \mathrm{Cl}$ \\
\hline
\end{tabular}

Heterogeneity: $\mathrm{Tau}^{2}=0.01 ; \mathrm{Chi}^{2}=8.71, \mathrm{df}=8(\mathrm{P}=0.37) ; \mathrm{I}^{2}=8.2 \%$

Test for overall effect: $Z=0.55(P=0.58)$

1.2.3 Methotrexate (pharmacy areas)

Berruyer 2015

Chauchat 2017

$-1.5(1.765)$

Guillemette 2014

$-0.4(0.353)$

$1.1(2.835)$

Janes 2015

$-0.2(0.362)$

Poupeau 2016

$-0.3(0.591)$

Roland 2017

$0.1(0.352)$

Subtotal $(95 \% \mathrm{Cl})$

Heterogeneity: $\mathrm{Tau}^{2}=0 ; \mathrm{Chi}^{2}=2.07, \mathrm{df}=5(\mathrm{P}=0.84) ; \mathrm{I}^{2}=0 \%$

Test for overall effect: $Z=0.92(P=0.36)$

\subsubsection{5-fluorouracil (pharmacy areas)}

Chauchat 2017

Sessink 2011

Simon 2016

Vyas 2016

$$
\begin{aligned}
& -0.3(0.334) \\
& -0.5(0.272) \\
& -0.4(1.313) \\
& -3.1(1.958)
\end{aligned}
$$

Subtotal $(95 \% \mathrm{Cl})$

Heterogeneity: $\mathrm{Tau}^{2}=0 ; \mathrm{Chi}^{2}=2.02, \mathrm{df}=3(\mathrm{P}=0.57) ; \mathrm{I}^{2}=0 \%$

Test for overall effect: $Z=2.25(P=0.02)$

\subsubsection{Cytarabine (pharmacy areas)}

Chauchat 2017

$\begin{array}{lll}0 & 0 & 0.4(0.731) \\ 0 & 0 & -1(0.762)\end{array}$

Simon 2016

$-1(0.762)$

\section{Subtotal $(95 \% \mathrm{CI})$}

Heterogeneity: $\mathrm{Tau}^{2}=0.42 ; \mathrm{Chi}^{2}=1.76, \mathrm{df}=1(\mathrm{P}=0.18) ; \mathrm{I}^{2}=43.19 \%$

Test for overall effect: $\mathrm{Z}=0.46(\mathrm{P}=0.65)$

\subsubsection{Gemcitabine (pharmacy areas)}

Chauchat 2017

$\begin{array}{llr}0 & 0 & -0(0.272) \\ 0 & 0 & -0.1(0.498)\end{array}$

4

$38.44 \%$

$0.71[0.37,1.38]$ $0.61[0.36,1.03]$

$0.65[0.05,8.58]$

$0.04[0,2.03]$

$1.12 \%$

$0.63[0.42,0.94]$

Simon 2016

$-0.1(0.498)$

Subtotal $(95 \% \mathrm{Cl})$

Heterogeneity: $\mathrm{Tau}^{2}=0 ; \mathrm{Chi}^{2}=0.04, \mathrm{df}=1(\mathrm{P}=0.83) ; \mathrm{I}^{2}=0 \%$

Test for overall effect: $Z=0.16(P=0.88)$

1.2.7 Irinotecan (pharmacy areas)

Chauchat 2017

0

$0 \quad-1(0.663)$

$100 \%$

$0.23[0.01,7.31]$

$0.66[0.33,1.32]$

$3[0.01,777.04]$

$0.82[0.4,1.67]$

$0.75[0.24,2.39]$

$1.16[0.58,2.31]$

$0.84[0.58,1.22]$

\section{Subtotal $(95 \% \mathrm{Cl})$}

0

$100 \%$

$0.36[0.1,1.33]$

$0.36[0.1,1.33]$

Heterogeneity: Not applicable

Test for overall effect: $Z=1.53(P=0.13)$

1.2.8 Docetaxel (pharmacy areas)

Chauchat 2017

0

$0 \quad 0(0)$

$0 \quad 0(0)$

$77.02 \%$

$22.98 \%$

$100 \%$

$0.58,1.69$

$0.88[0.33,2.33]$

$0.96[0.6,1.54]$

\section{Subtotal $(95 \% \mathrm{Cl})$}

Heterogeneity: Not applicable

Test for overall effect: Not applicable

1.2.9 Paclitaxel (pharmacy areas)

Chauchat 2017

0

$0 \quad-0.6(1.407)$

$100 \%$

$0.57[0.04,9.06]$ 


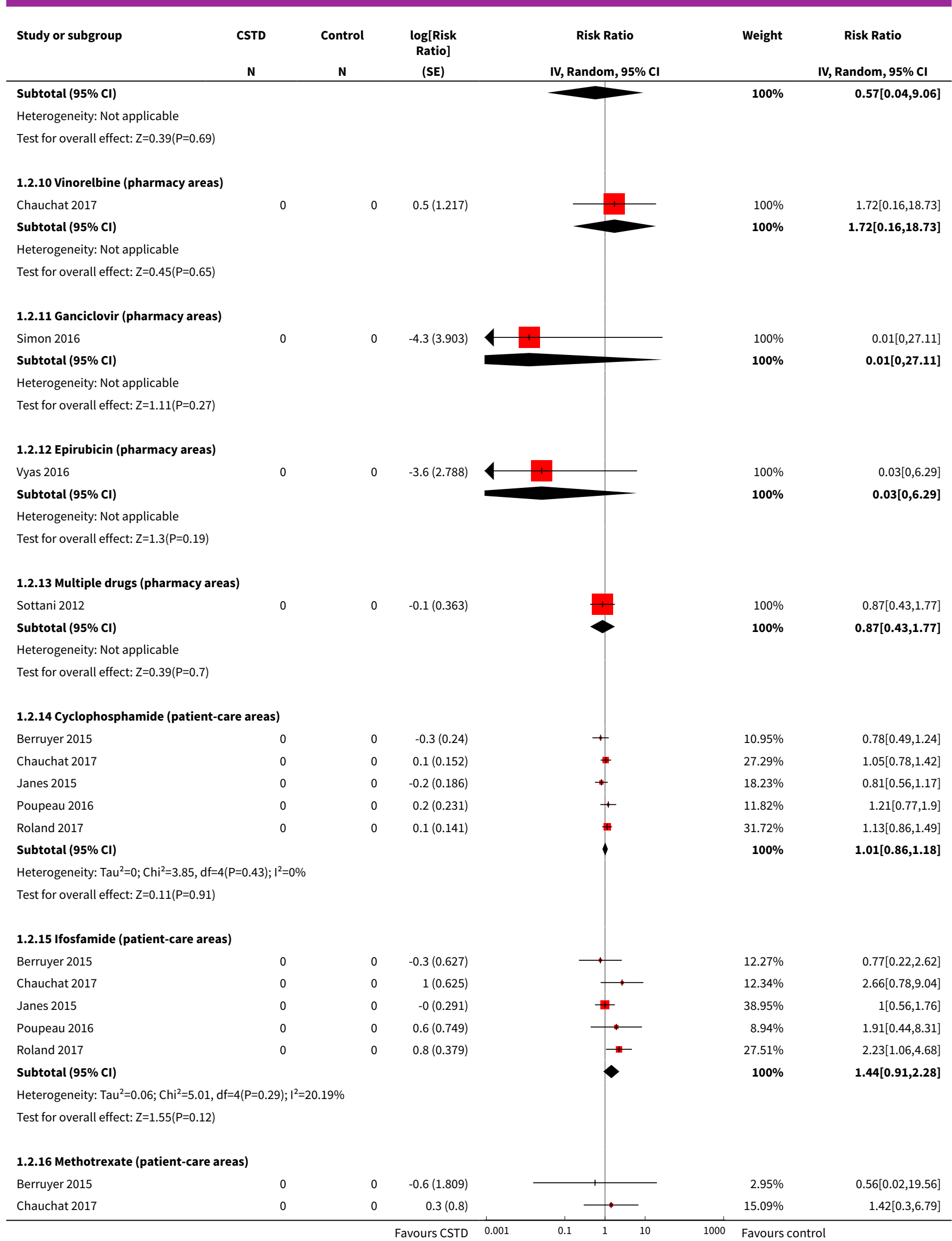

Closed-system drug-transfer devices plus safe handling of hazardous drugs versus safe handling alone for reducing exposure to 


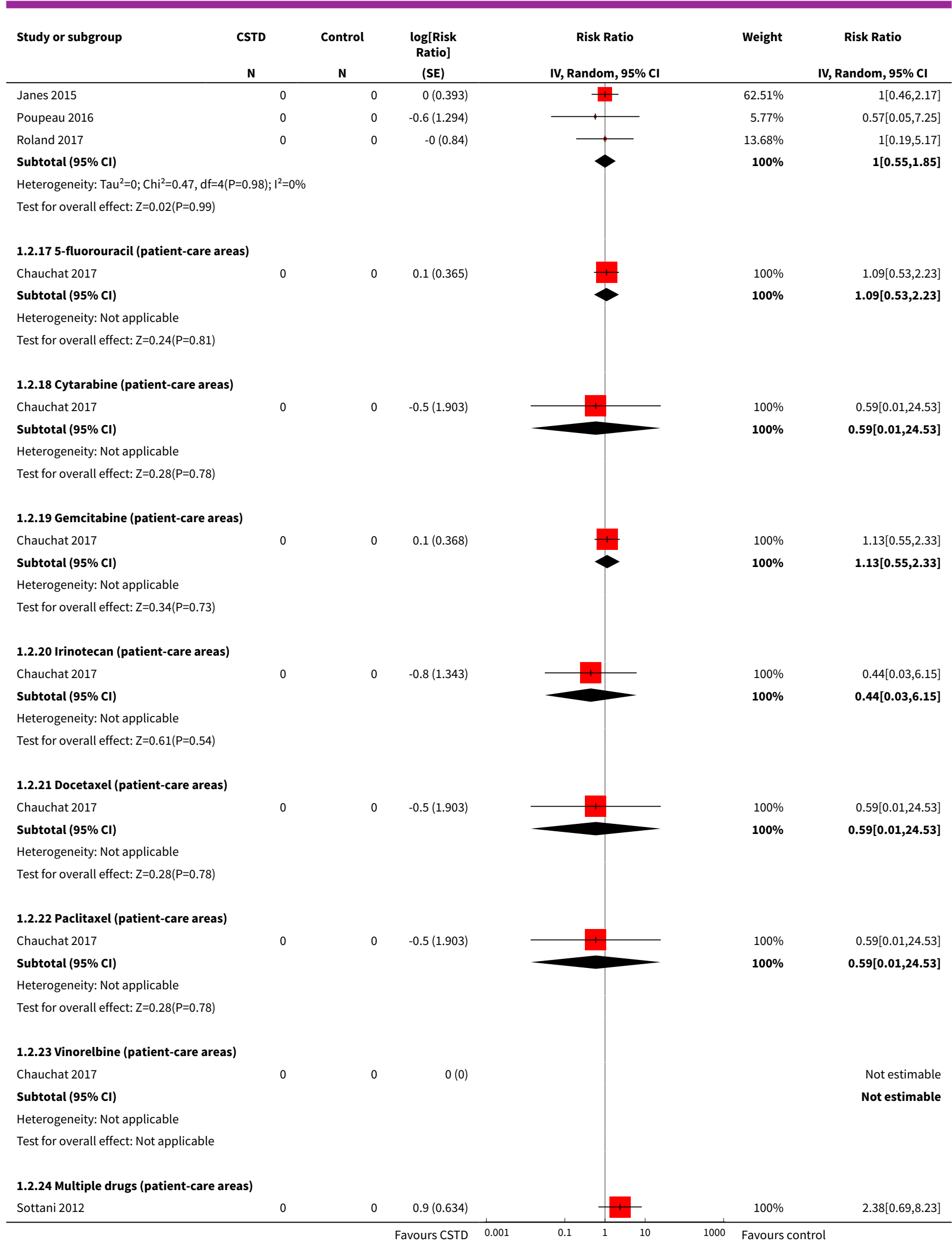

Closed-system drug-transfer devices plus safe handling of hazardous drugs versus safe handling alone for reducing exposure to 


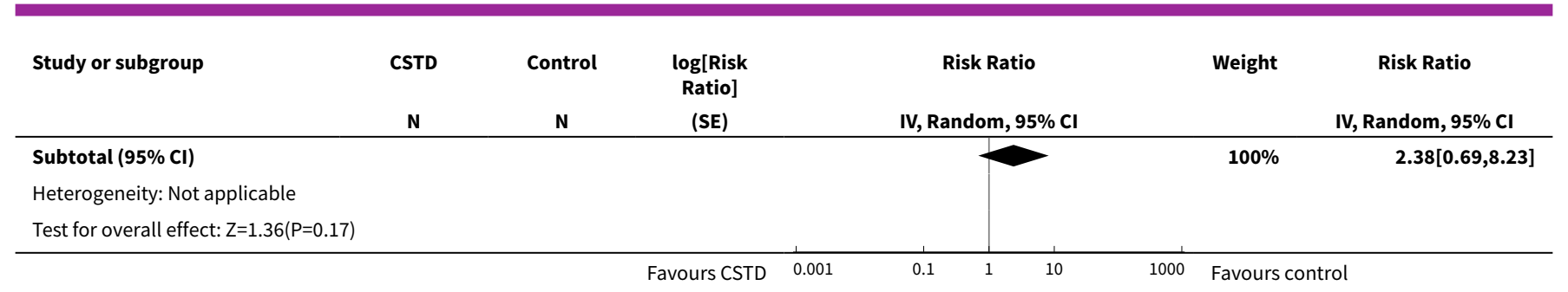

Analysis 1.3. Comparison 1 Closed-system transfer device plus safe handling versus safe handling alone, Outcome 3 Quantity of surface contamination $\left(\mathrm{pg} / \mathrm{cm}^{2}\right)$.

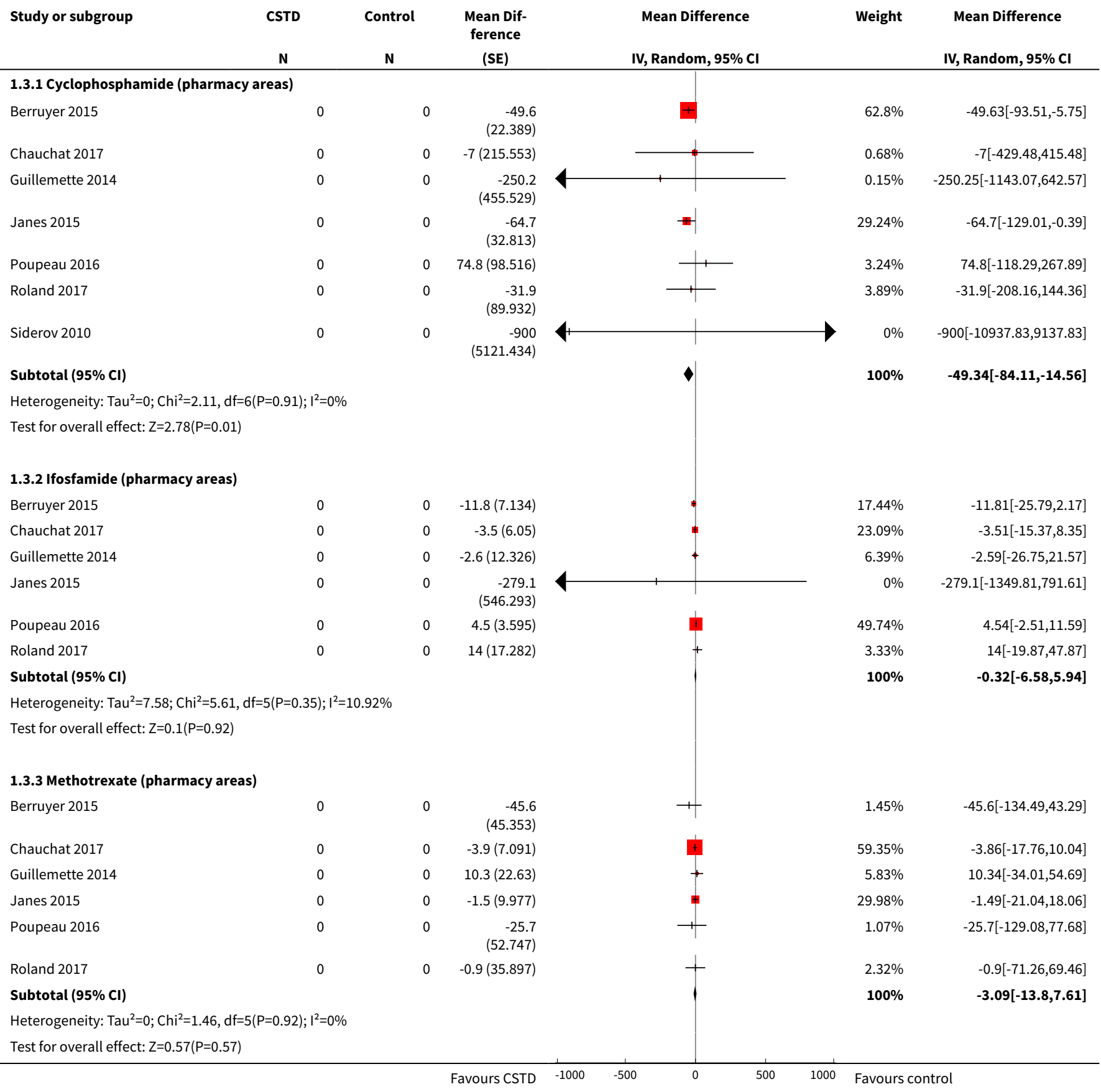

Closed-system drug-transfer devices plus safe handling of hazardous drugs versus safe handling alone for reducing exposure to 


\begin{tabular}{|c|c|c|c|c|c|c|}
\hline \multirow[t]{2}{*}{ Study or subgroup } & CSTD & Control & $\begin{array}{l}\text { Mean Dif- } \\
\text { ference }\end{array}$ & Mean Difference & Weight & Mean Difference \\
\hline & $\mathbf{N}$ & $\mathbf{N}$ & (SE) & IV, Random, 95\% CI & & IV, Random, 95\% CI \\
\hline
\end{tabular}

\subsubsection{5-fluorouracil (pharmacy areas)}

Chauchat 2017

Forges 2011

Vyas 2016

0

Subtotal $(95 \% \mathrm{CI})$

Heterogeneity: $\mathrm{Tau}^{2}=0 ; \mathrm{Chi}^{2}=0.27, \mathrm{df}=2(\mathrm{P}=0.87) ; \mathrm{I}^{2}=0 \%$

Test for overall effect: $Z=0.66(P=0.51)$

\subsubsection{Cytarabine (pharmacy areas)}

Chauchat 2017

0

$-0.6(7.691)$

Subtotal $(95 \% \mathrm{Cl})$

Heterogeneity: Not applicable

Test for overall effect: $Z=0.08(P=0.94)$

1.3.6 Gemcitabine (pharmacy areas)

Chauchat 2017

0

Subtotal $(95 \% \mathrm{Cl})$

Heterogeneity: Not applicable

Test for overall effect: $\mathrm{Z}=0.92(\mathrm{P}=0.36)$

1.3.7 Irinotecan (pharmacy areas)

Chauchat 2017

Subtotal $(95 \% \mathrm{Cl})$

Heterogeneity: Not applicable

Test for overall effect: $Z=0.93(P=0.35)$

\subsubsection{Epirubicin (pharmacy areas)}

Vyas 2016

0

Subtotal $(95 \% \mathrm{Cl})$

$-110(1.493)$

Heterogeneity: Not applicable

Test for overall effect: $Z=73.68(P<0.0001)$

1.3.9 Cyclophosphamide (patient-care areas)

Berruyer 2015

Chauchat 2017

Janes 2015

Poupeau 2016

Roland 2017

Subtotal $(95 \% \mathrm{CI})$

Heterogeneity: $\mathrm{Tau}^{2}=0 ; \mathrm{Chi}^{2}=3.71, \mathrm{df}=4(\mathrm{P}=0.45) ; \mathrm{I}^{2}=0 \%$

Test for overall effect: $Z=1.15(P=0.25)$

1.3.10 Ifosfamide (patient-care areas)

-32.7
$(35.575)$

(11.688)

$-151.8$

(160.456)

$-103.8$

(93.405)

$-1308.3$

(1097.619)

$-338.6$

$(425.566)$

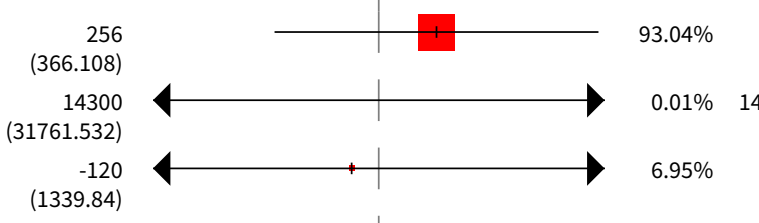

$256[-461.56,973.56]$

$14300[-47951.46,76551.46]$

$-120[-2746.04,2506.04]$

$100 \%$

$231.62[-460.52,923.76]$

$100 \%$

$-32.7[-102.43,37.03]$

$100 \%$

$-32.7[-102.43,37.03]$

$100 \%$

$-18.27[-56.89,20.35]$

$100 \%$

$-18.27[-56.89,20.35]$

$100 \%$

$-110[-112.93,-107.07]$

$100 \%$

$-110[-112.93,-107.07]$

$-10.8[-33.71,12.11]$

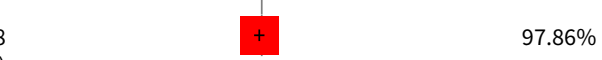

$0.52 \%$

$1.53 \%$

$0.01 \%$

$0.07 \%$

$100 \%$
$-151.8[-466.29,162.69]$

$-103.8[-286.87,79.27]$

$-1308.3[-3459.59,842.99]$

$-338.6[-1172.69,495.49]$

$-13.34[-36.01,9.32]$ 


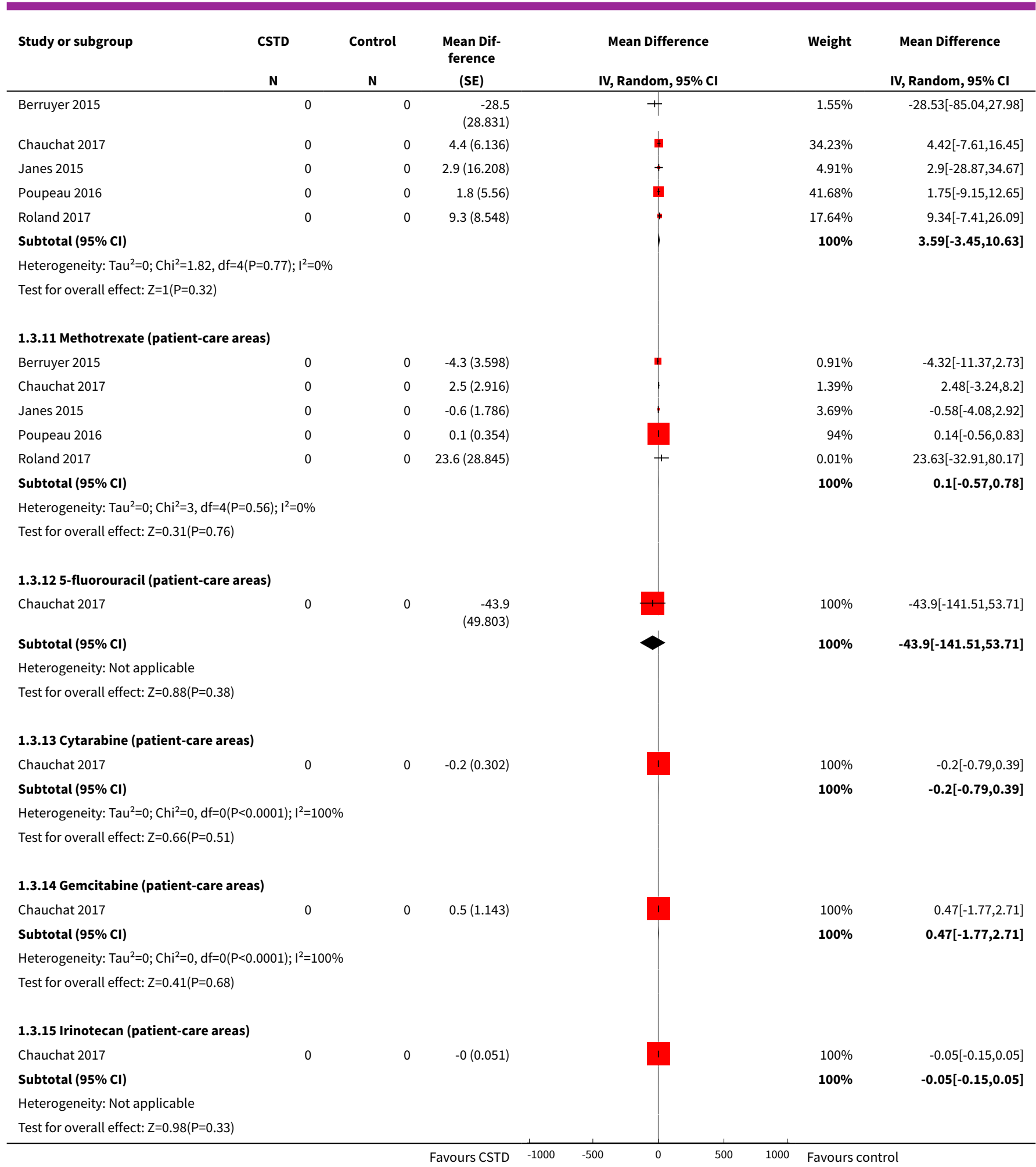


Comparison 2. Subgroup analysis (based on study design and device)

\begin{tabular}{|c|c|c|c|c|}
\hline Outcome or subgroup title & No. of studies & $\begin{array}{l}\text { No. of partici- } \\
\text { pants }\end{array}$ & Statistical method & Effect size \\
\hline 1 Urine tests for exposure (PhaSeal only) & 3 & & $\begin{array}{l}\text { Risk Ratio (Random, 95\% } \\
\mathrm{Cl} \text { ) }\end{array}$ & Subtotals only \\
\hline 1.1 Cyclophoshamide & 2 & & $\begin{array}{l}\text { Risk Ratio (Random, 95\% } \\
\mathrm{Cl} \text { ) }\end{array}$ & $0.83[0.46,1.52]$ \\
\hline 1.2 Cyclophosphamide or ifosfamide & 1 & & $\begin{array}{l}\text { Risk Ratio (Random, 95\% } \\
\text { Cl) }\end{array}$ & $0.09[0.00,2.79]$ \\
\hline $\begin{array}{l}2 \text { Proportion of surfaces contaminated } \\
\text { with cyclophosphamide in pharmacy ar- } \\
\text { eas: stratified by study design }\end{array}$ & 13 & & $\begin{array}{l}\text { Risk Ratio (Random, 95\% } \\
\mathrm{Cl} \text { ) }\end{array}$ & $0.89[0.78,1.01]$ \\
\hline 2.1 Uncontrolled before-after studies & 7 & & $\begin{array}{l}\text { Risk Ratio (Random, 95\% } \\
\mathrm{Cl} \text { ) }\end{array}$ & $0.87[0.76,0.99]$ \\
\hline 2.2 Cross-sectional studies & 6 & & $\begin{array}{l}\text { Risk Ratio (Random, 95\% } \\
\mathrm{Cl} \text { ) }\end{array}$ & $0.92[0.72,1.19]$ \\
\hline $\begin{array}{l}3 \text { Proportion of surfaces contaminated } \\
\text { with ifosfamide in pharmacy areas: strati- } \\
\text { fied by study design }\end{array}$ & 9 & & $\begin{array}{l}\text { Risk Ratio (Random, 95\% } \\
\mathrm{Cl} \text { ) }\end{array}$ & $0.94[0.74,1.19]$ \\
\hline 3.1 Uncontrolled before-after studies & 3 & & $\begin{array}{l}\text { Risk Ratio (Random, 95\% } \\
\mathrm{Cl} \text { ) }\end{array}$ & $0.85[0.64,1.14]$ \\
\hline 3.2 Cross-sectional studies & 6 & & $\begin{array}{l}\text { Risk Ratio (Random, 95\% } \\
\mathrm{Cl} \text { ) }\end{array}$ & $1.00[0.65,1.53]$ \\
\hline $\begin{array}{l}4 \text { Proportion of surfaces contaminated } \\
\text { with methotrexate in pharmacy areas: } \\
\text { stratified by study design }\end{array}$ & 6 & & $\begin{array}{l}\text { Risk Ratio (Random, 95\% } \\
\mathrm{Cl} \text { ) }\end{array}$ & $0.84[0.58,1.22]$ \\
\hline 4.1 Uncontrolled before-after studies & 1 & & $\begin{array}{l}\text { Risk Ratio (Random, 95\% } \\
\text { Cl) }\end{array}$ & $3.00[0.01,777.04]$ \\
\hline 4.2 Cross-sectional studies & 5 & & $\begin{array}{l}\text { Risk Ratio (Random, 95\% } \\
\mathrm{Cl} \text { ) }\end{array}$ & $0.83[0.57,1.22]$ \\
\hline $\begin{array}{l}5 \text { Proportion of surfaces contaminated } \\
\text { with } 5 \text {-fluorouracil in pharmacy areas: } \\
\text { stratified by study design }\end{array}$ & 4 & & $\begin{array}{l}\text { Risk Ratio (Random, 95\% } \\
\mathrm{Cl} \text { ) }\end{array}$ & $0.63[0.42,0.94]$ \\
\hline 5.1 Uncontrolled before-after studies & 2 & & $\begin{array}{l}\text { Risk Ratio (Random, 95\% } \\
\mathrm{Cl} \text { ) }\end{array}$ & $0.33[0.04,2.88]$ \\
\hline 5.2 Cross-sectional studies & 2 & & $\begin{array}{l}\text { Risk Ratio (Random, 95\% } \\
\text { Cl) }\end{array}$ & $0.71[0.38,1.34]$ \\
\hline $\begin{array}{l}6 \text { Proportion of surfaces contaminated } \\
\text { (PhaSeal only) }\end{array}$ & 8 & & $\begin{array}{l}\text { Risk Ratio (Random, 95\% } \\
\mathrm{Cl} \text { ) }\end{array}$ & Subtotals only \\
\hline 6.1 Cyclophosphamide (pharmacy areas) & 8 & & $\begin{array}{l}\text { Risk Ratio (Random, 95\% } \\
\mathrm{Cl} \text { ) }\end{array}$ & $0.88[0.78,0.99]$ \\
\hline
\end{tabular}

Closed-system drug-transfer devices plus safe handling of hazardous drugs versus safe handling alone for reducing exposure to 


\begin{tabular}{|c|c|c|c|c|}
\hline Outcome or subgroup title & No. of studies & $\begin{array}{l}\text { No. of partici- } \\
\text { pants }\end{array}$ & Statistical method & Effect size \\
\hline 6.2 Ifosfamide (pharmacy areas) & 4 & & $\begin{array}{l}\text { Risk Ratio (Random, 95\% } \\
\mathrm{Cl} \text { ) }\end{array}$ & $0.84[0.63,1.11]$ \\
\hline 6.3 Methotrexate (pharmacy areas) & 1 & & $\begin{array}{l}\text { Risk Ratio (Random, 95\% } \\
\mathrm{Cl} \text { ) }\end{array}$ & $3.00[0.01,777.04]$ \\
\hline 6.4 5-fluorouracil (pharmacy areas) & 2 & & $\begin{array}{l}\text { Risk Ratio (Random, 95\% } \\
\text { Cl) }\end{array}$ & $0.61[0.36,1.02]$ \\
\hline 6.5 Cytarabine (pharmacy areas) & 1 & & $\begin{array}{l}\text { Risk Ratio (Random, 95\% } \\
\mathrm{CI} \text { ) }\end{array}$ & $0.35[0.08,1.58]$ \\
\hline 6.6 Gemcitabine (pharmacy areas) & 1 & & $\begin{array}{l}\text { Risk Ratio (Random, 95\% } \\
\mathrm{Cl} \text { ) }\end{array}$ & $0.88[0.33,2.33]$ \\
\hline 6.7 Ganciclovir (pharmacy areas) & 1 & & $\begin{array}{l}\text { Risk Ratio (Random, 95\% } \\
\mathrm{Cl} \text { ) }\end{array}$ & $0.01[0.00,27.11]$ \\
\hline $\begin{array}{l}7 \text { Proportion of surfaces contaminated } \\
\text { (Tevadaptor only) }\end{array}$ & 1 & & $\begin{array}{l}\text { Risk Ratio (Random, 95\% } \\
\mathrm{Cl} \text { ) }\end{array}$ & Subtotals only \\
\hline 7.1 5-fluorouracil (pharmacy areas) & 1 & & $\begin{array}{l}\text { Risk Ratio (Random, 95\% } \\
\mathrm{Cl} \text { ) }\end{array}$ & $0.04[0.00,2.03]$ \\
\hline 7.2 Epirubicin (pharmacy areas) & 1 & & $\begin{array}{l}\text { Risk Ratio (Random, 95\% } \\
\mathrm{Cl} \text { ) }\end{array}$ & $0.03[0.00,6.29]$ \\
\hline $\begin{array}{l}8 \text { Quantity of surface contamination with } \\
\text { cyclophosphamide in pharmacy areas } \\
\left(\mathrm{pg} / \mathrm{cm}^{2}\right): \text { stratified by study design }\end{array}$ & 7 & & $\begin{array}{l}\text { Mean Difference (Ran- } \\
\text { dom, } 95 \% \mathrm{Cl} \text { ) }\end{array}$ & $\begin{array}{l}-49.34[-84.11 \\
-14.56]\end{array}$ \\
\hline 8.1 Uncontrolled before-after studies & 2 & & $\begin{array}{l}\text { Mean Difference (Ran- } \\
\text { dom, } 95 \% \mathrm{Cl} \text { ) }\end{array}$ & $\begin{array}{l}-255.35[-1144.66 \\
633.96]\end{array}$ \\
\hline 8.2 Cross-sectional studies & 5 & & $\begin{array}{l}\text { Mean Difference (Ran- } \\
\text { dom, } 95 \% \mathrm{Cl} \text { ) }\end{array}$ & $\begin{array}{l}-49.02[-83.82 \\
-14.22]\end{array}$ \\
\hline $\begin{array}{l}9 \text { Quantity of surface contamination with } \\
\text { ifosfamide in pharmacy areas }\left(\mathrm{pg} / \mathrm{cm}^{2}\right) \text { : } \\
\text { stratified by study design }\end{array}$ & 6 & & $\begin{array}{l}\text { Mean Difference (Ran- } \\
\text { dom, } 95 \% \mathrm{Cl} \text { ) }\end{array}$ & $-0.32[-6.58,5.94]$ \\
\hline 9.1 Uncontrolled before-after studies & 1 & & $\begin{array}{l}\text { Mean Difference (Ran- } \\
\text { dom, } 95 \% \mathrm{Cl} \text { ) }\end{array}$ & $\begin{array}{l}-2.59[-26.75 \\
21.57]\end{array}$ \\
\hline 9.2 Cross-sectional studies & 5 & & $\begin{array}{l}\text { Mean Difference (Ran- } \\
\text { dom, } 95 \% \mathrm{Cl} \text { ) }\end{array}$ & $-0.78[-8.58,7.03]$ \\
\hline $\begin{array}{l}10 \text { Quantity of surface contamination } \\
\text { with methotrexate in pharmacy areas } \\
\left(\mathrm{pg} / \mathrm{cm}^{2}\right) \text { : stratified by study design }\end{array}$ & 6 & & $\begin{array}{l}\text { Mean Difference (Ran- } \\
\text { dom, } 95 \% \mathrm{Cl} \text { ) }\end{array}$ & $-3.09[-13.80,7.61]$ \\
\hline 10.1 Uncontrolled before-after studies & 1 & & $\begin{array}{l}\text { Mean Difference (Ran- } \\
\text { dom, } 95 \% \mathrm{Cl} \text { ) }\end{array}$ & $\begin{array}{l}10.34[-34.01 \\
54.69]\end{array}$ \\
\hline
\end{tabular}




\begin{tabular}{|c|c|c|c|c|}
\hline Outcome or subgroup title & No. of studies & $\begin{array}{l}\text { No. of partici- } \\
\text { pants }\end{array}$ & Statistical method & Effect size \\
\hline 10.2 Cross-sectional studies & 5 & & $\begin{array}{l}\text { Mean Difference (Ran- } \\
\text { dom, } 95 \% \mathrm{Cl} \text { ) }\end{array}$ & $-3.92[-14.96,7.11]$ \\
\hline $\begin{array}{l}11 \text { Quantity of surface contamination } \\
\text { with } 5 \text {-fluorouracil in pharmacy areas } \\
\left(\mathrm{pg} / \mathrm{cm}^{2}\right) \text { : stratified by devices }\end{array}$ & 2 & & $\begin{array}{l}\text { Mean Difference (Ran- } \\
\text { dom, } 95 \% \mathrm{Cl} \text { ) }\end{array}$ & Subtotals only \\
\hline $\begin{array}{l}11.15 \text {-fluorouracil (pharmacy areas; } \\
\text { SpikeSwan) }\end{array}$ & 1 & & $\begin{array}{l}\text { Mean Difference (Ran- } \\
\text { dom, } 95 \% \mathrm{Cl} \text { ) }\end{array}$ & $\begin{array}{l}14300.0 \\
{[-47951.46} \\
76551.46]\end{array}$ \\
\hline $\begin{array}{l}11.25 \text {-fluorouracil (pharmacy areas; } \\
\text { Tevadaptor) }\end{array}$ & 1 & & $\begin{array}{l}\text { Mean Difference (Ran- } \\
\text { dom, } 95 \% \mathrm{Cl} \text { ) }\end{array}$ & $\begin{array}{l}-118.00[-2746.04 \\
2506.04]\end{array}$ \\
\hline $\begin{array}{l}12 \text { Quantity of surface contamination } \\
\text { with } 5 \text {-fluorouracil in pharmacy areas } \\
\left(\mathrm{pg} / \mathrm{cm}^{2}\right) \text { : stratified by study design }\end{array}$ & 3 & & $\begin{array}{l}\text { Mean Difference (Ran- } \\
\text { dom, } 95 \% \mathrm{Cl} \text { ) }\end{array}$ & $\begin{array}{l}231.62[-460.52 \\
923.76]\end{array}$ \\
\hline 12.1 Uncontrolled before-after studies & 1 & & $\begin{array}{l}\text { Mean Difference (Ran- } \\
\text { dom, } 95 \% \mathrm{Cl} \text { ) }\end{array}$ & $\begin{array}{l}-118.00[-2746.04 \\
2506.04]\end{array}$ \\
\hline 12.2 Cross-sectional studies & 2 & & $\begin{array}{l}\text { Mean Difference (Ran- } \\
\text { dom, } 95 \% \mathrm{Cl} \text { ) }\end{array}$ & $\begin{array}{l}257.87[-459.65 \\
975.38]\end{array}$ \\
\hline $\begin{array}{l}13 \text { Quantity of surface contamination } \\
\left(\mathrm{pg} / \mathrm{cm}^{2}\right) \text { : stratified by devices }\end{array}$ & 4 & & $\begin{array}{l}\text { Mean Difference (Ran- } \\
\text { dom, } 95 \% \mathrm{Cl} \text { ) }\end{array}$ & Subtotals only \\
\hline $\begin{array}{l}13.1 \text { Cyclophosphamide (pharmacy areas; } \\
\text { PhaSeal) }\end{array}$ & 2 & & $\begin{array}{l}\text { Mean Difference (Ran- } \\
\text { dom, } 95 \% \mathrm{Cl} \text { ) }\end{array}$ & $\begin{array}{l}-255.35[-1144.66 \\
633.96]\end{array}$ \\
\hline $\begin{array}{l}13.2 \text { Ifosfamide (pharmacy areas; } \\
\text { PhaSeal) }\end{array}$ & 1 & & $\begin{array}{l}\text { Mean Difference (Ran- } \\
\text { dom, } 95 \% \mathrm{Cl} \text { ) }\end{array}$ & $\begin{array}{l}-2.59[-26.75 \\
21.57]\end{array}$ \\
\hline $\begin{array}{l}\text { 13.3 Methotrexate (pharmacy areas; } \\
\text { PhaSeal) }\end{array}$ & 1 & & $\begin{array}{l}\text { Mean Difference (Ran- } \\
\text { dom, } 95 \% \mathrm{Cl} \text { ) }\end{array}$ & $\begin{array}{l}10.34[-34.01 \\
54.69]\end{array}$ \\
\hline $\begin{array}{l}\text { 13.4 5-fluorouracil (pharmacy areas; } \\
\text { SpikeSwan) }\end{array}$ & 1 & & $\begin{array}{l}\text { Mean Difference (Ran- } \\
\text { dom, } 95 \% \mathrm{Cl} \text { ) }\end{array}$ & $\begin{array}{l}14300.0 \\
{[-47951.46} \\
76551.46]\end{array}$ \\
\hline $\begin{array}{l}13.5 \text { 5-fluorouracil (pharmacy areas; } \\
\text { Tevadaptor) }\end{array}$ & 1 & & $\begin{array}{l}\text { Mean Difference (Ran- } \\
\text { dom, } 95 \% \mathrm{Cl} \text { ) }\end{array}$ & $\begin{array}{l}-118.00[-2746.04 \\
2506.04]\end{array}$ \\
\hline
\end{tabular}

Analysis 2.1. Comparison 2 Subgroup analysis (based on study design and device), Outcome 1 Urine tests for exposure (PhaSeal only).

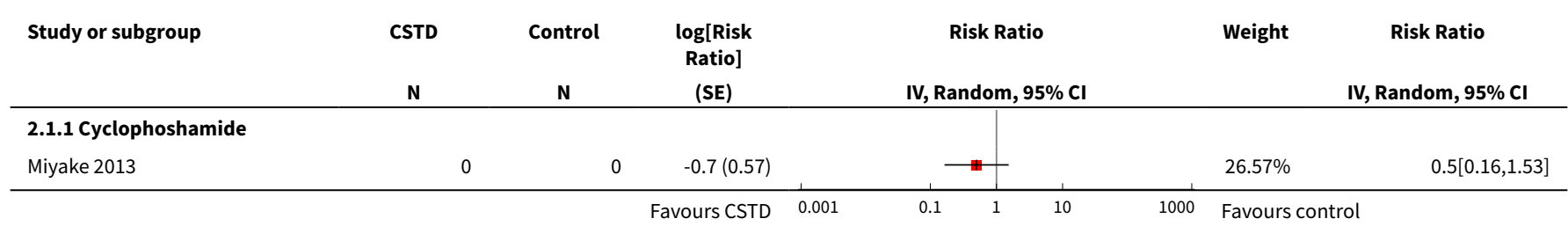




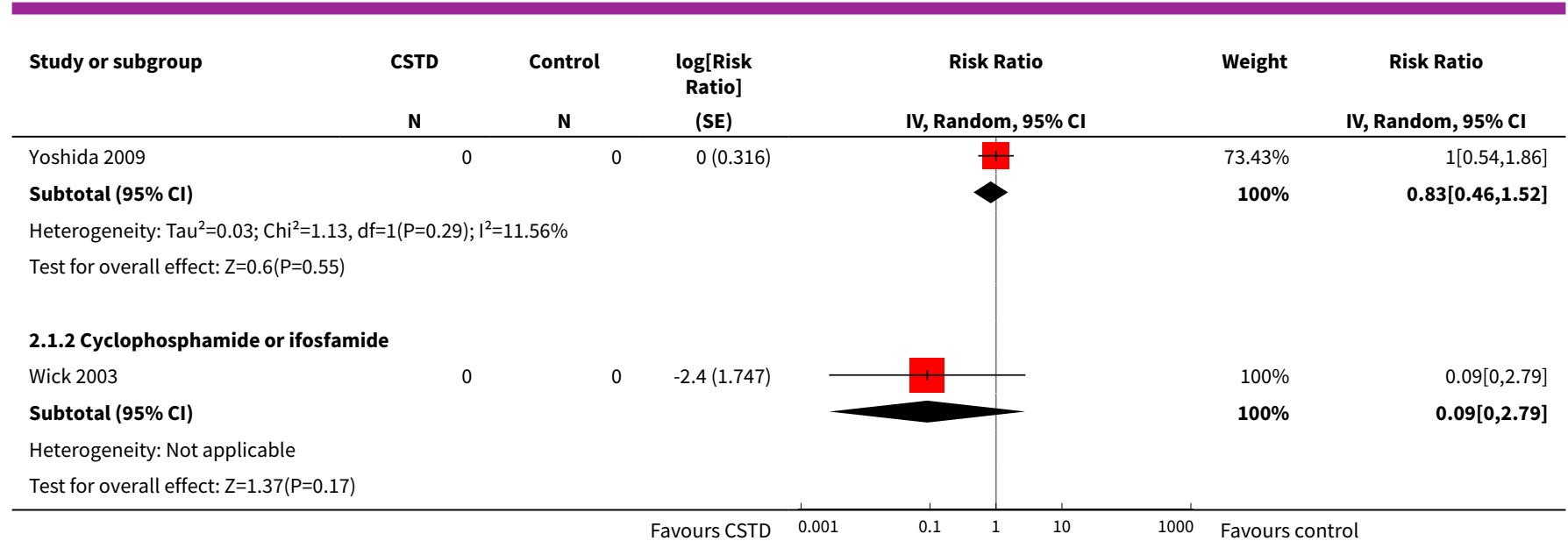

\section{Analysis 2.2. Comparison 2 Subgroup analysis (based on study design and device), Outcome 2 Proportion of surfaces contaminated with cyclophosphamide in pharmacy areas: stratified by study design.}

\begin{tabular}{|c|c|c|c|}
\hline \multirow[t]{2}{*}{ Study or subgroup } & CSTD & Control & \multirow{2}{*}{$\begin{array}{c}\log [\text { Risk } \\
\text { Ratio] } \\
\text { (SE) }\end{array}$} \\
\hline & $\mathbf{N}$ & $\mathbf{N}$ & \\
\hline \multicolumn{4}{|c|}{ 2.2.1 Uncontrolled before-after studies } \\
\hline Guillemette 2014 & 0 & 0 & $-0.9(0.951)$ \\
\hline Miyake 2013 & 0 & 0 & $-1.4(1.173)$ \\
\hline Sessink 2011 & 0 & 0 & $-0.1(0.096)$ \\
\hline Sessink 2013 & 0 & 0 & $-0(0.066)$ \\
\hline Siderov 2010 & 0 & 0 & $-0.2(0.157)$ \\
\hline Wick 2003 & 0 & 0 & $-1.1(0.516)$ \\
\hline Yoshida 2009 & 0 & 0 & $-0.3(0.186)$ \\
\hline
\end{tabular}

\section{Subtotal $(95 \% \mathrm{CI})$}

Heterogeneity: $\mathrm{Tau}^{2}=0.01 ; \mathrm{Chi}^{2}=7.65, \mathrm{df}=6(\mathrm{P}=0.26) ; \mathrm{I}^{2}=21.59 \%$

Test for overall effect: $Z=2.06(P=0.04)$

\subsubsection{Cross-sectional studies}

$\begin{array}{lllr}\text { Berruyer 2015 } & 0 & 0 & -1.1(0.434) \\ \text { Chauchat 2017 } & 0 & 0 & -0(0.155) \\ \text { Janes 2015 } & 0 & 0 & -0.2(0.201) \\ \text { Poupeau 2016 } & 0 & 0 & -0(0.227) \\ \text { Roland 2017 } & 0 & 0 & 0.2(0.148) \\ \text { Simon 2016 } & 0 & 0 & -0.3(0.523)\end{array}$

Subtotal $(95 \% \mathrm{CI})$

Heterogeneity: $\mathrm{Tau}^{2}=0.04 ; \mathrm{Chi}^{2}=9.76, \mathrm{df}=5(\mathrm{P}=0.08) ; \mathrm{I}^{2}=48.75 \%$

Test for overall effect: $\mathrm{Z}=0.61(\mathrm{P}=0.54)$

\section{Total $(95 \% \mathrm{CI})$}

Heterogeneity: $\mathrm{Tau}^{2}=0.02 ; \mathrm{Chi}^{2}=18.36, \mathrm{df}=12(\mathrm{P}=0.11) ; \mathrm{I}^{2}=34.65 \%$

Test for overall effect: $Z=1.77(P=0.08)$

Test for subgroup differences: $\mathrm{Chi}^{2}=0.17, \mathrm{df}=1(\mathrm{P}=0.68), \mathrm{I}^{2}=0 \%$

Weight Risk Ratio atio]

IV, Random, $95 \% \mathrm{CI}$

IV, Random, 95\% CI

$0.4[0.06,2.58]$

$0.46 \%$

$0.25[0.03,2.49]$

$0.3 \%$

$0.88[0.73,1.06]$

$0.96[0.84,1.09]$

$0.86[0.63,1.17]$

$0.33[0.12,0.92]$

$0.75[0.52,1.08]$

$0.87[0.76,0.99]$ 
Analysis 2.3. Comparison 2 Subgroup analysis (based on study design and device), Outcome 3 Proportion of surfaces contaminated with ifosfamide in pharmacy areas: stratified by study design.

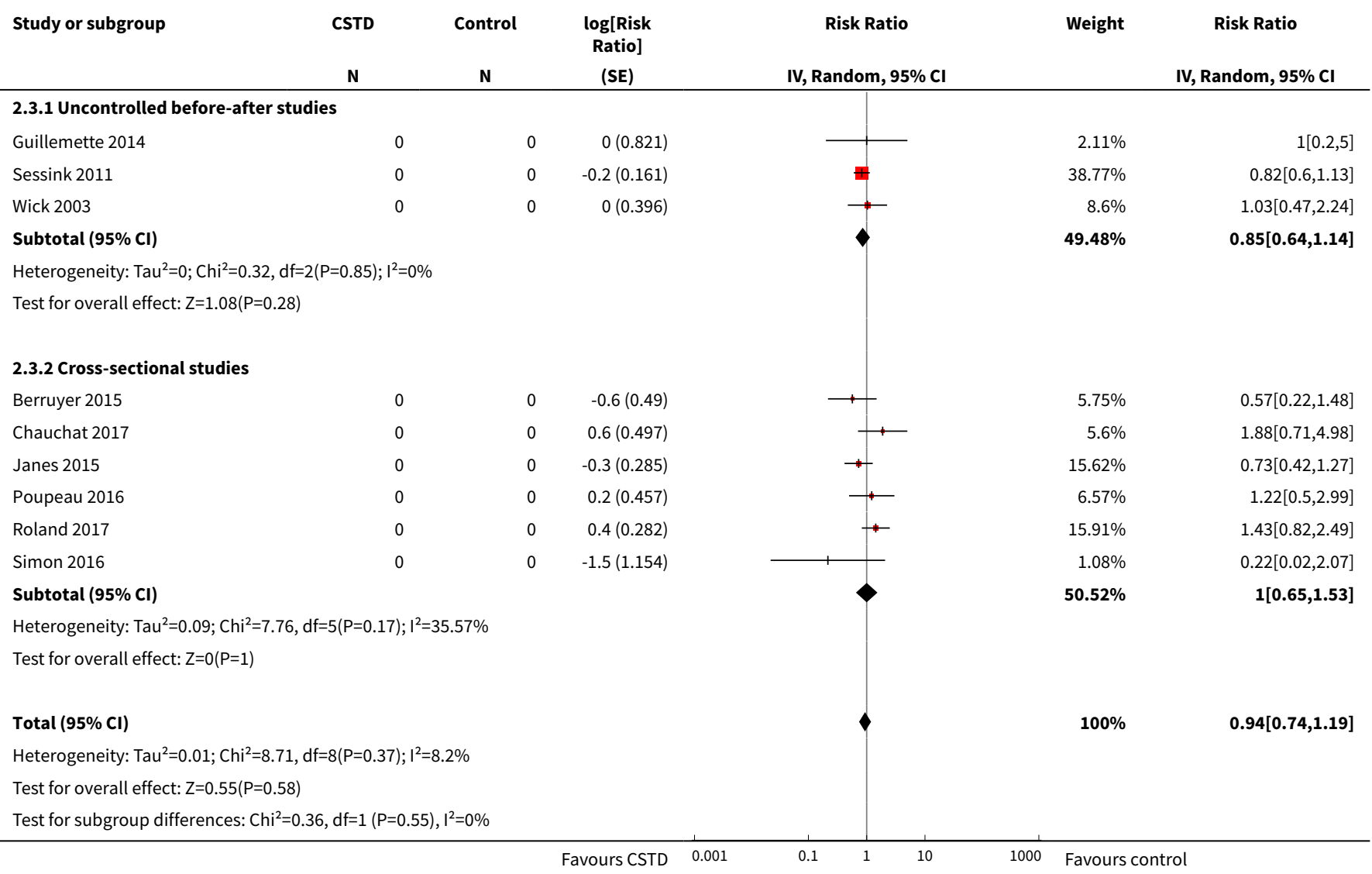

Analysis 2.4. Comparison 2 Subgroup analysis (based on study design and device), Outcome 4 Proportion of surfaces contaminated with methotrexate in pharmacy areas: stratified by study design.

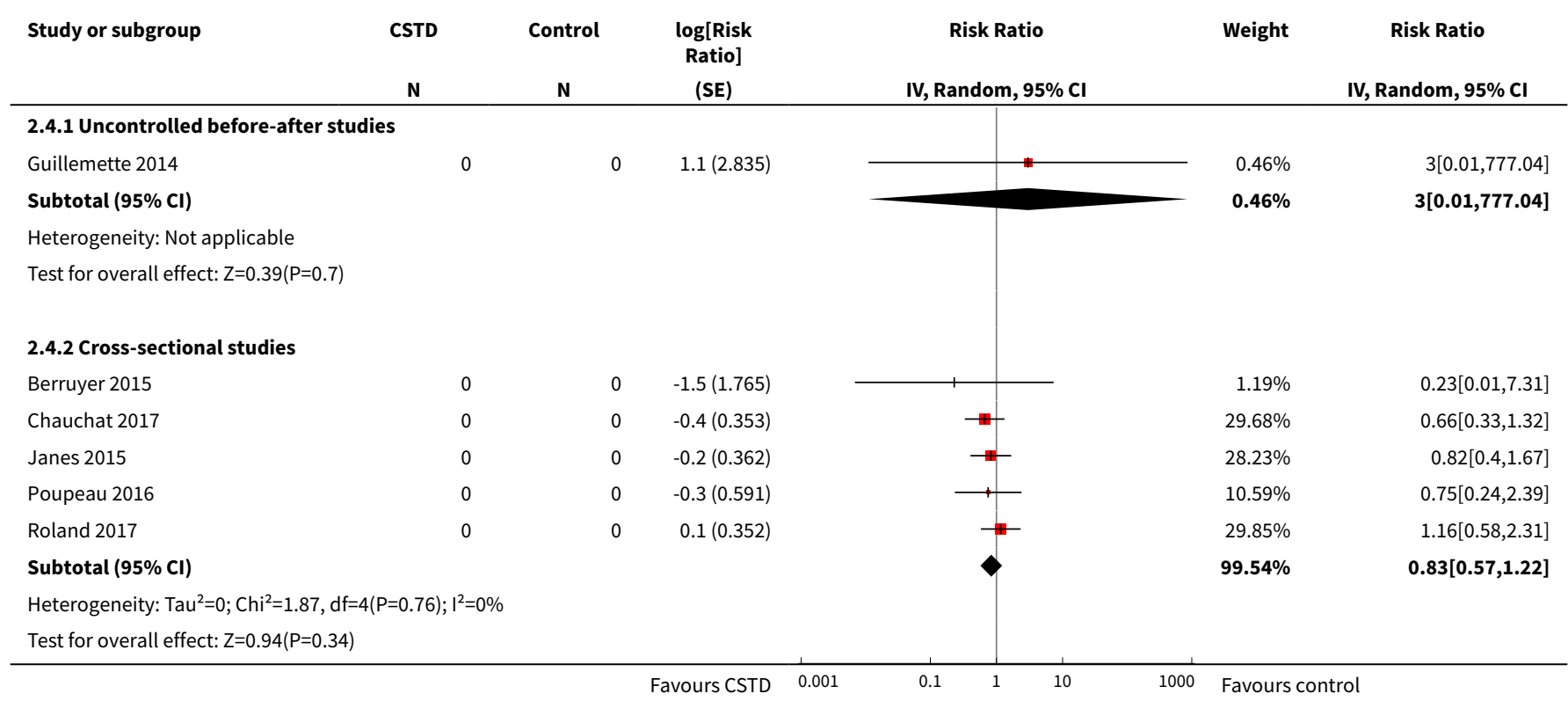




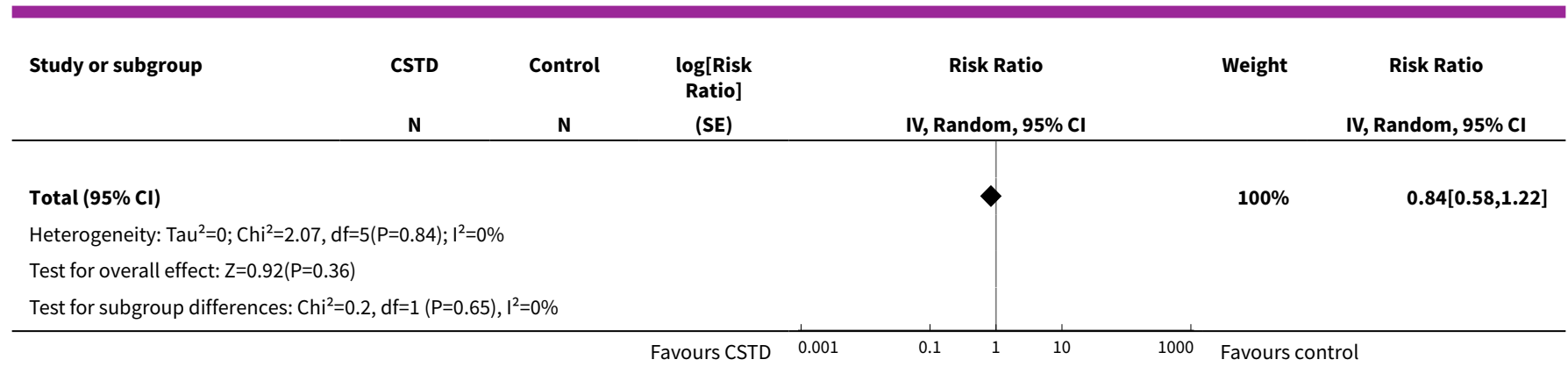

Analysis 2.5. Comparison 2 Subgroup analysis (based on study design and device), Outcome 5 Proportion of surfaces contaminated with 5-fluorouracil in pharmacy areas: stratified by study design.

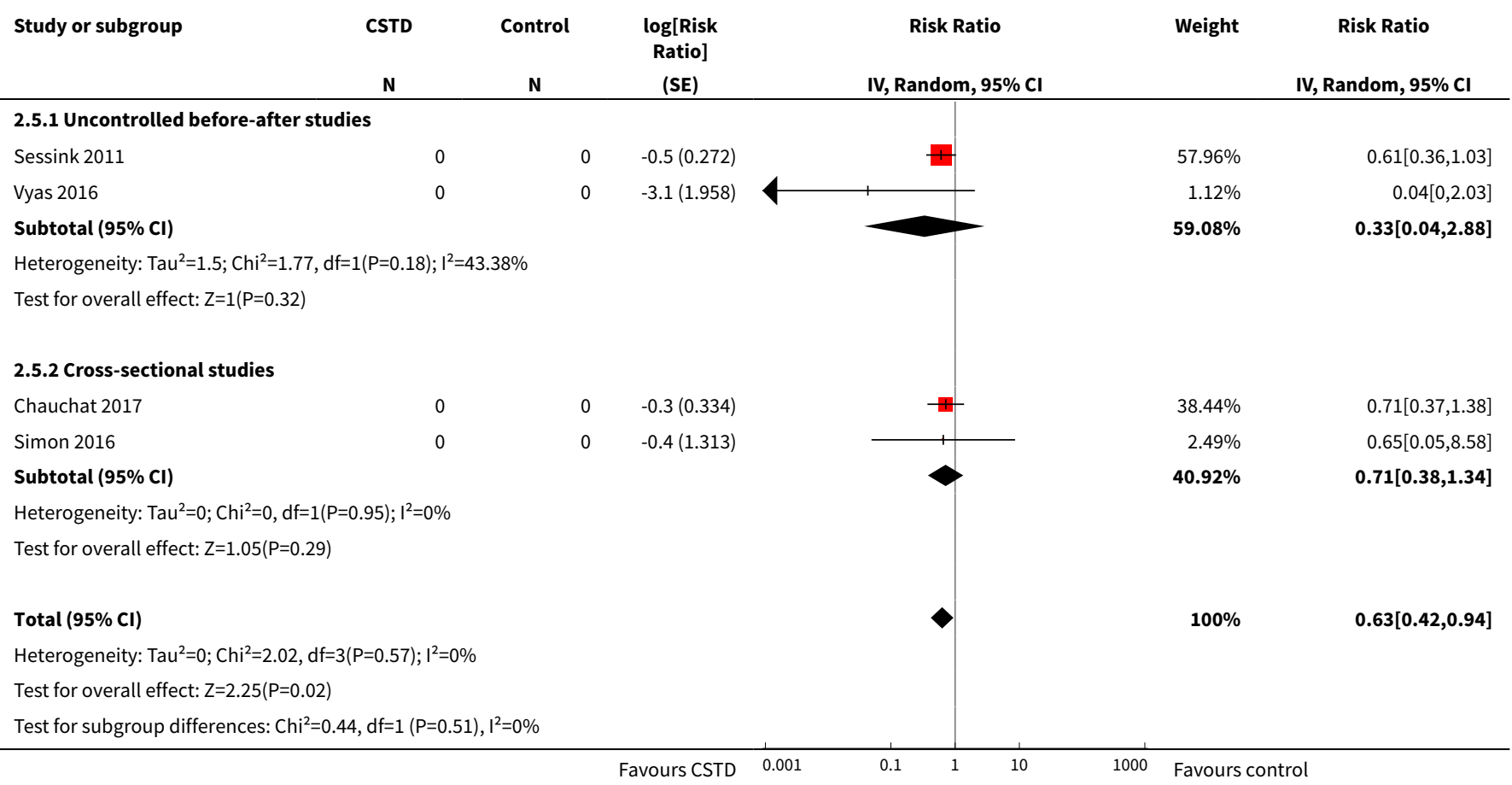

\section{Analysis 2.6. Comparison 2 Subgroup analysis (based on study design and device), Outcome 6 Proportion of surfaces contaminated (PhaSeal only).}

\begin{tabular}{|c|c|c|c|c|c|c|}
\hline \multirow[t]{2}{*}{ Study or subgroup } & \multirow{2}{*}{$\begin{array}{c}\text { CSTD } \\
\mathrm{N}\end{array}$} & \multirow{2}{*}{$\begin{array}{c}\text { Control } \\
\mathrm{N}\end{array}$} & \multirow{2}{*}{$\begin{array}{c}\text { log[Risk } \\
\text { Ratio] } \\
\text { (SE) }\end{array}$} & Risk Ratio & \multirow[t]{2}{*}{ Weight } & \multirow{2}{*}{$\begin{array}{c}\text { Risk Ratio } \\
\text { IV, Random, } 95 \% \mathrm{CI}\end{array}$} \\
\hline & & & & IV, Random, 95\% CI & & \\
\hline \multicolumn{7}{|c|}{ 2.6.1 Cyclophosphamide (pharmacy areas) } \\
\hline Guillemette 2014 & 0 & 0 & $-0.9(0.951)$ & +1 & $0.38 \%$ & $0.4[0.06,2.58]$ \\
\hline Miyake 2013 & 0 & 0 & $-1.4(1.173)$ & \begin{tabular}{l|l}
$*$ \\
$*$
\end{tabular} & $0.25 \%$ & $0.25[0.03,2.49]$ \\
\hline Sessink 2011 & 0 & 0 & $-0.1(0.096)$ & H & $28.23 \%$ & $0.88[0.73,1.06]$ \\
\hline Siderov 2010 & 0 & 0 & $-0.2(0.157)$ & + & $12.44 \%$ & $0.86[0.63,1.17]$ \\
\hline Simon 2016 & 0 & 0 & $-0.3(0.523)$ & 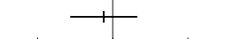 & $1.24 \%$ & $0.76[0.27,2.12]$ \\
\hline
\end{tabular}




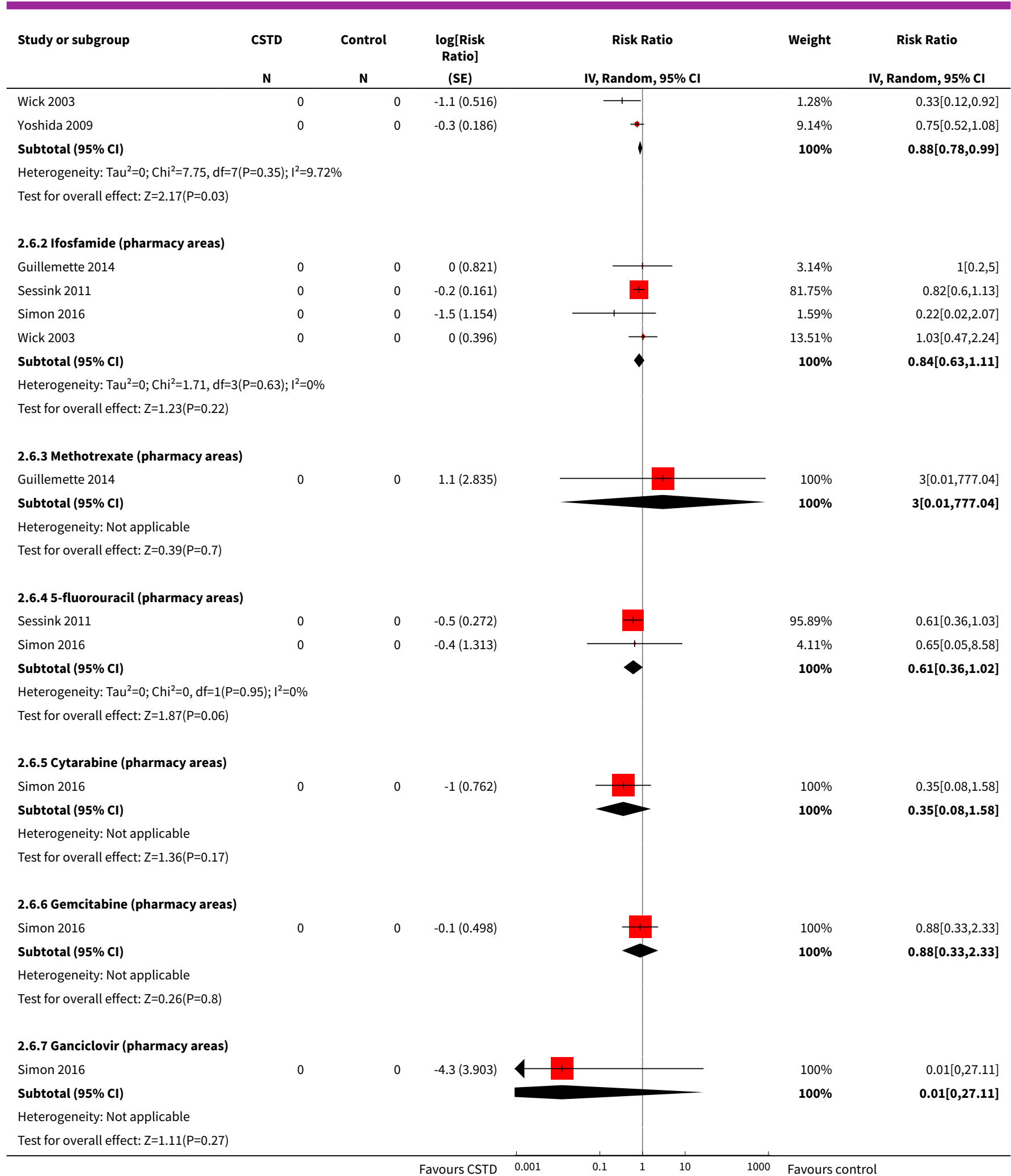

Closed-system drug-transfer devices plus safe handling of hazardous drugs versus safe handling alone for reducing exposure to 
Analysis 2.7. Comparison 2 Subgroup analysis (based on study design and device), Outcome 7 Proportion of surfaces contaminated (Tevadaptor only).

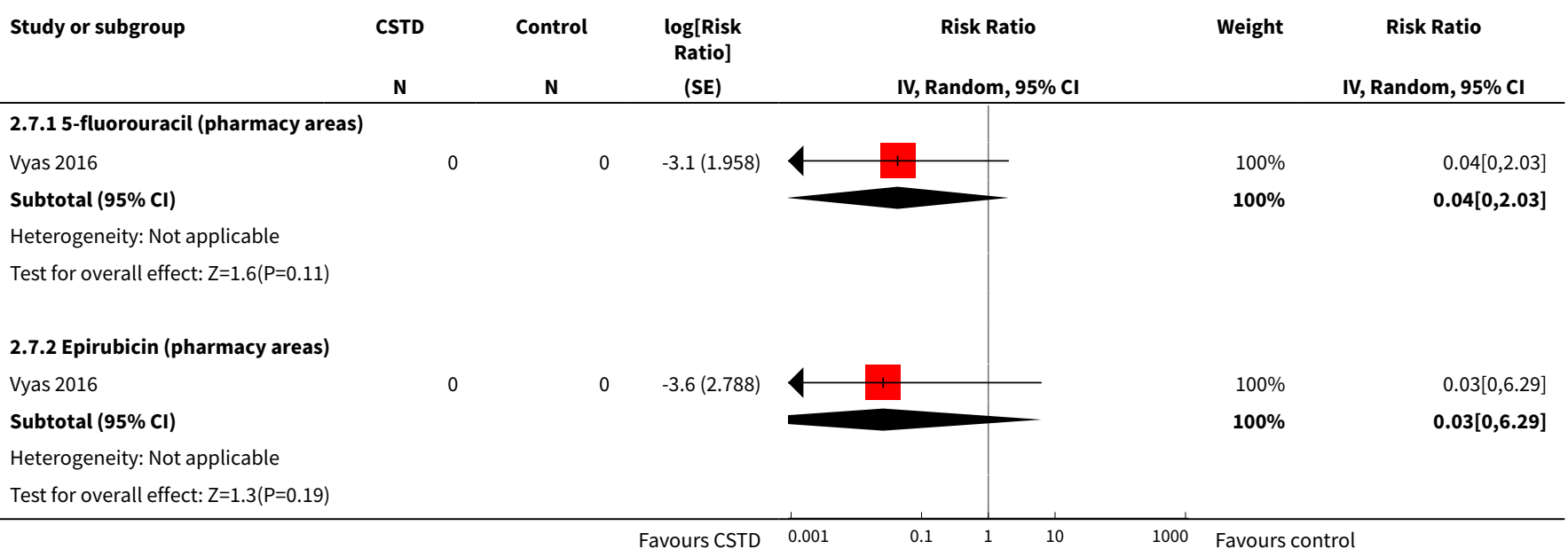

Analysis 2.8. Comparison 2 Subgroup analysis (based on study design and device), Outcome 8 Quantity of surface contamination with cyclophosphamide in pharmacy areas $\left(\mathrm{pg} / \mathrm{cm}^{2}\right)$ : stratified by study design.

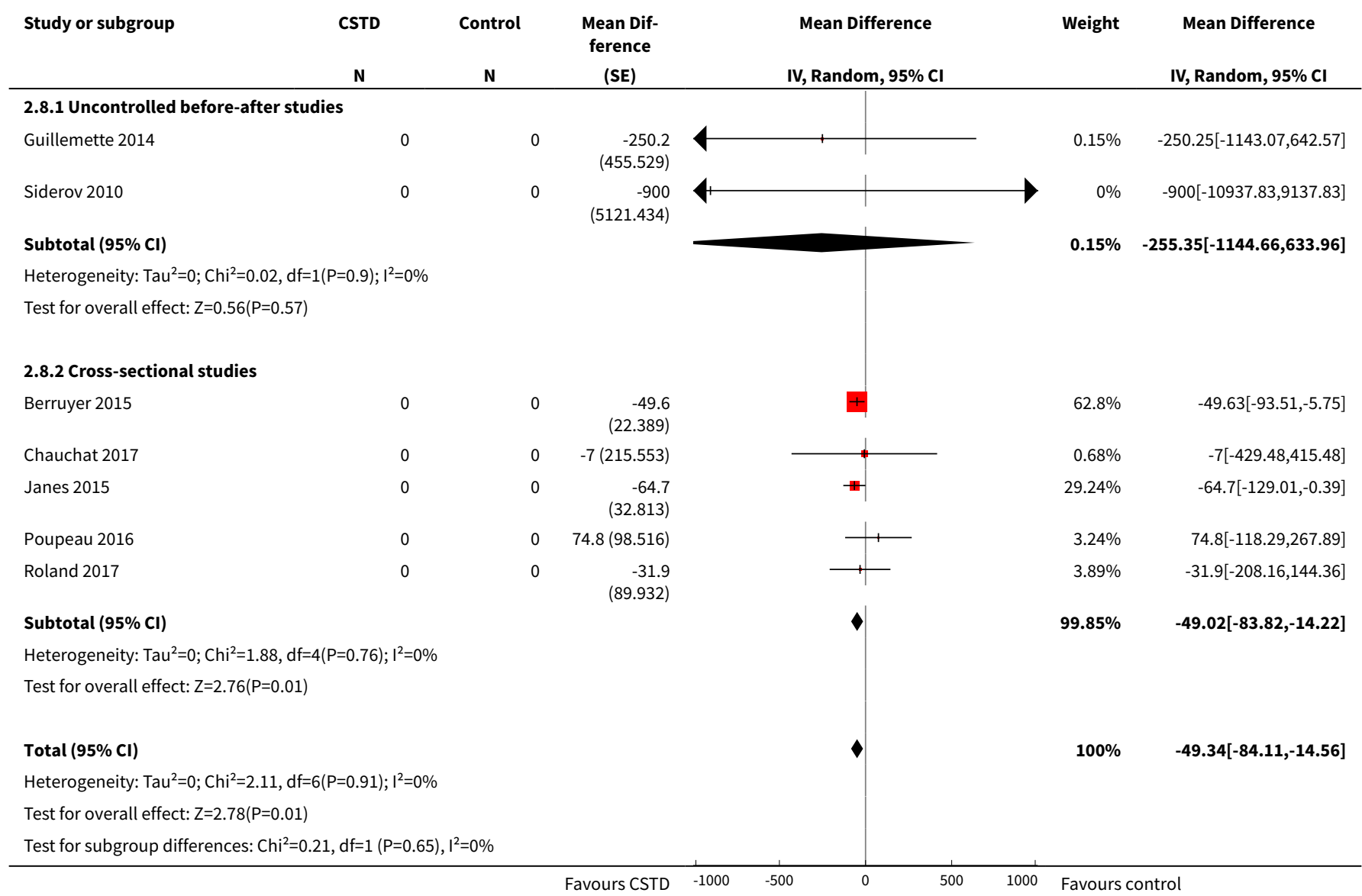


Analysis 2.9. Comparison 2 Subgroup analysis (based on study design and device), Outcome 9 Quantity of surface contamination with ifosfamide in pharmacy areas $\left(\mathrm{pg} / \mathrm{cm}^{2}\right)$ : stratified by study design.

\begin{tabular}{|c|c|c|c|c|c|c|}
\hline Study or subgroup & $\begin{array}{l}\text { CSTD } \\
\mathrm{N} \\
\end{array}$ & $\begin{array}{l}\text { Control } \\
\text { N }\end{array}$ & $\begin{array}{c}\text { Mean Dif- } \\
\text { ference } \\
\text { (SE) } \\
\end{array}$ & $\begin{array}{c}\text { Mean Difference } \\
\text { IV, Random, 95\% CI }\end{array}$ & Weight & $\begin{array}{c}\text { Mean Difference } \\
\text { IV, Random, } 95 \% \mathrm{CI}\end{array}$ \\
\hline \multicolumn{7}{|c|}{ 2.9.1 Uncontrolled before-after studies } \\
\hline Guillemette 2014 & 0 & 0 & $-2.6(12.326)$ & + & $6.39 \%$ & $-2.59[-26.75,21.57]$ \\
\hline Subtotal $(95 \% \mathrm{Cl})$ & & & & 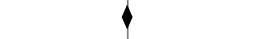 & $6.39 \%$ & $-2.59[-26.75,21.57]$ \\
\hline \multicolumn{7}{|c|}{ Heterogeneity: Not applicable } \\
\hline \multicolumn{7}{|c|}{ 2.9.2 Cross-sectional studies } \\
\hline Berruyer 2015 & 0 & 0 & $-11.8(7.134)$ & * & $17.44 \%$ & $-11.81[-25.79,2.17]$ \\
\hline Chauchat 2017 & 0 & 0 & $-3.5(6.05)$ & 申 & $23.09 \%$ & $-3.51[-15.37,8.35]$ \\
\hline Janes 2015 & 0 & 0 & $\begin{array}{r}-279.1 \\
(546.293)\end{array}$ & & $0 \%$ & $-279.1[-1349.81,791.61]$ \\
\hline Poupeau 2016 & 0 & 0 & $4.5(3.595)$ & 4 & $49.74 \%$ & $4.54[-2.51,11.59]$ \\
\hline Subtotal $(95 \% \mathrm{Cl})$ & & & & & $93.61 \%$ & $-0.78[-8.58,7.03]$ \\
\hline \multicolumn{7}{|c|}{ Heterogeneity: $\mathrm{Tau}^{2}=21.59 ; \mathrm{Chi}^{2}=5.55, \mathrm{df}=4(\mathrm{P}=0.24) ; \mathrm{I}^{2}=27.95 \%$} \\
\hline \multicolumn{7}{|c|}{ Test for overall effect: $Z=0.19(P=0.85)$} \\
\hline Total $(95 \% \mathrm{Cl})$ & & & & & $100 \%$ & $-0.32[-6.58,5.94]$ \\
\hline \multicolumn{7}{|c|}{ Heterogeneity: $\operatorname{Tau}^{2}=7.58 ; \mathrm{Chi}^{2}=5.61, \mathrm{df}=5(\mathrm{P}=0.35) ; \mathrm{I}^{2}=10.92 \%$} \\
\hline \multicolumn{7}{|c|}{ Test for overall effect: $Z=0.1(P=0.92)$} \\
\hline Test for subgroup dif & $\mathrm{df}=1(\mathrm{P}=0$ & ${ }^{2}=0 \%$ & & & & \\
\hline
\end{tabular}

\section{Analysis 2.10. Comparison 2 Subgroup analysis (based on study design and device), Outcome 10 Quantity of surface contamination with methotrexate in pharmacy areas $\left(\mathrm{pg} / \mathrm{cm}^{2}\right)$ : stratified by study design.}

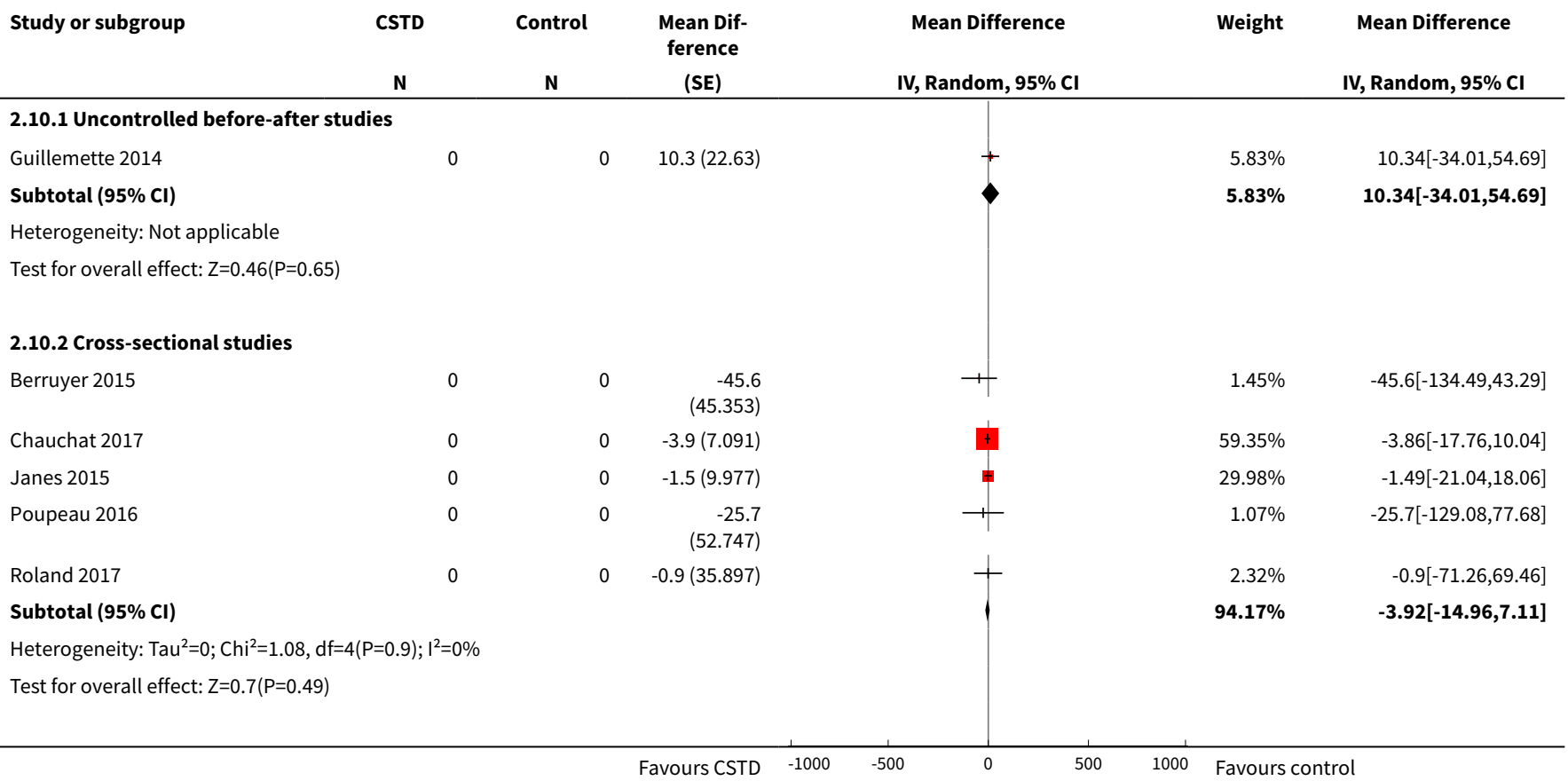

Closed-system drug-transfer devices plus safe handling of hazardous drugs versus safe handling alone for reducing exposure to 78 infusional hazardous drugs in healthcare staff (Review)

Copyright (c) 2019 The Cochrane Collaboration. Published by John Wiley \& Sons, Ltd. 


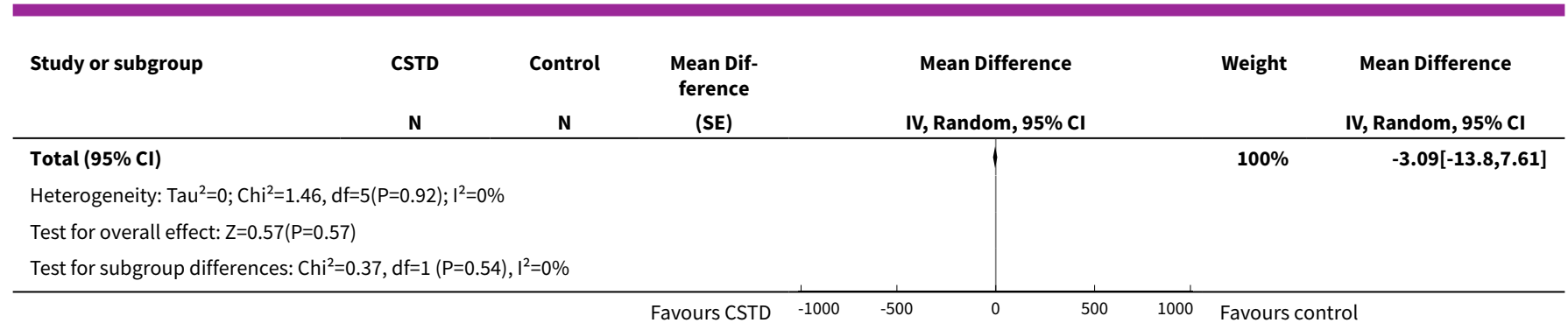

Analysis 2.11. Comparison 2 Subgroup analysis (based on study design and device), Outcome 11 Quantity of surface contamination with 5-fluorouracil in pharmacy areas $\left(\mathrm{pg} / \mathrm{cm}^{2}\right)$ : stratified by devices.

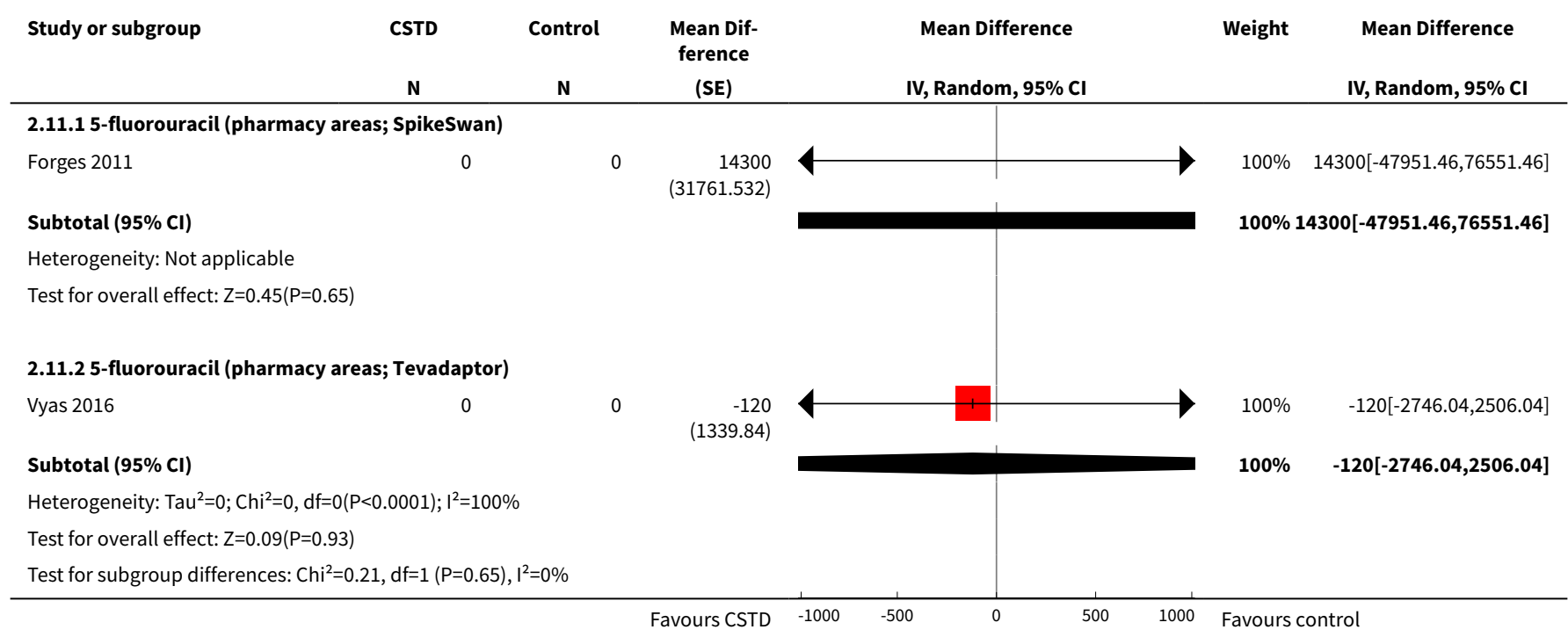

\section{Analysis 2.12. Comparison 2 Subgroup analysis (based on study design and device), Outcome 12 Quantity of surface contamination with 5 -fluorouracil in pharmacy areas $\left(\mathrm{pg} / \mathrm{cm}^{2}\right)$ : stratified by study design.}

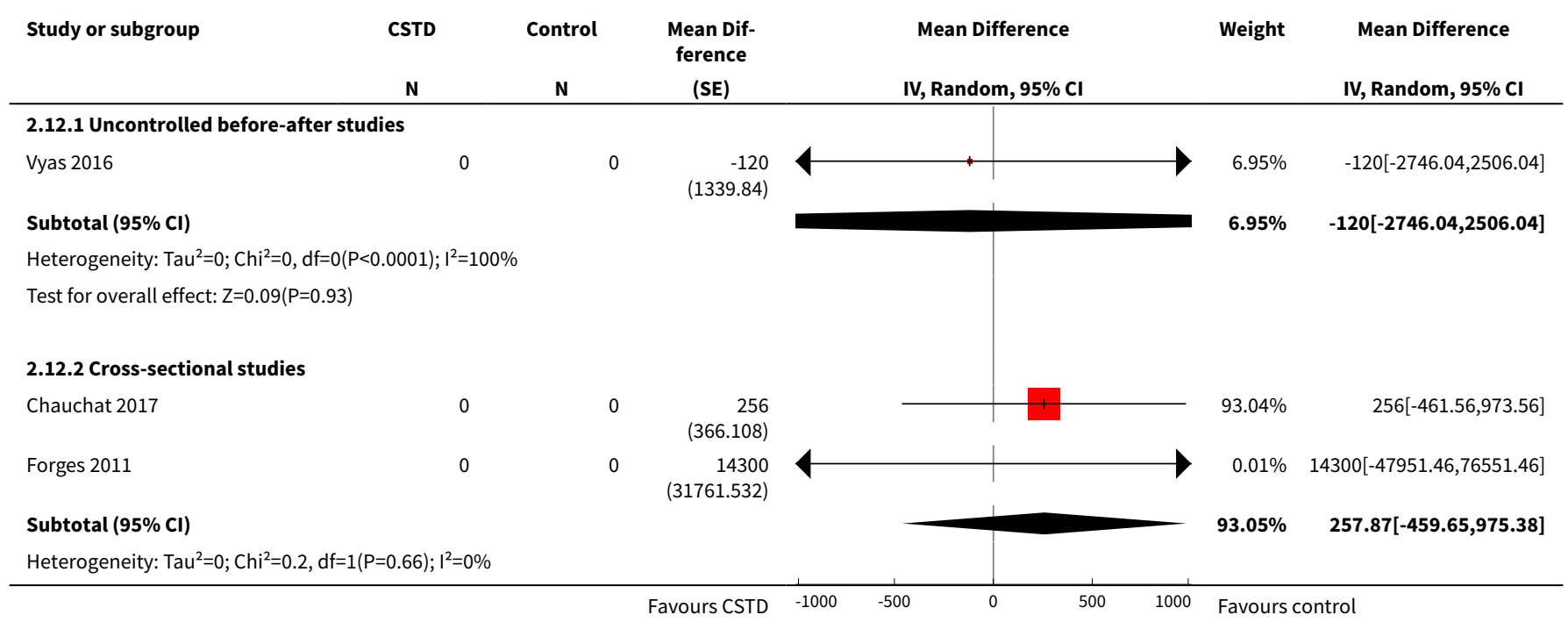




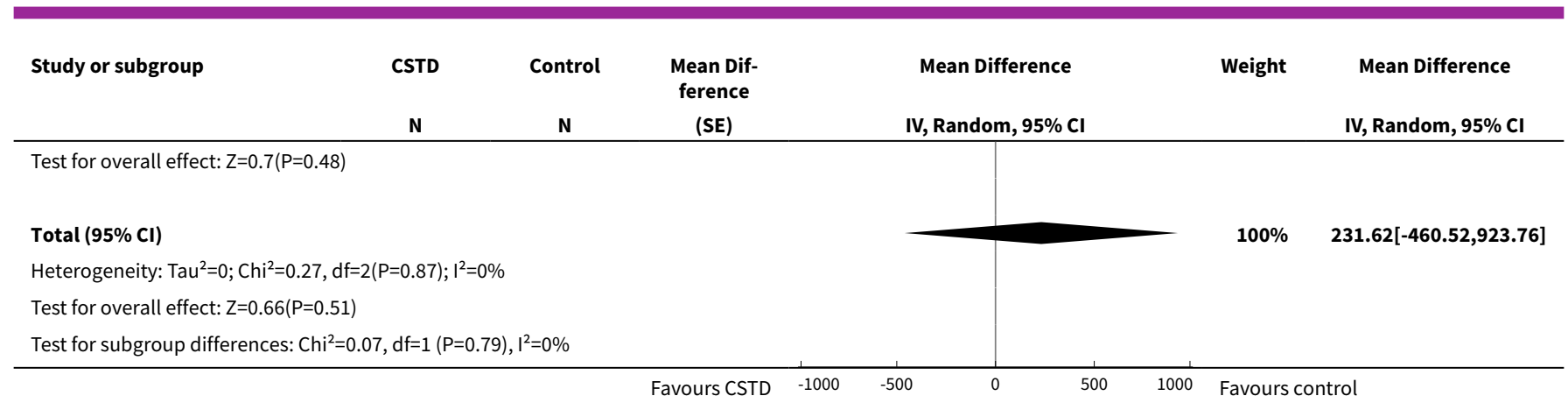

\section{Analysis 2.13. Comparison 2 Subgroup analysis (based on study design and device), Outcome 13 Quantity of surface contamination $\left(\mathrm{pg} / \mathrm{cm}^{2}\right)$ : stratified by devices.}

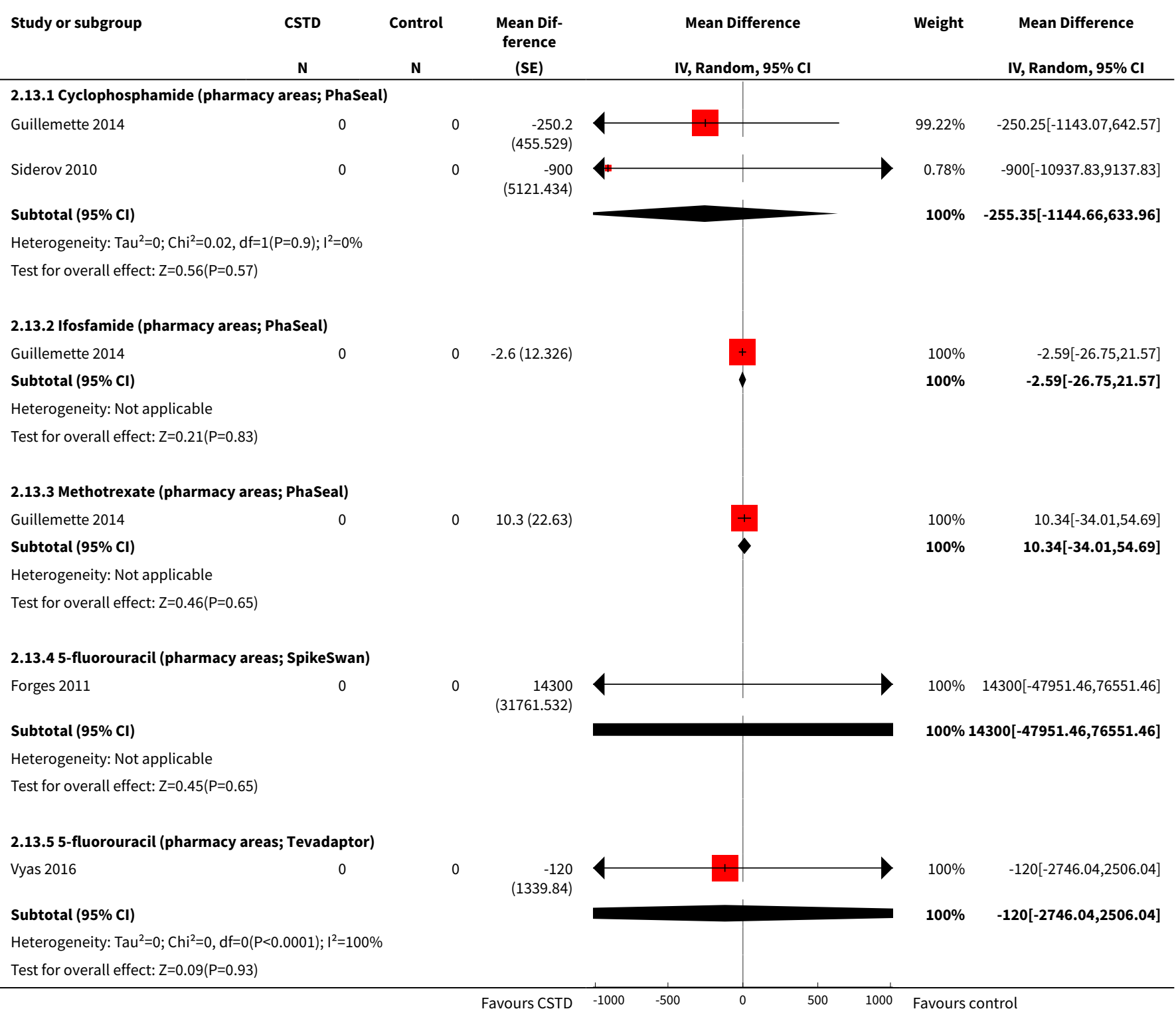




\section{Comparison 3. Sensitivity analysis}

\begin{tabular}{|c|c|c|c|c|}
\hline Outcome or subgroup title & No. of studies & $\begin{array}{l}\text { No. of partici- } \\
\text { pants }\end{array}$ & Statistical method & Effect size \\
\hline 1 Urine tests for exposure $(I C C=0.05)$ & 4 & & $\begin{array}{l}\text { Risk Ratio (Random, 95\% } \\
\mathrm{Cl} \text { ) }\end{array}$ & Subtotals only \\
\hline 1.1 Cyclophoshamide & 2 & & $\begin{array}{l}\text { Risk Ratio (Random, 95\% } \\
\mathrm{Cl} \text { ) }\end{array}$ & $0.82[0.44,1.52]$ \\
\hline 1.2 Cyclophosphamide or ifosfamide & 1 & & $\begin{array}{l}\text { Risk Ratio (Random, 95\% } \\
\mathrm{Cl} \text { ) }\end{array}$ & $0.09[0.00,1.99$ \\
\hline $\begin{array}{l}1.3 \text { Cyclophosphamide, ifosfamide, or } \\
\text { gemcitabine }\end{array}$ & 1 & & $\begin{array}{l}\text { Risk Ratio (Random, 95\% } \\
\mathrm{Cl} \text { ) }\end{array}$ & $0.0[0.0,0.0]$ \\
\hline 2 Urine tests for exposure $(\mathrm{ICC}=0.01)$ & 4 & & $\begin{array}{l}\text { Risk Ratio (Random, 95\% } \\
\mathrm{Cl} \text { ) }\end{array}$ & Subtotals only \\
\hline 2.1 Cyclophoshamide & 2 & & $\begin{array}{l}\text { Risk Ratio (Random, 95\% } \\
\mathrm{Cl} \text { ) }\end{array}$ & $0.81[0.43,1.51]$ \\
\hline 2.2 Cyclophosphamide or ifosfamide & 1 & & $\begin{array}{l}\text { Risk Ratio (Random, 95\% } \\
\mathrm{Cl} \text { ) }\end{array}$ & $0.09[0.01,1.48]$ \\
\hline $\begin{array}{l}\text { 2.3 Cyclophosphamide, ifosfamide, or } \\
\text { gemcitabine }\end{array}$ & 1 & & $\begin{array}{l}\text { Risk Ratio (Random, 95\% } \\
\mathrm{Cl} \text { ) }\end{array}$ & $0.0[0.0,0.0]$ \\
\hline 3 Urine tests for exposure $(I C C=0.00)$ & 4 & & $\begin{array}{l}\text { Risk Ratio (Random, 95\% } \\
\mathrm{Cl} \text { ) }\end{array}$ & Subtotals only \\
\hline 3.1 Cyclophoshamide & 2 & & $\begin{array}{l}\text { Risk Ratio (Random, 95\% } \\
\mathrm{Cl} \text { ) }\end{array}$ & $0.81[0.43,1.51]$ \\
\hline 3.2 Cyclophosphamide or ifosfamide & 1 & & $\begin{array}{l}\text { Risk Ratio (Random, 95\% } \\
\mathrm{Cl} \text { ) }\end{array}$ & $0.09[0.01,1.36]$ \\
\hline $\begin{array}{l}\text { 3.3 Cyclophosphamide, ifosfamide, or } \\
\text { gemcitabine }\end{array}$ & 1 & & $\begin{array}{l}\text { Risk Ratio (Random, 95\% } \\
\mathrm{Cl} \text { ) }\end{array}$ & $0.0[0.0,0.0]$ \\
\hline $\begin{array}{l}4 \text { Proportion of surfaces contaminat- } \\
\text { ed }(I C C=0.05)\end{array}$ & 15 & & $\begin{array}{l}\text { Risk Ratio (Random, 95\% } \\
\mathrm{Cl} \text { ) }\end{array}$ & Subtotals only \\
\hline $\begin{array}{l}\text { 4.1 Cyclophosphamide (pharmacy ar- } \\
\text { eas) }\end{array}$ & 13 & & $\begin{array}{l}\text { Risk Ratio (Random, 95\% } \\
\mathrm{Cl} \text { ) }\end{array}$ & $0.87[0.76,0.99]$ \\
\hline 4.2 Ifosfamide (pharmacy areas) & 9 & & $\begin{array}{l}\text { Risk Ratio (Random, 95\% } \\
\mathrm{Cl} \text { ) }\end{array}$ & $0.94[0.73,1.23$ \\
\hline 4.3 Methotrexate (pharmacy areas) & 6 & & $\begin{array}{l}\text { Risk Ratio (Random, 95\% } \\
\mathrm{Cl} \text { ) }\end{array}$ & $0.84[0.60,1.19]$ \\
\hline 4.4 5-fluorouracil (pharmacy areas) & 4 & & $\begin{array}{l}\text { Risk Ratio (Random, 95\% } \\
\mathrm{Cl} \text { ) }\end{array}$ & $0.62[0.42,0.92]$ \\
\hline 4.5 Cytarabine (pharmacy areas) & 2 & & $\begin{array}{l}\text { Risk Ratio (Random, 95\% } \\
\mathrm{Cl} \text { ) }\end{array}$ & $0.68[0.17,2.67]$ \\
\hline
\end{tabular}

Closed-system drug-transfer devices plus safe handling of hazardous drugs versus safe handling alone for reducing exposure to 


\begin{tabular}{|c|c|c|c|c|}
\hline Outcome or subgroup title & No. of studies & $\begin{array}{l}\text { No. of partici- } \\
\text { pants }\end{array}$ & Statistical method & Effect size \\
\hline 4.6 Gemcitabine (pharmacy areas) & 2 & & $\begin{array}{l}\text { Risk Ratio (Random, 95\% } \\
\text { Cl) }\end{array}$ & $0.95[0.64,1.43]$ \\
\hline 4.7 Irinotecan (pharmacy areas) & 1 & & $\begin{array}{l}\text { Risk Ratio (Random, 95\% } \\
\text { Cl) }\end{array}$ & $0.36[0.11,1.19]$ \\
\hline 4.8 Docetaxel (pharmacy areas) & 1 & & $\begin{array}{l}\text { Risk Ratio (Random, 95\% } \\
\text { Cl) }\end{array}$ & $0.0[0.0,0.0]$ \\
\hline 4.9 Paclitaxel (pharmacy areas) & 1 & & $\begin{array}{l}\text { Risk Ratio (Random, 95\% } \\
\text { Cl) }\end{array}$ & $0.57[0.05,7.13]$ \\
\hline 4.10 Vinorelbine (pharmacy areas) & 1 & & $\begin{array}{l}\text { Risk Ratio (Random, 95\% } \\
\text { Cl) }\end{array}$ & $1.72[0.20,15.25]$ \\
\hline 4.11 Ganciclovir (pharmacy areas) & 1 & & $\begin{array}{l}\text { Risk Ratio (Random, 95\% } \\
\mathrm{Cl} \text { ) }\end{array}$ & $0.01[0.00,3.43]$ \\
\hline 4.12 Epirubicin (pharmacy areas) & 1 & & $\begin{array}{l}\text { Risk Ratio (Random, 95\% } \\
\mathrm{Cl} \text { ) }\end{array}$ & $0.03[0.00,2.02]$ \\
\hline 4.13 Multiple drugs (pharmacy areas) & 1 & & $\begin{array}{l}\text { Risk Ratio (Random, 95\% } \\
\mathrm{Cl} \text { ) }\end{array}$ & $0.87[0.49,1.53]$ \\
\hline $\begin{array}{l}4.14 \text { Cyclophosphamide (patient-care } \\
\text { areas) }\end{array}$ & 5 & & $\begin{array}{l}\text { Risk Ratio (Random, 95\% } \\
\mathrm{Cl} \text { ) }\end{array}$ & $1.00[0.86,1.17]$ \\
\hline 4.15 Ifosfamide (patient-care areas) & 5 & & $\begin{array}{l}\text { Risk Ratio (Random, 95\% } \\
\mathrm{Cl} \text { ) }\end{array}$ & $1.46[0.91,2.34]$ \\
\hline $\begin{array}{l}4.16 \text { Methotrexate (patient-care ar- } \\
\text { eas) }\end{array}$ & 5 & & $\begin{array}{l}\text { Risk Ratio (Random, 95\% } \\
\text { Cl) }\end{array}$ & $1.01[0.57,1.76]$ \\
\hline $\begin{array}{l}4.175 \text {-fluorouracil (patient-care ar- } \\
\text { eas) }\end{array}$ & 1 & & $\begin{array}{l}\text { Risk Ratio (Random, 95\% } \\
\text { Cl) }\end{array}$ & $1.09[0.57,2.10]$ \\
\hline 4.18 Cytarabine (patient-care areas) & 1 & & $\begin{array}{l}\text { Risk Ratio (Random, 95\% } \\
\text { Cl) }\end{array}$ & $0.59[0.02,18.10]$ \\
\hline 4.19 Gemcitabine (patient-care areas) & 1 & & $\begin{array}{l}\text { Risk Ratio (Random, 95\% } \\
\text { Cl) }\end{array}$ & $1.13[0.58,2.20]$ \\
\hline 4.20 Irinotecan (patient-care areas) & 1 & & $\begin{array}{l}\text { Risk Ratio (Random, 95\% } \\
\text { Cl) }\end{array}$ & $0.44[0.04,4.97]$ \\
\hline 4.21 Docetaxel (patient-care areas) & 1 & & $\begin{array}{l}\text { Risk Ratio (Random, 95\% } \\
\text { Cl) }\end{array}$ & $0.59[0.02,18.10]$ \\
\hline 4.22 Paclitaxel (patient-care areas) & 1 & & $\begin{array}{l}\text { Risk Ratio (Random, 95\% } \\
\text { Cl) }\end{array}$ & $0.59[0.02,18.10]$ \\
\hline 4.23 Vinorelbine (patient-care areas) & 1 & & $\begin{array}{l}\text { Risk Ratio (Random, 95\% } \\
\text { Cl) }\end{array}$ & $0.0[0.0,0.0]$ \\
\hline
\end{tabular}




\begin{tabular}{|c|c|c|c|c|}
\hline Outcome or subgroup title & No. of studies & $\begin{array}{l}\text { No. of partici- } \\
\text { pants }\end{array}$ & Statistical method & Effect size \\
\hline $\begin{array}{l}4.24 \text { Multiple drugs (patient-care ar- } \\
\text { eas) }\end{array}$ & 1 & & $\begin{array}{l}\text { Risk Ratio (Random, 95\% } \\
\mathrm{Cl} \text { ) }\end{array}$ & $2.38[0.79,7.17]$ \\
\hline $\begin{array}{l}5 \text { Proportion of surfaces contaminat- } \\
\text { ed }(\text { ICC }=0.01)\end{array}$ & 15 & & $\begin{array}{l}\text { Risk Ratio (Random, 95\% } \\
\mathrm{Cl} \text { ) }\end{array}$ & Subtotals only \\
\hline $\begin{array}{l}5.1 \text { Cyclophosphamide (pharmacy ar- } \\
\text { eas) }\end{array}$ & 13 & & $\begin{array}{l}\text { Risk Ratio (Random, 95\% } \\
\mathrm{Cl} \text { ) }\end{array}$ & $0.83[0.73,0.96]$ \\
\hline 5.2 Ifosfamide (pharmacy areas) & 9 & & $\begin{array}{l}\text { Risk Ratio (Random, 95\% } \\
\text { Cl) }\end{array}$ & $0.89[0.66,1.21]$ \\
\hline 5.3 Methotrexate (pharmacy areas) & 6 & & $\begin{array}{l}\text { Risk Ratio (Random, 95\% } \\
\text { Cl) }\end{array}$ & $0.85[0.62,1.16]$ \\
\hline 5.4 5-fluorouracil (pharmacy areas) & 4 & & $\begin{array}{l}\text { Risk Ratio (Random, 95\% } \\
\mathrm{Cl} \text { ) }\end{array}$ & $0.57[0.33,0.97]$ \\
\hline 5.5 Cytarabine (pharmacy areas) & 2 & & $\begin{array}{l}\text { Risk Ratio (Random, 95\% } \\
\mathrm{Cl} \text { ) }\end{array}$ & $0.64[0.17,2.51]$ \\
\hline 5.6 Gemcitabine (pharmacy areas) & 2 & & $\begin{array}{l}\text { Risk Ratio (Random, 95\% } \\
\text { Cl) }\end{array}$ & $0.93[0.69,1.24]$ \\
\hline 5.7 Irinotecan (pharmacy areas) & 1 & & $\begin{array}{l}\text { Risk Ratio (Random, 95\% } \\
\mathrm{Cl} \text { ) }\end{array}$ & $0.36[0.12,1.08]$ \\
\hline 5.8 Docetaxel (pharmacy areas) & 1 & & $\begin{array}{l}\text { Risk Ratio (Random, 95\% } \\
\mathrm{Cl} \text { ) }\end{array}$ & $0.0[0.0,0.0]$ \\
\hline 5.9 Paclitaxel (pharmacy areas) & 1 & & $\begin{array}{l}\text { Risk Ratio (Random, 95\% } \\
\text { Cl) }\end{array}$ & $0.57[0.06,5.79]$ \\
\hline 5.10 Vinorelbine (pharmacy areas) & 1 & & $\begin{array}{l}\text { Risk Ratio (Random, 95\% } \\
\text { Cl) }\end{array}$ & $1.72[0.23,12.73]$ \\
\hline 5.11 Ganciclovir (pharmacy areas) & 1 & & $\begin{array}{l}\text { Risk Ratio (Random, 95\% } \\
\mathrm{Cl} \text { ) }\end{array}$ & $0.01[0.00,0.27]$ \\
\hline 5.12 Epirubicin (pharmacy areas) & 1 & & $\begin{array}{l}\text { Risk Ratio (Random, 95\% } \\
\mathrm{Cl} \text { ) }\end{array}$ & $0.03[0.00,0.62]$ \\
\hline 5.13 Multiple drugs (pharmacy areas) & 1 & & $\begin{array}{l}\text { Risk Ratio (Random, 95\% } \\
\mathrm{Cl} \text { ) }\end{array}$ & $0.87[0.57,1.32]$ \\
\hline $\begin{array}{l}5.14 \text { Cyclophosphamide (patient-care } \\
\text { areas) }\end{array}$ & 5 & & $\begin{array}{l}\text { Risk Ratio (Random, 95\% } \\
\mathrm{Cl} \text { ) }\end{array}$ & $1.00[0.85,1.17]$ \\
\hline 5.15 Ifosfamide (patient-care areas) & 5 & & $\begin{array}{l}\text { Risk Ratio (Random, 95\% } \\
\mathrm{Cl} \text { ) }\end{array}$ & $1.47[0.91,2.38]$ \\
\hline $\begin{array}{l}5.16 \text { Methotrexate (patient-care ar- } \\
\text { eas) }\end{array}$ & 5 & & $\begin{array}{l}\text { Risk Ratio (Random, 95\% } \\
\text { Cl) }\end{array}$ & $1.01[0.60,1.69]$ \\
\hline
\end{tabular}




\begin{tabular}{|c|c|c|c|c|}
\hline Outcome or subgroup title & No. of studies & $\begin{array}{l}\text { No. of partici- } \\
\text { pants }\end{array}$ & Statistical method & Effect size \\
\hline $\begin{array}{l}5.175 \text {-fluorouracil (patient-care ar- } \\
\text { eas) }\end{array}$ & 1 & & $\begin{array}{l}\text { Risk Ratio (Random, 95\% } \\
\text { Cl) }\end{array}$ & $1.09[0.59,2.00]$ \\
\hline 5.18 Cytarabine (patient-care areas) & 1 & & $\begin{array}{l}\text { Risk Ratio (Random, 95\% } \\
\mathrm{Cl} \text { ) }\end{array}$ & $0.59[0.02,13.92]$ \\
\hline 5.19 Gemcitabine (patient-care areas) & 1 & & $\begin{array}{l}\text { Risk Ratio (Random, 95\% } \\
\text { Cl) }\end{array}$ & $1.13[0.61,2.09]$ \\
\hline 5.20 Irinotecan (patient-care areas) & 1 & & $\begin{array}{l}\text { Risk Ratio (Random, 95\% } \\
\text { Cl) }\end{array}$ & $0.44[0.05,4.13]$ \\
\hline 5.21 Docetaxel (patient-care areas) & 1 & & $\begin{array}{l}\text { Risk Ratio (Random, 95\% } \\
\mathrm{Cl} \text { ) }\end{array}$ & $0.59[0.02,13.92]$ \\
\hline 5.22 Paclitaxel (patient-care areas) & 1 & & $\begin{array}{l}\text { Risk Ratio (Random, 95\% } \\
\mathrm{Cl} \text { ) }\end{array}$ & $0.59[0.02,13.92]$ \\
\hline 5.23 Vinorelbine (patient-care areas) & 1 & & $\begin{array}{l}\text { Risk Ratio (Random, 95\% } \\
\mathrm{Cl} \text { ) }\end{array}$ & $0.0[0.0,0.0]$ \\
\hline $\begin{array}{l}5.24 \text { Multiple drugs (patient-care ar- } \\
\text { eas) }\end{array}$ & 1 & & $\begin{array}{l}\text { Risk Ratio (Random, 95\% } \\
\mathrm{Cl} \text { ) }\end{array}$ & $2.38[0.89,6.33]$ \\
\hline $\begin{array}{l}6 \text { Proportion of surfaces contaminat- } \\
\text { ed }(I C C=0.00)\end{array}$ & 15 & & $\begin{array}{l}\text { Risk Ratio (Random, 95\% } \\
\mathrm{Cl} \text { ) }\end{array}$ & Subtotals only \\
\hline $\begin{array}{l}\text { 6.1 Cyclophosphamide (pharmacy ar- } \\
\text { eas) }\end{array}$ & 13 & & $\begin{array}{l}\text { Risk Ratio (Random, 95\% } \\
\mathrm{Cl} \text { ) }\end{array}$ & $0.82[0.72,0.94]$ \\
\hline 6.2 Ifosfamide (pharmacy areas) & 9 & & $\begin{array}{l}\text { Risk Ratio (Random, 95\% } \\
\text { Cl) }\end{array}$ & $0.85[0.59,1.21]$ \\
\hline 6.3 Methotrexate (pharmacy areas) & 6 & & $\begin{array}{l}\text { Risk Ratio (Random, 95\% } \\
\text { Cl) }\end{array}$ & $0.86[0.63,1.16]$ \\
\hline 6.4 5-fluorouracil (pharmacy areas) & 4 & & $\begin{array}{l}\text { Risk Ratio (Random, 95\% } \\
\text { Cl) }\end{array}$ & $0.55[0.32,0.94]$ \\
\hline 6.5 Cytarabine (pharmacy areas) & 2 & & $\begin{array}{l}\text { Risk Ratio (Random, 95\% } \\
\text { Cl) }\end{array}$ & $0.64[0.16,2.46]$ \\
\hline 6.6 Gemcitabine (pharmacy areas) & 2 & & $\begin{array}{l}\text { Risk Ratio (Random, 95\% } \\
\text { Cl) }\end{array}$ & $0.91[0.73,1.13]$ \\
\hline 6.7 Irinotecan (pharmacy areas) & 1 & & $\begin{array}{l}\text { Risk Ratio (Random, 95\% } \\
\text { Cl) }\end{array}$ & $0.36[0.13,1.05]$ \\
\hline 6.8 Docetaxel (pharmacy areas) & 1 & & $\begin{array}{l}\text { Risk Ratio (Random, 95\% } \\
\text { Cl) }\end{array}$ & $0.0[0.0,0.0]$ \\
\hline 6.9 Paclitaxel (pharmacy areas) & 1 & & $\begin{array}{l}\text { Risk Ratio (Random, 95\% } \\
\text { Cl) }\end{array}$ & $0.57[0.06,5.48]$ \\
\hline
\end{tabular}




\begin{tabular}{|c|c|c|c|c|}
\hline Outcome or subgroup title & No. of studies & $\begin{array}{l}\text { No. of partici- } \\
\text { pants }\end{array}$ & Statistical method & Effect size \\
\hline 6.10 Vinorelbine (pharmacy areas) & 1 & & $\begin{array}{l}\text { Risk Ratio (Random, 95\% } \\
\mathrm{Cl} \text { ) }\end{array}$ & $1.72[0.24,12.15]$ \\
\hline 6.11 Ganciclovir (pharmacy areas) & 1 & & $\begin{array}{l}\text { Risk Ratio (Random, 95\% } \\
\mathrm{Cl} \text { ) }\end{array}$ & $0.01[0.00,0.09]$ \\
\hline 6.12 Epirubicin (pharmacy areas) & 1 & & $\begin{array}{l}\text { Risk Ratio (Random, 95\% } \\
\mathrm{Cl} \text { ) }\end{array}$ & $0.03[0.00,0.42]$ \\
\hline 6.13 Multiple drugs (pharmacy areas) & 1 & & $\begin{array}{l}\text { Risk Ratio (Random, 95\% } \\
\mathrm{Cl} \text { ) }\end{array}$ & $0.87[0.60,1.26]$ \\
\hline $\begin{array}{l}6.14 \text { Cyclophosphamide (patient-care } \\
\text { areas) }\end{array}$ & 5 & & $\begin{array}{l}\text { Risk Ratio (Random, 95\% } \\
\mathrm{Cl} \text { ) }\end{array}$ & $1.00[0.85,1.17]$ \\
\hline 6.15 Ifosfamide (patient-care areas) & 5 & & $\begin{array}{l}\text { Risk Ratio (Random, 95\% } \\
\mathrm{Cl} \text { ) }\end{array}$ & $1.48[0.91,2.38]$ \\
\hline $\begin{array}{l}\text { 6.16 Methotrexate (patient-care ar- } \\
\text { eas) }\end{array}$ & 5 & & $\begin{array}{l}\text { Risk Ratio (Random, 95\% } \\
\mathrm{Cl} \text { ) }\end{array}$ & $1.01[0.61,1.67]$ \\
\hline $\begin{array}{l}6.175 \text {-fluorouracil (patient-care ar- } \\
\text { eas) }\end{array}$ & 1 & & $\begin{array}{l}\text { Risk Ratio (Random, 95\% } \\
\mathrm{Cl} \text { ) }\end{array}$ & $1.09[0.60,1.97]$ \\
\hline 6.18 Cytarabine (patient-care areas) & 1 & & $\begin{array}{l}\text { Risk Ratio (Random, 95\% } \\
\mathrm{Cl} \text { ) }\end{array}$ & $0.59[0.02,14.36]$ \\
\hline 6.19 Gemcitabine (patient-care areas) & 1 & & $\begin{array}{l}\text { Risk Ratio (Random, 95\% } \\
\mathrm{Cl} \text { ) }\end{array}$ & $1.13[0.62,2.06]$ \\
\hline 6.20 Irinotecan (patient-care areas) & 1 & & $\begin{array}{l}\text { Risk Ratio (Random, 95\% } \\
\mathrm{Cl} \text { ) }\end{array}$ & $0.44[0.05,3.93]$ \\
\hline 6.21 Docetaxel (patient-care areas) & 1 & & $\begin{array}{l}\text { Risk Ratio (Random, 95\% } \\
\mathrm{Cl} \text { ) }\end{array}$ & $0.59[0.02,14.36]$ \\
\hline 6.22 Paclitaxel (patient-care areas) & 1 & & $\begin{array}{l}\text { Risk Ratio (Random, 95\% } \\
\mathrm{Cl} \text { ) }\end{array}$ & $0.59[0.02,14.36]$ \\
\hline 6.23 Vinorelbine (patient-care areas) & 1 & & $\begin{array}{l}\text { Risk Ratio (Random, 95\% } \\
\mathrm{Cl} \text { ) }\end{array}$ & $0.0[0.0,0.0]$ \\
\hline $\begin{array}{l}6.24 \text { Multiple drugs (patient-care ar- } \\
\text { eas) }\end{array}$ & 1 & & $\begin{array}{l}\text { Risk Ratio (Random, 95\% } \\
\mathrm{Cl} \text { ) }\end{array}$ & $2.38[0.92,6.12]$ \\
\hline $\begin{array}{l}7 \text { Quantity of surface contamination } \\
\left(\mathrm{pg} / \mathrm{cm}^{2}\right)(\mathrm{ICC}=0.05)\end{array}$ & 9 & & $\begin{array}{l}\text { Mean Difference (Random, } \\
95 \% \mathrm{Cl} \text { ) }\end{array}$ & Subtotals only \\
\hline $\begin{array}{l}7.1 \text { Cyclophosphamide (pharmacy ar- } \\
\text { eas) }\end{array}$ & 7 & & $\begin{array}{l}\text { Mean Difference (Random, } \\
95 \% \mathrm{Cl} \text { ) }\end{array}$ & $\begin{array}{l}-49.47[-81.21 \\
-17.73]\end{array}$ \\
\hline 7.2 Ifosfamide (pharmacy areas) & 6 & & $\begin{array}{l}\text { Mean Difference (Random, } \\
95 \% \mathrm{Cl} \text { ) }\end{array}$ & $-0.95[-7.63,5.72]$ \\
\hline
\end{tabular}




\begin{tabular}{|c|c|c|c|c|}
\hline Outcome or subgroup title & No. of studies & $\begin{array}{l}\text { No. of partici- } \\
\text { pants }\end{array}$ & Statistical method & Effect size \\
\hline 7.3 Methotrexate (pharmacy areas) & 6 & & $\begin{array}{l}\text { Mean Difference (Random, } \\
95 \% \mathrm{Cl} \text { ) }\end{array}$ & $-2.78[-12.45,6.89]$ \\
\hline 7.4 5-fluorouracil (pharmacy areas) & 3 & & $\begin{array}{l}\text { Mean Difference (Random, } \\
95 \% \mathrm{Cl} \text { ) }\end{array}$ & $\begin{array}{l}224.25[-400.98 \\
849.49]\end{array}$ \\
\hline 7.5 Cytarabine (pharmacy areas) & 1 & & $\begin{array}{l}\text { Mean Difference (Random, } \\
95 \% \mathrm{Cl} \text { ) }\end{array}$ & $-0.6[-14.37,13.17]$ \\
\hline 7.6 Gemcitabine (pharmacy areas) & 1 & & $\begin{array}{l}\text { Mean Difference (Random, } \\
95 \% \mathrm{Cl} \text { ) }\end{array}$ & $-32.7[-96.40,31.00]$ \\
\hline 7.7 Irinotecan (pharmacy areas) & 1 & & $\begin{array}{l}\text { Mean Difference (Random, } \\
95 \% \mathrm{Cl} \text { ) }\end{array}$ & $\begin{array}{l}-18.27[-53.55 \\
17.01]\end{array}$ \\
\hline 7.8 Epirubicin (pharmacy areas) & 1 & & $\begin{array}{l}\text { Mean Difference (Random, } \\
95 \% \mathrm{Cl} \text { ) }\end{array}$ & $\begin{array}{l}-110.0[-112.32 \\
-107.68]\end{array}$ \\
\hline $\begin{array}{l}7.9 \text { Cyclophosphamide (patient-care } \\
\text { areas) }\end{array}$ & 5 & & $\begin{array}{l}\text { Mean Difference (Random, } \\
95 \% \mathrm{Cl} \text { ) }\end{array}$ & $\begin{array}{l}-30.44[-90.78 \\
29.90]\end{array}$ \\
\hline 7.10 Ifosfamide (patient-care areas) & 5 & & $\begin{array}{l}\text { Mean Difference (Random, } \\
95 \% \mathrm{Cl} \text { ) }\end{array}$ & $3.59[-2.88,10.07]$ \\
\hline $\begin{array}{l}\text { 7.11 Methotrexate (patient-care ar- } \\
\text { eas) }\end{array}$ & 5 & & $\begin{array}{l}\text { Mean Difference (Random, } \\
95 \% \mathrm{Cl} \text { ) }\end{array}$ & $0.10[-0.51,0.72]$ \\
\hline $\begin{array}{l}7.125 \text {-fluorouracil (patient-care ar- } \\
\text { eas) }\end{array}$ & 1 & & $\begin{array}{l}\text { Mean Difference (Random, } \\
95 \% \mathrm{Cl} \text { ) }\end{array}$ & $\begin{array}{l}-43.9[-133.57 \\
45.77]\end{array}$ \\
\hline 7.13 Cytarabine (patient-care areas) & 1 & & $\begin{array}{l}\text { Mean Difference (Random, } \\
95 \% \mathrm{Cl} \text { ) }\end{array}$ & $-0.20[-0.74,0.34]$ \\
\hline 7.14 Gemcitabine (patient-care areas) & 1 & & $\begin{array}{l}\text { Mean Difference (Random, } \\
95 \% \mathrm{Cl} \text { ) }\end{array}$ & $0.47[-1.59,2.53]$ \\
\hline 7.15 Irinotecan (patient-care areas) & 1 & & $\begin{array}{l}\text { Mean Difference (Random, } \\
95 \% \mathrm{Cl} \text { ) }\end{array}$ & $-0.05[-0.14,0.04]$ \\
\hline $\begin{array}{l}8 \text { Quantity of surface contamination } \\
\left(\mathrm{pg} / \mathrm{cm}^{2}\right)(\mathrm{ICC}=0.01)\end{array}$ & 9 & & $\begin{array}{l}\text { Mean Difference (Random, } \\
95 \% \mathrm{Cl} \text { ) }\end{array}$ & Subtotals only \\
\hline $\begin{array}{l}\text { 8.1 Cyclophosphamide (pharmacy ar- } \\
\text { eas) }\end{array}$ & 7 & & $\begin{array}{l}\text { Mean Difference (Random, } \\
95 \% \mathrm{Cl} \text { ) }\end{array}$ & $\begin{array}{l}-49.85[-78.93 \\
-20.77]\end{array}$ \\
\hline 8.2 Ifosfamide (pharmacy areas) & 6 & & $\begin{array}{l}\text { Mean Difference (Random, } \\
95 \% \mathrm{Cl} \text { ) }\end{array}$ & $-1.29[-7.89,5.32]$ \\
\hline 8.3 Methotrexate (pharmacy areas) & 6 & & $\begin{array}{l}\text { Mean Difference (Random, } \\
95 \% \mathrm{Cl} \text { ) }\end{array}$ & $-1.93[-10.50,6.64]$ \\
\hline 8.4 5-fluorouracil (pharmacy areas) & 3 & & $\begin{array}{l}\text { Mean Difference (Random, } \\
95 \% \mathrm{Cl} \text { ) }\end{array}$ & $\begin{array}{l}207.62[-351.04 \\
766.28]\end{array}$ \\
\hline
\end{tabular}




\begin{tabular}{|c|c|c|c|c|}
\hline Outcome or subgroup title & No. of studies & $\begin{array}{l}\text { No. of partici- } \\
\text { pants }\end{array}$ & Statistical method & Effect size \\
\hline 8.5 Cytarabine (pharmacy areas) & 1 & & $\begin{array}{l}\text { Mean Difference (Random, } \\
95 \% \mathrm{Cl} \text { ) }\end{array}$ & $-0.6[-13.23,12.03]$ \\
\hline 8.6 Gemcitabine (pharmacy areas) & 1 & & $\begin{array}{l}\text { Mean Difference (Random, } \\
95 \% \mathrm{Cl} \text { ) }\end{array}$ & $-32.7[-91.14,25.74]$ \\
\hline 8.7 Irinotecan (pharmacy areas) & 1 & & $\begin{array}{l}\text { Mean Difference (Random, } \\
95 \% \mathrm{Cl} \text { ) }\end{array}$ & $\begin{array}{l}-18.27[-50.63 \\
14.09]\end{array}$ \\
\hline 8.8 Epirubicin (pharmacy areas) & 1 & & $\begin{array}{l}\text { Mean Difference (Random, } \\
95 \% \mathrm{Cl} \text { ) }\end{array}$ & $\begin{array}{l}-110.0[-111.68 \\
-108.32]\end{array}$ \\
\hline $\begin{array}{l}8.9 \text { Cyclophosphamide (patient-care } \\
\text { areas) }\end{array}$ & 5 & & $\begin{array}{l}\text { Mean Difference (Random, } \\
95 \% \mathrm{Cl} \text { ) }\end{array}$ & $\begin{array}{l}-49.62[-133.49 \\
34.25]\end{array}$ \\
\hline 8.10 Ifosfamide (patient-care areas) & 5 & & $\begin{array}{l}\text { Mean Difference (Random, } \\
95 \% \mathrm{Cl} \text { ) }\end{array}$ & $3.59[-2.39,9.58]$ \\
\hline $\begin{array}{l}8.11 \text { Methotrexate (patient-care ar- } \\
\text { eas) }\end{array}$ & 5 & & $\begin{array}{l}\text { Mean Difference (Random, } \\
95 \% \mathrm{Cl} \text { ) }\end{array}$ & $0.06[-0.81,0.94]$ \\
\hline $\begin{array}{l}8.125 \text {-fluorouracil (patient-care ar- } \\
\text { eas) }\end{array}$ & 1 & & $\begin{array}{l}\text { Mean Difference (Random, } \\
95 \% \mathrm{Cl} \text { ) }\end{array}$ & $\begin{array}{l}-43.9[-126.66 \\
38.86]\end{array}$ \\
\hline 8.13 Cytarabine (patient-care areas) & 1 & & $\begin{array}{l}\text { Mean Difference (Random, } \\
95 \% \mathrm{Cl} \text { ) }\end{array}$ & $-0.2[-0.70,0.30]$ \\
\hline 8.14 Gemcitabine (patient-care areas) & 1 & & $\begin{array}{l}\text { Mean Difference (Random, } \\
95 \% \mathrm{Cl} \text { ) }\end{array}$ & $0.47[-1.43,2.37]$ \\
\hline 8.15 Irinotecan (patient-care areas) & 1 & & $\begin{array}{l}\text { Mean Difference (Random, } \\
95 \% \mathrm{Cl} \text { ) }\end{array}$ & $-0.05[-0.13,0.03]$ \\
\hline $\begin{array}{l}9 \text { Quantity of surface contamination } \\
\left(\mathrm{pg} / \mathrm{cm}^{2}\right)(\mathrm{ICC}=0.00)\end{array}$ & 9 & & $\begin{array}{l}\text { Mean Difference (Random, } \\
95 \% \mathrm{Cl} \text { ) }\end{array}$ & Subtotals only \\
\hline $\begin{array}{l}\text { 9.1 Cyclophosphamide (pharmacy ar- } \\
\text { eas) }\end{array}$ & 7 & & $\begin{array}{l}\text { Mean Difference (Random, } \\
95 \% \mathrm{Cl} \text { ) }\end{array}$ & $\begin{array}{l}-50.15[-78.51 \\
-21.79]\end{array}$ \\
\hline 9.2 Ifosfamide (pharmacy areas) & 6 & & $\begin{array}{l}\text { Mean Difference (Random, } \\
95 \% \mathrm{Cl} \text { ) }\end{array}$ & $-1.36[-7.81,5.09]$ \\
\hline 9.3 Methotrexate (pharmacy areas) & 6 & & $\begin{array}{l}\text { Mean Difference (Random, } \\
95 \% \mathrm{Cl} \text { ) }\end{array}$ & $-1.32[-9.47,6.84]$ \\
\hline 9.4 5-fluorouracil (pharmacy areas) & 3 & & $\begin{array}{l}\text { Mean Difference (Random, } \\
95 \% \mathrm{Cl} \text { ) }\end{array}$ & $\begin{array}{l}198.18[-338.80 \\
735.17]\end{array}$ \\
\hline 9.5 Cytarabine (pharmacy areas) & 1 & & $\begin{array}{l}\text { Mean Difference (Random, } \\
95 \% \mathrm{Cl} \text { ) }\end{array}$ & $-0.6[-12.93,11.73]$ \\
\hline 9.6 Gemcitabine (pharmacy areas) & 1 & & $\begin{array}{l}\text { Mean Difference (Random, } \\
95 \% \mathrm{Cl} \text { ) }\end{array}$ & $-32.7[-89.74,24.34]$ \\
\hline
\end{tabular}




\begin{tabular}{|c|c|c|c|c|}
\hline Outcome or subgroup title & No. of studies & $\begin{array}{l}\text { No. of partici- } \\
\text { pants }\end{array}$ & Statistical method & Effect size \\
\hline 9.7 Irinotecan (pharmacy areas) & 1 & & $\begin{array}{l}\text { Mean Difference (Random, } \\
95 \% \mathrm{Cl} \text { ) }\end{array}$ & $\begin{array}{l}-18.27[-49.86 \\
13.32]\end{array}$ \\
\hline 9.8 Epirubicin (pharmacy areas) & 1 & & $\begin{array}{l}\text { Mean Difference (Random, } \\
95 \% \mathrm{Cl} \text { ) }\end{array}$ & $\begin{array}{l}-110.0[-111.48 \\
-108.52]\end{array}$ \\
\hline $\begin{array}{l}9.9 \text { Cyclophosphamide (patient-care } \\
\text { areas) }\end{array}$ & 5 & & $\begin{array}{l}\text { Mean Difference (Random, } \\
95 \% \mathrm{Cl} \text { ) }\end{array}$ & $\begin{array}{l}-53.61[-141.33 \\
34.10]\end{array}$ \\
\hline 9.10 Ifosfamide (patient-care areas) & 5 & & $\begin{array}{l}\text { Mean Difference (Random, } \\
95 \% \mathrm{Cl} \text { ) }\end{array}$ & $3.60[-2.27,9.46]$ \\
\hline $\begin{array}{l}9.11 \text { Methotrexate (patient-care ar- } \\
\text { eas) }\end{array}$ & 5 & & $\begin{array}{l}\text { Mean Difference (Random, } \\
95 \% \mathrm{Cl} \text { ) }\end{array}$ & $0.03[-1.02,1.08]$ \\
\hline $\begin{array}{l}\text { 9.12 5-fluorouracil (patient-care ar- } \\
\text { eas) }\end{array}$ & 1 & & $\begin{array}{l}\text { Mean Difference (Random, } \\
95 \% \mathrm{Cl} \text { ) }\end{array}$ & $\begin{array}{l}-43.9[-124.84 \\
37.04]\end{array}$ \\
\hline 9.13 Cytarabine (patient-care areas) & 1 & & $\begin{array}{l}\text { Mean Difference (Random, } \\
95 \% \mathrm{Cl} \text { ) }\end{array}$ & $-0.2[-0.69,0.29]$ \\
\hline 9.14 Gemcitabine (patient-care areas) & 1 & & $\begin{array}{l}\text { Mean Difference (Random, } \\
95 \% \mathrm{Cl} \text { ) }\end{array}$ & $0.47[-1.39,2.33]$ \\
\hline 9.15 Irinotecan (patient-care areas) & 1 & & $\begin{array}{l}\text { Mean Difference (Random, } \\
95 \% \mathrm{CI} \text { ) }\end{array}$ & $-0.05[-0.13,0.03]$ \\
\hline
\end{tabular}

Analysis 3.1. Comparison 3 Sensitivity analysis, Outcome 1 Urine tests for exposure $($ ICC $=0.05)$.

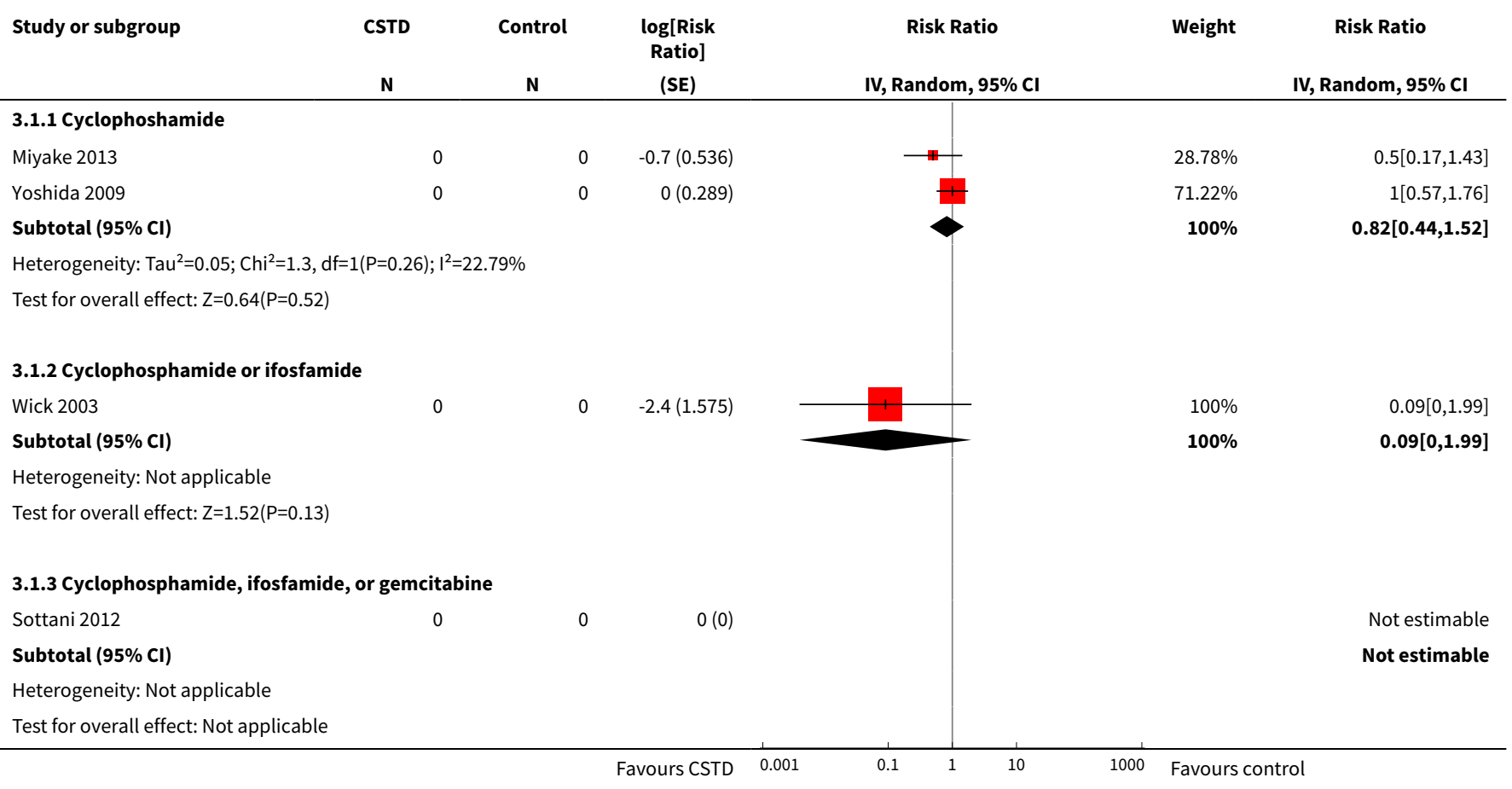


Analysis 3.2. Comparison 3 Sensitivity analysis, Outcome 2 Urine tests for exposure (ICC $=0.01)$.

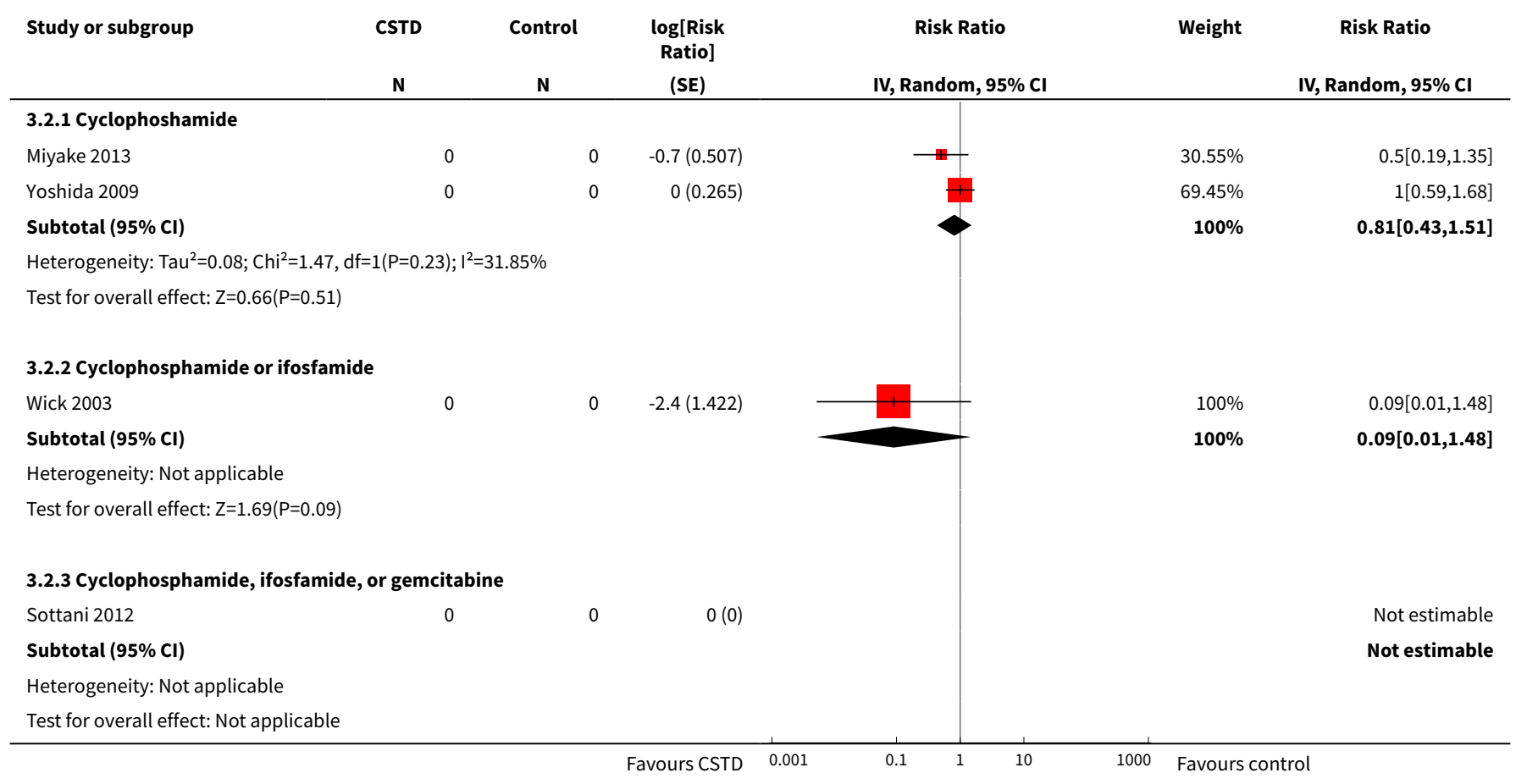

Analysis 3.3. Comparison 3 Sensitivity analysis, Outcome 3 Urine tests for exposure (ICC $=0.00$ ).

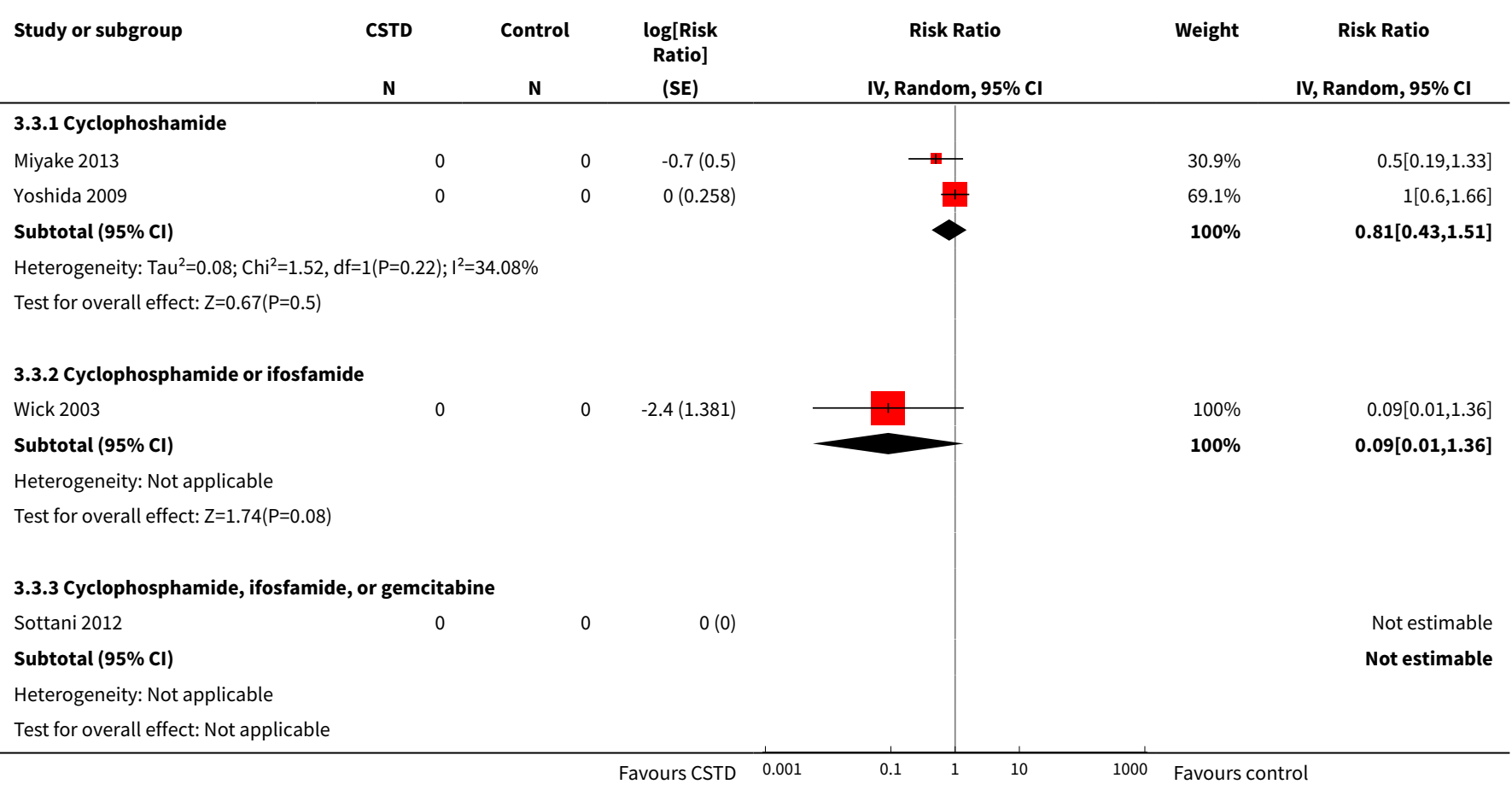


Analysis 3.4. Comparison 3 Sensitivity analysis, Outcome 4 Proportion of surfaces contaminated (ICC $=0.05$ ).

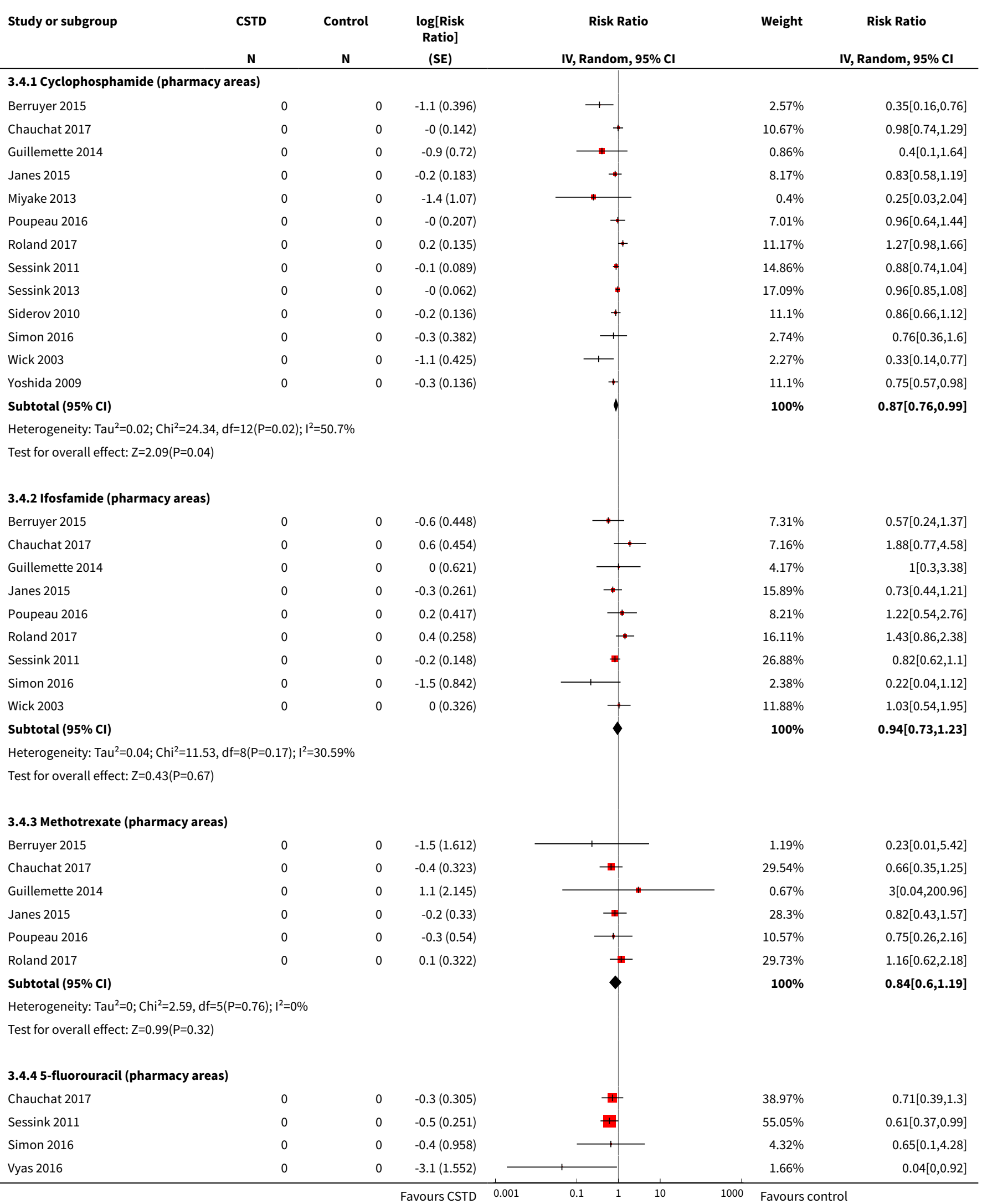




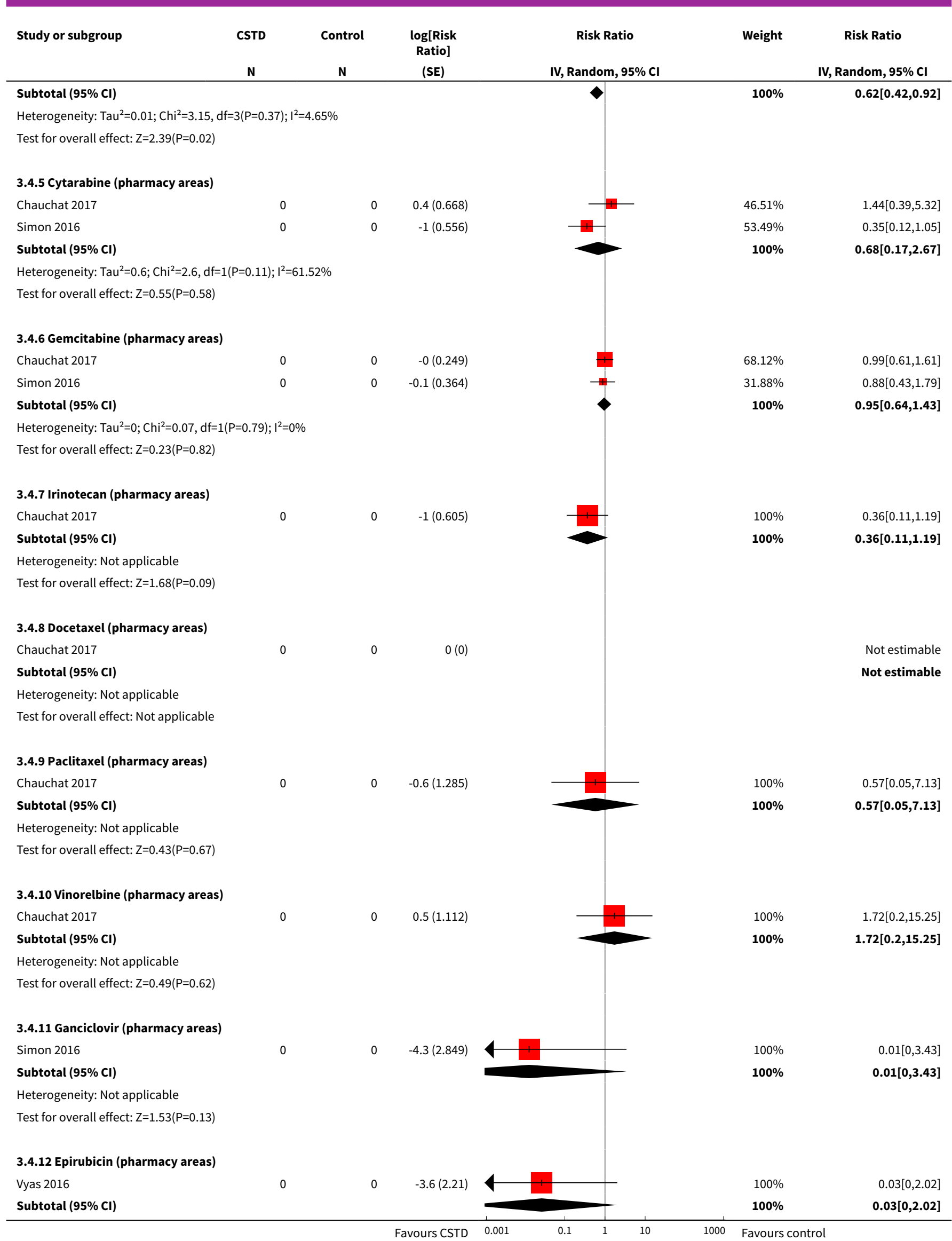

Closed-system drug-transfer devices plus safe handling of hazardous drugs versus safe handling alone for reducing exposure to 


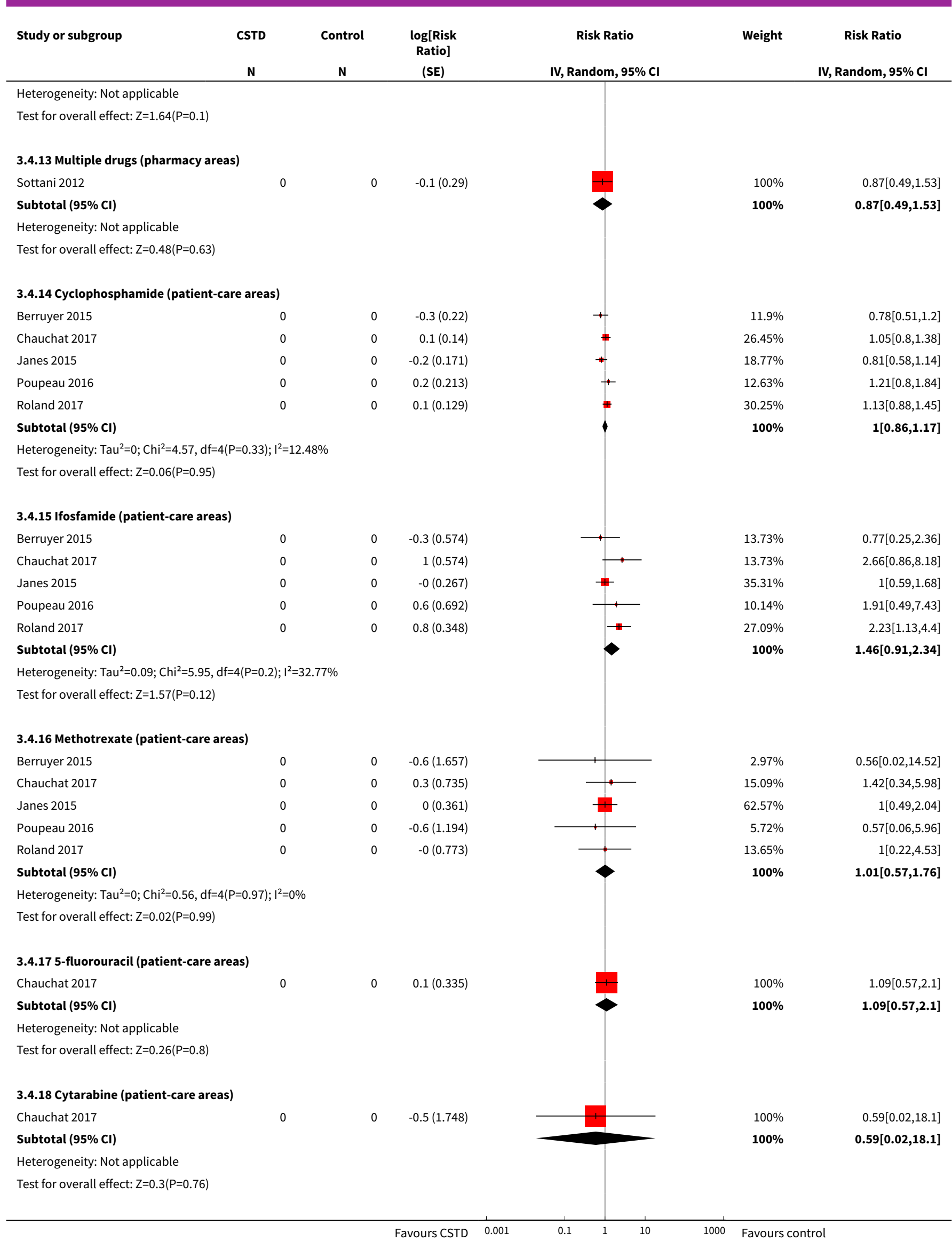

Closed-system drug-transfer devices plus safe handling of hazardous drugs versus safe handling alone for reducing exposure to 


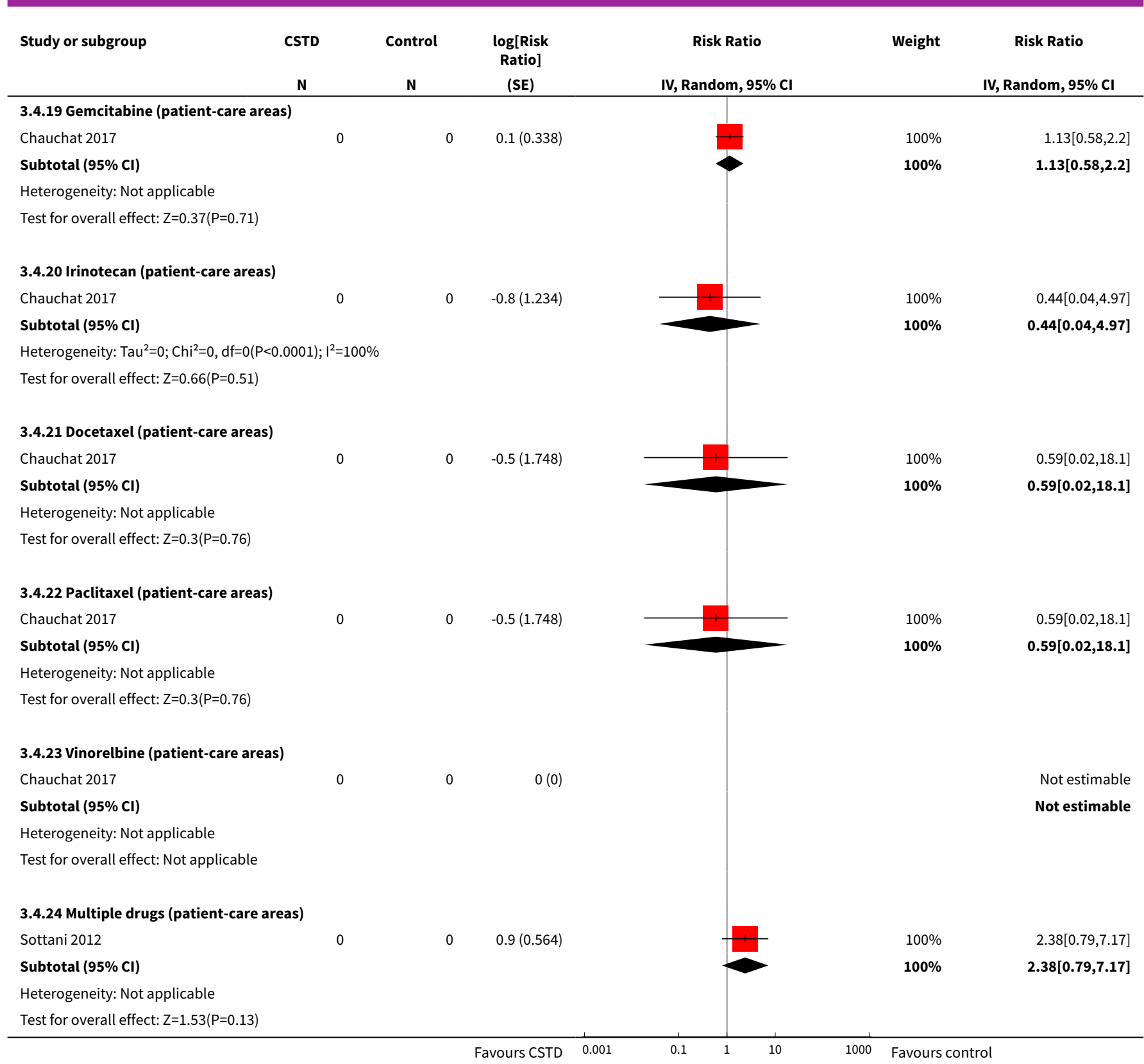

Analysis 3.5. Comparison 3 Sensitivity analysis, Outcome 5 Proportion of surfaces contaminated (ICC $=0.01)$.

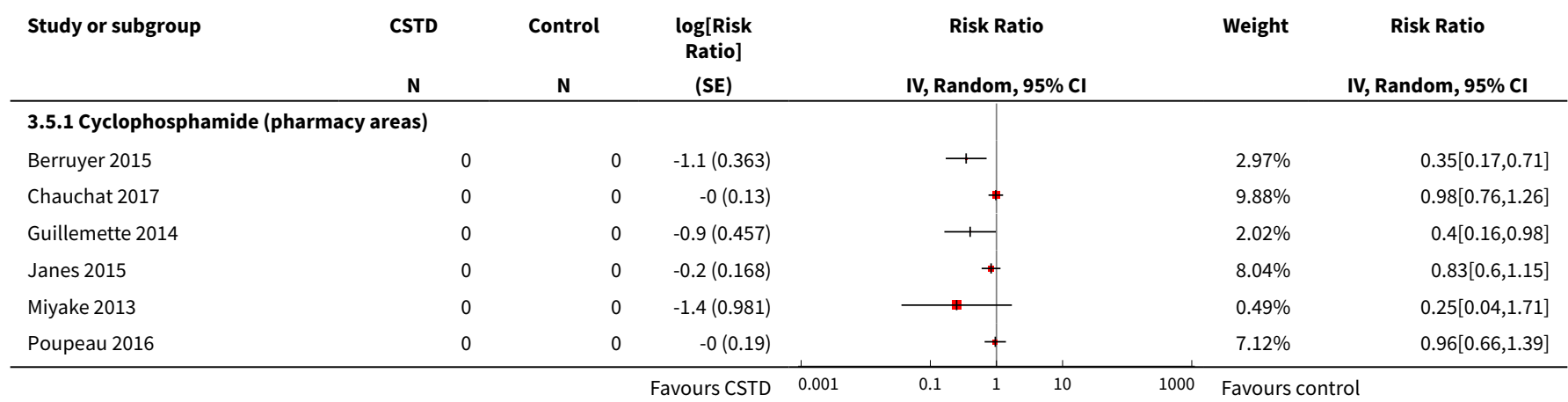




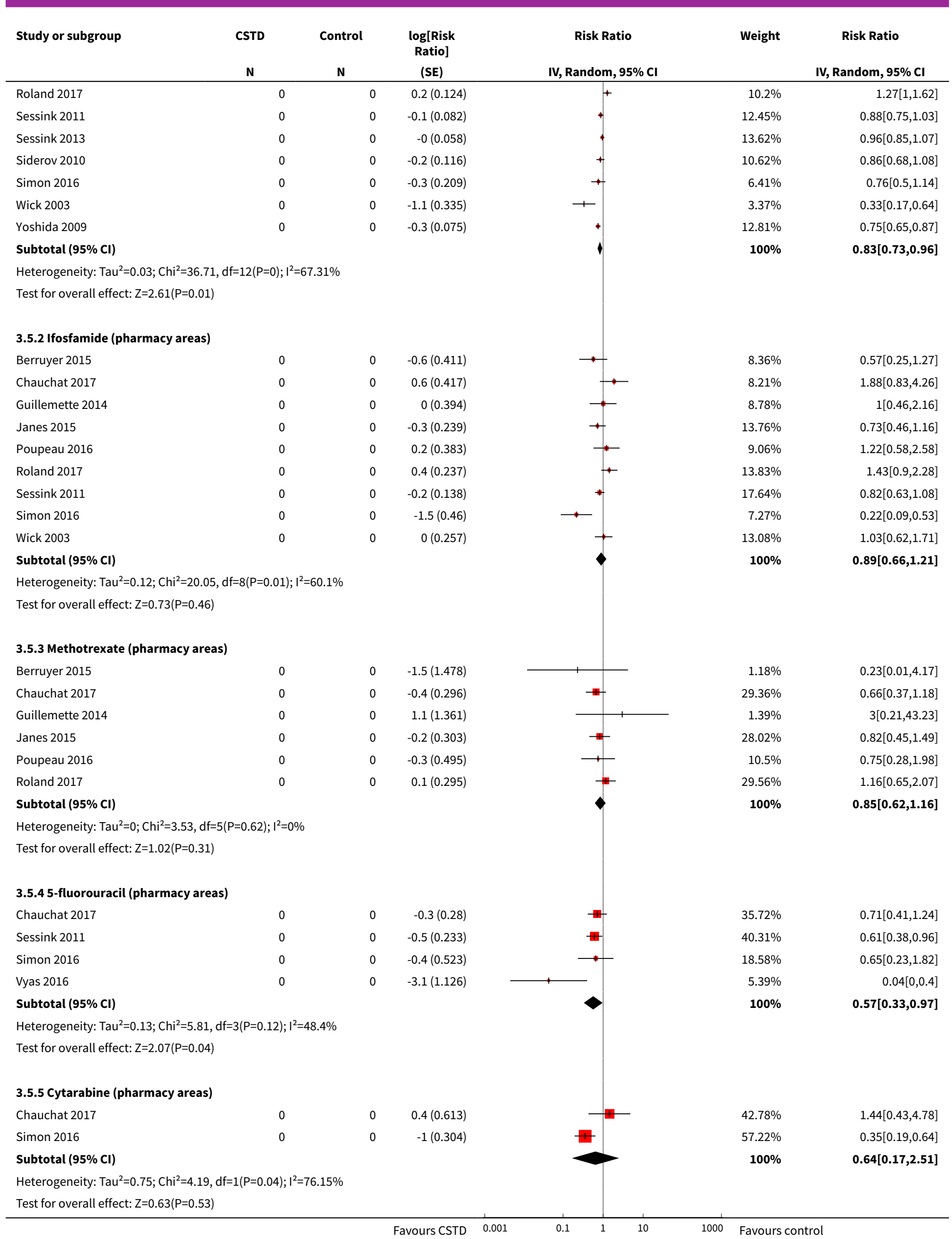

Closed-system drug-transfer devices plus safe handling of hazardous drugs versus safe handling alone for reducing exposure to 


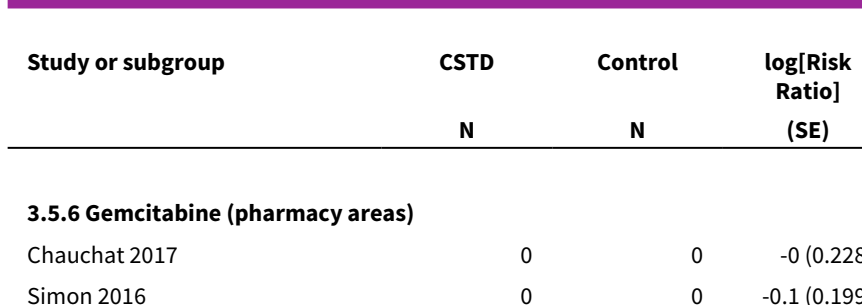

\section{Subtotal $(95 \% \mathrm{CI})$}

Heterogeneity: $\mathrm{Tau}^{2}=0 ; \mathrm{Chi}^{2}=0.15, \mathrm{df}=1(\mathrm{P}=0.69) ; \mathrm{I}^{2}=0 \%$

Test for overall effect: $Z=0.52(P=0.61)$

\subsubsection{Irinotecan (pharmacy areas)}

Chauchat 2017

Heterogeneity: Not applicable

Test for overall effect: $Z=1.83(P=0.07)$

\subsubsection{Docetaxel (pharmacy areas)}

Chauchat 2017

\section{Subtotal $(95 \% \mathrm{Cl})$}

Heterogeneity: Not applicable

Test for overall effect: Not applicable

3.5.9 Paclitaxel (pharmacy areas)

Chauchat 2017

Heterogeneity: Not applicable

Test for overall effect: $Z=0.47(P=0.64)$

3.5.10 Vinorelbine (pharmacy areas)

Chauchat 2017

\section{Subtotal $(95 \% \mathrm{CI})$}

Heterogeneity: Not applicable

Test for overall effect: $Z=0.53(P=0.59)$

3.5.11 Ganciclovir (pharmacy areas)

Simon 2016

Subtotal $(95 \% \mathrm{Cl})$

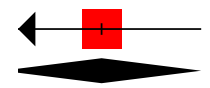

Heterogeneity: Not applicable

Test for overall effect: $Z=2.8(P=0.01)$

3.5.12 Epirubicin (pharmacy areas)

Vyas 2016

Subtotal $(95 \% \mathrm{Cl})$

Heterogeneity: $\mathrm{Tau}^{2}=0 ; \mathrm{Chi}^{2}=0, \mathrm{df}=0(\mathrm{P}<0.0001) ; \mathrm{I}^{2}=100 \%$

Test for overall effect: $\mathrm{Z}=2.26(\mathrm{P}=0.02)$

3.5.13 Multiple drugs (pharmacy areas)

Sottani 2012

0

$-0.1(0.214)$

$-3.6(1.604)$

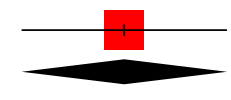

$100 \%$

$0.03[0,0.62]$

$100 \%$

$0.03[0,0.62]$

Subtotal $(95 \% \mathrm{Cl})$

Heterogeneity: Not applicable

Test for overall effect: $\mathrm{Z}=0.65(\mathrm{P}=0.51)$

3.5.14 Cyclophosphamide (patient-care areas)

$100 \%$

$1.72[0.23,12.73]$

$1.72[0.23,12.73]$
Not estimable Not estimable

$0.57[0.06,5.79]$ $\mathbf{0 . 5 7}[0.06,5.79]$

$100 \%$

$0.01[0,0.27]$

$\mathbf{0 . 0 1}[0,0.27]$
$0.88[0.6,1.3]$

$0.93[0.69,1.24]$ 


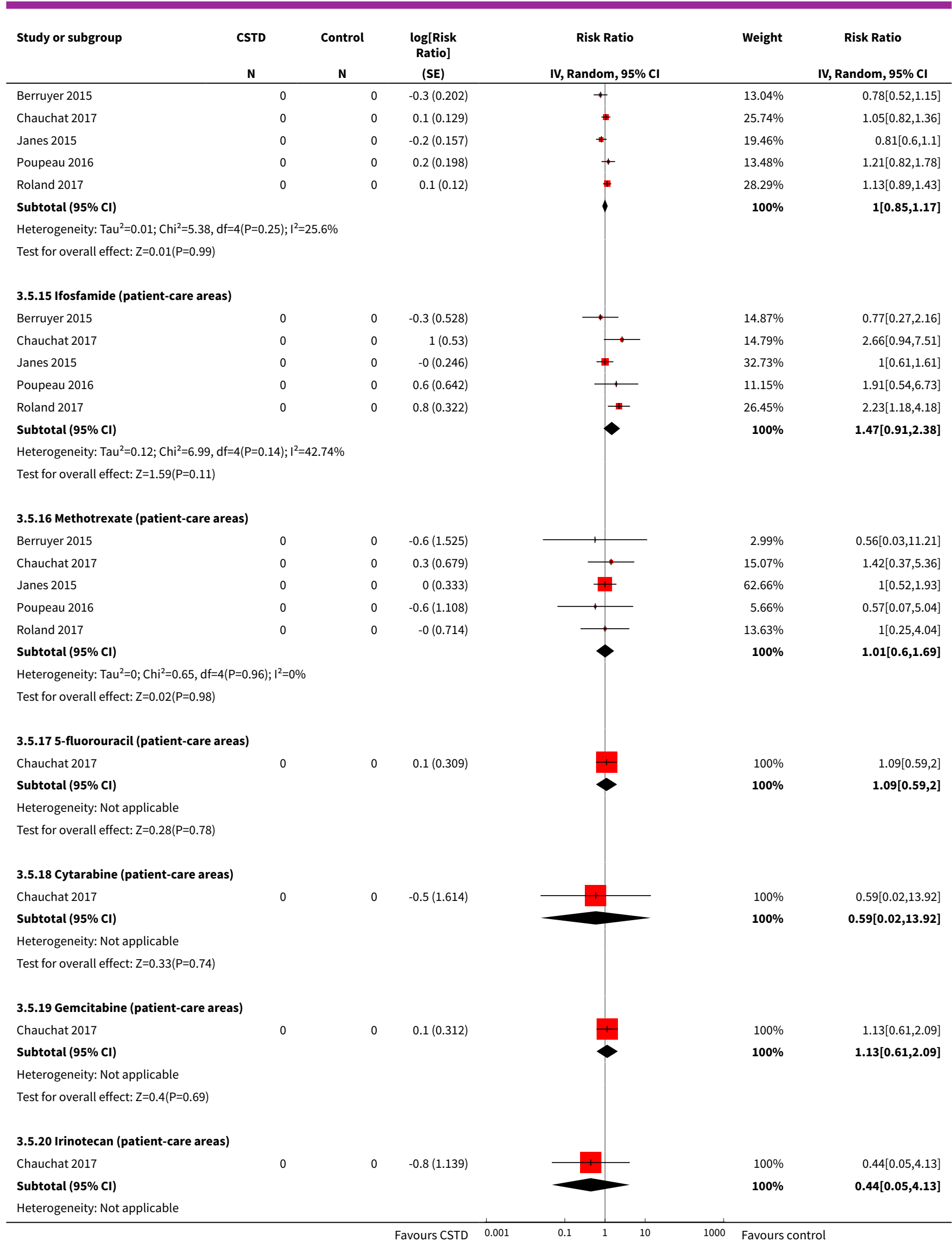

Closed-system drug-transfer devices plus safe handling of hazardous drugs versus safe handling alone for reducing exposure to 


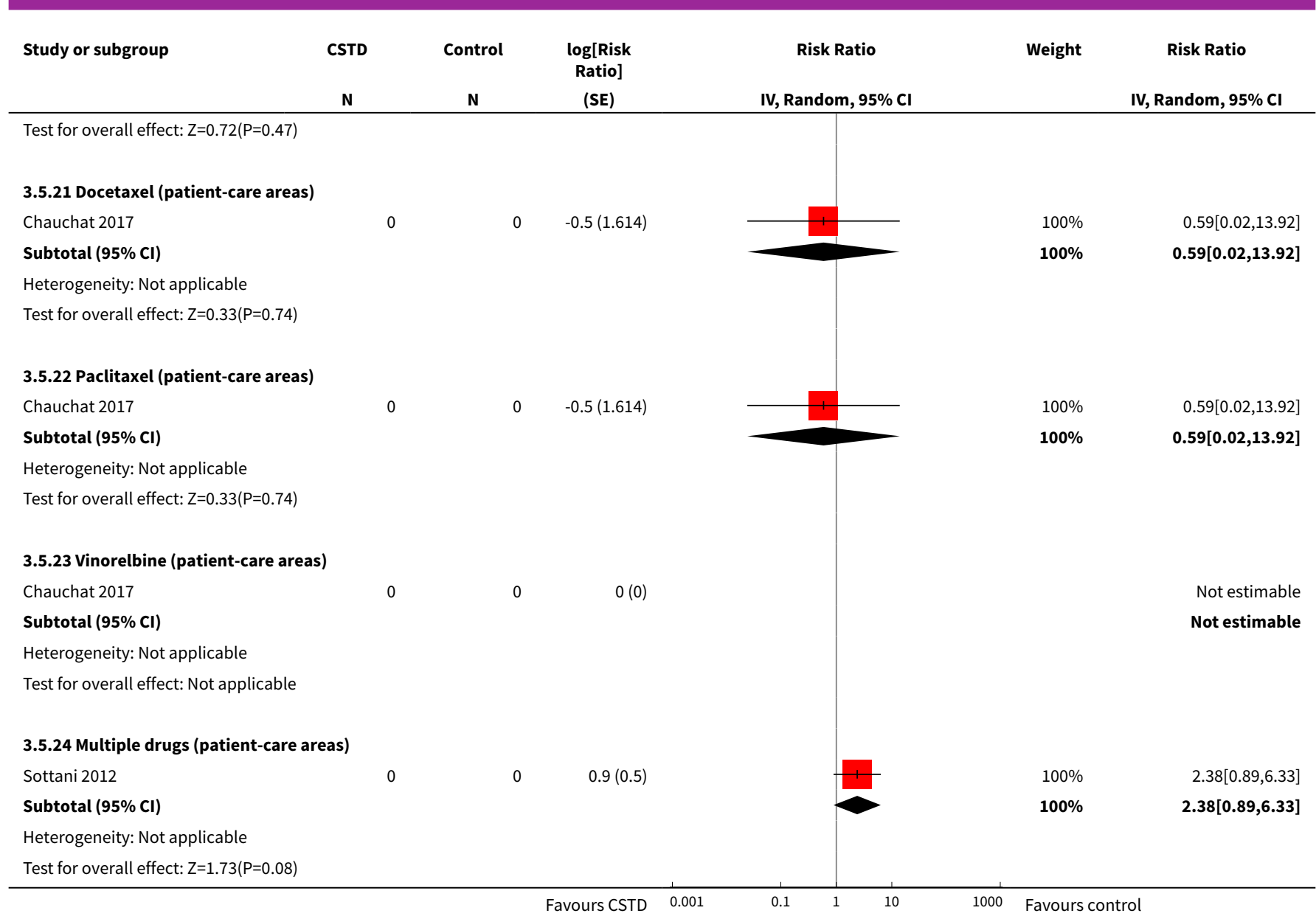

Analysis 3.6. Comparison 3 Sensitivity analysis, Outcome 6 Proportion of surfaces contaminated $($ ICC $=0.00)$.

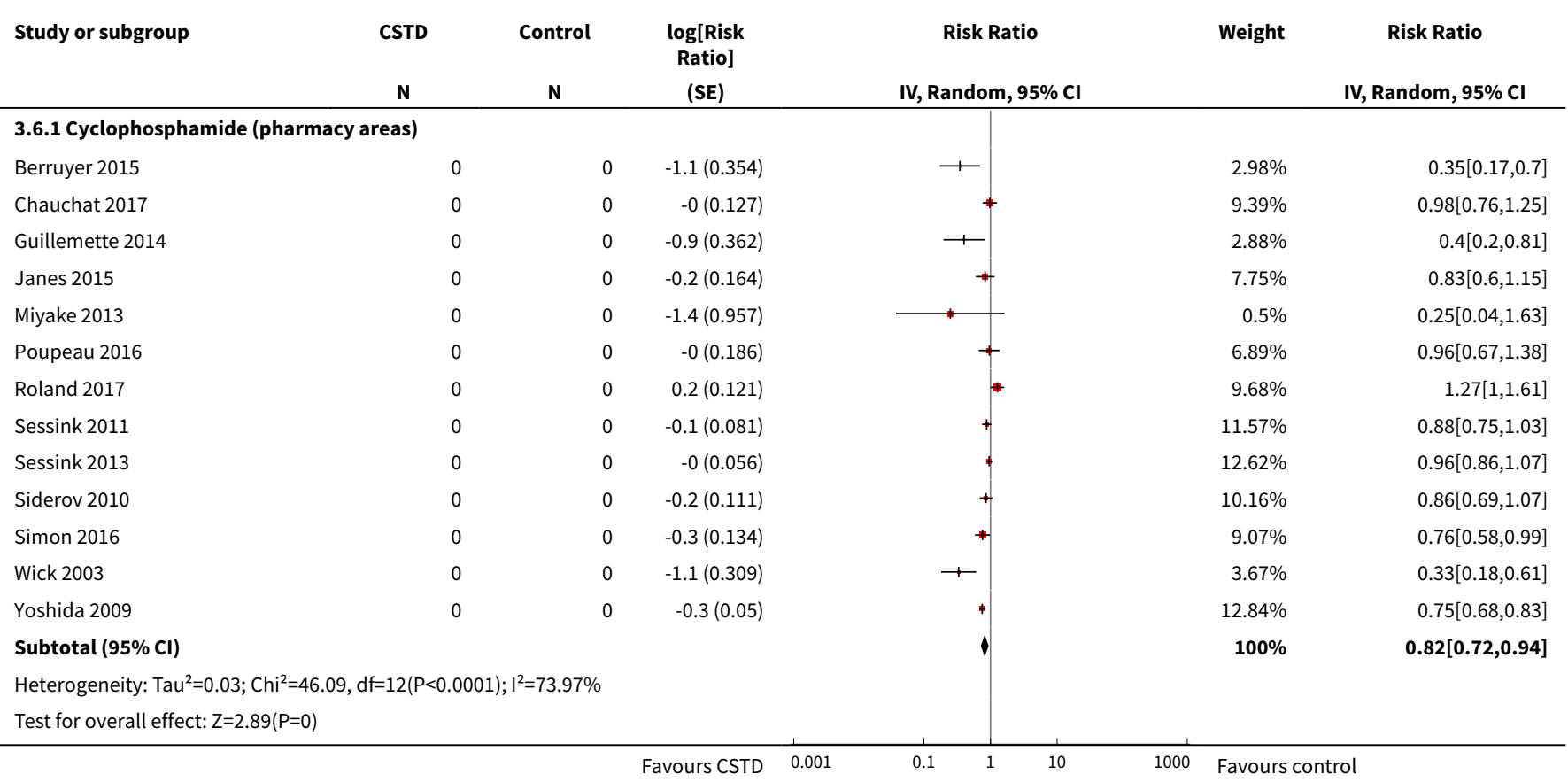

Closed-system drug-transfer devices plus safe handling of hazardous drugs versus safe handling alone for reducing exposure to 


\begin{tabular}{|c|c|c|c|}
\hline \multirow[t]{2}{*}{ Study or subgroup } & CSTD & Control & \multirow{2}{*}{$\begin{array}{c}\text { log[Risk } \\
\text { Ratio] } \\
\text { (SE) }\end{array}$} \\
\hline & $\mathbf{N}$ & $\mathbf{N}$ & \\
\hline \multicolumn{4}{|c|}{ 3.6.2 Ifosfamide (pharmacy areas) } \\
\hline Berruyer 2015 & 0 & 0 & $-0.6(0.401)$ \\
\hline Chauchat 2017 & 0 & 0 & $0.6(0.407)$ \\
\hline Guillemette 2014 & 0 & 0 & $0(0.313)$ \\
\hline Janes 2015 & 0 & 0 & $-0.3(0.233)$ \\
\hline Poupeau 2016 & 0 & 0 & $0.2(0.374)$ \\
\hline Roland 2017 & 0 & 0 & $0.4(0.231)$ \\
\hline Sessink 2011 & 0 & 0 & $-0.2(0.135)$ \\
\hline Simon 2016 & 0 & 0 & $-1.5(0.295)$ \\
\hline Wick 2003 & 0 & 0 & $0(0.236)$ \\
\hline
\end{tabular}

\section{Subtotal $(95 \% \mathrm{Cl})$}

Heterogeneity: Tau $^{2}=0.21 ; \mathrm{Chi}^{2}=33.88, \mathrm{df}=8(\mathrm{P}<0.0001) ; \mathrm{I}^{2}=76.39 \%$

Test for overall effect: $Z=0.9(P=0.37)$

\subsubsection{Methotrexate (pharmacy areas)}

Berruyer 2015

Chauchat 2017

Guillemette 2014

Janes 2015

Poupeau 2016

Roland 2017

\section{Subtotal $(95 \% \mathrm{CI})$}

Heterogeneity: $\mathrm{Tau}^{2}=0 ; \mathrm{Chi}^{2}=4.17, \mathrm{df}=5(\mathrm{P}=0.53) ; \mathrm{I}^{2}=0 \%$

Test for overall effect: $\mathrm{Z}=1(\mathrm{P}=0.32)$

\subsubsection{5-fluorouracil (pharmacy areas)}

Chauchat 2017

Sessink 2011

Simon 2016

Vyas 2016

\section{Subtotal $(95 \% \mathrm{Cl})$}

Heterogeneity: $\mathrm{Tau}^{2}=0.16 ; \mathrm{Chi}^{2}=7.45, \mathrm{df}=3(\mathrm{P}=0.06) ; \mathrm{I}^{2}=59.73 \%$

Test for overall effect: $Z=2.2(P=0.03)$

\subsubsection{Cytarabine (pharmacy areas)}

Chauchat 2017

$\begin{array}{lll}0 & 0 & 0.4(0.598) \\ 0 & 0 & -1(0.195)\end{array}$

$-3.1(0.991)$

Simon 2016

0

$-1(0.195)$

\section{Subtotal $(95 \% \mathrm{Cl})$}

Heterogeneity: $\mathrm{Tau}^{2}=0.78 ; \mathrm{Chi}^{2}=4.96, \mathrm{df}=1(\mathrm{P}=0.03) ; \mathrm{I}^{2}=79.84 \%$

Test for overall effect: $\mathrm{Z}=0.65(\mathrm{P}=0.51)$

3.6.6 Gemcitabine (pharmacy areas)

Chauchat 2017

Simon 2016

0

Risk Ratio

\section{Subtotal $(95 \% \mathrm{Cl})$}

Heterogeneity: Tau $^{2}=0 ; \mathrm{Chi}^{2}=0.21, \mathrm{df}=1(\mathrm{P}=0.64) ; \mathrm{I}^{2}=0 \%$

Test for overall effect: $Z=0.9(P=0.37)$

3.6.7 Irinotecan (pharmacy areas)

Chauchat 2017

0

$\begin{array}{rr}8.84 \% & 0.57[0.26,1.25] \\ 8.73 \% & 1.88[0.85,4.18] \\ 10.63 \% & 1[0.54,1.85] \\ 12.38 \% & 0.73[0.46,1.15] \\ 9.37 \% & 1.22[0.59,2.54] \\ 12.42 \% & 1.43[0.91,2.25] \\ 14.31 \% & 0.82[0.63,1.07] \\ 11.02 \% & 0.22[0.12,0.38] \\ 12.31 \% & 1.03[0.65,1.64] \\ \mathbf{1 0 0} \% & \mathbf{0 . 8 5}[\mathbf{0 . 5 9}, \mathbf{1 . 2 1}]\end{array}$

$1.16 \%$

$0.23[0.01,3.9]$

$0.66[0.38,1.17]$

$3[0.36,24.87]$

$0.82[0.46,1.47]$

$0.75[0.29,1.93]$

$1.16[0.66,2.04]$

$0.86[0.63,1.16]$
$0.71[0.42,1.22]$ $0.61[0.39,0.95]$ $0.65[0.34,1.26]$ $0.04[0.01,0.31]$

$0.55[0.32,0.94]$ 


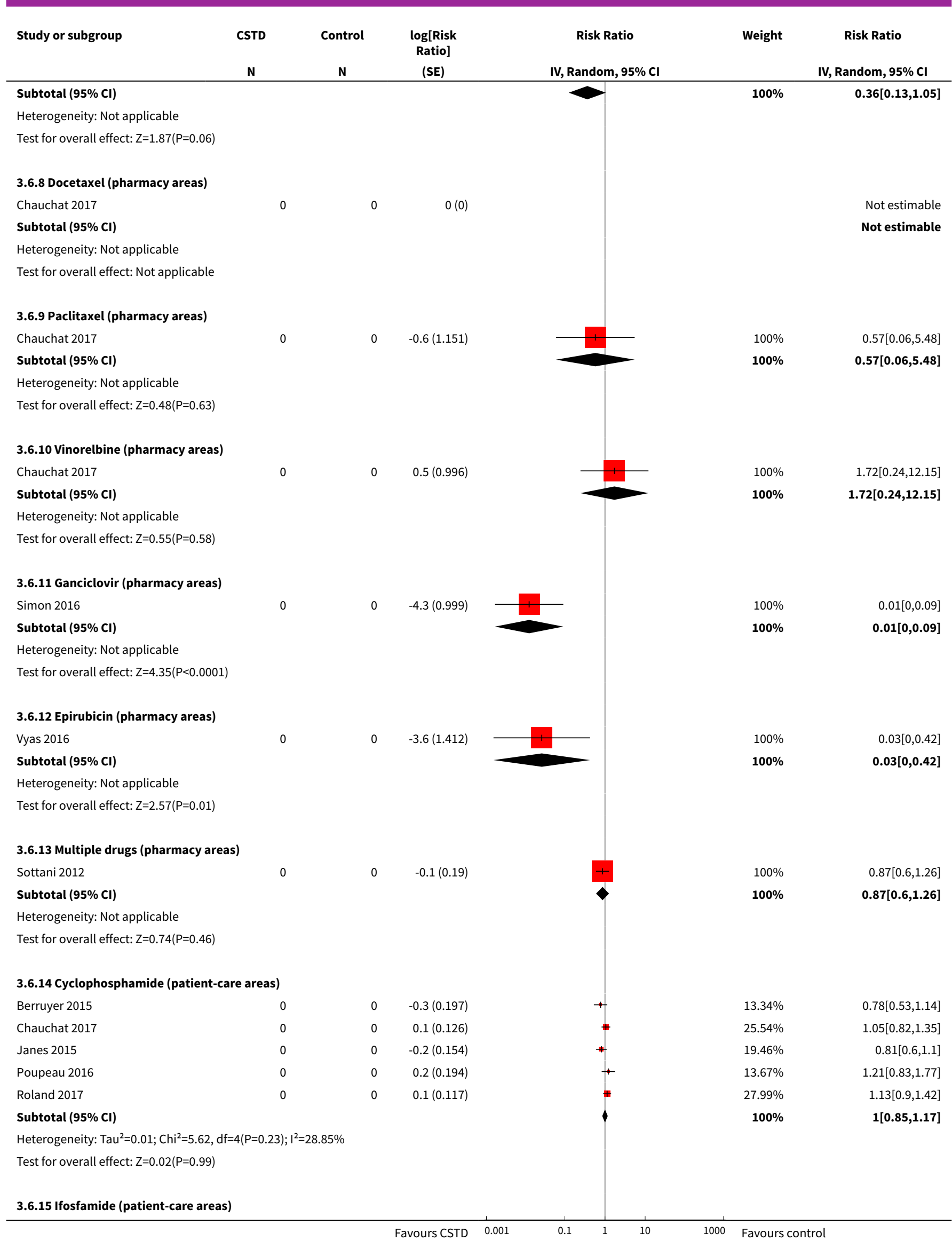

Closed-system drug-transfer devices plus safe handling of hazardous drugs versus safe handling alone for reducing exposure to 


\begin{tabular}{|c|c|c|c|}
\hline \multirow[t]{2}{*}{ Study or subgroup } & CSTD & Control & \multirow{2}{*}{$\begin{array}{c}\text { log[Risk } \\
\text { Ratio] } \\
\text { (SE) }\end{array}$} \\
\hline & $\mathbf{N}$ & $\mathbf{N}$ & \\
\hline Berruyer 2015 & 0 & 0 & $-0.3(0.516)$ \\
\hline Chauchat 2017 & 0 & 0 & $1(0.518)$ \\
\hline Janes 2015 & 0 & 0 & $-0(0.241)$ \\
\hline Poupeau 2016 & 0 & 0 & $0.6(0.628)$ \\
\hline Roland 2017 & 0 & 0 & $0.8(0.315)$ \\
\hline \multicolumn{4}{|l|}{ Subtotal $(95 \% \mathrm{Cl})$} \\
\hline \multicolumn{4}{|c|}{ Heterogeneity: $\operatorname{Tau}^{2}=0.13 ; \mathrm{Chi}^{2}=7.3, \mathrm{df}=4(\mathrm{P}=0.12) ; \mathrm{I}^{2}=45.2 \%$} \\
\hline \multicolumn{4}{|c|}{ Test for overall effect: $Z=1.6(P=0.11)$} \\
\hline \multicolumn{4}{|c|}{ 3.6.16 Methotrexate (patient-care areas) } \\
\hline Berruyer 2015 & 0 & 0 & $-0.6(1.502)$ \\
\hline Chauchat 2017 & 0 & 0 & $0.3(0.664)$ \\
\hline Janes 2015 & 0 & 0 & $0(0.326)$ \\
\hline Poupeau 2016 & 0 & 0 & $-0.6(1.085)$ \\
\hline Roland 2017 & 0 & 0 & $-0(0.698)$ \\
\hline
\end{tabular}

\section{Subtotal $(95 \% \mathrm{Cl})$}

Heterogeneity: $\mathrm{Tau}^{2}=0 ; \mathrm{Chi}^{2}=0.68, \mathrm{df}=4(\mathrm{P}=0.95) ; \mathrm{I}^{2}=0 \%$

Test for overall effect: $Z=0.02(P=0.98)$

\subsubsection{5-fluorouracil (patient-care areas)}

Chauchat 2017

Heterogeneity: Not applicable

Test for overall effect: $\mathrm{Z}=0.28(\mathrm{P}=0.78)$

\subsubsection{Cytarabine (patient-care areas)}

Chauchat 2017

Risk Ratio

Subtotal $(95 \% \mathrm{CI})$

IV, Random, $95 \% \mathrm{CI}$

IV, Random, 95\% Cl

$15.15 \%$

$0.77[0.28,2.11]$

$15.07 \%$

$2.66[0.96,7.33]$

$32.07 \%$

$1[0.62,1.6]$

$1.91[0.56,6.55]$

$2.23[1.2,4.13]$

$26.27 \%$

$1.48[0.91,2.38]$

Heterogeneity: Not applicable

Test for overall effect: $Z=0.33(P=0.75)$

3.6.19 Gemcitabine (patient-care areas)

Chauchat 2017

\section{Subtotal $(95 \% \mathrm{Cl})$}

Heterogeneity: Not applicable

Test for overall effect: $Z=0.41(P=0.68)$

3.6.20 Irinotecan (patient-care areas)

Chauchat 2017

\section{Subtotal $(95 \% \mathrm{CI})$}

Heterogeneity: Not applicable

Test for overall effect: $Z=0.73(P=0.46)$

3.6.21 Docetaxel (patient-care areas)

Chauchat 2017

$0 \quad 0 \quad-0.5(1.63)$

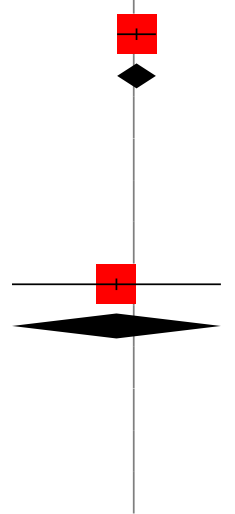

$100 \%$

$0.59[0.02,14.36]$

$100 \%$

$0.59[0.02,14.36]$

$100 \%$

\section{$0.59[0.02,14.36]$}

\section{Subtotal $(95 \% \mathrm{Cl})$}

Heterogeneity: Not applicable

Test for overall effect: $Z=0.33(P=0.75)$

3.6.22 Paclitaxel (patient-care areas)

Chauchat 2017

0

$0 \quad-0.5(1.63)$

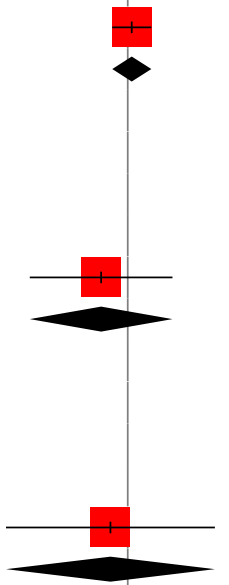

$1.13[0.62,2.06]$

$100 \%$

$1.13[0.62,2.06]$

$0.44[0.05,3.93]$

$100 \%$

$\mathbf{0 . 4 4}[0.05,3.93]$ 


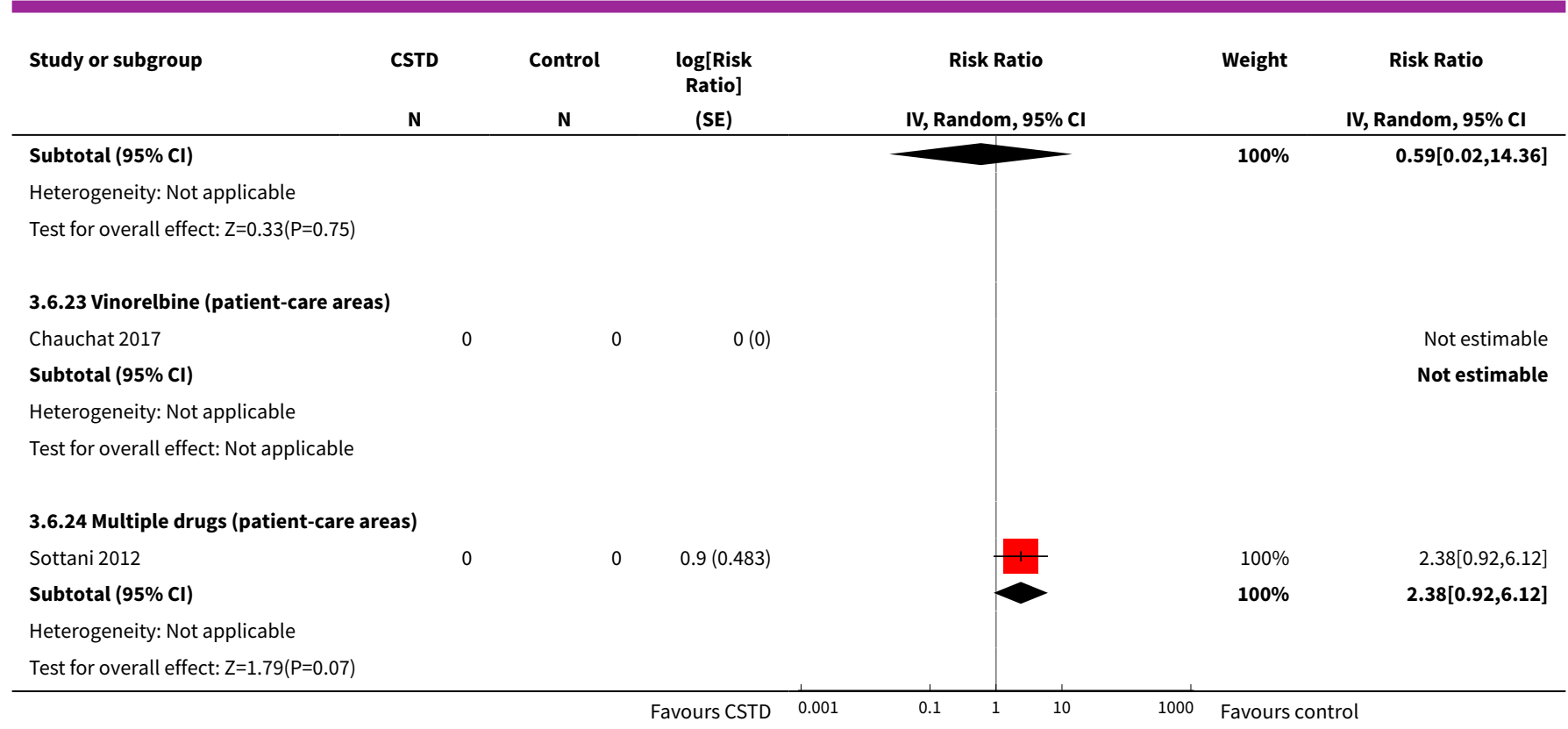

Analysis 3.7. Comparison 3 Sensitivity analysis, Outcome 7 Quantity of surface contamination $\left(\mathrm{pg} / \mathrm{cm}^{2}\right)(\mathrm{ICC}=0.05)$.

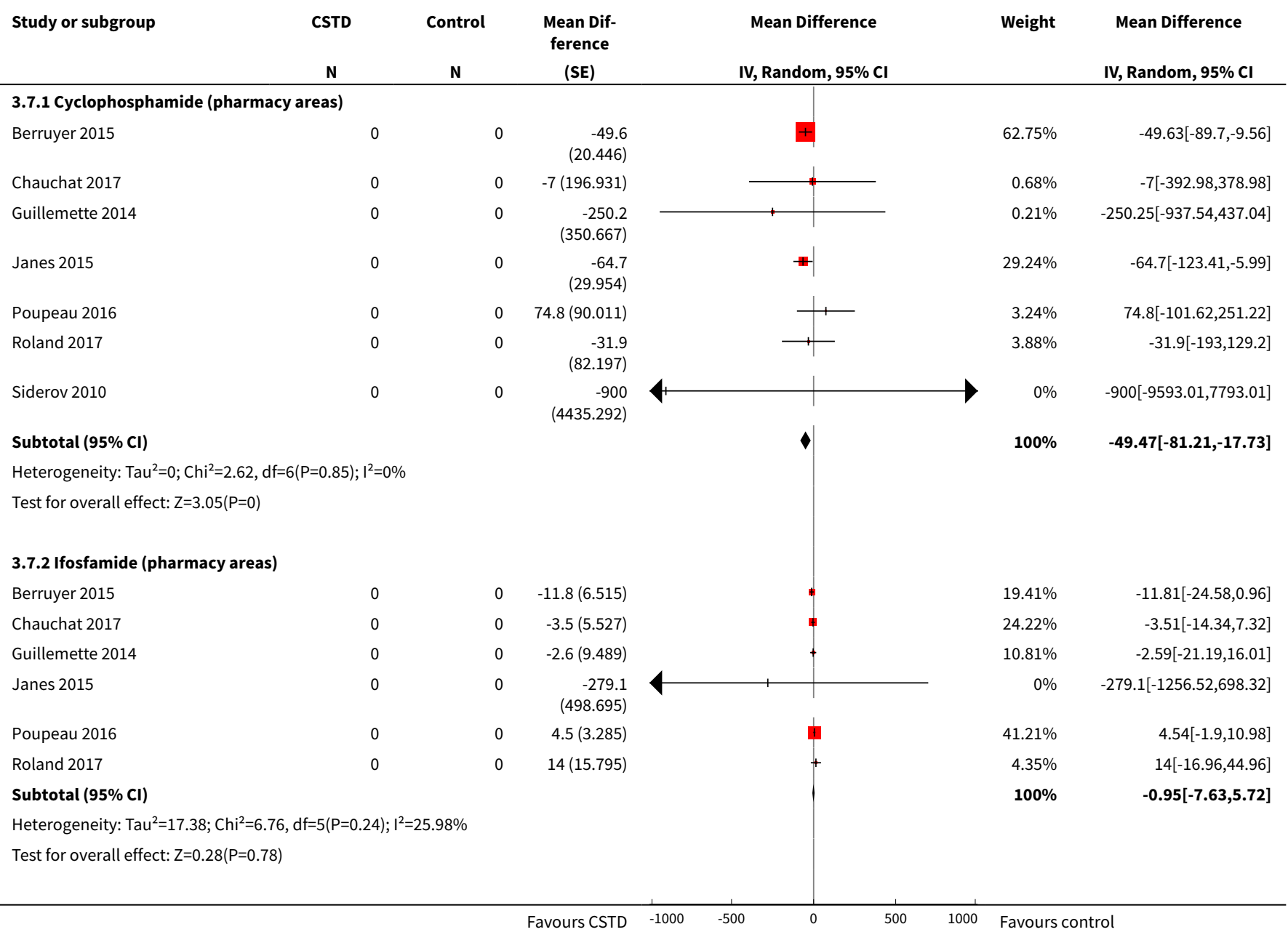

Closed-system drug-transfer devices plus safe handling of hazardous drugs versus safe handling alone for reducing exposure to 


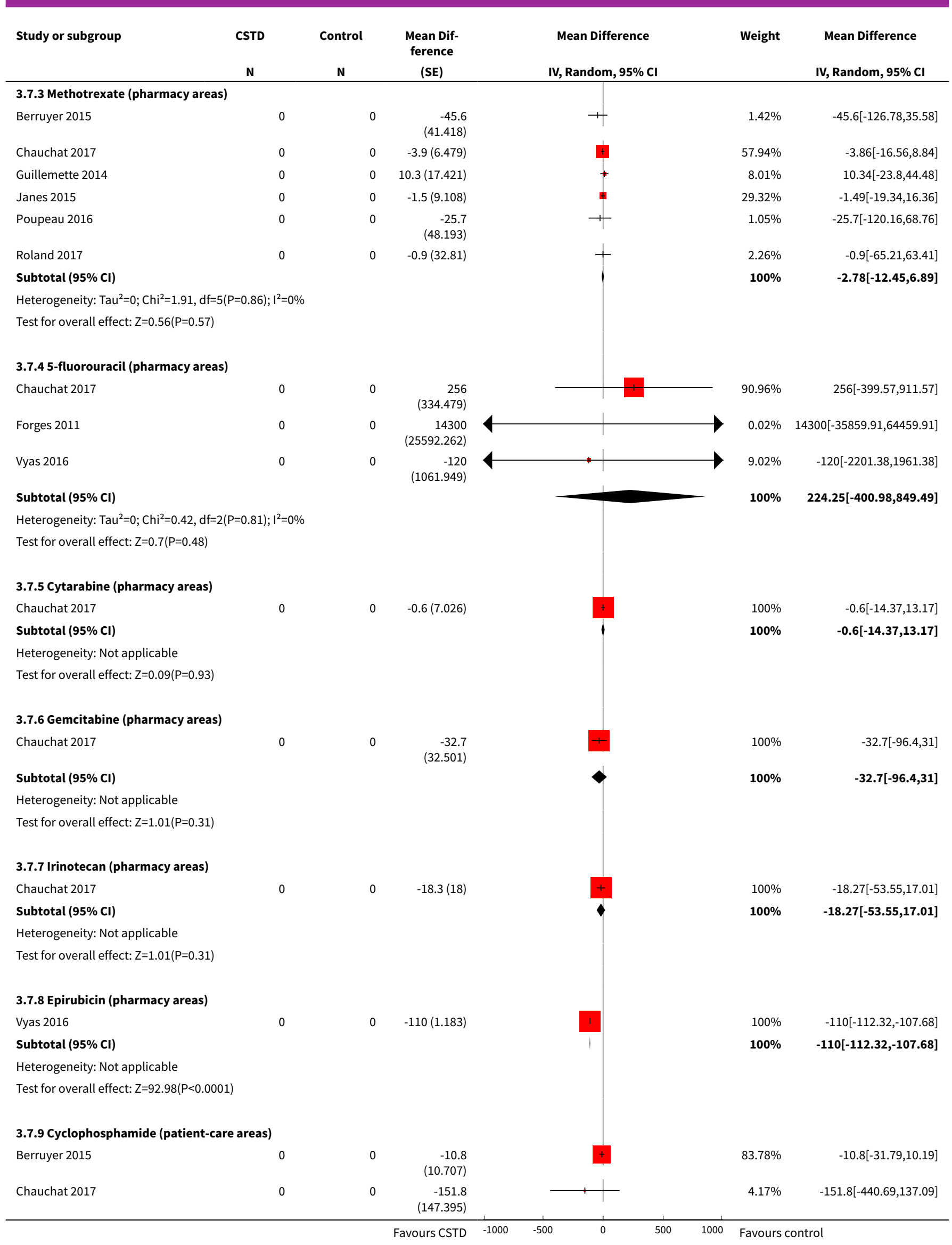

Closed-system drug-transfer devices plus safe handling of hazardous drugs versus safe handling alone for reducing exposure to 


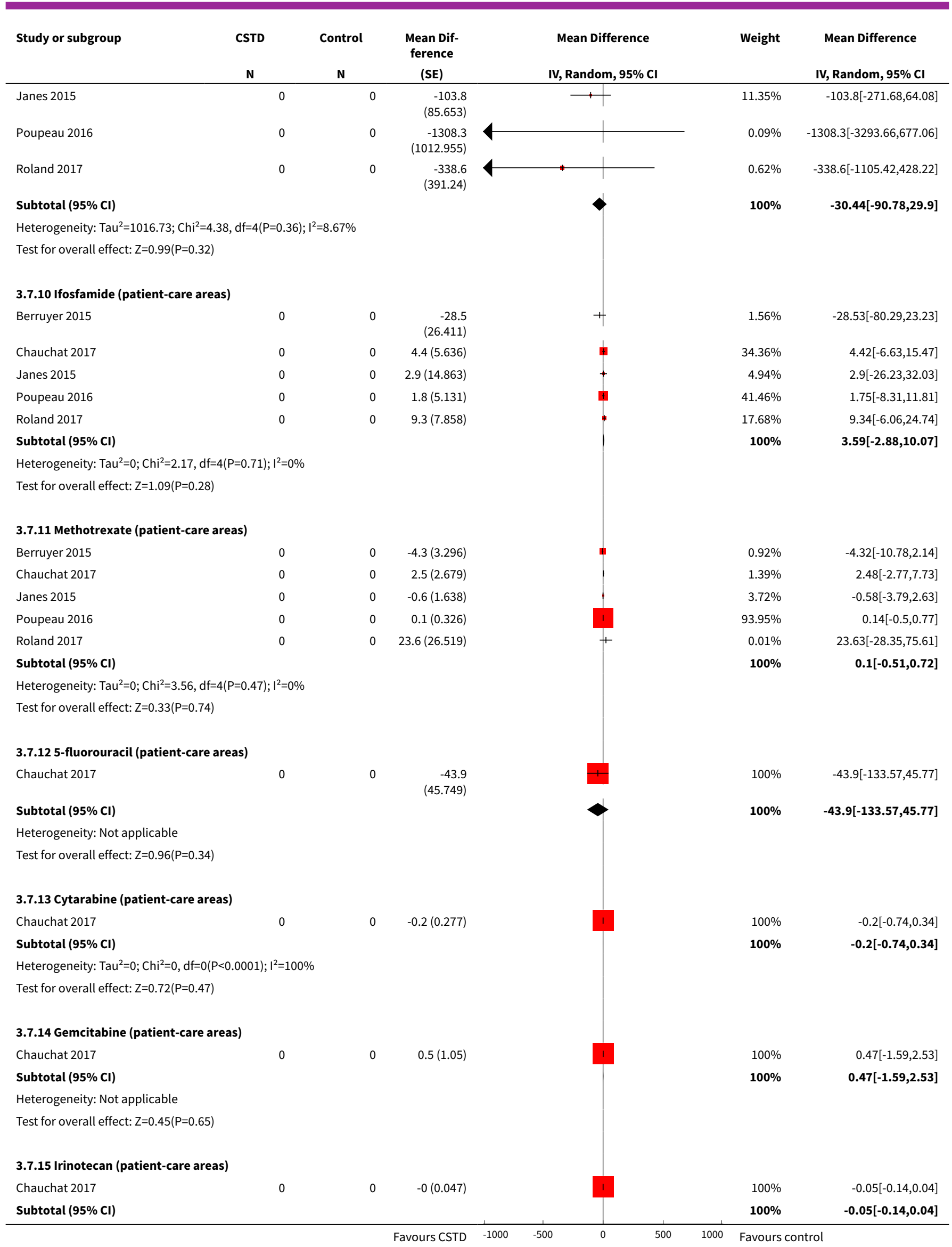

Closed-system drug-transfer devices plus safe handling of hazardous drugs versus safe handling alone for reducing exposure to 


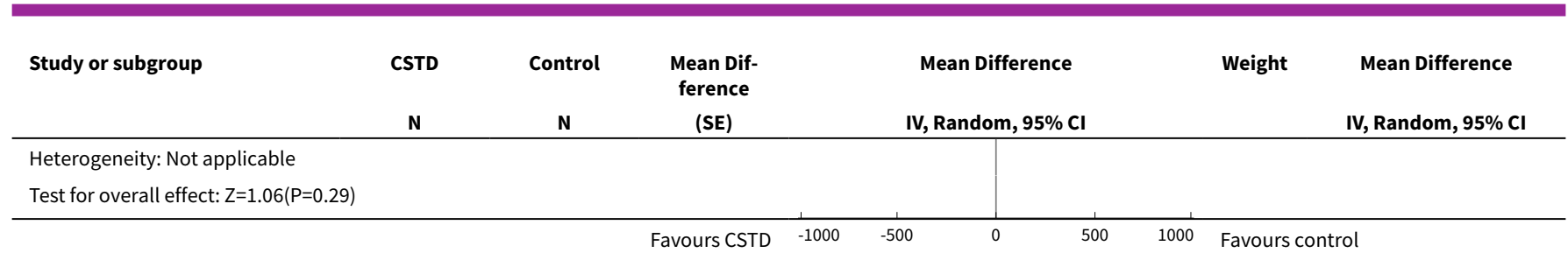

Analysis 3.8. Comparison 3 Sensitivity analysis, Outcome 8 Quantity of surface contamination $\left(\mathrm{pg} / \mathrm{cm}^{2}\right)(\mathrm{ICC}=0.01)$.

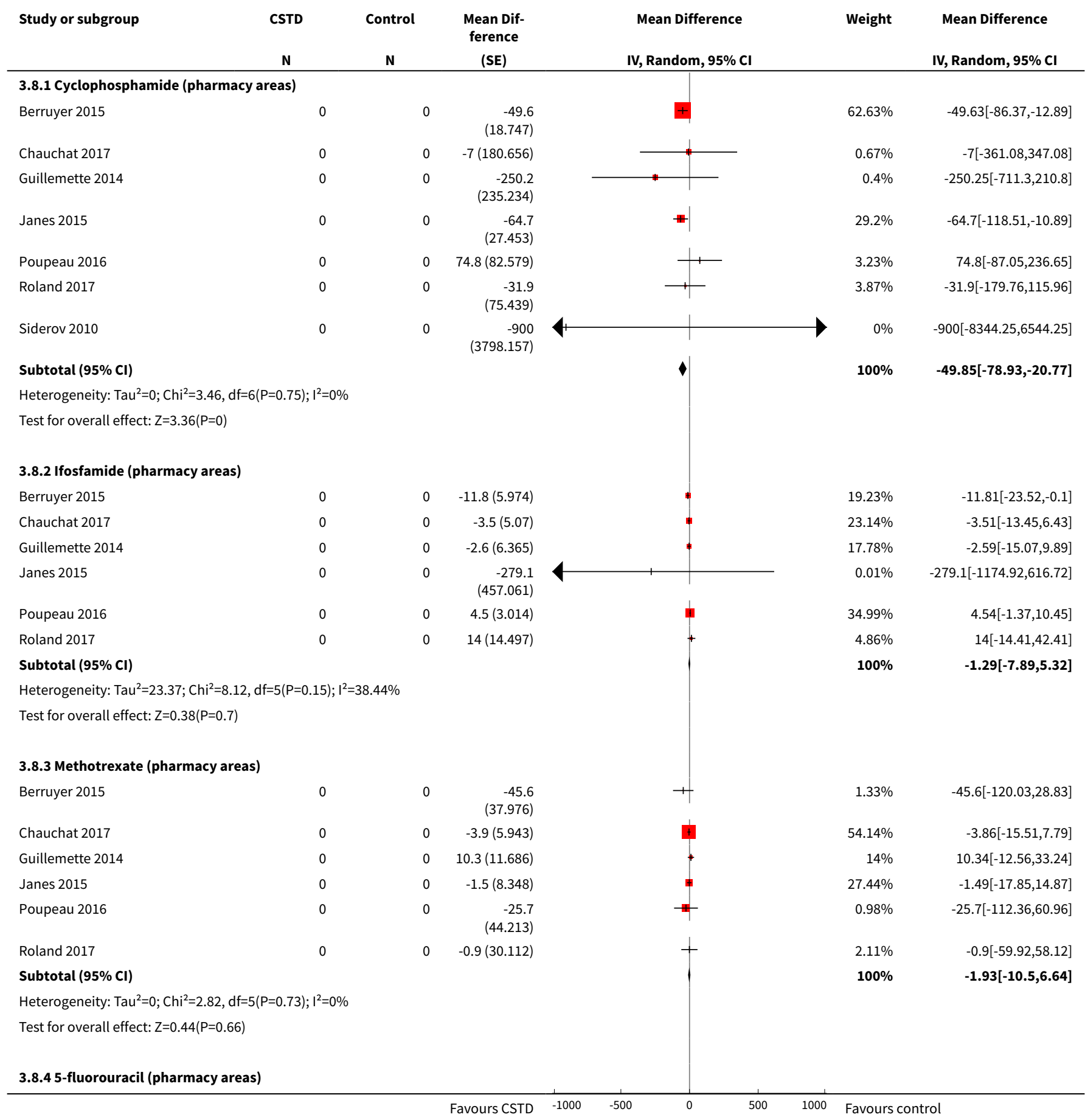

Closed-system drug-transfer devices plus safe handling of hazardous drugs versus safe handling alone for reducing exposure to 


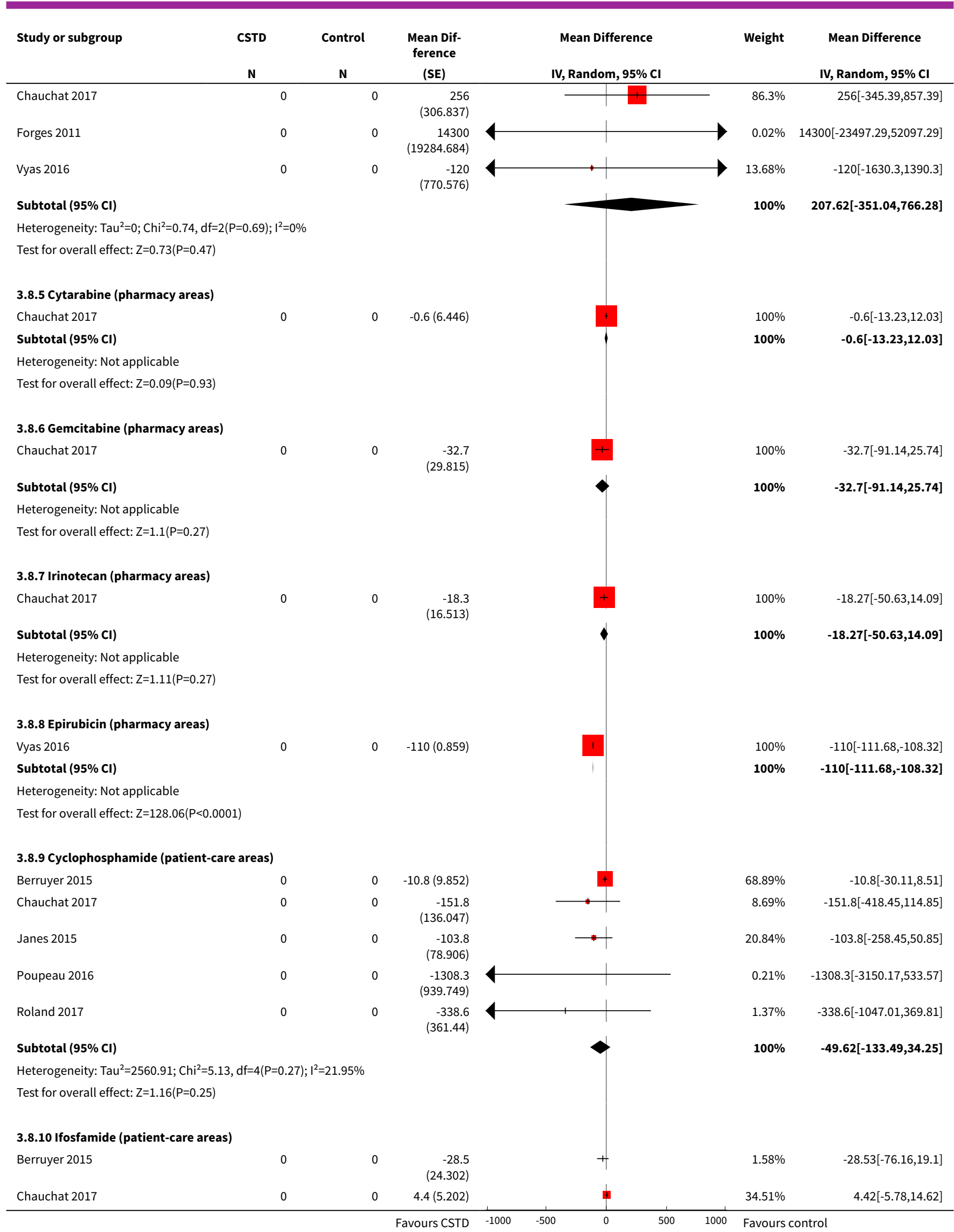

Closed-system drug-transfer devices plus safe handling of hazardous drugs versus safe handling alone for reducing exposure to 


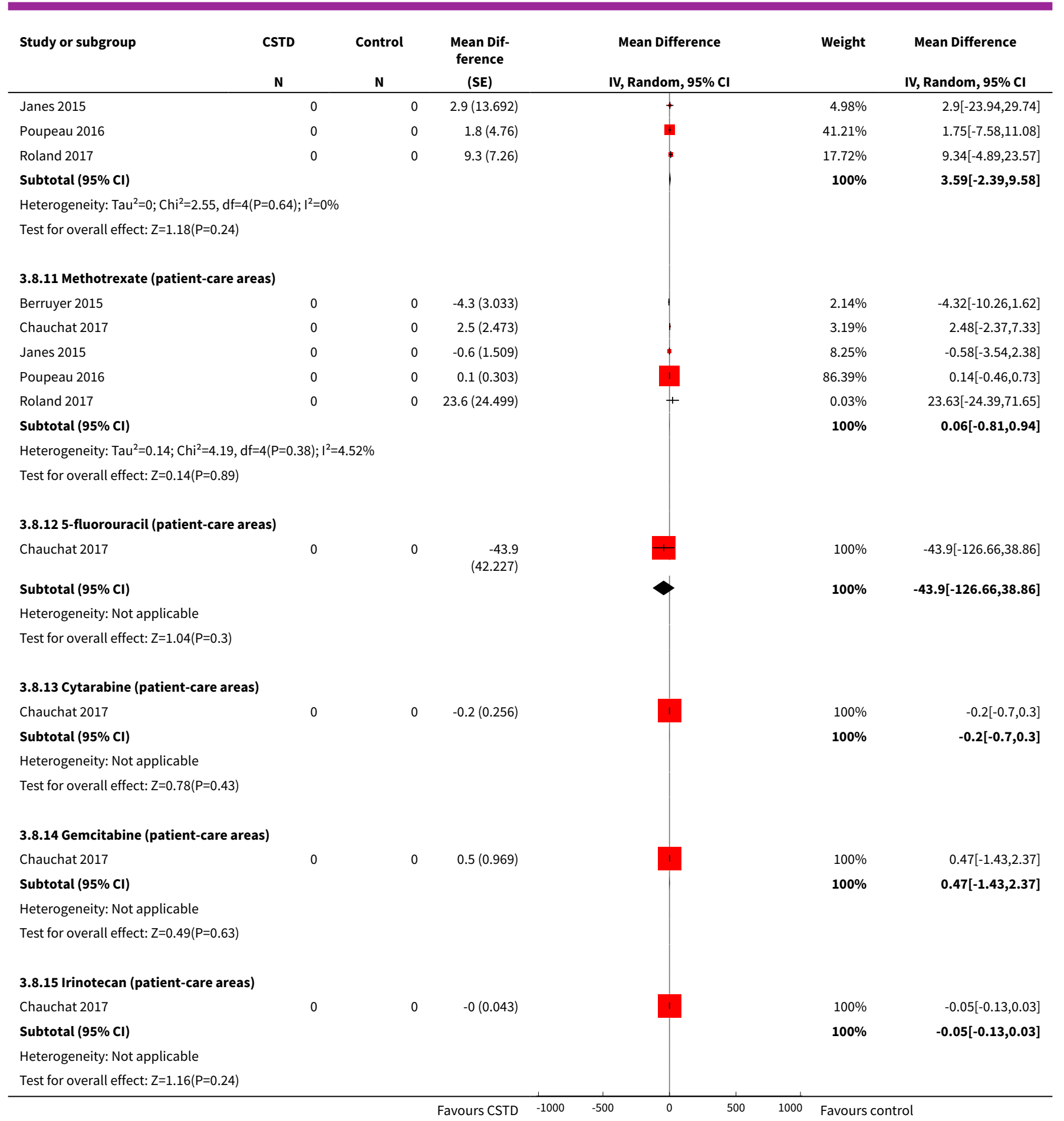

Analysis 3.9. Comparison 3 Sensitivity analysis, Outcome 9 Quantity of surface contamination $\left(\mathrm{pg} / \mathrm{cm}^{2}\right)(\mathrm{ICC}=0.00)$.

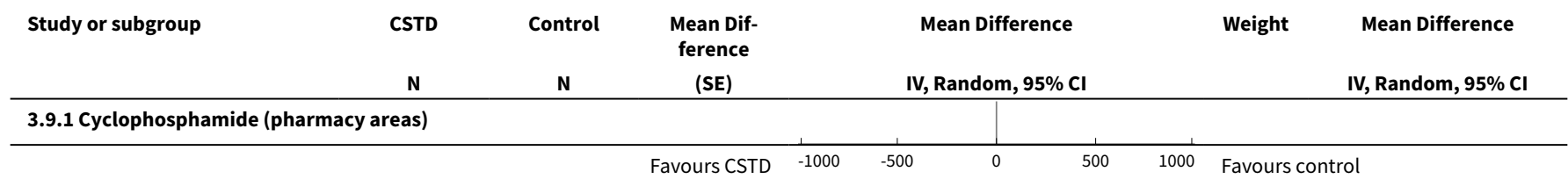




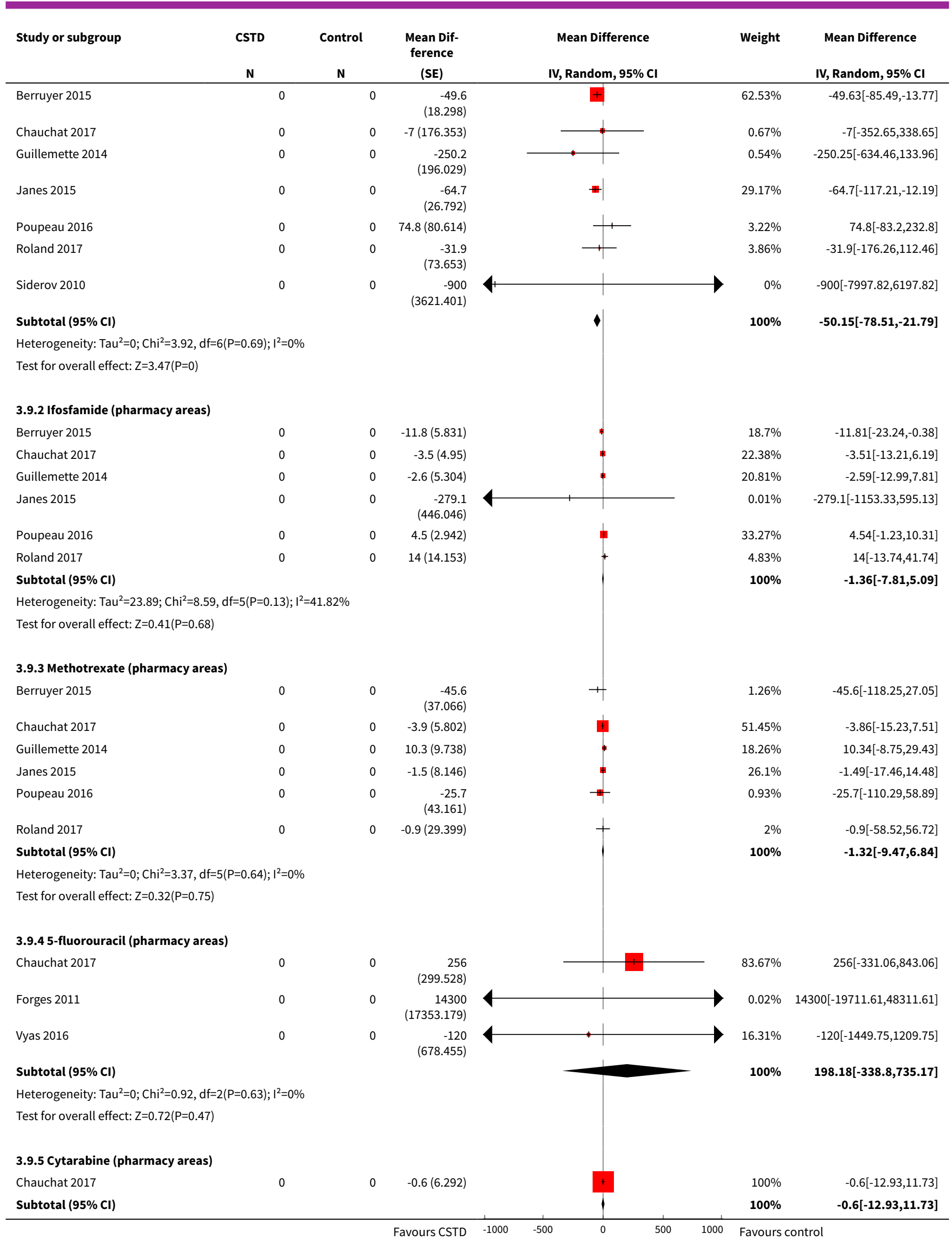

Closed-system drug-transfer devices plus safe handling of hazardous drugs versus safe handling alone for reducing exposure to 


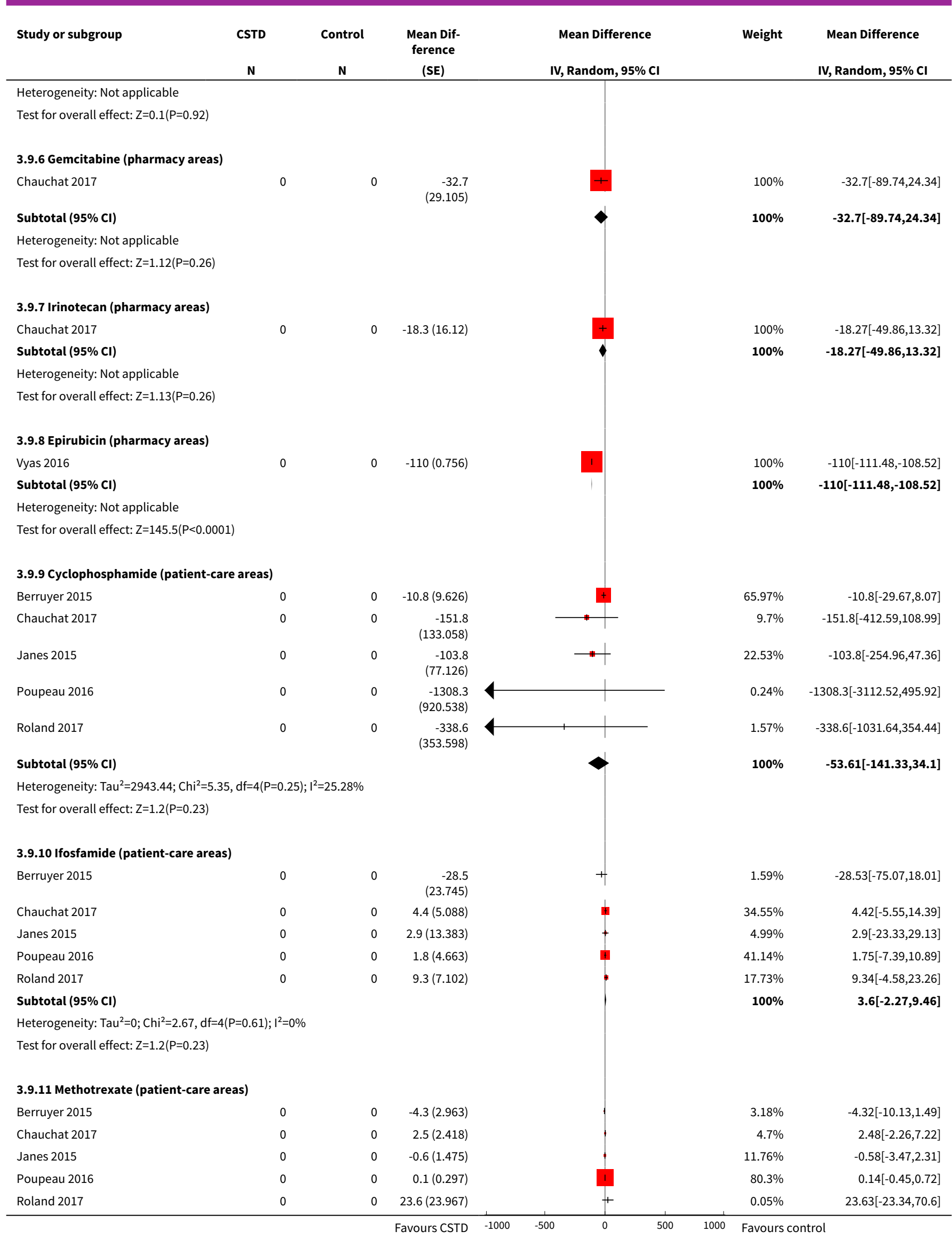

Closed-system drug-transfer devices plus safe handling of hazardous drugs versus safe handling alone for reducing exposure to 


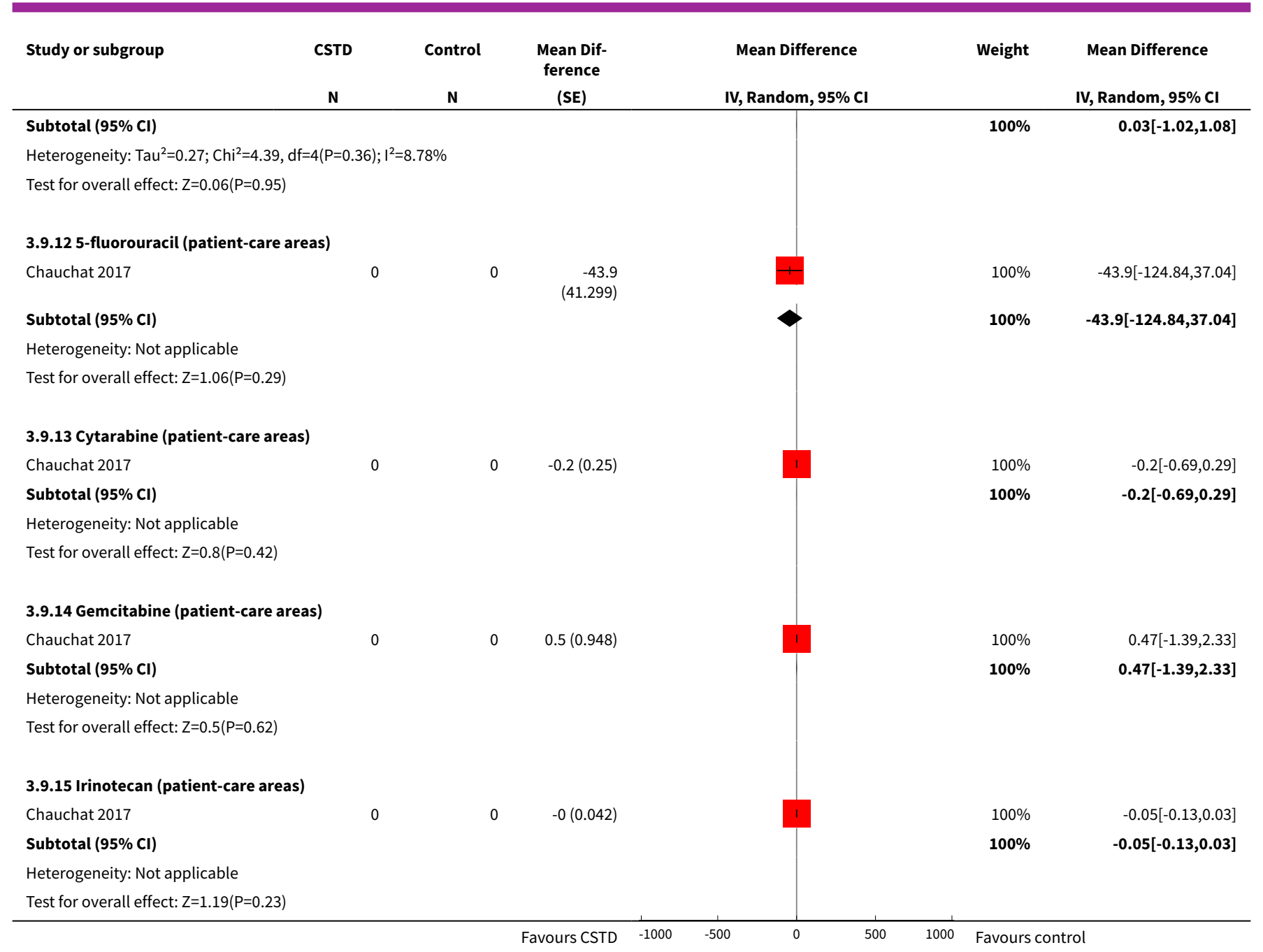

\section{ADDITIONAL TABLES}

Table 1. Potential cost savings

\begin{tabular}{|c|c|c|c|c|c|c|}
\hline $\begin{array}{l}\text { Study } \\
\text { name }\end{array}$ & Country & $\begin{array}{l}\text { Number of } \\
\text { hospitals }\end{array}$ & $\begin{array}{l}\text { Device } \\
\text { used }\end{array}$ & Method of calculation & $\begin{array}{l}\text { Cost differ- } \\
\text { ence in orig- } \\
\text { inal curren- } \\
\text { cya }\end{array}$ & $\begin{array}{l}\text { Cost differ- } \\
\text { ence in USD } \\
2017 \text { equiva- } \\
\text { lent }^{\mathrm{a}}\end{array}$ \\
\hline Chan 2016 & Malaysia & 1 & Not stated & $\begin{array}{l}\text { Actual costs of drugs and CSTD used } \\
\text { during the period }\end{array}$ & $\begin{array}{l}\text { (2015) MYR } \\
+148,632\end{array}$ & $\begin{array}{l}(2017) \text { USD } \\
+221,818\end{array}$ \\
\hline $\begin{array}{l}\text { Edwards } \\
2013\end{array}$ & USA & 1 & Phaseal & $\begin{array}{l}\text { Actual costs for CSTD, actual costs for } \\
\text { drug use in CSTD group and hypothet- } \\
\text { ical calculation of drugs necessary if } \\
\text { CSTD was not used }\end{array}$ & $\begin{array}{l}\text { (2012) USD } \\
-596,491\end{array}$ & $\begin{array}{l}(2017) \text { USD } \\
-642,656\end{array}$ \\
\hline $\begin{array}{l}\text { Juhasz } \\
2016\end{array}$ & Hungary & 2 & Tevadaptor & $\begin{array}{l}\text { Simulation costs based on potential } \\
\text { drug left behind in the vial; costs of } \\
\text { CSTD were not included }\end{array}$ & $\begin{array}{l}\text { (2014) EUR } \\
-70,913\end{array}$ & $\begin{array}{l}(2017) \text { USD } \\
-61,202\end{array}$ \\
\hline
\end{tabular}


Table 1. Potential cost savings (Continued)

\begin{tabular}{|c|c|c|c|c|c|c|}
\hline Mullot 2008 & France & 1 & $\begin{array}{l}\text { Phaseal/ } \\
\text { Tevadaptor }\end{array}$ & $\begin{array}{l}\text { Actual costs of drugs and CSTD used } \\
\text { during the period }\end{array}$ & $\begin{array}{l}(2006) \text { EUR } \\
+160,680\end{array}$ & $\begin{array}{l}\text { (2017) USD } \\
+155,144\end{array}$ \\
\hline $\begin{array}{l}\text { Ozyaman } \\
2016\end{array}$ & Turkey & 1 & Phaseal & $\begin{array}{l}\text { Simulation costs based on potential } \\
\text { drug left behind in the vial; costs of } \\
\text { CSTD were not included }\end{array}$ & $\begin{array}{l}(2014) \text { EUR } \\
-22,064\end{array}$ & $\begin{array}{l}\text { (2017) USD } \\
-23,370\end{array}$ \\
\hline
\end{tabular}

CSTD: closed-system transfer device.

aNegative sign indicates cost savings and positive sign indicates increased costs due to the use of CSTD.

\section{AP P E N D I CES}

\section{Appendix 1. MEDLINE search strategy}

1. (closed-system transfer device* or closed system transfer device* or CSTD or closed-system drug transfer device* or closed system drug transfer device ${ }^{\star}$ or closed-system drug-transfer device* or closed system drug-transfer device* or CSDTD).tw.

2. (Phaseal or Spikes or Equashield or Texium or SmartSite or Alaris or VialShield or LifeShield or ChemoClave or Tevadaptor or OnGuard or HDClean).tw.

3. (effect ${ }^{\star}$ or control or controls* or controla* or controle* or controli* or controll* or evaluation* or program $\left.{ }^{\star}\right)$.tw.

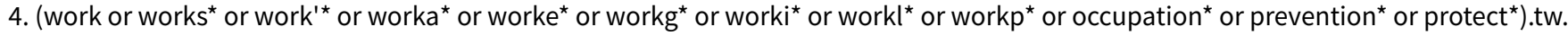

5. 2 and 3 and 4

6.1 or 5

\section{Appendix 2. Cochrane search strategy}

\#1 (closed-system transfer device* or closed system transfer device* or CSTD or closed-system drug transfer device* or closed system drug transfer device* or closed-system drug-transfer device ${ }^{\star}$ or closed system drug-transfer device* or CSDTD)

\#2 (Phaseal or Spikes or Equashield or Texium or SmartSite or Alaris or VialShield or LifeShield or ChemoClave or Tevadaptor or OnGuard or HDClean)

\#3 (effect* ${ }^{\star}$ or control or controls ${ }^{\star}$ or controla* or controle* or controli $^{\star}$ or controll* or evaluation ${ }^{\star}$ or program $^{\star}$ )



$\# 5 \# 2$ and \#3 and \#4

\#6 \#1 or \#5

\section{Appendix 3. Embase search strategy}

1. (closed-system transfer device* or closed system transfer device* or CSTD or closed-system drug transfer device* or closed system drug transfer device* or closed-system drug-transfer device* or closed system drug-transfer device* or CSDTD).tw.

2. (Phaseal or Spikes or Equashield or Texium or SmartSite or Alaris or VialShield or LifeShield or ChemoClave or Tevadaptor or OnGuard or HDClean).tw.

3. (effect ${ }^{\star}$ or control or controls ${ }^{\star}$ or controla* or controle $^{\star}$ or controli ${ }^{\star}$ or controll ${ }^{\star}$ or evaluation* or program $^{\star}$ ).tw.

4. (work or works ${ }^{\star}$ or work ${ }^{\prime \star}$ or worka ${ }^{\star}$ or worke ${ }^{\star}$ or workg* or worki $^{\star}$ or workl ${ }^{\star}$ or workp ${ }^{\star}$ or occupation ${ }^{\star}$ or prevention ${ }^{\star}$ or protect $\left.^{\star}\right)$.tw.

5.2 and 3 and 4

6.1 or 5

Closed-system drug-transfer devices plus safe handling of hazardous drugs versus safe handling alone for reducing exposure to 


\section{Appendix 4. OSH-UPDATE search strategy}

All Fields: closed-system transfer device ${ }^{\star}$ OR closed system transfer device* OR CSTD OR closed-system drug transfer device* OR closed system drug transfer device* OR closed-system drug-transfer device* OR closed system drug-transfer device* OR CSDTD

\section{Appendix 5. CINAHL search strategy}

S1 (closed-system transfer device* or closed system transfer device* or CSTD or closed-system drug transfer device* or closed system drug transfer device* or closed-system drug-transfer device* or closed system drug-transfer device* or CSDTD)

S2 (Phaseal or Spikes or Equashield or Texium or SmartSite or Alaris or VialShield or LifeShield or ChemoClave or Tevadaptor or OnGuard or HDClean)

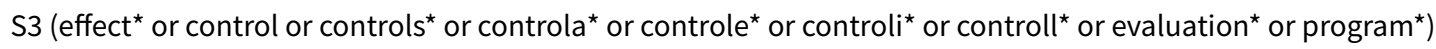

S4 (work or works ${ }^{\star}$ or work'* or worka* or worke* or workg* or worki* or workl* or workp* or occupation* or prevention* or protect*)

S5 S2 and S3 and S4

$\mathrm{S} 6 \mathrm{~S} 1$ or S5

\section{Appendix 6. Science Citation Index (including Conference Proceedings) search strategy}

\#1 TS=(closed-system transfer device* or closed system transfer device* or CSTD or closed-system drug transfer device ${ }^{\star}$ or closed system drug transfer device* or closed-system drug-transfer device* or closed system drug-transfer device ${ }^{\star}$ or CSDTD)

\#2 TS=(Phaseal or Spikes or Equashield or Texium or SmartSite or Alaris or VialShield or LifeShield or ChemoClave or Tevadaptor or OnGuard or HDClean)

\#3 TS=(effect ${ }^{\star}$ or control or controls* or controla* or controle* or controli* or controll ${ }^{\star}$ or evaluation ${ }^{\star}$ or program ${ }^{\star}$ )

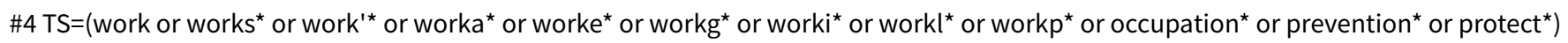

\#5 \#2 AND \#3 AND \#4

\#6 \#1 OR \#5

\section{Appendix 7. NHS Economic Evaluation Database (NHS EED) search strategy and Cost-Effectiveness Analysis Registry (CEA) at Tufts University search strategy}

1. closed-system transfer device

2. closed system transfer device

3. CSTD

4. closed-system drug transfer device

5. closed system drug transfer device

6. closed-system drug-transfer device

7. closed system drug-transfer device

8. CSDTD

9. Phaseal

10. Spikes

11. Equashield

12. Texium

13. SmartSite

14. Alaris

15. VialShield

Closed-system drug-transfer devices plus safe handling of hazardous drugs versus safe handling alone for reducing exposure to 
16. LifeShield

17. ChemoClave

18. Tevadaptor

19. OnGuard

20. HDClean

Appendix 8. ClinicalTrials.gov and World Health Organization (WHO) trials portal search strategy

(Intervention)

1. closed-system

2. CSTD

3. CSDTD

4. Phaseal

5. Spikes

6. Equashield

7. Texium

8. SmartSite

9. Alaris

10. VialShield

11. LifeShield

12. ChemoClave

13. Tevadaptor

14. OnGuard

15. HDClean 


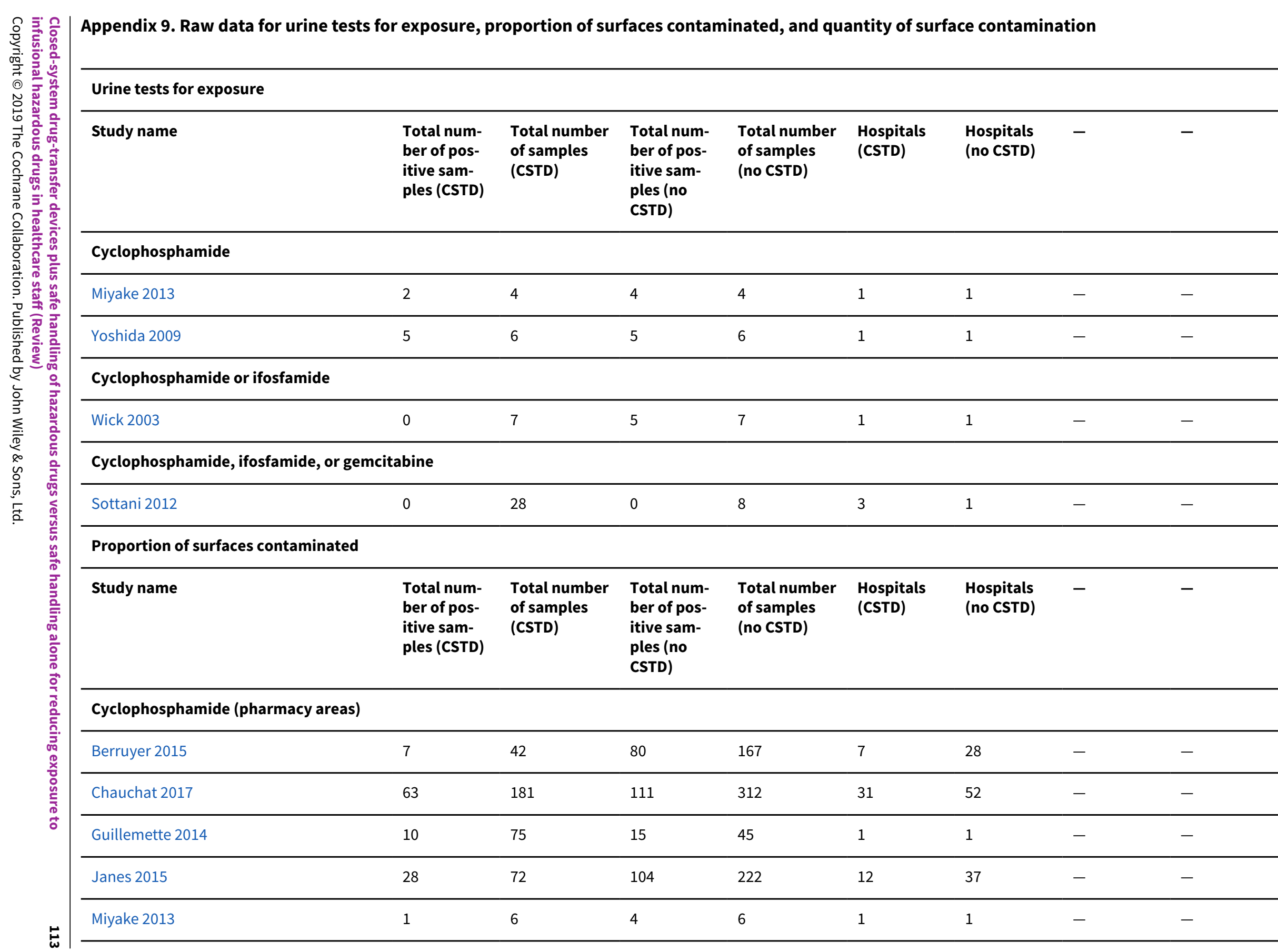




\begin{tabular}{|c|c|c|c|c|c|c|c|c|c|}
\hline 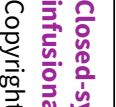 & $\begin{array}{l}\text { (Continued) } \\
\text { Poupeau } 2016\end{array}$ & 25 & 71 & 74 & 202 & 12 & 34 & - & - \\
\hline กับ & Roland 2017 & 64 & 134 & 96 & 256 & 23 & 43 & - & - \\
\hline 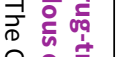 & Sessink 2011 & 78 & 114 & 89 & 114 & 22 & 22 & - & - \\
\hline 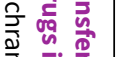 & Sessink 2013 & 114 & 143 & 119 & 143 & 30 & 30 & - & - \\
\hline 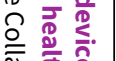 & Siderov 2010 & 18 & 22 & 21 & 22 & 2 & 2 & - & - \\
\hline 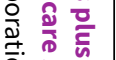 & Simon 2016 & 55 & 143 & 73 & 144 & 1 & 1 & - & - \\
\hline 象尊 & Wick 2003 & 7 & 21 & 17 & 17 & 1 & 1 & - & - \\
\hline 贻 & Yoshida 2009 & 102 & 136 & 127 & 127 & 1 & 1 & - & - \\
\hline $\overrightarrow{\frac{\sigma}{2}}$ & Ifosfamide (pharmacy areas) & & & & & & & & \\
\hline 흥 & Berruyer 2015 & 6 & 42 & 42 & 167 & 7 & 28 & - & - \\
\hline 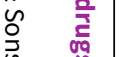 & Chauchat 2017 & 12 & 181 & 11 & 312 & 31 & 52 & - & - \\
\hline 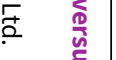 & Guillemette 2014 & 20 & 75 & 12 & 45 & 1 & 1 & - & - \\
\hline$\stackrel{\mathscr{\omega}}{\vec{D}}$ & Janes 2015 & 17 & 72 & 72 & 222 & 12 & 37 & - & - \\
\hline 를 & Poupeau 2016 & 9 & 71 & 21 & 202 & 12 & 34 & - & - \\
\hline 苞 & Roland 2017 & 27 & 134 & 36 & 256 & 23 & 43 & - & - \\
\hline$\stackrel{\overrightarrow{0}}{7}$ & Sessink 2011 & 51 & 114 & 62 & 114 & 22 & 22 & - & - \\
\hline 突. & Simon 2016 & 12 & 143 & 56 & 144 & 1 & 1 & - & - \\
\hline 总 & Wick 2003 & 14 & 21 & 11 & 17 & 1 & 1 & - & - \\
\hline 夏 & Methotrexate (pharmacy areas) & & & & & & & & \\
\hline & Berruyer 2015 & 0 & 42 & 8 & 167 & 7 & 28 & - & - \\
\hline & Chauchat 2017 & 15 & 181 & 39 & 312 & 31 & 52 & - & - \\
\hline
\end{tabular}




\begin{tabular}{|c|c|c|c|c|c|c|c|c|c|}
\hline 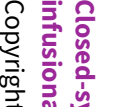 & $\begin{array}{l}\text { (Continued) } \\
\text { Guillemette } 2014\end{array}$ & 5 & 75 & 1 & 45 & 1 & 1 & - & - \\
\hline 䍃管 & Janes 2015 & 12 & 72 & 45 & 222 & 12 & 37 & - & - \\
\hline 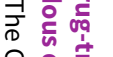 & Poupeau 2016 & 5 & 71 & 19 & 202 & 12 & 34 & - & - \\
\hline 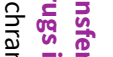 & Roland 2017 & 17 & 134 & 28 & 256 & 23 & 43 & - & - \\
\hline $\begin{array}{ll}0 \\
0 \\
0\end{array}$ & 5-fluorouracil (pharmacy areas) & & & & & & & & \\
\hline 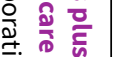 & Chauchat 2017 & 17 & 181 & 41 & 312 & 31 & 52 & - & - \\
\hline 党总 & Sessink 2011 & 23 & 114 & 38 & 114 & 22 & 22 & - & - \\
\hline 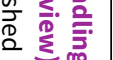 & Simon 2016 & 13 & 143 & 20 & 144 & 1 & 1 & - & - \\
\hline 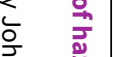 & Vyas 2016 & 1 & 32 & 20 & 28 & 1 & 1 & - & - \\
\hline 흥 & Cytarabine (pharmacy areas) & & & & & & & & \\
\hline 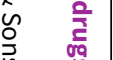 & Chauchat 2017 & 5 & 181 & 6 & 312 & 31 & 52 & - & - \\
\hline$\frac{1}{0}$ & Simon 2016 & 26 & 143 & 74 & 144 & 1 & 1 & - & - \\
\hline$\stackrel{\mathscr{\omega}}{\vec{\omega}}$ & Gemcitabine (pharmacy areas) & & & & & & & & \\
\hline 를 & Chauchat 2017 & 27 & 181 & 47 & 312 & 31 & 52 & - & - \\
\hline$\frac{\pi}{0}$ & Simon 2016 & 62 & 143 & 71 & 144 & 1 & 1 & - & - \\
\hline$\stackrel{\overrightarrow{\mathrm{o}}}{=}$ & Irinotecan (pharmacy areas) & & & & & & & & \\
\hline 突. & Chauchat 2017 & 4 & 181 & 19 & 312 & 31 & 52 & - & - \\
\hline$\frac{0}{8}$ & Docetaxel (pharmacy areas) & & & & & & & & \\
\hline $\begin{array}{l}1 \\
0 \\
0 \\
0\end{array}$ & Chauchat 2017 & 0 & 181 & 0 & 312 & 31 & 52 & - & - \\
\hline & Paclitaxel (pharmacy areas) & & & & & & & & \\
\hline & Chauchat 2017 & 1 & 181 & 3 & 312 & 31 & 52 & - & - \\
\hline
\end{tabular}




\begin{tabular}{|c|c|c|c|c|c|c|c|c|c|}
\hline 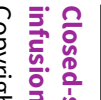 & $\begin{array}{l}\text { (Continued) } \\
\text { Vinorelbine (pharmacy areas) }\end{array}$ & & & & & & & & \\
\hline รั้ & Chauchat 2017 & 2 & 181 & 2 & 312 & 31 & 52 & - & - \\
\hline 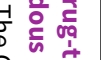 & Ganciclovir (pharmacy areas) & & & & & & & & \\
\hline 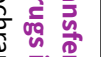 & Simon 2016 & 1 & 143 & 78 & 144 & 1 & 1 & - & - \\
\hline 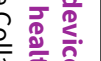 & Epirubicin (pharmacy areas) & & & & & & & & \\
\hline 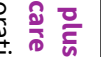 & Vyas 2016 & 0 & 32 & 16 & 28 & 1 & 1 & - & - \\
\hline 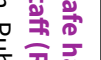 & Multiple drugs (pharmacy areas) & & & & & & & & \\
\hline 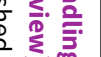 & Sottani 2012 & 33 & 69 & 22 & 40 & 3 & 1 & - & - \\
\hline$\stackrel{0}{\vec{g}}$ & Cyclophosphamide (patient-care areas) & & & & & & & & \\
\hline 잉 & Berruyer 2015 & 17 & 40 & 88 & 161 & 7 & 28 & - & - \\
\hline$\underset{\frac{2}{2}}{\frac{2}{c}}$ & Chauchat 2017 & 63 & 166 & 106 & 294 & 31 & 52 & - & - \\
\hline$\frac{\widehat{c}}{\frac{0}{3}}$ & Janes 2015 & 27 & 59 & 120 & 213 & 12 & 37 & - & - \\
\hline 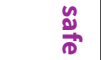 & Poupeau 2016 & 24 & 62 & 57 & 178 & 12 & 34 & - & - \\
\hline 을 & Roland 2017 & 60 & 121 & 106 & 241 & 23 & 43 & - & - \\
\hline$\stackrel{2}{0}$ & Ifosfamide (patient-care areas) & & & & & & & & \\
\hline$\stackrel{\vec{o}}{\frac{T}{7}}$ & Berruyer 2015 & 4 & 40 & 21 & 161 & 7 & 28 & - & - \\
\hline 竞. & Chauchat 2017 & 9 & 166 & 6 & 294 & 31 & 52 & - & - \\
\hline$\frac{\pi}{\frac{x}{0}}$ & Janes 2015 & 16 & 59 & 58 & 213 & 12 & 37 & - & - \\
\hline $\begin{array}{l}= \\
0 \\
0\end{array}$ & Poupeau 2016 & 4 & 62 & 6 & 178 & 12 & 34 & - & - \\
\hline & Roland 2017 & 19 & 121 & 17 & 241 & 23 & 43 & - & - \\
\hline & Methotrexate (patient-care areas) & & & & & & & & \\
\hline
\end{tabular}




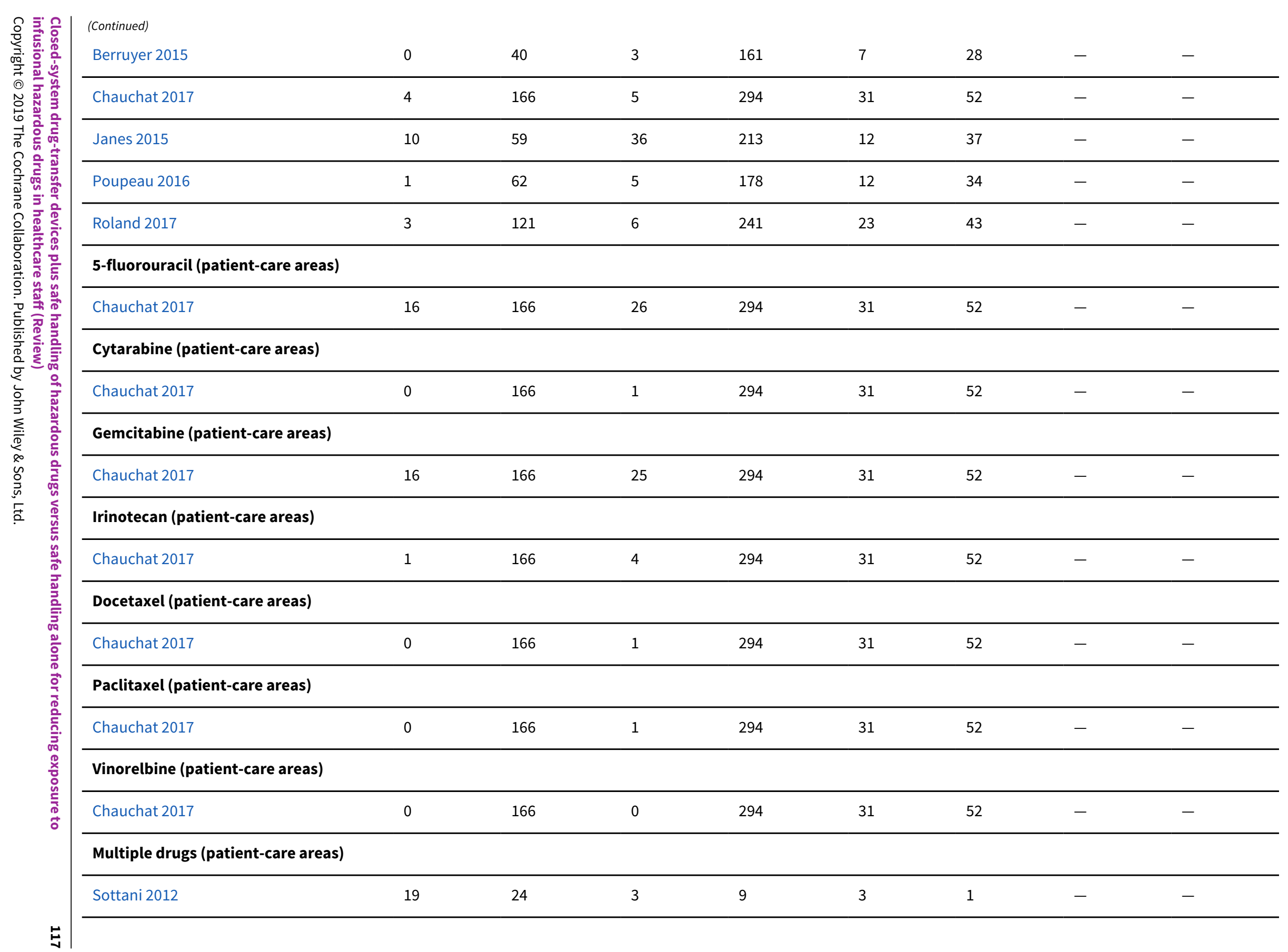




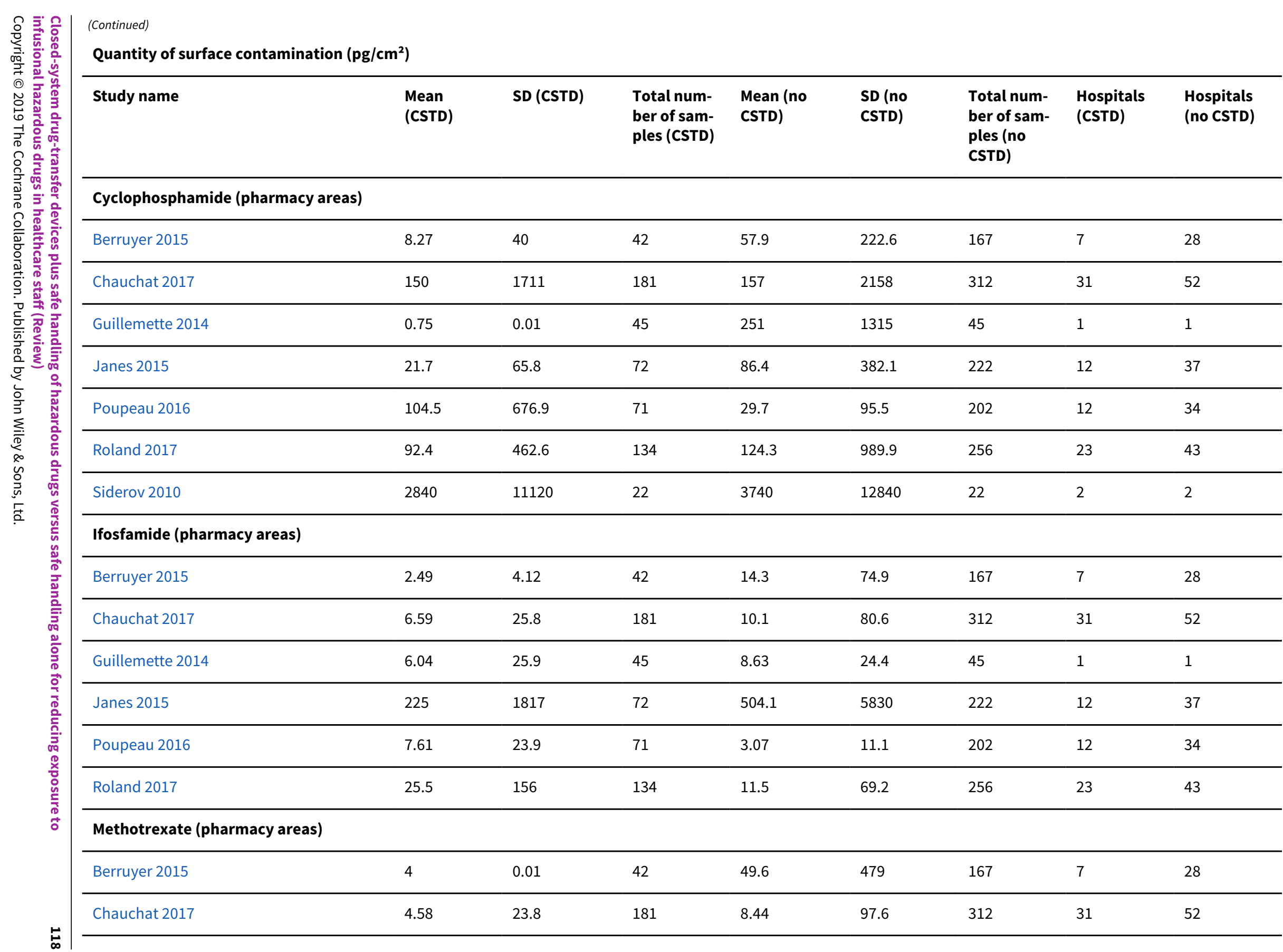




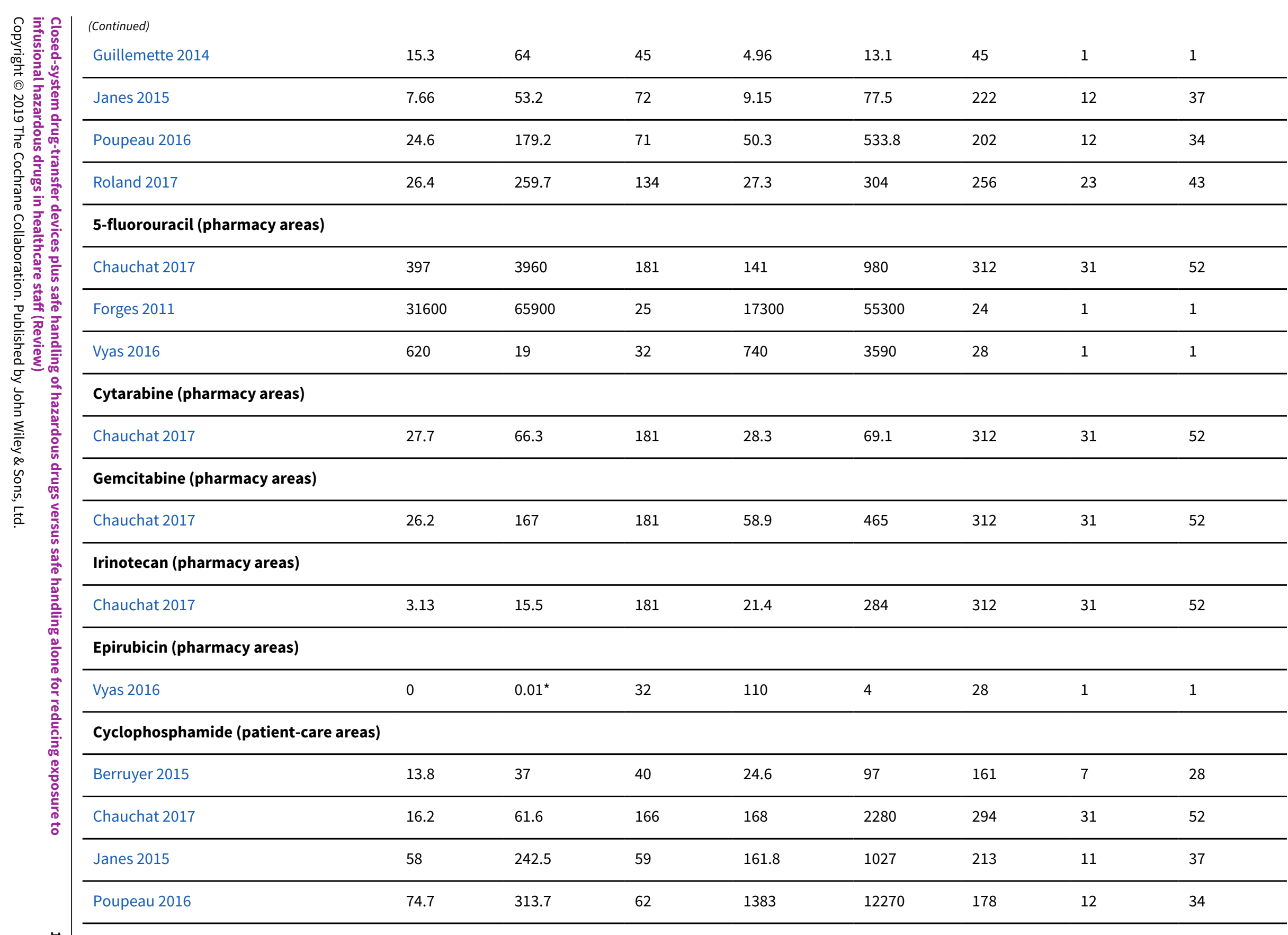




\begin{tabular}{|c|c|c|c|c|c|c|c|c|c|}
\hline 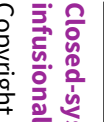 & $\begin{array}{l}\text { (Continued) } \\
\text { Roland } 2017\end{array}$ & 53.2 & 274.8 & 121 & 391.8 & 5475.6 & 241 & 23 & 43 \\
\hline 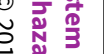 & \multicolumn{9}{|l|}{ Ifosfamide (patient-care areas) } \\
\hline 寅品高 & Berruyer 2015 & 1.97 & 3.67 & 40 & 30.5 & 301.2 & 161 & 7 & 28 \\
\hline 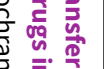 & Chauchat 2017 & 9.01 & 64.4 & 166 & 4.59 & 16.3 & 294 & 31 & 52 \\
\hline 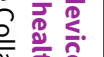 & Janes 2015 & 17.3 & 91.4 & 59 & 14.4 & 89.4 & 213 & 11 & 37 \\
\hline  & Poupeau 2016 & 5.52 & 30.9 & 62 & 3.77 & 33.6 & 178 & 12 & 34 \\
\hline 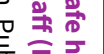 & Roland 2017 & 12.3 & 77.5 & 121 & 2.96 & 13.9 & 241 & 23 & 43 \\
\hline 越 & \multicolumn{9}{|l|}{ Methotrexate (patient-care areas) } \\
\hline$\stackrel{0}{\frac{9}{2}}$ & Berruyer 2015 & 4 & 0.01 & 40 & 8.32 & 37.6 & 161 & 7 & 28 \\
\hline 을 & Chauchat 2017 & 3.9 & 30.9 & 166 & 1.42 & 5.32 & 294 & 31 & 52 \\
\hline 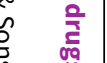 & Janes 2015 & 1.75 & 6.81 & 59 & 2.33 & 17.2 & 213 & 11 & 37 \\
\hline$\frac{0}{0}$ & Poupeau 2016 & 0.782 & 2.22 & 62 & 0.646 & 1.23 & 178 & 12 & 34 \\
\hline 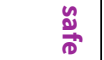 & Roland 2017 & 24.7 & 263.6 & 121 & 1.07 & 6.51 & 241 & 23 & 43 \\
\hline 产 & \multicolumn{9}{|l|}{ 5-fluorouracil (patient-care areas) } \\
\hline 苟 & Chauchat 2017 & 44.6 & 132 & 166 & 88.5 & 686 & 294 & 31 & 52 \\
\hline$\stackrel{\overrightarrow{0}}{\underline{T}}$ & \multicolumn{9}{|l|}{ Cytarabine (patient-care areas) } \\
\hline 竞. & Chauchat 2017 & 20.1 & 1.51 & 166 & 20.3 & 3.79 & 294 & 31 & 52 \\
\hline 紊 & \multicolumn{9}{|l|}{ Gemcitabine (patient-care areas) } \\
\hline $\begin{array}{l}\overline{2} \\
0 \\
0 \\
0\end{array}$ & Chauchat 2017 & 3.95 & 10.1 & 166 & 3.48 & 9.14 & 294 & 31 & 52 \\
\hline & \multicolumn{9}{|l|}{ Irinotecan (patient-care areas) } \\
\hline & Chauchat 2017 & 1.51 & 0.147 & 166 & 1.56 & 0.698 & 294 & 31 & 52 \\
\hline
\end{tabular}




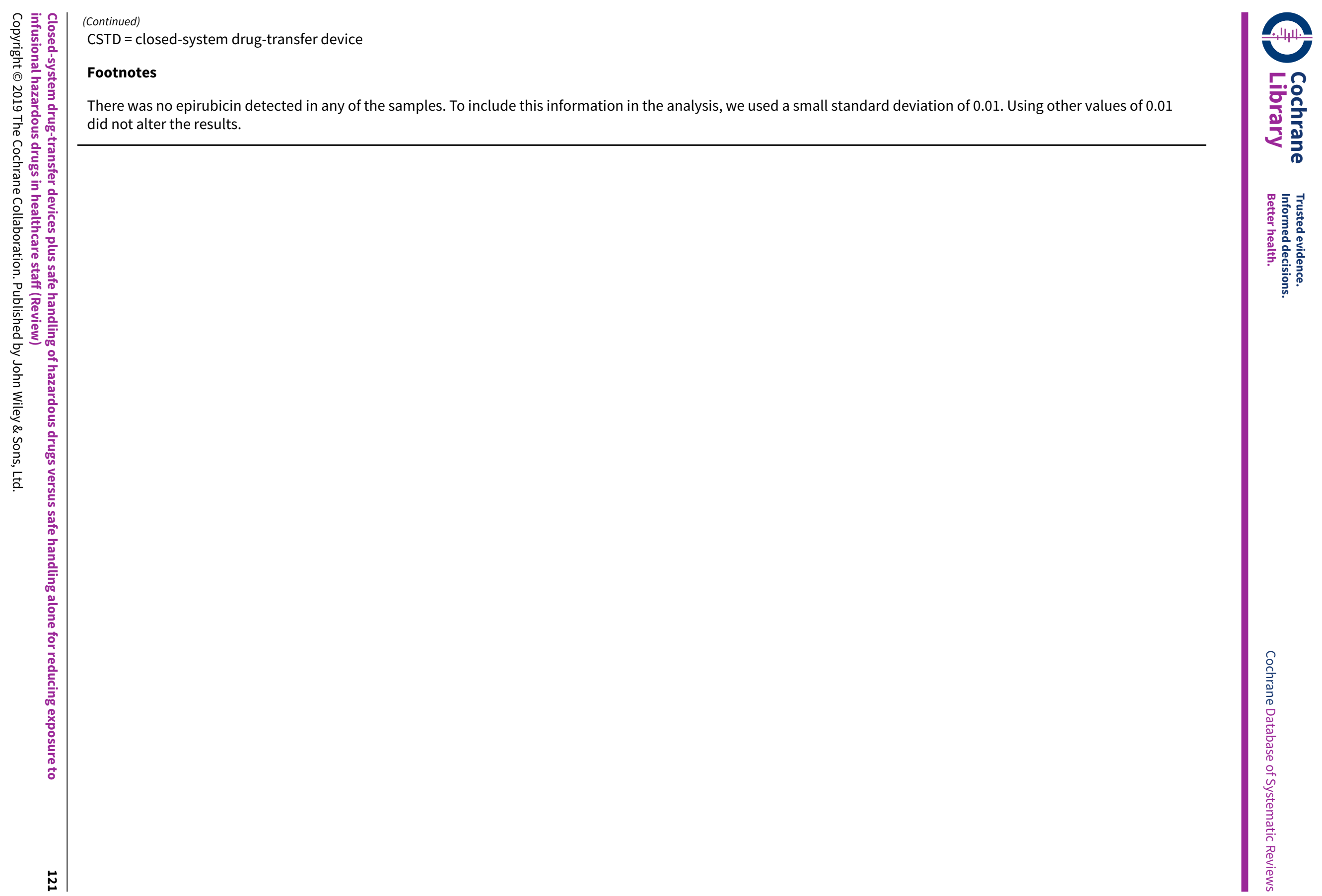


Appendix 10. Raw data from interrupted time series for quantity of surface contamination with cyclophosphamide $\left(\mathrm{pg} / \mathrm{cm}^{2}\right)$

\begin{tabular}{|c|c|c|c|}
\hline Cyclophosphamide & Phase & $\begin{array}{l}\text { Closed-system drug transfer device } \\
(0=\text { not used; } 1=\text { used })\end{array}$ & Time \\
\hline 17.6 & 0 & 0 & 1 \\
\hline 34.4 & 0 & 0 & 2 \\
\hline 6.4 & 0 & 0 & 3 \\
\hline 12.8 & 0 & 0 & 4 \\
\hline 6.8 & 0 & 0 & 5 \\
\hline 10.8 & 0 & 0 & 6 \\
\hline 3.8 & 1 & 1 & 7 \\
\hline 2.4 & 1 & 1 & 8 \\
\hline 3.6 & 1 & 1 & 9 \\
\hline 5.8 & 1 & 1 & 10 \\
\hline 4 & 1 & 1 & 11 \\
\hline 3.6 & 1 & 1 & 12 \\
\hline 10 & 2 & 0 & 13 \\
\hline 27.8 & 2 & 0 & 14 \\
\hline 8.4 & 2 & 0 & 15 \\
\hline 27.4 & 2 & 0 & 16 \\
\hline 7.8 & 2 & 0 & 17 \\
\hline 3.8 & 2 & 0 & 18 \\
\hline
\end{tabular}

\section{FEE D B A C K}

\section{Comments from Assistant Professor Martha Polovich, 16 October 2018}

\section{Summary}

I have been an oncology nurse for almost 40 years. I wish to comment on the systematic review conducted by Gurusamy et al. There are several reasons to question the conclusion reached by the authors that closed system drug-transfer devices (CSTDs) provide no benefit. While comparing results from multiple studies can provide evidence for or against an intervention, the studies must compare the same interventions in the same population. In this review, that was not the case. The studies in the review included only two that involved nurses. Exposure risks and work environments vary significantly based on drug handling activity (e.g. drug preparation and administration), yet the authors considered them the same by combining studies in the review. More importantly, since nurses were underrepresented in the research, and data were not reported separately by professional group, it is difficult to draw conclusions about the benefit of CSTDs in 
reducing nurses' exposure from this review. The review intended to compare safe handling alone versus CSTDs plus safe handling. Safe handling was defined as the use of class II biological safety cabinets (BSC) or isolators and limited personal protective equipment (PPE). This definition assumes that "safe handling" was implemented similarly in all study sites, which is not supported in the literature. Since BSCs are not used for hazardous drug administration, PPE was the only "safe handling" in the two studies that included nurses. Research demonstrates that PPE use among nurses varies considerably.[1,2] Nurses have no other engineering controls to reduce hazardous drug exposure during drug administration. CSTDs provide a level of protection that is otherwise not available. Several researchers have concluded that CSTDs have benefit.[3-5] Multiple guidelines support their use.[6-8] I fear that the results of this review will be used to make decisions about the value of using CSTDs for hazardous drug administration, when the quality of the review is in question.

References:

1. Boiano JM, Steege AL, Sweeney MH. Adherence to safe handling guidelines by health care workers who administer antineoplastic drugs. Journal of Occupational and Environmental Hygiene, 2014. 11: p. 728-40. doi: 10.1080/15459624.2014.916809.

2. Polovich M, Clark PC. Factors influencing oncology nurses' use of hazardous drug safe-handling precautions. Oncology Nursing Forum, 2012 May 1;39(3):E299-309. doi: 10.1188/12.0NF.E299-E309.

3. Silver SR, Steege AL, Boiano JM. Predictors of adherence to safe handling practices for antineoplastic drugs: A survey of hospital nurses. Journal of Occupational and Environmental Hygiene, 2016;13(3):203-12. doi: 10.1080/15459624.2015.1091963.

4. Sessink PJ, Trahan J, Coyne JW. Coyne, Reduction in surface contamination with cyclophosphamide in 30 US hospital pharmacies following implementation of a closed-system drug transfer device. Hospital Pharmacy, 2013 Mar;48(3):204-12. doi: 10.1310/hpj4803-204.

5. Vyas N, Turner A, Clark JM, Sewell GJ. Evaluation of a closed-system cytotoxic transfer device in a pharmaceutical isolator. Journal of Oncology Pharmacy Practice, 2016 Feb;22(1):10-9. doi: 10.1177/1078155214544993. Epub 2014 Jul 29.

6. Polovich M, Olsen MM, eds. Safe handling of hazardous drugs. 3rd ed. 2018, Oncology Nursing Society: Pittsburgh, PA.

7. American Society of Health System Pharmacists, ASHP Guidelines on Handling Hazardous Drugs. American Journal of Health-System Pharmacy, 2018. In Press.

8. U.S. Pharmacopeial Convention, USP General Chapter $<800>$ Hazardous Drugs -- Handling in Healthcare Settings, in USP Compounding Compendium. 2017: Rockville, MD.

Conflict of Interest statement: I have received speaker fees and travel reimbursement from Becton Dickinson, the makers of PhaSeal, in the past year.

\section{Reply}

Thank you for your interest in our Cochrane review.

Feedback states that PPE use among nurses varies considerably.

We fully agree that there is variation in nurses' safe handling practices. We evaluated whether CSTD in addition to safe handling is beneficial and did not evaluate whether CSTD is beneficial when the drugs are not handled safely. In the background section of the review, we describe various safe handling practices, giving some examples and not an exhaustive list. The studies do not list all the safe handling practices in a detailed manner, for example, how priming, connecting or disconnecting intravenous lines were done. We have listed the safe handling practices reported in the studies in the 'Characteristics of included studies'.

Feedback states that we defined safe handling as the use of class II biological safety cabinets (BSC) or isolators and limited personal protective equipment (PPE). This definition assumes that "safe handling" was implemented similarly in all study sites, which is not supported in the literature. Since BSCs are not used for hazardous drug administration, PPE was the only "safe handling" in the two studies that included nurses. Feedback also states that nurses have no other engineering controls to reduce hazardous drug exposure during drug administration and that CSTDs provide a level of protection that is otherwise not available.

To us, knowing that biological safety cabinets may not have been used in the pharmacy only emphasizes the fact that there is no evidence of benefit for the CSTD. If they had been used, the added effect of CSTD would be even smaller. Therefore, CSTDs do not provide "a level of protection that is otherwise not available". On the contrary, one can even speculate that nurses who think that there is evidence for CSTD being effective may not use personal protection resulting in harm to them, particularly when the nurses may be exposed to surfaces contaminated with patient excreta against which CSTD do not offer any protection.

Feedback states that: "There are several reasons to question the conclusion reached by the authors that closed system drug-transfer devices (CSTDs) provide no benefit. While comparing results from multiple studies can provide evidence for or against an intervention, the studies must compare the same interventions in the same population. In this review, that was not the case. The studies in the review included only two that involved nurses. Exposure risks and work environments vary significantly based on drug handling activity (e.g. drug preparation and administration), yet the authors considered them the same by combining studies in the review. More importantly,

Closed-system drug-transfer devices plus safe handling of hazardous drugs versus safe handling alone for reducing exposure to 
since nurses were underrepresented in the research, and data were not reported separately by professional group, it is difficult to draw conclusions about the benefit of CSTDs in reducing nurses' exposure from this review."

We fully agree with the statement that it is not possible to determine whether CSTD is beneficial for nurses because separate data was not available for specific professional groups. In fact, in the Overall completeness and applicability of evidence, we mention: "Therefore, the evidence is mainly applicable for pharmacists and pharmacy technicians. Most of the studies that provide information for this review evaluated the use of PhaSeal; therefore the findings are mostly applicable to PhaSeal".

Feedback states that: "Several researchers have concluded that CSTDs have benefit. Multiple guidelines support their use. I fear that the results of this review will be used to make decisions about the value of using CSTDs for hazardous drug administration..."

We fully agree that several authors and guidelines have concluded that CSTDs are beneficial, which is different from our conclusions. In fact, in our review, we explain the reason for the differences by stating, "Ignoring the design effect by not adjusting the effect estimates for intracluster correlation can lead to an underestimation of random errors (Killip 2004); consequently this could lead to erroneous conclusions".

Feedback states that: “...the quality of the review is in question”. It may be that you have confused the quality of studies included in our review with the quality of our review. We identified multiple shortcomings in the studies but there is nothing more we can do about this than report the problems in detail.

We have followed the PRISMA guidance and Cochrane MECIR standards in the conduct and reporting of our work. This has ensured the highest obtainable validity and reliability, or quality for our Cochrane systematic review. Unfortunately, we are able to make conclusions only based on the information provided in the study reports and replies to our questions provided by the study authors (who provided these). There are only certain types of errors such as ignoring design effect that we were able to account for, but not systematic errors in the studies. This is why we highlighted the evidence as very low quality evidence and called for new high quality primary research studies, which can answer whether adding CSTD to safe handling practices is beneficial. Based on the best available systematic review methodology and utilising the very low quality evidence available from the included studies, we have no alternative than to conclude that there is no evidence to support or refute the use of CSTD in addition to safe handling practices.

\section{Contributors}

Gurusamy KS, Best LMJ, Tanguay C, Lennan E, Korva M, Bussières J-F.

Conflict of Interest statement: We have nothing more to declare beyond what is already stated in Declarations of interest.

\section{WHAT'S NEW}

\begin{tabular}{lll}
\hline Date & Event & Description \\
\hline 27 January 2019 & Amended & $\begin{array}{l}\text { Following feedback, we included an additional study which we } \\
\text { had erroneously excluded. This did not alter the discussion or } \\
\text { conclusions significantly. We have now clarified that 'health ben- } \\
\text { efit' means 'beneficial short-term or long-term health outcomes'. } \\
\text { We have rephrased the conclusions to better indicate the uncer- } \\
\text { tainty of the evidence. }\end{array}$
\end{tabular}

\section{CONTRIBUTIONSOFAUTHORS}

Conceiving the protocol and review: KG.

Designing the protocol and review: KG.

Co-ordinating the protocol and review: KG.

Designing search strategies: KG.

Selecting studies and data extraction: KG, LB, CT. 
Writing the protocol and review: KG.

Providing general advice on the protocol and review: LB, CT, EL, MK, and JFB.

Securing funding for the protocol and review: KG.

\section{DECLARATIONS OF INTEREST}

Kurinchi Gurusamy:Lawrence Best and I received a grant for GBP 12,000 from the UK Oncology Nursing Society to conduct this Cochrane Review.

Lawrence Best: Kurinchi Gurusamy and I received a grant for GBP 12,000 from the UK Oncology Nursing Society to conduct this Cochrane Review.

Cynthia Tanguay: I am a member of the Working Committee on the Safe Handling of Hazardous Drugs established by the Association paritaire pour la santé et la sécurité du travail du secteur affaires sociales (ASSTSAS).

Elaine Lennan: None known.

Mika Korva: None known.

Jean-François Bussières: I am a member of the Working Committee on the Safe Handling of Hazardous Drugs established by the Association paritaire pour la santé et la sécurité du travail du secteur affaires sociales (ASSTSAS).

The outcomes used in this Cochrane review were chosen by the funders of this review, the board of the UK Oncology Nursing Society, who represent the target population of the interventions evaluated. However, the peer referees also considered these outcomes to be the most important.

\section{SOURCES OF SUPPORT}

\section{Internal sources}

- No sources of support supplied

\section{External sources}

- UK Oncology Nursing Society Board, UK.

Grant to the sum of GBP 12,000 provided to Kurinchi Gurusamy and Lawrence Best.

\section{DIFFERENCES BETWEEN PROTOCOLANDREVIEW}

1. To improve clarity, we have renamed historically controlled studies as uncontrolled before-after studies.

2. We made a clear distinction between exposure and contamination. This is an alteration in terms used rather than a conceptual difference. There was no alteration in the primary or secondary outcomes except for the separation of exposure and contamination, which we pooled under a single term 'exposure' and the separation of health effects into different primary outcomes since these require different periods of follow-up.

3. We did not search the European Network of Health Economic Evaluation Databases (EURONHEED), as this has been decommissioned.

4. We have moved changes or differences in layout, changes or differences in policies, education, training, and experience of healthcare staff, and differences in the supervision for drug preparation or drug administration that might lead to less contamination compared to the intervention from confounding factors to co-interventions and assessed these under the 'bias due to deviations from intended interventions' domain, as these confounding factors are co-interventions.

5. We analysed the data separately for different drugs based on peer-review feedback as the amount of drugs used are different in different hospitals, leading to different exposure and contamination.

6. Although we did not specify in the protocol, we performed separate analyses for pharmacy and patient-care areas, since the level of exposure and contamination are quite different in these areas. We have now specified that we performed separate analyses.

7. We converted all costs to US dollars (USD) rather than UK pound sterling (GBP), since the World Economic Outlook Database provided the purchasing power parities in US dollars.

8. We also performed a subgroup analysis of uncontrolled before-after studies versus cross-sectional studies, as these were the two types of studies that contributed data for the analysis. This can assess the impact of trend in improvement of safe handling practices that could be problematic in uncontrolled before-after studies.

9. We performed a sensitivity analysis evaluating the influence of different intracluster correlation coefficients to determine if the differences in conclusions between our systematic review and primary research studies could be because of the lack of adjustment for cluster effect in primary research studies. We did not use these sensitivity analyses for interpreting the results. 


\section{NOTES}

Parts of the 'Methods' section and Appendix 1 to Appendix 6 of this review are based on a standard template established by the Cochrane Work Review Group. This review is independent research funded by the UK Oncology Nursing Society. The views expressed in this publication are those of the authors and not necessarily those of the UK Oncology Nursing Society.

\section{INDEX TERMS}

\section{Medical Subject Headings (MeSH)}

*Hazardous Substances [analysis] [urine]; *Nursing Staff, Hospital; *Pharmacists; *Pharmacy Technicians; Antineoplastic Agents [analysis] [urine]; Chemical Safety [*instrumentation] [*methods]; Cyclophosphamide [analysis] [urine]; Deoxycytidine [analogs \& derivatives] [analysis] [urine]; Endocrine Disruptors [analysis] [urine]; Fluorouracil [analysis] [urine]; Ifosfamide [analysis] [urine]; Observational Studies as Topic; Occupational Exposure [prevention \& control]

\section{MeSH check words}

Adult; Humans 